\title{
G.SENM. ALPENFLORA.
}

FLORA DER WESTALPEN

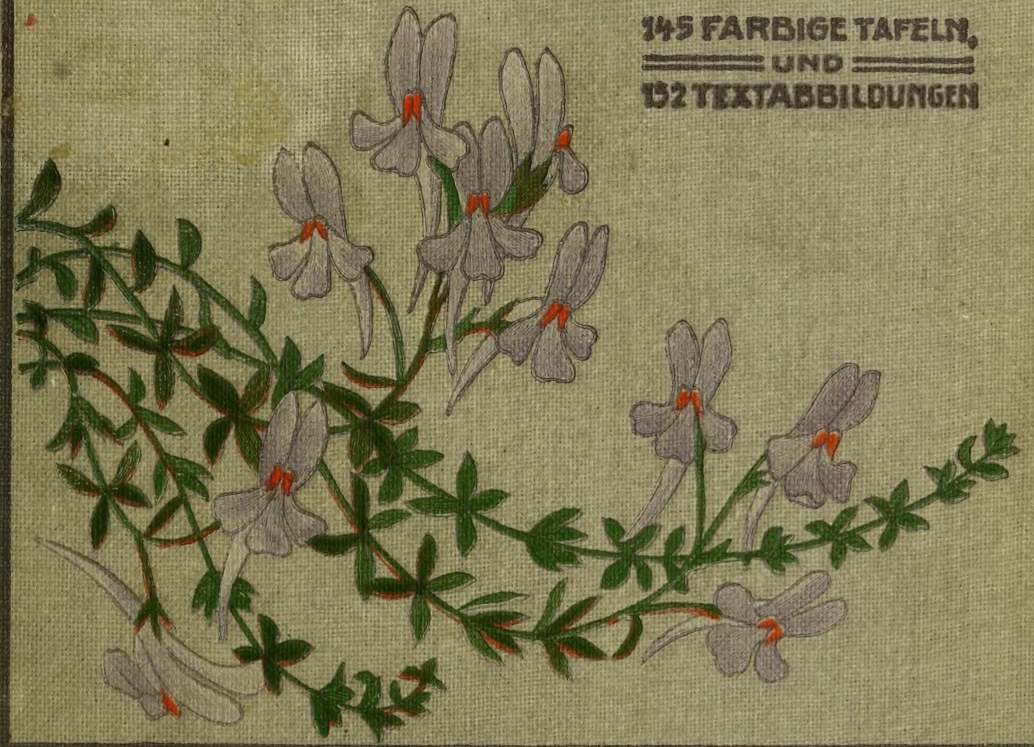

\section{SAMMLUNG NATUR}

WISSENSCHAFTLICHER TASCHENBUICHER

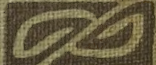




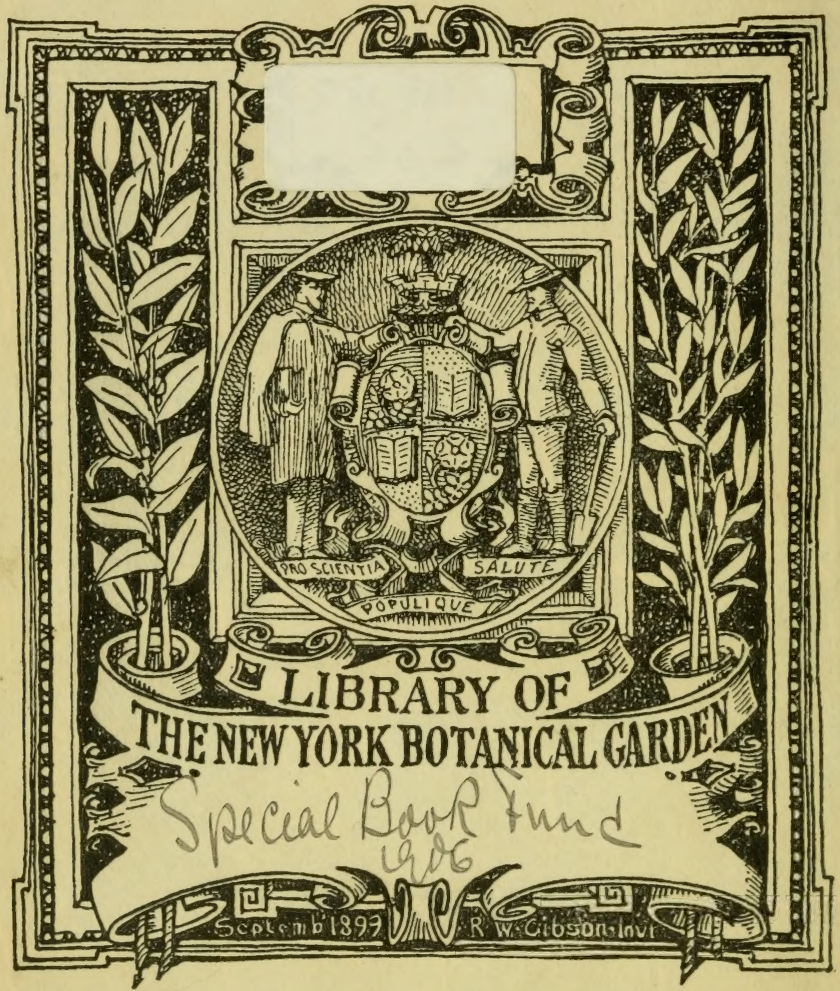



$5,-$ 



\title{
Sammlung \\ naturwiffenfchaftlicher \\ Tafchenbücher
}

\author{
II. \\ Alpen-Flora \\ von
}

G. Senn

We ftalpen

Heidelberg

Carl Winter's Univerlitätsbuchhandlung 



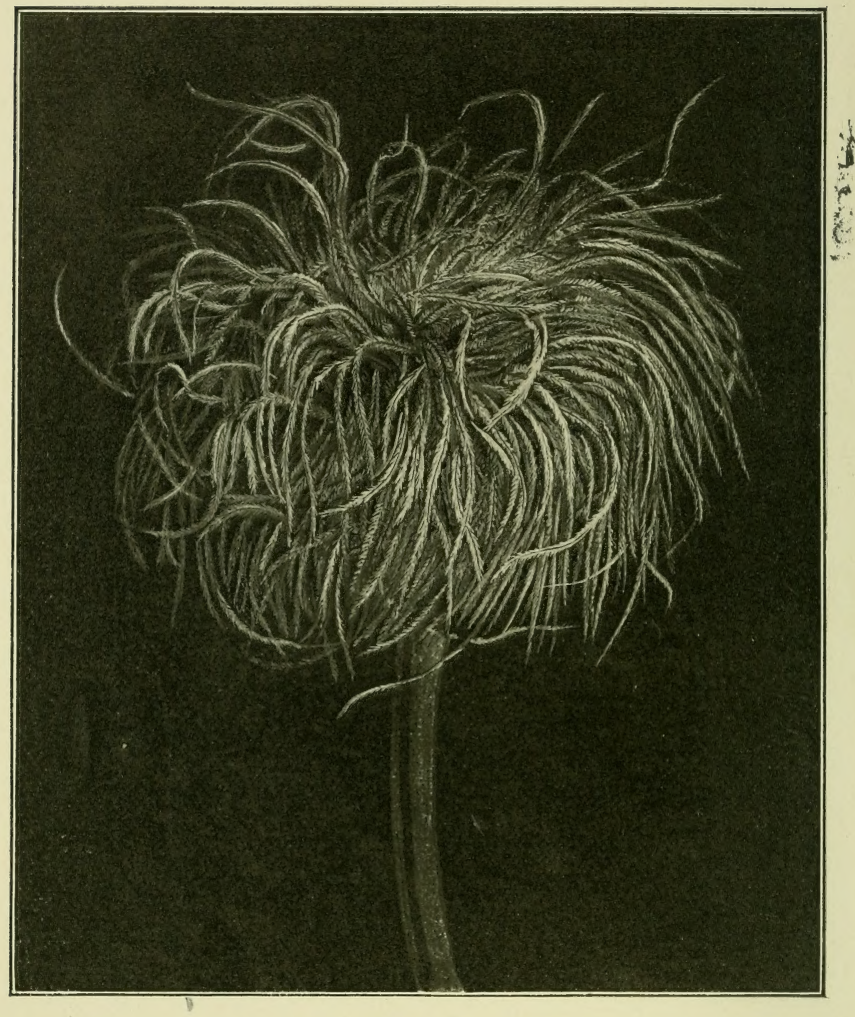

Fruchtkopfchen von Anemone alpina. (Tafel 5.) 


\section{Alpen-Flora}

von

\section{Dr. G. Senn}

Privatdozent an der Univerítät Baiel

Mit 144 farbigen Tafeln nach am Standorte gemalten Aquarellen von C. Kaftner, und I5 Textabbildungen

\section{Weftalpen}

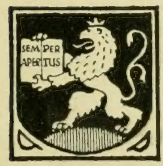

\section{Heidelberg}

Carl Winter's Univeriitätsbuchhandlung 


\section{.538}

Alle Rechte, beionders das Recht der Überietzung in fremde Sprachen, werden vorbehalten. 


\section{Vorwort.}

"Wie, fchon wieder eine illuftrierte Alpenflora!", fo denkt wohl mancher, der die im Handel hefindlichen, ähnlichen Bücher kennt. Diefe zeigen aber gerade, welche Schwierigkeiten es der modernen Reproduktionstechnik macht, Pflanzen naturgetreu in Farben wiederzugeben. Jede Vervollkommmung ift daher lebhaft zu begrüfsen und zu unterftiitzen, und fo habe ich mich gerne bereit finden laffen, zu den wirklich guten Reproduktionen vorzüglicher Originale, die mir vom Verlag zur Verfügung geftellt wurden, den Text zu bearbeiten, um fo mehr, als dabei die Möglichkeit geboten war, die Lebensbedingungen, welche die Geftalt der Alpenflora in fo weitgehendem Maße becinfluffen, kurz zu fchildern und dadurch das Intereffe weiterer Kreife an diefen Fragen zu wecken.

Bei meiner Arbeit lag mir der von Her'n Profeffor Flahault (Montpellier) für die gleichzeitig erfcheinende franzöfifche Ausgabe verfafte Text vor. Ich habe demfelben aufser der Charakteriftik der Arten befonders die Angaben über Verbreitung und Höhengrenzen entnommen. Letztere wurden nach Schröter (Alpenflora, Pflanzenleben) Ergänzt. Die formale Artbefchreibung kürzte ich ab, und Charakterifierte fie auch durch Kleindruck als etwas in eliefem populären Buche Nebenfächliches, da ja in demTelben die Abbildungen die Befchreibungen erfetzen follen. Alles jedoch, was man auch dem beften Bilde nicht anfehen Kram: Blütezeit, Art der Beftüubung und Samenausfaat, 
Standor't und Verbreitung der Arten, ift ausführlicher behandelt und grof gedruckt, da es das gerade für den Laien intereffantefte ift. Den Abfchnitt über die Lebensbedingungen der Alpenpflanzen habe ich auf Grund eigener Beobachtungen und der Originalliteratur verfafst, welche ich fchon früher für akademilche Vorlefungen durchgearbeitet hatte.

Die Gefchichte der Alpenflora, welche die oft auffallende geographilche Verbreitung der Arten zu erklären verfucht, mufte allerdings des Raumes wegen unberïcklichtigt bleiben. Sie wird die Einleitung eines in Ausficht genommenen zweiten Bändchens bilden, das in der Auswahl der abgebildeten Pflanzen befonders die Oftalpen berückfichtigen wird.

Sowohl in einleitenden wie in dem die einzelnen Arten behandehnden Teile wurden die botanifchen Kunftausdrücke möglichft vermieden. Wo fie der Kürze halber doch zur Anwendung kamen, erläutern die dazugehörigen Abbildungen ihre Bedeutung.

lch hoffe, dafo der Mlpenfreund diefes Büchlein als angenehmen und anregenden, von jeder Pedanteric freien Begleiter gerne auf leine Wanderungen mit fich nehmen werde.

Bafel, im Juli 1906.

G. Senn. 


\section{Literatur.}

Jerofeh, M. Gefchichte und Herkunft der fchweizerifchen Alpenflora (nit Verbreitungstabelle). Engelmann, Leipzig 1903.

Knuth, P. Handbuch der Blütenbiologie. II. Bd. Engelmann, Leipzig 1898/99.

Schimper, A. F. W. Pflanzengeographie aut phyliologifcher Grundlage. G. Fifcher, Jena 1898.

Schröter, C. Das Pflanzenleben der Alpen. A. Rauftein, Zürich 1904.

Vogler, P. Über die Verbreitungsmittel der fchweizerifchen Apenpflanzen. Differtation Zürich 1901. (Auch ,Elora“" 1901, Bd. 89, Ergänzungsband.) Warming, E. Lehrbuch der ökologifchen Pflanzengeographie. Bornträger, Berlin 1902.

Ausführliche Angaben ïber das alpine Klima hei: H a n $и$, Handbuch der Klimatologie. 2. Aufl. I. Bd. 1897. 



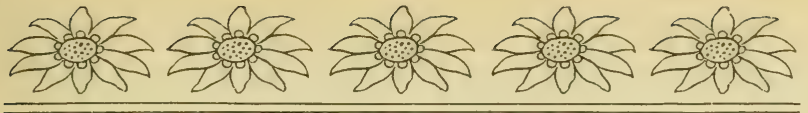

\section{Regifter.}

Die kurfivgedruckten Zahlen beziehen lich auf den I., allgemeinen Teil, die übrigen Zahlen auf den II. Teil. Fettgedruckte Ziffern weilen auf eine Tafel und ein beigedruckter Stern auf eine Textabbildung.

Achillea atrata 42

- herba rota $73 \mathbf{B}$

- moschata 42

- nana $14,3773 \mathrm{~A}$

- tanacetifolia $73^{*}$

Achillée naine $73 \mathrm{~A}$

Ackelei, Alpen- 7

- gewöhnliche 7

Aconit tue-loup s

Aconitum Lycoctonum 30, 8

- Napellus 30

-- paniculatum 8*

Adelgras 121 *

Adenostyles albifrons $\mathbf{6 7}$

- alpina 67

- leucophylla 67 *

Affodill, subalpiner 132*

Ail Victoriale $133 \mathbf{\Lambda}$

Airelle rouge $\mathbf{9 2}$

Ajuga pyramidalis $\mathbf{1 2 1}$

Alchemilla alpina $\mathbf{4 1}$

- pentaphyllea 10, 41*

- vulgaris 41 *

Alchémille des Alpes $\mathbf{4 1}$
Alder, Green- 128

Algen 39

Alnus viridis 128

Allermannsharnifch $\mathbf{1 3 3} \mathbf{\Lambda}$

Allium fallax $133^{*}$

- Schoenoprasum 133 B

- senescens $133 *$

- Victorialis 13:3 $\mathrm{A}$

Alpen, Wallifer- 2

- -Doft, weißsblättriger $\mathbf{6 7}$

- glöckchen \%,95

- —, kleines 95

- -kalk 41

- -lattich $65 \mathrm{~B}$

- rebe $\mathbf{1 0}$

- -rose, rauhhaarige 42,91 *

- - rostblättrige 42,91

- -lcharte, niedrige $\mathbf{7 6}$

- -lüßholz 29

Alpweiden (Salix) 9

Amaryllideen 135

Ampfer, Alpen- 30

Ancolie des Alpes 7

Androsace blane de lait $100 \mathrm{~A}$ 
Androsace carnea 41, $100 \mathrm{~B}$

- Chamaejasme 36, $100^{*}$

- couleur de chair 100B

- glacialis 42

- helvetica $99 \mathbf{A}$

- imbricata 37, 96*

- lactea 41, $100 \mathrm{~A}$

- milk white $100 \mathrm{~A}$

- pubescens 41,99B

- septentrionalis $101 *$

- de Suisse, Swiss $99 \mathrm{~A}$

Anemone 22, 4-6, 42, 47

- alpina $35,42,5$

- baldensis 4

- Frühlings- 4*

- Halleri $6^{*}$

- narcissiflora 6

- Pulsatilla 35

- silvestris 35

- sulfurea 42,5

- vernalis $10,4^{*}$

Anémone des Alpes 5

- fraise 4

- à fleurs de narcisse 6 Anemony, narcissus-flowered 6 Antennaria carpathica $68^{*}$

- dioica 37, 68 B

Anthocyan 17

Anthrena (Biene) 138

Anthyllis montana 25

- Vulneraria affinis $\mathbf{2 5}$

Aquilegia alpina 24, 7

- vulgaris 7

Arabis alpina $13^{*}$

-. caerulea $13^{*}$

Arctostaphylos uva ursi 91

Aretia Vitaliana 101

Armeria alpina 124

- maritima $124^{*}$

Armoise noiratre $69 \mathbf{B}$

Arnica montana 63

Aronicum Clusii 64*
Aronicum scorpioides 64

Arternisia atrata 69 B

- glacialis 69 *

- Mutellina 69 A

Artenreichtum 43, 48

Asphodelus subalpinus 132*

Aspidium Lonchitis 142

Asplenium septentrionale 41 , 143 B

- viride $143^{*}$

Aster alpinus 62

Astragale épineux 33

- sainfoin 34

Astragalus alopecuroides $33^{*}$

- alpinus $\mathbf{2 6}$

- aristatus 33

- Onobrychis 34

Astrance, grande de 59

Astrantia major 59

- minor 59*

Athamanta cretensis 55*

Atmungswärme 7

Atragene alpina $\mathbf{1 0}$

Augenwurz, kretiliche 5ว Aune vert 128

Aurikel $97^{*}$

Ausdauernde Pflanzen 5

Ausläung der Samen 46

Avens, creeping- 47

- mountain- 42

Bärentraube 91

Bärenwurz 56

Bärlapp, Keulen- 144B

- Tannen 5, 144 I

Baldmoney $\mathbf{5 6}$

Baldrian, Berg- $\mathbf{6 0}$

- weidenblättriger $\mathbf{6 1}$

Barometer 1

Bartfchie, Alpen- 111

Bartsia alpina 111

Bartsie des Alpes 111 
Balalt 41

Bastard Vetch, Astragalus- $\mathbf{2 6}$

- alpine 27

Bear's ear, sticky $98 \mathrm{~A}$

Behaarung 37

Beifuf, fchwärzlicher $\mathbf{6 9} \mathbf{B}$

Bell-flower, Allioni's 85

- bearded 8:3

- of Mt. Cenis $\mathbf{8 7}$

- rhombic leaved $\mathbf{8 8}$

- spiked 86

- tufted $\mathbf{8 4}$

Bellidiastrum Michelii 70

Bellis perennis 70

Bells, Yevering- 40

Benoîte rampante 47

Berardia subacaulis 76

Berardie, kurzstengelige 76

Berglinle, Alpen- 27

- kälteliebende $26^{*}$

- lïidländiliche 27 *

- tragantartige $\mathbf{2 6}$

Bergwind 42

Berneralpen 28

Berufkraut, Alpen- $65 \mathbf{~ A}$

- einköpfiges $65^{*}$

Beltäubung 45

Bétoine herissée 118

Betonica Alopecurus 118

- hirsuta 118

Betonie, Fuchsichwanz- 118

- rauhhaarige 118

Betony, rough-haired 118

Betula nana $128 *$

Bibernell, grofer $1 \%$, 58

Bienenblumen 24

- -zuchtftatiftik 16

Billenkraut 103

Bird's eye 98B

Birke, Zwerg- 128*

Biscutella laevigata 14

Bitterwort, Snow- 105
Bitterwort, Yellow $\mathbf{1 0 6}$

Blätter 15

Blafer (Tirol) 14

Blechnum Spicant 41

Bluebottle, mountain $\mathbf{7 4}$

Blüten, Lichteinflufs auf 18

- biologie 21

- ltaub 22

Boden $38 \mathrm{ff}$.

- -temperatur 6

Bonnier, G. 8, 15

Boraginaceen $102-103$

Botryche en croissant $143 \mathrm{~A}$

Botrychium Lunaria $143 \mathrm{~A}$

Boucage grand 55

Boule d'or 9

Bränderli 1:36

Braunklee $\mathbf{3 0}$

Breakstone, alpine $\mathbf{4 1}$

Brenner, W. 35, 36

Brillenfichötchen $\mathbf{1 4}$

Brutknolpen 4

Buclie 39

Bugle en pyramide 121

-, pyramidic $\mathbf{1 2 1}$

Bugrane à feuilles rondes $\mathbf{3 5}$ - du Mont-Cenis $\mathbf{3} \mathbf{6}$

Bulbocodium vernum 130*

Buphthalmum grandiflorum 70 \%

Bupleurum longifolium 23, 57 — stellatum 57*

Buplèvere à longues feuilles $\mathbf{5 7}$ Burnet, great $\mathbf{4 6}$

Bufchweide 126*

Butterbur, white leaved $\mathbf{6 7}$ Butterwort, alpine $\mathbf{9 3} \mathbf{B}$

\section{- common 93 $\mathbf{A}$}

Cacalie à feuilles blanches $\mathbf{6 7}$ Cacteen 35

Calamintha alpina $116^{*}$ 
Caltha palustris $9 *$

Camarine noive $125 \mathrm{~A}$

Campanula 24, \$3-90

- Allionii 85̃

- alpestris 85

- barbata \$3

- bononiensis $88 *$

- cenisia $\mathbf{8 7}$

- excisa 88

- latifolia $83 *$

- linifolia $85^{*}$

-. medium 84

- persicifolia $86^{*}$

- pusilla $87^{*}$

-- rhomboidalis $\mathbf{8 8}$

- rotundifolia 85

- Scheuchzeri $87 *$

- speciosa 84*

- spicata 86

- thyrsoidea $\mathbf{8 4}$

Cimpanulaceen 62, $83-90$ Campamule d'Altioni $\mathbf{5 5}$

- barbue S:3

- en épi $\mathbf{8 6}$

- à fenilles rhomboidales SS

- it flewrs en thyrse $\mathbf{8 4}$

- du Mont-Cenis $\mathbf{8 7}$

Canche 92

Caprifoliaceen 61

Garbon 142

Carlina acaulis $74 *$

Centaurea montana $\mathbf{7 4}$

- nervosa 75

- uniflora 75

Centaurée à une fleur $\mathbf{7 5}$

- des montagnes 74

Cephalaria alpina $60^{*}$

Cerinthe 102

- alpina 103*

- lesser 103

- minor 10:3

Chamaeorchis alpina 136 *
Chardon bleu $\mathbf{5 5}$

Chast-weed (68 B

Chives 13:3 B

Chrysanthème des Alpes $\mathbf{6 6}$

Ciboulctte 1:3:3 B

Cinerarie 71

Cinquefoil, golden $\mathbf{4 4}$

- large flowered $\mathbf{4 5}$

Circaea alpina $48 \%$

Civette 13:3 $\mathbf{B}$

Claw, Wolf's 144B

Clematis alpina $\mathbf{1 0}$

Clématite des Alpes $\mathbf{1 0}$

Clover, alpine $\mathbf{2 9}$

- brown :30

Coeloglossum green- 139 A

- viride $139 \mathbf{A}$

Colchicum autumnale 130

Coltsfoot, alpine $\mathbf{6 5} \mathbf{B}$

Columbine, alpine 7

Compoliten 62-52 $(60), 83$,

$89,122)$

Coniferen 129

Corallorrhiza innata 140 *

Corn-flower, mountain $\mathbf{7 4}$

Coronilla coronata (montana) $34 *$

Cortusa Matthioli 94

Cortuse de Matthiole :4

Cotoneaster tomentosa 42 *

Cow-berry $\mathbf{9 2}$

Crake-berry $125 \mathrm{~A}$

Cranesbill, Water- 22

\section{- Wood- 283}

Crassulaceen 53, 54

Crépicle dorée 78

- naine 79

Crepis albida 79

- aurea 19, 78

- blattarioides 79 *

- grandiflora 78

- pygmaea 79 
Crowberry 125 A

Crowfoot, Glacier's :

- Pyienean- 1

Gruciferen 20, 12-14

Cyclamen europaeum 96 - d'Europe 96

Cyperaceen 141

Cypripedium Calceolus 138*

Cylisus alpinus $36^{*}$

Daisy, Alpine Moon- $\mathbf{6 6}$ Daphne Mezereum 2\%, 125* -. striata 1\%, 2\%, 12513 - strié 125B

Delphinium elatum 7 *

Dentaria digitata 12 *

Dianthus caesins $18^{*}$

- neglectus 17 B

- Seguieri 17*

- silvestris $17 \mathrm{~A}$

- subacaulis 18A

Digitale jaune à grandes fleurs 115

Digitalis ambigua 115

- grandiflora 115

- lutea $115^{*}$

- purpurea 115

Dipsaceen $\mathbf{6 0}(61,62)$

Doldengewächfe 5.5-59)

Doradille septentrionale 14:

Doronicum cordatum 63 *

Dotterblume, Sumpf- 9*

Draba aizoides $14^{*}$

Drachenkopf, öfterreichifcher $120^{*}$

- Ruyfch's 120

Drachenmaul, Pyrenäen- $118^{*}$ Dracocéphale de Ruigsch $\mathbf{1 2 0}$ Dracocephalum austriacum 120 *

- Ruyschianum 120

Dragon's head, Ruysch's 120
Droseraceen 16

Dryade à huit pétates $\mathbf{4 2}$

Dryas octopetala 42

Dryopteris, Aspidium- 142*

Duft der Alpenpflanzen 17

Eberefche, Zwerg- 46*

Edelkaftanie 96

Edelraute 69 A

- Gletfcher- $69 *$

Edelweif 14, 6S A

Églantier des Alpes $4: 3$

Ehrenpreis, Allioni's 114B

- Felsen- 114A

- unbeblätterter $114^{*}$

Eichen 15, 35

- farn $142 *$

Einfifchtal 48

Eifenhut, rifpiger $S^{*}$

- Wolfs- $\mathbf{s}$

Eiszeit 40

Empetrum nigrum 35, $195 \mathrm{~A}$

Engadin 3, 28, 43

Enzian, Alpen- 104*

- bayrifcher 105 $\mathrm{A}$

- Burfer's 106 *

- des Cilufius 104*

- deutfcher 107

- Feld- 107

- Frühlings- $105 \mathrm{C}$

- gefranfter 109

- gelber $\mathbf{1 0 6}$

- Kochs 104

- punktierter 108

- purpurrotel 108*

- Schnee- 105 B

- schwalbenwurzblättriger $107 *$

- zarter $109^{*}$

Epervière Tainense $\mathbf{8 0}$

- orangée 81

Épilobe de Fleischer 45 
Epilobium Fleischeri 48 Epipogon aphyllus 140* Eranthis 10

Erdfcheibe, europäifche $\mathbf{9 6}$

Erica carnea 42,91

Ericaceen 91-92 (39)

Erigeron alpinus $65 \mathrm{~A}$

- uniflorus $65^{*}$

Erinus alpinus 113*

Eriophorum alpinum 141 *

- vaginatum 141

Eritrichium nanum 102

Erle, Grün- 128

Eryngo, alpine 55

Eryngium alpinum $\mathbf{5 5}$

Efparfette, Berg- 32

Etoile jaune de Liottard 131 A

Fahne (der Papilionaceen) 24 Fair maid of France 2 Faltenlilie, fpätblühende $\mathbf{1 3 1} \mathbf{B}$ Falterblumen 24

Farbe der Alpenblumen 19

Farn, Eichen- 142*

-, Lanzen- 142

- nordifcher Streifen- 143 B

Farne 142, 143

Feldfpat 40

Felsboden 31

Felwort, Spring-105 C

Fenovil des Alpes $\mathbf{5 6}$

Fern, Holly- 142

Fettkraut, Alpen- 98B

- gewöhnliches $93 \mathrm{~A}$

Fettpflanzen 53, 54

Feuchtigkeit 27

- relative, der Luft 31

Feuchtigkeitspflanzen 33

Fex, Val 42

Fieberklee, dreiblättriger 110 *

Filices 142, 143

Fingerhut, blafgelber 115
Fingerhut, gelber $115 *$

- roter 115

Fingerkraut, goldgelhes $\mathbf{4 4}$

- großsblumiges $\mathbf{4 5}$

- kälteliebendes $44 *$

- schlitzblättriges $44^{*}$

- Schnee- 46*

- seidenglänzendes 45 *

Finfteraarhorn 4

Fiv-moss $144 \mathrm{~A}$

Flaw-flower, alpine 5

Flax, alpine 24

Fleabane, alpine $65 \mathrm{~A}$

Fliegen 23

Flockenblume, Berg- 74

- einblütige $\mathbf{7 5}$

- nervige 75

Fluhblume $97 *$

Föhn 44, 47

Forget-me-not, Dwarf- 102

Fortpflanzung 45

Foxglove, pale-yellow $\mathbf{1 1 5}$

Frauenmantel, Alpen- 41

- gewöhnlicher 41*

Frauenfchuh 138*

Fremdbeftäubung 21

Fritillaria delphinensis 132*

Fruchtreife 11

Frühling, Alpen-, Tal- 10

- Flora 10

Gänfeblümchen 70

Gänfediftel, Alpen- 82

Gänfekreffe, Alpen- 13*

- blaue $13^{*}$

Gagea Liottardi 10, $131 \mathrm{~A}$

Galeopsis intermedia $\mathbf{1 1 6}$

Galéopsis à petites fleur's $\mathbf{1 1 6}$

Gamander, Berg- 119*

Gamskress 3

Geißsblatt 25

- -gewächle 61 
Gelbftern, Liottard's 131 A Gemfenblümchen 101

Gemskreffe, Alpen-14\%

- -wurz, herzblättrige $63^{*}$

Génépi $69 \mathrm{~A}$

Genévrier nain 129

Gentian, Bavarian 105 A

- dotted $10 \mathrm{~S}$

- Field- 107

- fringed 109

- Koch's 104

Gentiana alpina 104*

- asclepiadea 107*

- bavarica $105 \mathrm{~A}$

- Burseri 106*

- campestris 107

- ciliata 109

- Clusii 104*

- excisa 104

- germanica 18, 107

- Kochiana 104

- latifolia 104

- lutea 106, 130

- nivalis $\mathbf{1 0 5} \mathbf{B}$

- punctata 108

- purpurea $108^{*}$

- tenella $109^{*}$

- verna $105 \mathrm{C}$

- vulgaris $104^{*}$

Gentianaceen 104-110

Gentiane de Bavière $105 \mathrm{~A}$

- champêtre 107

- frangée $\mathbf{1 0 9}$

- grande bleue 104

- jaune 106

- des neiges $\mathbf{1 0 5} \mathbf{B}$

- ponctriée 108

- printanière $105 \mathrm{C}$

Geranium argenteum 22*

- cinereum 22

- macrorrhizum 23*

- rivulare 22
Geranium silvaticum 28

Géranium des forêts $\mathbf{2 3}$

- des ruissenux 22

Germer, weifer 130

Geröllboden 31

Gesse jaune 31

Gelteinsfchutt 31

Geum montanum 47 *

- reptans 47

Gletfcher, Eiszeit- 30, 41

Globeflower 9

Globulaire à feuilles en cœur.

122

Globularia cordifolia 122

- heard-leaved 122

- nana $122 *$

Glockenblume, ährige $\mathbf{8 6}$

- Allioni's 85

- ausgefchnittene 88

- bärtige \$3

- Bolognefer 88*

- breitblättrige $83^{*}$

- des Mt. Cenis $\mathbf{8 7}$

- Garten- 84

- kleine $87^{*}$

- leinblättrige $85^{*}$

- pfirfichblättrige $86^{*}$

- rautenblättrige $\mathbf{8 8}$

- rundblättrige 85

- Scheuchzers 87*

- fchöne 84*

- ftraußsblütige 84

Gneiß3 40

Goldregen, Alpen- 36*

Granit 40

Grasnelken, Alpen- 124

- Meer- 124*

Grassette des Alpes 93B

- commune $93 \mathrm{~A}$

Grass of Parnassus $16 \mathrm{~B}$

Graubündner Oberland 43

Gregoria Vitaliana 101 
Grimm the Collier $\mathbf{8 1}$

Größse der Alpenpflanzen 8

Ground-heel Allioni's 114B

Groundsel, Leopard's bane- 72

Grünerle 128

Grundmoräne 30, 41

Günfel, kriechender 121

- pyramidentörmiger $\mathbf{1 2 1}$

Gymnadenia conopea $\mathbf{1 3 7}$

- odoratissima 1\%, 137 \%

- long-spured 138

Gymnadénia c̀ longéperon 137

Gymnofpermen 129

Gypskraut, kriechendes $20 \mathrm{~A}$

Gyplophila repens $20 \mathrm{~A}$

- creeping $20 \mathrm{~A}$

Gypsophile rampante $20 \mathrm{~A}$

Haarbildung $3 y$

Habichtskraut

- grasnelkenblättriges 81 *

- Ohrchen- 80*

- orangerotes 81

- wolliges 80

Hagrofe, Alpen- 43

Hahnenfufigewächfe $1-10$

Hahnenfuf, Alpen- 2

- Berg- 2*

- eilenhutblättriger 2

-, Gift- $3^{*}$

-, Gletficher- 3

- herzblättriger $1^{*}$

- Pyrenäen- 1

- Seguier's 3

Hare's Lettuce, alpine 82

Hare's-tail-msh 141

Hartheugewächfe 21

Hafenlattich, roter 78

Halenohr, langblättriges $\mathbf{5 i}$

- Stern- 57*

Hauhechel des Mt. Genis $\mathbf{3 6}$

- rundblättriger 3j
Hauhechel, Strauch- 3อ* Hauswurz, Berg- 54

- Dach- 53*

- Spinnwebe- 53

Hawksbeard, golden 78

- Dwarf- 79

Hawli-roeed, woolly 80

Hedysarum obscurum 34, 32

Heidekraut, fleifchrotes 91

Heidelbeere 92

Heilglöckchen, Matthioli's 94

Hellébore blane 130

Helleborus niger 10

Helmkraut, Alpen- 117

Hemp-nettle, middle $\mathbf{1 1 6}$

Herba rota $73 \mathbf{B}$

Herblt 11

Herbltzeitlofe 130

Herminium alpinum 136 *

Herzblatt, Sumpf- 18, 16

Heu, Alpen- 16

Hexenkraut, Alpen- 48*

Hieracium aurantiacum 19, 81

- Auricula 80*

- lanatum 37, 80

- staticifolium $81 *$

Himbeere, Felfen- $43^{*}$

Himmelsherold 102

Hohlzahn, mittlerer $\mathbf{1 1 6}$

Hohlzunge, grüne $139 \mathrm{~A}$

Holly-fern 142

Holzpflanzen 9, 11

Homogyne alpina 6j B

Honeysuckle, alpine 32

Honigausfeheidung 20

- -blumen 23

- -ertrag, -gehalt 16

Horminum pyrenaicum 118 * Hornklee 37*

Honseleek, Cobweb- 53

- mountcin 54

Hugueninia tanacetifolia $\mathbf{1 3}$ 
Hummelblumen 24

Hummeln 25, 8

Hungerblume, Mauerpfeffer$14 *$

Hutchinsia alpina 14*

Hyacinthe 131

Hygrophyten 33

- roletten 36

Hypericum Richeri 21

- quadrangulum 21 \%

Jahresringe 11

Infekten 20

- -blütler 45,46

- -fauna der Alpen 25

Internodien 13

Johanniskraut Richers, 21

- vierkantiges 21 *

Joubarbe, fausse 101

- des montagnes 54

- toile d'araignée 53

Ifothermen 2

Juniper, Dwarf- 129

Juniperus communis 129

- nana 129

- Sabina 129*

Jura 40

- -kalk 41

Käfer 23

Kalkgehalt des Bodens 39

- -pflanzen 41

Kartoffelftaude 13, 103

Katzenpfötchen 68 B

- der Karpathen 68*

Keller, R. 19

Kellerhals, geftreifter 125 B

Kerner, A. 9, 14

Kidney Vetch 25

Kiefelboden 39

- -pflanzen 41

Klappertopf, kleinblütiger $111^{*}$
Klee, Alpen- 24, 28, 29

- Berg- 29*

- bleicher $28^{*}$

- Braun- 30

- Fellen- $30^{*}$

- kolbiger $30^{*}$

- kriechender 28*

- Wiefen- 25

Knabenkraut, breitblättriges

\section{8}

Knapweed, one-flowered $\mathbf{7 5}$

Knöterich, knöllchentragender

$123 \mathrm{~A}$

Knot-grass, bulbiferous $123 \mathrm{~A}$

Konkurrenz der Arten 42

Körbchenblütler 62-80

Korallenwurz, eingewachsene $140^{*}$

Krautweide (Salix) 127*

Krebswurz des Cilusius 64*

- Skorpions- 64

Kreuzblütler 12-14

Kreuzkraut gemswurzähn-

$$
\text { liches } 72
$$

- graues $\%$

- herzblättriges 72

- orangerotes $72 *$

- weißblättriges 71 *

Kronwicke 34*

Küchenfchelle, schwefelgelbe 5 Kugelblume, herzblättrige 122

- Zwerg- 122 *

Kugelgeftalt der Pflanzen 3.i

Labiaten 116-121

Lactuca perennis 77

Läger, Lägerflora 30

Längenwachstum der Wurzeln 8

Läufekraut, beblättertes 112*

- knolliges 112A

- quirlblättriges 112B

G. Senn, Alpenflora. 
Laiteron des A7pes 82

Laitue à fleurs pourpres 79 Lathyrus heterophyllus $31^{*}$

- luteus 31

Lattich, Alpen- 65

- mehrjähriger 77 *

Lauch, Schnitt- 133 B

- täufchender $133^{*}$

Lavande vraie 119

Lavandula vera 119

Lavendel, echter 119 (116)

Lavender, true 119

Leberbalfam, Alpen- 113*

Leek, Victory- $133 \mathrm{~A}$

Leimkraut, ftengellofes $19 \mathrm{~B}$

- Wallifer $19 *$

Lein, Alpen- 24

Leinkraut, Alpen- 133

- niederliegendes 133

Leinpflanze 16

Lentibulariaceen 93

Leontodon Taraxaci $78 *$

Leontopodium alpinum $3 \%$, $68 \mathrm{~A}$

Lettuce, alpine Have's 82

\section{- purple 77}

Leucanthemum alpinum 66

- coronopifolium $66^{*}$

Licht 12

- alpines 13

- -menge 13

Lichtblume, Frühlings- 130*

Lichtnelke, Alpen- 18B

- Jupiters 19 A

Ligusticum Mutellina 56*

Liliaceen 131-135 (136)

Lilie 131

- Feuer- 134*

Liliengewächfe 131-135

Lilium croceum 134 *

- Martagon 134

Lily, mountain- 134
Lin des Alpes 24

Linaive des Alpes 113

Linaigrette à gaîne $\mathbf{1 4 1}$

Linaria alpina $\mathbf{1 1 3}$

- supina 113

Linnæa borealis $61^{*}$

Linnæe, nordifche $61 *$

Linum alpinum 24

Lippe der Blüte 24

Lippenblütler 116-121

Lis Martagon 134

Listera cordata 139 *

Liftere, herzblättrige 139 *

Lloydia serotina $131 \mathrm{~B}$

- late flowering 131B

Lloydie tardive $131 \mathrm{~B}$

Lockapparat 24

Löwenzahn 62

Lotus corniculatus 37 *

Lousewort, bulbiferous $112 \mathrm{~A}$

Luftdruck 1

- -temperatur 2

- - bei der Schneeschmelze 10

Lunetière 14

Lychnis alpina $18 \mathrm{~B}$

- Flos Jovis $19 \mathrm{~A}$

Lycnide des Alpes 18 B

- flew de Jupiter 19 A

Lycopode à massue 144B

Lycopodium clavatum 144 B

- Selago 5, $144 \mathrm{~A}$.

\section{Männertreu 136}

Märzglöckchen 10

Mais 7

Manette 136

Mannsfchild, dichtbeblätterter 96 *

- fleifchroter 100 B

- milchweifer 100 A

- nordifcher 101* 
Mannsfchild, weichhaariger

\section{$99 \mathrm{~B}$}

- Schweizer- $99 \mathbf{A}$

- zottiger $99^{*}$

- Zwergjasmin- 100 \%

Mannstreu, Alpen- 55

Man's shield, flesh-coloured $100 \mathrm{~B}$

- furrowed $99 \mathbf{B}$

Margerite 17, 62

Margottet 12

Martagon, Lilium 134

Master-wort, great 59

Matte 29

Mattenblümchen 70

- -boden 30

Mauerpfeffer 51

Mehrjährige Pflanzen 5

Mélinet à petites fleurs 103

Menyanthes trifoliata $110^{*}$ (104)

Meum athamanticum $\mathbf{5 6}$

- Mutellina 56*

Mezereon, striped $125 \mathrm{~B}$

Milchlattich, Plumiers 82*

Millepertuis de Richer $\mathbf{2 1}$

Mohn, Alpen- 11

- Bündner- 11

Mondraute $143 \mathrm{~A}$

Montblanc-Gebiet 12

Moon Daisy, alpine 66

Noonwort $143 \mathrm{~A}$

Moorbildung 41

Mosse, chub-144B

- fir- $144 \mathrm{~A}$

Mother of thousands 113

Mountain sanicle, Matthi-

$$
\text { oli's } 94
$$

Mousse-serpent 144 B

Muguet verticillé $\mathbf{1 3 5}$

Mulgedium alpinum 82

- Plumieri 82*
Muttern 56*

Myosotis alpestris 102*

- nain 102

- pyrenaica 102

Myrrhis odorata $58 *$.

Nachtfalter 24

Nacktdrüfe, tSechmücken- 137

- wohlriechende $137 *$

Nacktlamige 129

Nadelhölzer 129

Narrenkappe 7

Narcissus poeticus $135^{*}$

Narziffe der Dichter 135*

Nebel 28

- -tage 13

Nelke, blaugrüne $18 *$

- kurzftengelige 18 B

- lange überfehene 17 B

- Wald- 24, $17 \mathrm{~A}$

Nelkengewächle $17-20$

Nelkenwurz, Berg- 47*

- kriechende 47

Nigritella (nigra) angustifolia

$$
1 \%, 136
$$

-, black $\mathbf{1 3 6}$

Nivalflora 4

Nuphar pumilum 11*

Nymphieaceen 11

Oberflächenverkleinerung $3 \dot{4}$

Eillet à courte tige $\mathbf{1 8} \mathrm{A}$

- des forêts $17 \mathbf{A}$

- du Lautaret 17 B

Onobrychis montana 32

Ononis cenisia $\mathbf{3 6}$

- fruticosa $35^{*}$

- rotundifolia 35

Orchidaceen 136-140

Orchis, Alpen-Ziverg- 136*

- conopea 137

- elder-smelling 139B 
Orchis, à fenilles larges $\mathbf{1}: 38$ - globosa 140

- globular 140

- globuleux $\mathbf{1 4 0}$

- Hollunder- 1:9 B

- Kugel- 110

- lavige-leaved 138

- latifolia 138

- d̀ odew de sureau $139 \mathrm{~B}$

- sambucina $139 \mathrm{~B}$

- vanillé 136

- verdatre $139 \mathrm{~A}$

- viridis $139 \mathrm{~A}$

Oxyria digyna 10, 12:3 $\mathbf{B}$ - ì deux styles $\mathbf{1 2 3 \mathrm { B }}$

Oxytropide des champs $\mathbf{3 8 \Lambda}$ - puante $\mathbf{3 8 \mathbf { B }}$

Oxytropis carnpestris $38 \mathrm{~A}$

- field- $\mathbf{3 8 \mathbf { A }}$

- foetida $38 \mathbf{B}$

- lapponica 37 \%

- montana 38*

- stinking $\mathbf{3 8 \mathbf { B }}$

Panicaut des Alpes $\mathbf{5 5}$

Pansy, alpine 15

Papaver aipinum 11

- rhaticum 11

Papilionaceen 19, 24, 25-38

Paradisia Liliastrum 132

- Lily-like 13:

Paradisie-lis 132

Parnassia palustris 18, 19,

\section{$16 \mathrm{~B}$}

Parnassic des marais $\mathbf{1 6} \mathbf{B}$

Pavot des Alpes 11

Pea, yellow $\mathbf{3 1}$

Pediculaire tubérense $\mathbf{1 1 2 \mathrm { A }}$

- verticillée $112 \mathrm{~B}$

Pedicularis foliosa $112 *$

- tuberosa 112A

- verticillata $\mathbf{1 1 2} \mathbf{B}$
Peftilenzwurz, schneeweife $62 *$

Petasites niveus $62 *$

Pfaffenröhrlein-Löwenzahn $78 *$

Pfefferminz 116

Phaca alpina $\mathbf{2 7}$

- astragalina $\mathbf{2 6}$

- australis 27*

- frigida $26^{*}$

Phaque des Alpes 27

- astragale $\mathbf{2 6}$

Phyteuma betonicifolium $\mathbf{8 9}$

- Charmelii 89*

- Halleri 89

- hemisphæricum $90^{*}$

- orbiculare 90

- pauciflorum $90 \%$

Pied de chat $\mathbf{6 5 \mathbf { B }}$

- de lion $\mathbf{6 8 \mathbf { A }}$

Pimpinell, large 58

Pimpinella magna $1 \%, 58$

Pimprenielle, grande $\mathbf{5 s}$

Pinguicula alpina 93 B

- vulgaris 9: $\mathbf{A}$

Pink, Custion $\mathbf{1 9} \mathbf{B}$

- nearly acaulous $18 \mathrm{~A}$

- a long time not observed

\section{$17 \mathrm{~B}$}

- Woor- $17 \mathbf{A}$

l'ippau, goldroter 78

- groliblumiger $7 \mathrm{~S}$

- lichabenkrautartiger 79*

- weislicher 79

- /swerg- 79

Pirola minor :39

- secunda 40

- uniflora $399^{*}$

Pirole, petite $\mathbf{3 9}$

- unilatérale 40

Plantaginaceen 121 (122)

Plantago alpina 121 * 
Platanthera 16

Platterbfe, gelbe $\mathbf{3 1}$

- verfchiedenblättrige 31 *

Plumbagaceen 124

Pollenblumen 22

Polfterpflanzen 45 ;

Poly mountain 111

Polygonatum verticillatum 135

Polygonum viviparum 4, 123 A

Poppy, alpine 11

Potentilla aurea $\mathbf{4 4}$

- caulescens 46

- frigida $44^{*}$

- grandiflora 45

- multifida 44*

- nitida 45*

- nivalis $46^{*}$

- silvestris $45^{*}$

- Tormentilla $45^{*}$

Potentille dorée $\mathbf{4 4}$

- ¿̀ grandes fleur's $\mathbf{4 5}$

Preißiblbeere $\mathbf{9 2}$

Prenanthes purpurea $\mathbf{7 7}$

Primel, klebrige 9S $\mathbf{A}$

- langblütige 98*

- mehlige 98 B

- Piemontefer 97*

- Itinkende $\mathbf{9 7}$

Primeln 3\%, 39, 94-101

Prime-rose, stinking $\mathbf{9 7}$

Primevère farineuse $\mathbf{9 S \mathbf { B }}$

- puante 97

- visqueuse $98 \mathrm{~A}$

Primula Auricula 42, 97*

- farinosa 10, 27, 98B

- graveolens $\mathbf{9 7}$

- hirsuta 42, 95 $\mathrm{A}$

- latifolia $\mathbf{9 7}$

- longiflora 98*

- pedemontana $97 \%$

- viscosa $98 \mathrm{~A}$

Prothallium 142
Quendel, wilder 117

- wollhariger 117 *

Radiaire 59

Ragged Robin, alpine $\mathbf{1 S B}$ - of Jupiter $\mathbf{1 9} \mathbf{A}$

Raiponce à feuilles de bétoine S9

- à fleurs globuleuses $\mathbf{9 0}$

Rampion, betony-leaved $\mathbf{5 9}$

- globular 90

Ranunculaceen 35, 1-10, 40 Ranunculus aconitifolius 23, 35,2

- aclis 35

- alpestris 10, 35, 2

- glacialis 4, 3

- montanus $10,35,2$ *

- parnassifolius 1 *

- pyrenæus 1

- Seguieri 3

- Thora :3*

Rapunzel, betonicablättrige $\mathbf{8 9}$

- Charmelis 89*

- halbkugelige $90^{*}$

- Hallers 89*

-- kugelige $\mathbf{9 0}$

- wenigblütige $90^{*}$

Rafenbildung 14

Rauke, öfterreichifche 12

- rainfarnblättrige $\mathbf{1 3}$

Paulchbeere, fchwarze $125 \mathrm{~A}$

- (Sumpf-) 92*

Raute, Mond- 14:3 A

Red Rattle, verticillate $112 B$

Regen 28

Réglisse des Alpes $\mathbf{2 9}$

Renoncule à feuilles d'aconit $\mathbf{2}$

- des glaciers $\mathbf{3}$

- des Pyrénées 1

Renouée vivipare $123 \mathrm{~A}$ 
Rest-Harrow, alpine $\mathbf{3 5}$

- of Mont-Cenis 36

Rhaharber 123

Rhamuus alpina 24*

Rhinantus minor $111^{*}$

Rhododrendron ferrugineum 42,91

- hirsutum 42, 91*

- mst-leaved 91

Phonegletlicher 48

Rindsauge, grofes $70 *$

Ritterfporn, hoher 7 *

Rocket, Austrian 12

- Tansy-leaved 13

Rollblätter 35

Roquette autrichienne 12

- ì feuilles de tanaisie 1:3

Rosa alpina 48

- glanca $43^{*}$

Rofe 22, 4:3

- mitblaugrünen Blättern $4: 3$

- alpine 43

Rofengewächle 40-47

Rofenwurz 54*

Rofettenbildung 14, 36

Rolifloren 40-47

Rubus saxatilis $43 *$

Rumex alpinus 30

Sadebaum 129*

Säuerling, zweigriffliger 123 B

Säugetiere als Samenverbreiter 47

Sainfoin des Alpes $\mathbf{3 2}$

Salix Arbuscula 126*

- glauca 126

- herbacea 127 *

- reticulata 127

- retusa 127 .

Salomonsfiegel, quirlblättriger

\section{5}

Salomon's seal, verticillate $\mathbf{1 3 5}$
Samen 46

Sanguisorba officinalis 46

Sanicle, Matthioli's mountain 94

Saponaire faux-basilic $\mathbf{2 0 ~ B}$

Saponaria lutea $20 *$

- ocymoides $\mathbf{2 0} \mathbf{B}$

Saturei, Alpen- $116^{*}$

Satzbohne 34

Sanle glanque $\mathbf{1 2 6}$

- réticulé 127

Saussurea alpina 76 *

- depressa 76

- short 76

- tridactyla 4

Sanssurée déprimée $\mathbf{7 6}$

Saxifraga aizoides $37,51 \mathrm{~A}$

- aizoon 52 B

- androsacea $36,50 *$

- aspera $49^{*}$

- biflora 52*

- bryoïdes $36,49 \mathbf{B}$

- Cotyledon 41

- cuneifolia 49 A

- exarata 5113

- muscoirles 51*

- oppositifolia 52 A

- rotundifolia $36, \mathbf{5 0}$

- stellaris 5, 50*

Saxifragaceen $36,49-52$

Saxifrage ì feuilles en coin

49) 1

- mosslike $49 \mathrm{I}$

- monsse 49B

- à fenilles opposées $\mathbf{5 2} \mathbf{A}$

- opposite-leaved 52 $\mathbf{A}$

- pain d'oisean 51 A

- à fenilles rondes 50

- round-leaved 50

- sillomée 5113

- Stone-crop $51 \mathbf{A}$

- toujours verte $\mathbf{5 2} \mathbf{B}$ 
Schachblume des Dauphiné $132 *$

Schafgarbe, rainfarnblättrige $73^{*}$

- Zwerg- 73: $\mathbf{\Lambda}$

Scharte, Alpen- $76^{*}$

- nacktltengelige $75^{*}$

Schattenleite 10

Schlüffelblumen 10

Schnee 28

- flora 10

- -freie Zeit, Dauer der 9

- -glöckchen 10

-- -grenze 3,4

- -pflanzen 10

- schmelze 10

Schnittlauch 1:38 B

Schuppenkopf, Alpen- $60^{*}$

Scrophulariaceen 20,111-115

$(116,121,122)$

Scutellaria alpina $\mathbf{1 1 7}$

Sedum acre 51

- Rhodiola 54*

- roseum 54*

Seerole, kleine gelbe 11 *

Seidelbaft 125*

Seifenkraut, bafilienartiges

\section{$20 \mathrm{~B}$}

- gelbes $20^{*}$

Sélagine $144 \mathrm{~A}$

Selbltheftäubung 21

Sempervivum arachnoideum $36,41,53$

-- montanum อ̃

- tectorum 53*

Senecio aurantiacus 73 *

- Cineraria 71

- cordatus 30,72

- Doronicum 72

- incanus 71

- leucophyllus $71 *$
Seneggon blanchâtre $\mathbf{7 1}$

- Doronic 72

Serpentin 41

Serratula nudicaulis 75 *

Seseli Libanotis 14

Sieversia reptans $\mathbf{4 7}$

Silberdiltel, kurzltengelige 74 *

Silberwurz 42

Silene acaulis 14, 19 B

- vallesia $19 *$

Silène sans tiges $\mathbf{1 9 1 3}$

Sileneen $17-20$

Sinau, fünf blättriger 41 *

Sisymbrium austriacum 12

- tanacetifolium 13:

Sliull-cap, alpine 117

Soap-wort, trailing $20 \mathrm{~B}$

Solanaceen 10 ?

Soldanella alpina \%, 10,95

- pusilla 10,95

Soldanelle des Alpes $\mathbf{9 5}$

Sommer, Alpen- 11

Sonchus alpinus 82

- Plumieri 82*

Sonnblick, hoher 7

Sonnenfeite 10

- strahlung 6,12

Sorbus Chamaemespilus $46^{*}$

Sorrel, monntain 12313

Sow-bread, european 96

Spalierwuchs 9

Speedwell, Rock- 114

Spitzbergen 7

Spitzkiel, Berg- 38*

- Feld- $38 \mathrm{~A}$

- lappländifcher $37^{*}$

- ftinkender 38 B

Spleemoort, northern $143 \mathrm{~B}$

Sporen 142

Sporn der Blüte 24

Stachys densiflora 118

Stärke (-mehl) 16 
Staggerwort, Gray $\mathbf{7 1}$

Star, Liottard's yellow-of Bethlehem 1:31 A

Starwort, alpine $\mathbf{6 2}$

Statice des Alpes $\mathbf{1 2 4}$

Steinbrech, Birnmoos- $49 \mathrm{~B}$

- gefurchter 51B

- gegenblättriger 52 A

- immergrüner 52 B

- keilblättriger $49 \mathrm{~A}$

- Mannsfchild- 50*

- Mauerpfeffer 51 A

- moosartiger 51*

- rauher 49*

- rundblättriger 50

- Stern- 50*

- zweiblütiger 52*

Steinbrecharten 36

Steinkohlenzeit 142

Steinmifpel, wollige $42 *$

Stengelglieder 13

Sterndolde, großse $\mathbf{5 9}$

- kleine $59^{*}$

Sternliebe $\mathbf{7 0}$

Stiefmütterchen 5

Stonebreak, evergreen $\mathbf{5 2} \mathbf{B}$

- furrowed $\mathbf{5 1 \mathbf { B }}$

- wedge-leaved $49 \mathrm{~A}$

Storchfichnabel, afchgrauer 22

- Bach- 22

- dickwurzliger $23^{*}$

- Silber- 22*

- Wald- 23

Streifenfarn, grüner 143 *

- nordifcher $143 \mathrm{~B}$

Süßdolde, duftende 5̌*

Süßholz, Alpen- 29

Süßklee, dunkler 32

Sumpfherzblatt $\mathbf{1 6 B}$

Swertia perennis, -nial 110

Swertie vivace $\mathbf{1 1 0}$
Tabakpflanze 103

Täfchelkraut, rundblättriges $12 \%$

Tagfalter $2 \dot{t}$

Talwind 44, 47

Tannen 11

Tarant, blauer 110

Taubenfchwanz 15, 98

Temperatur, -gradient 2

- täglicher Gang der 6

Tertiärperiode 40

Teucrium montanum $119 *$

Thalictrum aquilegifolium 10*

Thermotropismus 9

Thlaspi rotundifolium 12*

Thorowax, long leaved 57

Thrift, alpine $\mathbf{1 2 4}$

Thymelæaceen 125

Thymian 26, 116

Thymus lanuginosus 117 *

- Serpyllum 26, 117

Todflax, alpine $\mathbf{1 1 3}$

Tollkirlehe 103

Tonboden 30, 31

Toque des Alpes 117

Torfmoore 39, 40

Tormentill 45 *

Tragant, Efparfetten- $\mathbf{3 4}$

- Fuchslchwanz- 33*

- Stachel- 33

Tranfpiration 33

Trètle des Alpes $\mathbf{2 9}$

- alpestre 28

- brun 30

Trefoil, alpine 28

Trichterlilie, weiß3e $\mathbf{1 3 2}$

Trifolium alpestre 28

- alpinum 29

- badium $\mathbf{3 0}$

- montanum 29*

- pallescens 28*

- repens $28 *$ 
Trifolium saxatile $30 *$

- spadiceum $30^{*}$

Trockenheitspflanzen 33

Trollblume, europäilche 9

Trollins europaeus 9

Türkenbund 134

Tulpe 131

Turtmann-Tal 48

Tussilage des Alpes $65 \mathrm{~B}$

Tutsan, Richer's 21

Umbelliferen $35, \mathbf{5 5 - 5 9}$

Urgeftein 40

Vaccinium Myrtillus 92

- Vitis Idaea 92

- uliginosum 92*

Valerian, mountain 60

- willow-leaved 61

Valeriana montana $\mathbf{6 0}$

- saliunca 61

Valériane des montagnes $\mathbf{6 0}$

- à fenilles de saule $\mathbf{6 1}$

Val Fex 42

Vanillegeruch 17

Vegetationsperiode,Kürze der 5

Veilchen 24, 26

- des Mont-Cenis 15

- fiederblättriges $15 *$

- langfporniges 15

- Sumpf- $16^{*}$

- zweiblütiges $16 \mathrm{~A}$

Véraire blanc $\mathbf{1 3 0}$

Veratrum album 130

- white 180

Vergerette des Alpes $65 \mathrm{~A}$

Vergifomeinnicht 17

- Alpen- 102*

Veronica Allionii 114B

- aphylla $114^{*}$

- fruticans $114 \mathrm{~A}$

- saxatilis 114A
Véronique d'Allioni 114B

- des rochers $114 \mathrm{~A}$

Verfuchsgarten, alpiner 14

Verteilung der Würme im Jahre 9

Verzweigung 15

Vesce des bois $\mathbf{3 7}$

Vetch, Sainfoin $\mathbf{3 4}$

- thorny 33

- wood- 37

Vicia Faba $3 \dot{x}$

- silvatica 37

Viola biflora $27, \mathbf{1 6} \mathrm{A}$

- calcarata 24, 2\%, 15

- cenisia 2\%, 15

- palustris $16^{*}$

- pinnata $15^{*}$

- tricolor 5

Violette éperonnée $\mathbf{1 5}$

- à deux fleurs $16 \mathrm{~A}$

- two-flowered $16 \mathrm{~A}$

Violle 12

Virgin's bower, alpine $\mathbf{1 0}$

Vögel als Samenverbreiter 47

Vogler, Paul 47

Vulnéraire 25

Wacholder, gewöhnlicher 129

- Zwerg- 9, 11, 129

Wachsauslcheidung 37

Wachsblume, Alpen- 103 *

- kleine 10:

Wachstum der Pflanzen 7

- Längen- der Wurzeln S

Wärmeausftrahlung 7

Waldgrenze 3

Waldwicke $\mathbf{3 7}$

Wallis 28

Wallifer Alpen 2, 43

Wafferabgabe 33

- -ausfcheidende Organe 36 
Wafferdampf 12, 28

Wafferdoft, weiß̧blättriger $67^{*}$

Wafferfpalten 36,49

Wegdorn, Alpen- 24*

Wegerich, Alpen- 121*

Weide (Salix-) Bufch- 126*

- graugrüne $\mathbf{1 2 6}$

- Kraut- $127 *$

- netzadrige $\mathbf{1 2 7}$

- ftumpf blättrige 127 *

Weideboden 29, 30

Weidenröschen, Fleifcher's 48

Weihnachtsrofe 10

Weizen 7

Wicke, Wald- 37

Widerbart, blattloler 140 *

Wielen 29

Wiel'enkopf, offizineller $\mathbf{4 6}$

Wiefenraute, ackeleiblättrige $10^{*}$

Willow glancescent 126

- reticulated 127

Willow-herb, Fleischer's 48

Wind 43

- -blütler 45, 46

Windflower of Monte Baldo 4 Windformen 45

- richtung 43, 44

Windröschen, Alpen- 5

- vom Monte Baldo 4

- narcifblumiges 6

Windltärke 44

Wintergreen, lesser $\mathbf{3 9}$

Wintergrün, einblütiges $39 *$
Wintergrün, einfeitswendiges

\section{0}

-- kleines $\mathbf{3 9}$

Winterling 10

Winterpflanzen 10

- Alpen- 11

Wohlverleih 63

Wolf's-bane, yellow 8

- claw 144B

Wolfsmilchfchwärmer 98

Wolkenbildung 28

Wollgras, Alpen- 141*

- fcheidiges 141

Wucherblume, Alpen- 66

- krähenfuf́blättrige $66 *$

Wuchs, niedriger 9, 34

Wundklee 25

Wurmoood, black 69B

- Mutellina 69 A

Wurzeln 8, 15

Wurzelentwickelung 37

Xerophyten 33

Yarrow, Dwarf- $73 \mathbf{A}$

Yellow Star of Bethlehem, Liottard's $131 \mathrm{~A}$

Yevering bells $\mathbf{4 0}$

Zahnwurz, gefingerte 12 *

Zermatter 'Tal $8 \dot{x}$

Zucker 16

- reichtum 17

Zufammenfaffung 48

Zwergorchis, Alpen- 136*. 
I.

Allgemeiner Teil. 
Wer je aus der Ebene in die Alpen gereift ift, der kennt die allmähliche Veränderung, welche fich mit zunelımender Höhe in der Pflanzenwelt abfipielt. An Stelle der Getreide- und Kartoffelïcker treten faftige Graswiefen, die nach oben vom Bergwald begrenzt werden. Ift man in demfelhen einige hundert Meter geftiegen, fo wird er allmählich lichter und geht fchliefalich in eine niedere Vegetation von verkümmerten Bäumen oder Sträuchern üher, die fich zuletzt in den Alpwiefen und Weiden verliert. Mit diefen ift die Heimat der Alpenflora erreicht.

Diefe Folge von verfchiedenen Pflanzenbeftänden beobachtet man aber nicht nur in den Alpen Europas, fondern in jedem Gebirge, das eine gewiffe Höhe erreicht, in den Anden Amerikas fo gut wie in den mächtigen Gebirgen der afrikanifchen oder adiatifchen Tropenländer. Alle tragen von einer beftimmten Höhe an ihre Alpenfloren, dic überall durch den niederen gedrungenen Wuchs und die Fülle der Bläten ausgereichnet find.

Durch die Tatfache endlich, das man im hohen Norden am Strande des Neeres diefelben Blumen pflïcken kamn wie auf den Appenpaiffen, wird man zu der Auffaffung gedrängt, dafs die Alpenflora nicht ein Monopol unferer europäilchen Alpen ift, fondern ïberall da vorkommt, wo ähnliche klimatifche Bedingungen herrfchen.

Den Einflufs derfelben auf die Pflanzenwelt zu erforfchen, bildet eine anziehende Aufgabe der Pflanzenphyfiologie, die gerade in den letzten Jahrzehnten manche intereffante Tatfache aufgedeckt hat. Die Hauptrefultate diefer Forfchungen will ich im Folgenden wiederzugeben verfuchen. 


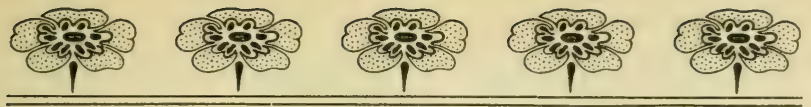

\section{Die Lebensbedingungen der Pflanzen in den Alpen.}

\section{Der Luftdruck.}

Alle Unterfchiede zwifchen dem Klima der Höhen und des Tieflandes find in letzter Linie auf die mit der' Höhe zunehmende Luftverdünnung, refp. auf die $\mathrm{Ab}$ nahme des Luftdruckes zurückzuführen. Gerade wie in Seen oder im Meere die tieferen Wafferfchichten unter dem Drucke der daraufliegenden ftehen, fo auch die tieferen Schichten des Luftmeeres, auf deffen Grunde wir leben. Da aber im Vergleich zum Waffer die Luft viel ftärker zufammendrückbar ift, zeigt fie in den tiefften Gegenden, am Meeresftrand, eine viel gröfsere Dichtigkeit, als einige taufend Meter ïber dem Meere. Die Luft wird daher mit zunehmender Höhe dünner, was befonders die Luftfchiffer oft am eigenen Leibe in unangenehmer IVeife erfahren mülfen. Genauen Auffchlufs über die Dichtigkeit refp. den Druck der Luft gibt uns das Barometer, weshalb ja diefes Inftrument zu Höhenmeffungen verwendet wird.

Wie Kulturverfuche im Tieflande mit künftlich verdünnter Luft gezeigt haben, wachlen die Pflanzen bei geringerem Luftdruck rafcher als unter normalen Verhältniffen. Die Luftverdünnung als folche kann alfo nicht den niedrigen Wuchs der Alpenflora hervorrufen, was ja auch die nordifchen Pflanzen beweifen, die, obgleich unter

G. Senn, Alpenflora. 
grof3em Druck gewachfen, ebenfo niedrig bleiben wie ihre Verwandten in den Alpen.

Die geringe Dichtigkeit der Luft übt alfo an und für fich auf das Wachstum der Alpenpflanzen keinen merkbaren Einfluf aus.

\section{Die Temperatur.}

\section{a. Die Luftemperatur in den Alpen und ihr Einfluß auf die Pflanzen.}

Eine dirckte Folge der Luftverdünnung in bedeutenden Höhın ift die für uns befonders fpürbare Abnahme der Luftemperatur, weshalb ja gerade der Aufenthalt in den Bergen als Sommerfrilche bezeichnet wird. Die Meteorologie hat die wichtige Tatlache feftgeftellt, daf mit $100 \mathrm{~m}$ Steigung das Jahresmiltel der Luftemperatur durchfchnittlich um $0,57^{\circ}$ finkt, oder bei $170 \mathrm{~m}$ um $1^{0}$ Cielfus. Diefe Zahl $\left(0, \tilde{s} 7^{\circ}\right)$, der Temperatursradient, ift allerdings bedeutenden Schwankungen unterworfen, indem er

$$
\text { im Sommer } 0,71^{\circ}
$$

auf der Südleite der Alpen $0,69^{\circ}$

auf der Nordfeite der Alpen $0,55^{0}$ heträgl.

Anch an frei auffeigenden Bergen (\%. B. Rigi) und befonder's bei freiem Auffieg im Ballon nimmil die Temperatur rafcher ah als beim Auftieg in einem Tale. Aus allen diefen Gründen liegen die Orte mit gleichem Jahresmittel, die man fich durch Linien, die Ifothermen, verbunden denken kann, nicht in gleicher Höhe. Für die Schweiz z. B. wurde von de Quervain*) feltgeftellt, dafis die Ifothermen der Mittagstemperaturen in den grofen Malliven der lüdlichen Wallifer Alpen (Monte Rofa) und

*) Gerlands Beiträge zur Geophyfik. Bd. VI. 1903. Heft 4. 
des Engadins beträchtlich höher liegen als in der übrigen Schweiz, fodaf allo diefe Gebiete wärmer find, als man bei ihrer Höhe erwarten follte. Diefe Begünftigung ift darauf zuräckzuführen, dafs in diefen hohen, mit tiefen Tälern durchzogenen Gebieten die tagsüber erwärmte Luft von den Winden nicht fo rafch weggeführt und durch kalte erfetzt werden kann, wie dies bei freiftehenden Bergen der Fall ift.

Diefe Wärmeverteilung fpiegelt fich nun in der auffallendften Weife in der fenkrechten Verbreilung der Pflanzen wieder. Wie in der Einleitung ausgeführt wurde, beginnt das eigentliche Gebiet der Alpenflora an der oberen Waldgrenze. Es ift daher wichtig, die Lage derfelben zu kennen. In verfchiedenen Gegenden liegt diefelbe in fehr verfchiedener Höhe. So fteigen z. B. die Alpenpflanzen im hohen Norden bis ans Meeresufer hinah, im Himalaya trifft man fie erft in Höhen an $(3800-4000 \mathrm{~m})$, die in unfern Alpen mit ewigem Schnee bedeckt lind. Wie fchon aus diefen beiden Beifpielen erlichtlich ift, wird die Lage der oberen Waldgrenze durch die Temperaturverhältniffe bedingt, was von de Quervain durch Feftlellung der Tatfache aufs fchlagendlte bewiefen wurde, daf die mittleren Mittagstemperaturen an der Waldgrenze überall gleich find. Infolgedeffen nimmt diefelbe im allgemeinen denfelben Verlauf wie die Ifothermen, fodaf auch fie im Monte Rola-Gebiet und im Engadin heträchtlich höher liegt als fonft, wie aus folgender Tabelle hervorgeht.

$\begin{array}{rc}\text { Jura } & 1400-1600 \mathrm{~m}, \\ \text { Voralpen } & 1650 \\ \text { Hochalpen } & 1800 \\ \text { Hochalpen } & 2050 \quad,\end{array}$
franzöfifch - italienifche Alpen, Wallis, Engadin $2200-2300, \cdot$

Die obere Grenze der Alpenflora, wenigftens ihres gefchloffenen Areals, wird durch die Schneegrenze gebildet, die ebenfalls, wenn auch nicht fo genau, mit den 
Die Temperatur.

Ifothermen zufammenfällt, fodaß die Schneegrenze mit der Waldgrenze mehr oder weniger parallel verläuft. Die Schneegrenze liegt:

Nördliche Hochalpen 2500-2800 m,

Balmhorn bis Finfteraarhorn

Montblane bis Matterhorn

Monte Rola

2950

3100

Telfiner Alpen

Bernina- und Spöl-Alpen

3260

2750

Der gefchloffene Beftand der alpinen Flora bildet alfo in unfern Alpen einen etwa $1000 \mathrm{~m}$ breiten Gürtel, der jedoch befonders nach oben nicht fcharf begrenzt ift.

Weit entfernt davon, dafa die Schneegrenze dem Pflanzenwuchs Halt gebietet, zeigen die fchneefreien Stellen der über der Schneegrenze gelegenen Höhen eine befonders charakterifierte und meift befonders farbenprächtige Flora: die Nivalflora, deren Vertreter auf die höchften Spitzen hinauffteigen. So wurde wenig unterhalb des Gipfels des Finfterarhor'ns bei $4270 \mathrm{~m}$ ein blühendes Exemplar von Ramunculus glacialis (Tafel 3) gefunden. Damit ift aber die höchfte Grenze für die Blütenpflanzen noch keineswegs erreicht, da Saussurea tridactyla, eine Verwandte der auf Tafel 76 abgebildeten Form, in Weft-Tibet noch bei $5800 \mathrm{~m}$ wächft, allo in einer Höhe, welche von unfern Alpengipfeln gar nicht erreicht wird.

Es fcheinen allerdings einzelne Pflanzen unferer Alpen zu ihrer völligen Entfaltung, befonders ihrer anfpruchsvolleren Organe, der Blüten und Früchte, nicht ftets eine genügende Wärmemenge zu erhalten, fodaf fie gezwungen werden, die der Erhaltung ihrer Art dienenden Samen durch rafcher ausgebildete Organe, die fogenannten Brutknofpen, zu erfetzen. Das auf Tafel $123 \mathrm{~A}$ abgebildete Polygonum ririparum ift ein fchönes Beifpiel hiefür. Die untere Hälfte der Blütenähre ift meift von zwiebelähnlichen Knöllchen befetzt, die oft fchon auf der Mutterpflanze Blätter und Würzelchen treiben, fodaß fie fich 
gleich nach ihrem Abfallen zu einem jungen Pflänzchen entwickeln können. Da aber auch Ähren vorkommen, die nur Blüten, oder folche, die nur Brutknofpen tragen, ift zu vermuten, dafs äußsere Einflüffe die Art der l'ortpflanzung beftimmen. Ich nehme an, es fei die niedrige Temperatur, welche den Ausfchlag gibt; es ift jedoch nicht ausgefchloflen, dafs zu fchwaches Licht oder zu große Feuchtigkeit, die ja in den Alpen meift gleichzeitig mit niedriger Temperatur eintreten, die Bildung der Blüten hindern und dadurch diejenige der Brutknofpen förder'n. Außer bei dem genannten Knöterich kommen gelegentlich folche Brutknofpen bei Saxifraga stellaris (II. Teil Seite 50), bei verfchiedenen Alpengräfern und beim Bürlapp, Lycopodium Selago ('Tafel 144A), vor.

Die wenigften Alpenpflanzen find übrigens darauf angewiefen, ihren ganzen Entwicklungsgang vom Samen bis zur Fruchtbildung in einem Sommer zu durchlaufen. Da die Mehrzahl der Alpenpflanzen ausdanernd, mehrjährig ift, brauchen fie nicht fchon in erften Sommer Stengel, Blätter und Blüten zu bilden, und gehen jedenfalls nicht, wie die einjährigen Kräuter der Ebene, nach der Fruchtbildung zugrunde. Befonders die Nivalflora (die über der Schneegrenze gedeiht) befitzt nach Heer nur $4 \%$ einjährige Arten, während diefelben in der Ebene etwa $50 \%$, alfo die Hälfte aller Arten, ausmachen. Daf dabei wirklich die niedere Temperatur und die Kürze der Vegetationsperiode den Ausfchlag gibt, geht aus den Verfuchen Bonniers und Kerners hervor, in denen verfchiedene einjährige Kräuter der Ebene, z. B. das Stiefmütterchen (Viola tricolor), auf alpinem Standorte mehrjährig wurden. Statt am Ende des Sommers Früchte auszubilden, trieben fie $\mathrm{Ab}$ leger, die überwinterten. Die Pflanzen waren fomit zweijährig geworden.

Überhaupt legen die meiften Alpenpflanzen die Blütenknofpen fchon im Herbft an, fodaf im Frühling ihre Entfaltung in wenigen Tagen vollzogen werden kann. 


\section{b. Die Bodentemperatur in den Alpen, der tägliche Gang der Temperatur und ihr Einfluß auf die Pflanzen.}

Neben der allgemeinen Erniedrigung der Lufttemperatur mit zunehmender Höhe find die während eines Tages eintretenden Wärmefchwankungen befonders für die Wuchsform der Alpenpflauzen von großser Bedentung. Weil die dünnere Luft nicht fo viel Wärme abforthieren kann als die dichtere der Ebene, gelangt eine größsere Wärmemenge bis zum Buden und zu den darauf befindlichen Gegenftänden. Die Erwärmung derfelben durch die Sommenftrahlung ift daher in den Alpen ftärker als in der Ebene, fodaß wir als Gegenftück zur niedrigen Luftemperatur in den Alpen hohe Bodentemperaturen zı verzeichnen haben. Der Temperaturunterfchierl zwifchen einem befchatteten Ort, an dem nur die Luftlemperatur zur Geltung kommt, und einem befonnten, an welchem die fift ungefohwichte Somnenftrahlung wirkt, ift daher in den Alpen viel grölser als in der Ebene, wie folgende Tabelle zeigt:

Ort

Temperaturen in
Höhe Zentigradeu (Celfius)

in $\mathrm{m}$ im an der

Schatten Sonne

Unterfchied

Witby, England

20

33

38

5

Puntrelina

1800

27

Bernina-Häufer Engadin 2:3:30)

19

41

17

Diavolezza

2980

6

46

60

27

54.

Diefe Tatfache fpiegelt lich auch bei der Meffung der' Bodentemperaturen wieder. Die Unterfchiede zwilichen Boden- und Luftemperatur find allerdings viel geringer als die in obiger Tabelle angegebenen, da der Boden nicht fohwal\% ift, wie das bei diefen Meffungen verwendete 'Thermometer, mul da er ron cier Luft ftets abgekühlt wird, was bei obigen Meffungen vermieden wurde. 


$\begin{array}{lrrrr}\text { Ort } & \begin{array}{c}\text { Höhe } \\ \text { in } \mathrm{m}\end{array} & \begin{array}{c}\text { Temperaturen in } \\ \text { Zentigraden (Celfius) } \\ \text { der Luft }\end{array} & \begin{array}{c}\text { der Boden- } \\ \text { oberfläche }\end{array} & \text { Unterfehie } \\ & 50 & 21 & 20 & -1, \\ \text { es Faulhorns } & 2680 & 8 & 16 & +8 .\end{array}$

Brülfel

Gipfel des Faulhorns 2680

Während alfo die Temperatur der Luft auf dem Faulhorn $13^{\circ}$ niedriger ift als in Brülfel, fteht die Bodentemperatur nur um 4." zurück. In den nordifchen Ländern, \%. B. in Spilzbergen, ift dagegen die Bodentemperatur um $1^{0}$ niedriger als die Lulttemperatur, weil die Sonnenftrahlen fehı l'chief auf den Boden treflen.

Allerdings ift der Boden nicht inftande, die tagsüber aufgenommene Wärme lange feftzuhalten, dir die Alpenluft keine fo dichte, warmhaltende Decke über ihn ausbreitet, wie dies die dichtere Luft der Ebene tut. So beträgt auf dem Hohen Somnblick in Kärnten $(3100 \mathrm{~m})$ die nächtliche Wärmeausftrahlung faft das Doppelte von derjenigen in Zürich $(450 \mathrm{~m})$.

Damit fich das Wachslum der Pflanze vollziehen kann, ift eine gewiffe Temperafur notwendig, deren Höhe allerdings bei den verfchiedenen Pflanzen verfchieden ift. So beginnt z. B. das Wachstum des Weizens bei $-5^{0} \mathrm{C}$, fteigt his zu $+99^{\circ} \mathrm{C}$; nimmt von da an wieder ab, um bei $+4^{0}{ }^{\circ}$ ganz aufzuhören. Bei Pflanzen wïrmerer Gegenden, z. B. dem Muis, beginnt das Wachstum erft bei $+90^{0} \mathrm{C}$ und hört bei $+46^{\circ} \mathrm{C}$ auf. Meines Wiffens find diefe Temperaturgrenzen für das Wachstum eigentlicher Alpenpflanzen noch nicht beftimmt worden. Da aber der Weizen mit leinem Wachstumsheginn bei $-5{ }^{\circ} \mathrm{C}$ nirgends in die Alpenregion hinauffeigt, ift anzunehmen, daßs die Alpenpflanzen bei ebenfo tiefen, vielleicht noch tieferen Temperaturen zu wachlen beginnen. Ein hübfches Beifpiel für das Wachstum bei niederer Temperatur liefert das Alpenglöcklein, Soldanella (Tafel!) das zuweilen mit feinem Blütenfchaft, wohl dank leiner' Atmungswïme, Öffnmengen in die Schneedecke fchmilzl und die Blüten über dem Schnee entfaltet, während Blätter 
Die Temperatur.

und Wurzeln vom Schnee bedeckt und vom kalten Schmelzwaffer befpült werden.

Die mitgeteilten Zahlen über Luft- und Bodentemperaturen geben uns wichtige Auffchlüffe über die von der Wachstumsgefchwindigkeit abhängige Größe der Alpenpflanzen. Da, wie wir fpäter (S. 14) fehen werden, die Pflanzen hauptfächlich nachts wachfen, find wenigftens inre oberirdifchen Teile von der Lufttemperatur in den Alpen wenig begïnftigt. Das Wachstum der Stengel und Blätter ift daher fo gering, dafo die Gewächfe, auch folche, die aus der Ebene in die Alpen verpflanzt wurden, niedrig und kurzftengelig bleiben, und dafis die aus demfelben Grunde klein bleibenden Blätter meiftens dicht gedıängt an den Stengehı ftehen, öfter's zu grundftändigen Rofetten vereinigt.

Unter gïnftigeren Bedingungen vollzieht fich das Wachstum der unterirdifchen Teile, der Wureln. Wie wir Seite 7 gefehen, ftehen die in den Alpen beobachteten Bodentemperaturen hinter denjenigen der Ebene nur wenig zurück, sodaf3 die Wurzeln in ihrem Lüngenwachstum nicht gehemmt find wie die oberirdifehen Teile, $11 \mathrm{~m}$ fo weniger, als fie, dem Licht entzogen, auch am Tage bei ltark erwärmtem Boden wachlen können. Infolgedeffen belitzen die Alpenpflanzen ein reichentwickeltes Syftem ron Wurzeln, deren Länge im Vergleich mit den oberirdilchen Teilen unverhältnismäßig groß ift. Die Kulturverfuche von Bonnier*) mit Pflanzen der Ebene auf alpinem Standorte haben fogar gezeigt, daß die unterirdifchen Teile in den Alpen abfolut größser und ftärker werden als an den Exemplaren der Ebene, obwohl deren oberirdifche Teile fünf- bis fechsmal größer find als bei den in den Alpen gewachfenen Exemplaren derfelben Art. Obwohl zu diefer mächtigen Wurzelentwicklung der Alpenpflanzen, wie wir (S. 16 und S. 38) fehen werden, auch

*) G. Bonnier, Annales des Sciences naturelles. Botanique. 7. Serie. XX. 1894. 
die guten Ernährungsverhältniffe beitragen, wird fie doch erft durch die hohe Bodentemperatur und die Abwefenheit des Lichtes ermöglicht.

Der niedrige Wuchs der Alpenpflanzen wird fomit in erfter Linie durch die niedrige Temperatur bedingt, die ja auch die hervorragendfte Eigenfchaft der nordifchen Klimate bildet, welche teilweife diefelben, jedenfalls auch nur zwergige Pflanzen beherbergen.

Eine befondere Art des Zwergwuchfes, den fogenannten Spalierwuchs, zeigen faft alle Holzpflanzen der alpinen Region, fo die Alpweiden (Tafel 127), der Wacholder (Tafel 129) und andere. Derfelbe kommt dadurch zuftande, daf fich die jungen Triebe nicht fenkrecht erheben, fondern fich dem Boden oder den Steinen anfchmiegen, wahrfcheinlich durch deren höhere Temperatur angezogen (Thermotropismus). Sollte diefe Auffaffung durch Verfuche als richtig erwiefen werden, fo wäre der Spalierwuchs als eine Schutzmaßregel gegen die niedrigen Lufttemperaturen aufzufaffen.

\section{c. Die Verteilung der Wärme}

im Laufe des Jahres und ihr Einfluß auf die Alpenpflanzen.

Für die Pflanzen ift nicht nur die Verteilung der Wärme auf einem Berge oder während eines Tages von Bedeutung, fondern ebenfofehr der Gang der Temperatur im Laufe des Jahres. In erfter Linie ift die Dauer der fchneefreien Zeit von Wichligkeit. Kerner hat aus 16jährigen Beobachtungen folgende Zahlen für die Schattengrenze des mittleren Inntales berechnet:

bei $600 \mathrm{~m} 9$ Monate fchneefrei,

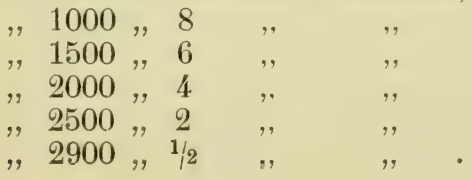


Dabei ftellt fich die Sonnenfeite natürlich beffer als die Schattenfeite, und zwar fo, dafs bei $100 \mathrm{~m}$ Steigung die fchneefreie Zeit auf der Südleite nur um 10 Tage, in Nordlage aber um $11^{1 / 2}$ Tage kürzer wird.

Infolge der fpäten Schneefchmelze in der Höhe ift die Dauer eines Frühlingstages in den Alpen bedeutend lïnger als in der Ebene, wohei auferdem die Sonne l'chon viel höher ftehl, was fich beides in der Lufttemperatur bei der Schneelchmelze deutlich widerfpiegelt; lie beträgt:

$$
\begin{gathered}
\text { bei } 600 \mathrm{~m}-0,7^{\circ} \mathrm{C} \\
. \quad 1000,,+5,1^{\circ} \mathrm{C} \\
, 1500 ",+6,2^{\circ} \mathrm{C} \\
,, 2000,,+7,0^{\circ} \mathrm{C}
\end{gathered}
$$

Infolgedefien unterfcheidet fich der Alpen- vom Talfrühling bedeutend. Während die Schnee- oder Winterpflanzen, welche während oler gleich nach der Schneefchmelze ans dem Boden hervorbechen und ihre Bläten entfalten, in der Ehene nur in kleiner Zahl vorhanden lind (\%. B. der Winterling, Eranthis, und die Weihnurhtsrofe, ITelleborus niger), prangen infolge der verhailtnismäfig langen 'Tage und der hohen Lufttemperatur die Alpenmatten im dichteften l'lor, fohald der schnee anch nur teilweife das Feld gerëumb. Von den elwa acht diele alpine Schneeflorat bildenden Pflanzen leien folgende genannt: Soldanella alpina und pufilla (Tiafel 95), der weifhlütige Ranunculus alpestris (II. Teil S. 2), Anemone remalis (II. Teil S. 4). (ianger Liottardi (Tafel 131 A), Alchemilla pentaphyllea (II. Teil S 41).

Gröfseren Anfjurch an Wäme macht die nach völligem Verfchwinden des schnees ertheinende alpine Frühlingsflora, zu welcher elwa folgende drten gehören: Kamunculus montanus (II. Teeil s' 2), Gentianu

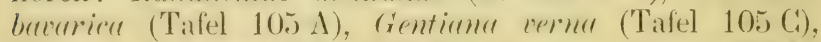
Proimulu furinose (Tafel 98 B), Orylria digymu (Tafel 123 B), welchen in der Ebene Schnee- und Mär-zylöchichen und Schliiflelblumen entlprechen. 
Die Blütezeit diefer beiden mit fo wenig Wärme zufriedenen Gefellfchaften rückt parallel mit der Schneefchmelze aus den tieferen in die höheren Lagen empor, bis dann von der Schneegrenze an aufwärts alles zugleich blüht: Schneeflora, Frühlingsflora und die nur einen kurzen Sommer geniefende Nivalflora. Hier ift es alfo, wo der Herbft und der Frühling fich gatten", fodaß wir nur im gefchloffenen Beftand der Alpenflura, unterhalb der Schneegrenze einen Frühling, Sommer und Herbft unterfcheiden können.

Der Alpenfommer ift durch das Blühen des Hauptkontingents der Alpenpflanzen charakterifiert, deren Aufzählung viel zu weit führen würde; es fei nur an die großen Familien der Papilionaceen (Tafel 25ff.), Saxifrogeen (Tafel 49 fo.), Kompofiten (Tafel 62 ff.), Scrophlular iuceen (Tafel 111 ff.) und Oichideen (Tafel 136ff.) erinnert.

Der II erbft, d. h. die Fruchtreife, fïllt etwa mil dem der Ebene zufammen. Genaue Angaben ïber den Begimn der Fruchtreife in den Alpen fehlen allerdings noch, aber es muf jedem Befucher der Alpen auffallen, wie hald die Blülenprachl vorïher ift, und wie fchon anfangs September manche Pflanzen ihre Früchte gezeitigt haben. Dies ift anch notwendig, da allerdings vorerlt nicht die Kälte, fondern die Trockenheit des Bodens den Stoffwechlel der Pflanzen bald ein Ende bereitet. Mit dem endgültigen Einfchmeien beginnt dann der lange Alpenwinter.

Es ift alfo den Pflanzen der Alpenregion für ihren ganzen Entwicklungsigang im Vergleich zu denjenigen der Ebene eine kurze Spanne Zeit gewäht, was belonders in der Breite der Jahresringe in den Stämmchen der Holzpflanzen zur Geltung kommt. Während man bei Tamnen- oder Wacholderfämmen tieferer Stindorte die Jahresringe ohne weiteres z:̈hlen kann, ftehen fie in den Stämmen aus höherer Lage fo dicht, daf man fich beim Zählen derfelben eines Vergrößerungsglafes be- 
dienen muf. Die Pflanze braucht die während der kurzen Periode aktiven Lebens gefammelten Stoffe für die Ausbildung der nahrungsaufnelimenden (Wurzeln, Blätter) und der famenbildenden (Blüten) Organe, und kann fich daher den Luxus eines mächtigen Holzkörpers nicht leiften; daher der Mangel an Baumwuchs in der alpinen Region.

Aus alledem ergibt fich, daf die in den Alpen lebenden Pflanzen keine großen Anfprüche auf Wärme machen dürfen. Ihrer Fähigkeit, fchon bei niedrigen Temperaturen zu wachfen, verdanken fie ihr Gedeihen in fo bedeutenden Höhen wie ihre Verwandten in den polaren Ländern. Die Alpenflora ift alfo eine ausgefprochene Kälteflora.

\section{Das Licht.}

Da die Luft nicht nur die Wärme-, fondern auch die Lichtftrahlen zu abforbieren vermag, hängt auch die Menge des auf den Erdboden gelangenden Lichtes von der Luftmenge ab, die es vorher durchdrungen hat. Die mit zunehmender Höhe eintretende Abnahme der Luftfchicht, welche auf dem Boden ruht, hat auch eine Abnahme der Lichtabforption zur Folge; die Sonnenftrahlung nimmt daher zu, und zwar noch rafcher als die Abnahme des Luftdruckes. Es kommt nämlich noch ein Zweites hinzu. Wie wir fpäter fehen werden, ift dünne Luft nicht imftande, viel Walferdampf aufzunehmen. Da nun derfelbe viel Licht abforbiert, in der Alpenluft aber in viel kleinerer Menge vorhanden ift als in der Ebene, gelangen in der Höhe die Somnenftrahlen faft ungefchwächt auf den Boden, was gleichzeitig ausgeführte Beobachtungen von Violle und Margottet in verfchiedenen Höhen des Montblanc-Gebietes ergeben haben. 
Setzten fie die bis zur äußeren Grenze unferes Luftmeeres gelangende Menge des Sonnenlichtes gleich 100, fo ergaben ihre Meffungen folgende Zahlen:

Höhe in Luftdruck Dampffpannung Lichtmenge

Montblanc-Gipfel

Grands Mulets

$\mathrm{m}$

4810 in $\mathrm{mm}$

3050

430

1,0

in $\%$

Boffongletfcher

Paris

$1200 \quad 661$

60

94

89

79

68.

In der Ebene (Paris) gelangen fomit nur etwa ${ }^{2 / 3}$ der urfprünglichen Lichtmenge bis zur Erdoberfläche, während fchon in den Voralpen $(1200 \mathrm{~m})$ die Pflanzen ${ }^{4} / 5$, an der Schneegrenze $9 / 10$ der urfprünglichen Lichtmenge genießsen.

Dies allerdings nur bei wolkenlofem Himmel! Bei der ftarken Bewölkung, die fich in den Alpen befonders im Sommer geltend macht, und bei den vielen Nebeltagen (67 und darüber im Sommerhalbjahr) fällt natürlich der Lichtgenuf nicht fo grof aus. Trotzdem herrfcht in den Alpen, was ja jeder Amateurphotograph weif, auch bei trübem Wetter ftärkeres Licht als in der Ebene.

\section{Der Einfluß des alpinen Lichtes auf die Pflanzen.}

Da die grünen Pflanzen mehr als alle andern Organismen, befonders bei ihrer Ernährung, vom Licht abhängig find, ift es begreiflich, daf lie für Helligkeitsunterfchiede empfindlich find und entfprechend reagieren.

a. Der Stengel.

Es ift eine bekannte Tatfache, dafs die Stengel, welche die Kartoffeln im dunkeln Keller treiben, viel länger find als diejenigen der auf den Feldern wachfenden Kartoffelftauden. Dies tritt befonders deutlich hervor, wenn man die zwifchen je zwei Blättern befindlichen Stengelftücke, die Stengelglieder oder Internodien, miteinander vergleicht. Ihr Längenunterfchied wird, wie genaue Unterfuchungen ergaben, durch die Unterfchiede 
in der Lichtftärke hervorgerufen, indem das Licht das Wachstum hemmt, und zwar um fo mehr, je ftärker es ift. Die Alpenpflanzen, deren Stengel wïhrend der Nacht infolge der niederen Luftemperatur nicht wachfen können, werden bei Tage, da höhere Temperatur herrfcht, durch das ftarke Licht am Wachstum verhindert. Die Folge davon ift ihr kurzer gedrungener Wuchs, der häufig auch hei folchen Pflanzen zu Rafen- und Rofettenbildung fiihrt, deren Verwandte in der Ebene hochftengelig und gleichmäß3ig beblättert find, fo \%. B.: Actitlea nana (Tafel $73 \mathrm{~A}$ ) und Silene acaulis (Tafel 19B).

Werden jedoch lolche Pflanzen in der Ebene kultiviert, fo verlingern fich die Stengel; beim Ecielweifs ltreckt fich auch der Blïlenftand, lodafs der an alpinen Exemplaren gedrungen erfcheinende Stern zerfahren ausfieht. Wird dagegen am Ebenenltandort das Alpenklima dadurch nachgeahmt, dafs die Pflanze nachts in den Eislchrank und tagsüber möglichft fonnig geltellt wird, (i) bleibt auch der gedrungene Wuchs erhalten.

Ungekchrt verkürzen die Pflanzen des Tieflandes im alpinen Klima ihre Stengel, was durch Verkürzung der einzehnen Stengetglieder und durch Verringerung ihrer Zahl erzielt wird; zugleich tritt auch die Verzweigung viel ftärker hervor. So kultivierte Kerner*) eine weiß̧hlühende Doldenpflanze (Seseli Libonotis, ähnlich der auf Tafel is abgebildeten) in einigen Exemplaren in Wien und in leinem appinen Verluchsgarten an Blater (Tirol) bei etwa $2000 \mathrm{~m}$ Höhe. Die Meffumgen der Pflanzen ergaben:

Stengelhöhe

Zahl der Stengelglieder Wien

Bla fer

Liinge jedes stengelgliedes Urfirung der Ïlte

$100 \mathrm{~cm}$

10

$15-24 \mathrm{~cm}$

1 ()— $20 \mathrm{~cm}$

aus den mittleren uml 5

oberen Blattwinkeln Blattwinkeln

Zahl der Blütendolden 20 5 .

*) Kerner, Pflanzenleben. Bd. II. Seite 501 ff. (I. Aufl.) 
Das alpine Licht (verbunden mit der niederen Temperatur während der Nacht) erzeugt allo kürzere und weniger zahlreiche Stengelglieder, jedoch eine frühere und ftärkere Verzweigung, wodurch die gedrungenbufchigen Wuchsformen entftehen.

\section{b. Die Wurzeln.}

Dat3 die in Boden fteckenden Wurzeln bei ihrem Wachstum vom Licht nicht gehemmt werden, liegt auf der Hand. Diefem Lmftand und der befonder's wiihrend des Tages erhöhten, aber auch nachts nicht fehr tiefen Bodentemperatur verdanken die Wurzeln der Alpenpflanzen ihre bedeutende Entwicklung. (Vergleiche auch Seite 8 und Seite 38.)

\section{c. Die Blätter.}

Die Blätter, welche eigentlich die mit Sonnenenergie betriebenen Laboratorien der Pflanze darftellen, find begreiflicherweile der Zufuhrnenge der Betriebsenergie, der Lichtmenge, angepafist. Schon an Pflanzen des Tieflandes, z. B. den Lïhen, kann man die an der Oberflïche der Krone gewachlenen Sonnenblätler von den im Innern entftandenen an Form und Dicke unterfcheiden. Sie find meift tiefer gelappt und zugleich dicker. Nllerdings ift ihre Geftalt in erfter Linie von den Feuchtigkeitsverhältniffen abhängig (vergleiche S. 35), ihre Gröfe und Dicke wird jedoch, wie die Verfuche Bomniers erwiefen hahen, durch dic Lichtftïrke bedingt. Starkes Licht hemmt nämlich nicht nur das Längenwachstum der Stengel, fondern auch das Flïchenwachstum der Blätter, fodaf diefelben an den Alpenpflanzen allgemein kleiner find als an den Tieflandpflanzen. IVas aber an Größse verloren geht, wird durch gröfsere Dicke (zuweilen faft die doppelte) und durch eine zweckmäfigigere innere Einrichtung, eine leiltungsfähigere Organifation erfetzt. So intereflant gerade letztere ift, muf ich doch verzichten, näher auf fie einzugehen, da fie nur dem mit einem Mikrolkop bewaffneten Auge zugänglich ift. 
Wie die Stengel, fo verlieren auch die Blätter der Alpenpflanzen in der Ebene ihre alpine Form und Struktur, während fich umgekehrt die Blätter von Tieflandpflanzen auf alpinem Standorte den dafelbft herrfchenden Lichtverhältniffen anpaffen, wenn fie nicht, wie dies bei einzelnen Formen feftgeftellt wurde, in dem ihnen zu ftarken Alpenlicht vergilben und zugrunde gehen (Leinpflanze).

Jedenfalls find die Blätter der Alpenpflanzen trotz ihrer Kleinheit vorzügliche Ernährungsorgane. Genaue Unterfuchungen über die Menge der in beftimmter Zeit verarbeiteten Kohlenfäure der Luft und die daraus gebildete Menge von Zucker und Stärke fehlen allerdings vorläufig, doch kann der Reichtum der Alpenpflanzen an folchen Stoffen aus andern Tatfachen abgefchätzt werden.

Dafs das Alpenheu viel kräftiger ift als dasjenige der Ebene, geht fchon aus dem viel reicheren Ertrag der alpinen Milchwirtlchaft hervor.

Auferdem ïbertrifft auch die Honigausfcheidung in den Blüten der Alpenpflanzen diejenige der Tieflandpflanzen beträchtich, was fchon aus einer Bienenzuchtftatiftik des franzöfifchen Département des Pyrénées hervorgeht, das vom Meeresfpiegel bis zu $1500 \mathrm{~m}$ faft 20000 ziemlich gleichmäßig verteilte Bienenftöcke befitzt. Der Honigertrag eines Stockes beläuft fich durchfchnittlich

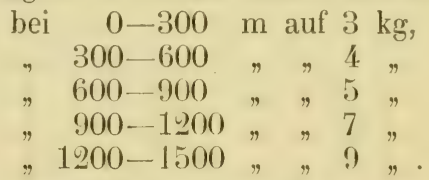

Obwohl dabei die alpine Höhe noch gar nicht erreicht ift, hat fich der Ertrag bei $1500 \mathrm{~m}$ dem Tieflande gegenüber verdreifacht, was auf einen größseren Honiggehalt der Bergblumen zurückgeführt werden muf, da z. B. der Sporn der Orchideenblüte, der als Honigrefervoir dient, bei der weißblütigen Platanther Ebene nur zu einem Drittel, auf den höheren Stand- 
orten bis über die Hälfte feiner Länge mit dem költlichen Stoff gefüllt ift.

Einen ebenfalls indirekten, aber fehr wichtigen Beweis für den Zuckerreichtum der Alpenpflanzen liefert die Tatfache, dafs ihre Stengel und Blätter, und fehrr oft auch die Blüten, rotviolett gefärbt find. Der diel'e Färbung hervorrufende Farbftoff, welcher, wie z. B. das Verryißmeinnicht zeigt, fehr leicht in Blau übergehen kann, wird als Anthocyan bezeichnet. Er befindet fich in wïßriger Löfung in der Pflanze, weshalb er beim 'Trocknen derfelben meiftens verdirbt, während die an Körnchen gebundenen gelben und grünen Farbftoffe viel weniger veränderlich find. Laboratoriumsverfuche haben nun gezeigt, dafs manche Pflanzen, die gewöhnlich kein Anthocyan bilden, imftande find, dies zu tun, fobald man ihren Zuckergehalt erhöht, was in der Natur befonders durch ftarke Belichtung gefchieht, die die Verarbeitung der Kohlenfäure zu Zucker fördert. Diefer Fall tritt ftets ein, wenn Gewächfe des Tieflandes in alpine Höhen verpflanzt werden. Es ift deshalb ganz allgemein eine Zunahme des Anthocyans zu konftatieren, indem die Farbe blaner oder roter Blüten gefteigert wird, oder fonft grüne und farblofe Organe, z. B. weißse Blüten, Anthocyan ausbilden. Letztere find daher bei Arten mit weiter Verbreitung am tiefen Standorte weiß, in der Höhe dagegen rot, wofür der große Bibernell (Pimpinella magna, Tafel 58) ein treffendes Beifpiel liefert. Tritt in grünen Pflanzenteilen rotes Anthocyan auf, fo erfcheinen diefelben rotbraun. So zeigten die weifen Margueriten unferer Felder im Alpengarten Kerners rotbraune Blätter und rote Blüten.

Mit der ftarken Ernährung der Alpenpflanzen fteht auch der ftarke Duft vieler alpiner Arten im Zufammenhang. Daphne striata (Tafel 125 B), Nigritella angustifolia (Tafel 136) und Gymnadenia odoratissima (Seite 137) ftrömen einen Vanillegeruch aus, wie er keiner unferer Tieflandpflanzen in folchem Grade zukommt.

G. Senn, Alpenflora. 
Alle diefe Eigenfchaften verdanken die Alpenpflanzen der großen Lichtfülle, welche von den Blïttern in fo vollkommener Weile zur Bildung von Zucker und der daraus bereiteten Stoffe verwertet wird.

\section{d. Die Blüten.}

Der Einflufs des alpinen Lichtes auf die Blüten ift nicht minder auffallend als derjenige auf die Blätter. Es ift eine allen Blumenfreunden bekannte Tatfache, daf3 die Pflanzen zur Ausbildung von Bläten mehr Licht bedïrfen als zur Bildung von Stengehn und Blättern. Es gelang logar fchon, eine Pflanze 7 Jahre lang in fchwachem Lichte zu üp)igem Wachstum zu veranlaffen, ohne dafs fich je eine Blütenknofpe gezeigt hätte. Starkes Licht fördert fomit die Blïtenbildung, während es zugleich das Wachstum ron Stengel und Blïttern hemmt. Dementliprechend trägt in den $\Lambda$ pen faft jeder Zweig Blüten, wodurch bei cler ftarken Ver'zweigung der alpinen Gewäichfe (vergleiche Seite 14) eine verhailtnismäßsig grofe Zahl von Blüten erzeugt wird.

Auch zeitlich find die Blumen der Alpenpflanzen den Tieflandprlanzen gegenüber im Vorfprung. Letztere blühen, in die Alpen rerpflanzt, frïher als an ihrem tiefen Standort, obwohl die Bildung von Stengeln und Blättern fpäter erfolgt als im Tale. Mchrere Arten mit weiter Verbreitung blühen deshalh in den Alpen fchon im Juli, fo z. B. Permassiu pulustris (Tafel 16 B) und Gentiana yrommicu (II. Teil S. 107), withlend fie auf den Hügehn (ler Ehene (rft einen Monat füiter ihre Blüten entfalten. Hänfig hört man auch von der auffallenden Gröfe der Alpenblumen fiprechen. Cienaue Meffungen haben jedoch gezeigt, dafs die Blüten in den Alpen meift nicht gröfser, fondern kleiner werden als am tieferen Standort, und nur im Verhältnis zur Kleinheit ihrer Träger grof erfcheinen.*) Ein bekanntes Beifpiel hiefür ift das Herz-

*) R. Keller. Die Blüten alpiner Pflanzen, ihre Gröfse und Farbenintenfität. B. Schwabe. Balel 1887. 
blatt, Parnassia palustris (Tafel 16B), deffen Blütendurchmeffer in der Ebene 2,3--3,4 cm, in den Alpen dagegen nur etwa $2 \mathrm{~cm}$ beträgt, wobei die ganze Pflanze in der Ebene his $30 \mathrm{~cm}$, in den Alpen nur 10 cm erreicht. Die Kleinheit der Blumenblïtler alpiner Blïten ift fchon deshalb zu crwarten, weil ja auch die gr ïnen Blätter in der Alpenregion an Größze abnehmen.

Wenm man alfo auch den Alpenpflanzen den Ruhm befonderer Blütengrößse abfprechen muf, ift derjenige der größeren Farbenintenfität über jeden Zweifel erhaben. Der Reichtum an rotem Farbltoff, dem Anthocyan, der bereits für alle Organe der Alpenpflanzen hervorgehoben wurde, kommt in den Blüten am ftärkften zur Geltung. Nicht nur find alle auf alpinem Standort entwickelten Blüten ftärker gefärbt als die im Tieflande gewachfenen; nicht nur erhalten Pflanzen, die unten weifs blühen, in den Höhen rote Blumen, fondern es entftehen auch nene Farben, die wir in der Ebene umfonft frchen. Tritt nämlich in einer Blïte, die in der Ebene gelb gefürbt ift, neben die gelben Farbftoffkörnchen noch das rote Anthocyan, fo enffteht ein lenchtendes. fattes Orangerot, das unferer Ebsenenflora fehlt. Als Beifpiele feien die auf Tafel 78 und 81 abgebildeten (reppis anren und Hievocium aurantiacum genannt.

Es find aber nicht nur die einzelnen Blüten der in der Höhe gewachfenen Pflanzen ftïrker gefürbt als diejenigen der Ehene, fonder'n ganze Familien (befonders folche, die an die intelligenteren Infekten angepafat find) befitzen in den Alpen mehr rote Blüten als im Tiefland. Für die Schweiz wurden z. B. bei den Primulaceen (Tafel 25 ff.) durch Keller folgende Verhältniffe feftgeftellt:

Alpen

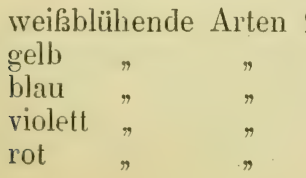

$8,33 \%$

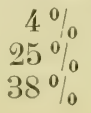

Eberie

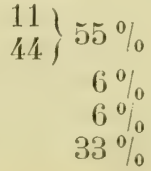


Während alfo die blauen Blüten in beiden Gebieten ungefähr in demfelben Verhältnis vertreten find, gehen die gelben und weißen in den Alpen zugunften der violetten und roten bedeutend zurück. Dies gilt auch für die Cruciferen und Scrophularineen. Angefichts unferer Erfahrungen über die Bildungsbedingungen des roten Farbftoffes, des Anthocyans, wird wohl niemand die Anficht für unbegründet halten, daßs man in diefem ftarken Hervortreten roter Blüten einen Erfolg der jahrtaufendelangen Wirkung des ftarken Alpenlichtes erblicken mülfe.

Zufammenfaffend kann fomit gefagt werden, daf alles, was uns die Alpenpflanzen wertvoll (gutes Heu, viel Honig) und angenehm macht (viele fchön gefärbte Blumen mit gutem Geruch), eine Wirkung des ftarken Höhenlichtes ift. Die Alpenflora ift fomit nicht nur als eine Kälteflora, fondern auch als eine ausgefprochene Lichtflor a $\mathrm{zu}$ bezeichnen.

\section{Die Infekten.}

Lange bevor ein Botaniker den Unterfchied zwifchen Blumen aus tieferen Gegenden und den in den Alpen gewachfenen in Farbe, Geruch und Honigreichtum feftgeftellt hatte, kannten ihn die Infekten, welche auf ihre Weife Botanik trieben. Diefelbe befteht darin, daf fie fich die Blumen merken, die ihnen zugänglich find, und die ihmen am meiften Honig darbieten. Sie werden dabei, wie neuere Verfuche gezeigt haben, hauptlächlich durch ihren Sinn für Geruch und Farbe, einige auch durch ihren Formenfinn geleitet.

Man ift leicht verfucht, in der Honigausfcheidung der Blumen die vorforgliche Hand der Mutter Natur zu erblicken, welche das Pflanzengefchlecht veranlaft, ihren fechsbeinigen Kinderchen, den Infekten, eine mühelofe Befchaffung unentgeltlicher Nahrung zu ermöglichen. 
Aber ebenfowenig wie wir Stadtleute erhalten die Schmetterlinge und Bienen den Honig gefchenkt. Denjenigen Pflanzen, bei welchen die Befruchtung nicht wie z. B. bei den Gräfern durch den Wind vermittelt werden kann, erweifen fie allerdings unbewußst mit ihrem Honigfammeln den wichtigen Dienft, den an ihren Haaren abgeftreiften Blütenftaub aus der einen Blïte auf den Stempel einer anderu derfelben Art zu bringen, wodurch die Befruchtung vollzogen wird. Denn obwohl beide Organe, die männlichen Staubgefäße und die weiblichen Stempel, meift in einer Blüte vereinigt find und dicht beifammen ftehen, ift es doch in vielen Fällen unmöglich, daf der Blütenftaub zu der Narbe und von ihr zu den im Fruchtknoten enthaltenen Eiern der

Pflanze gelange.

Jedenfalls ift, wie zuerft Darwins Verfuche gezeigt haben, eine Befruchtung mit Blütenftaub aus einer anderen Blüte, die fogen. Fremdbeftäubung, vorteilhafter als die Befruchtung mit Staub aus derfelben Blüte, als Selbftbeftäubung, indem fchon in der zweiten Generation bei Fremdbeftäubung mehr Früchte und aus deren Samen kräftigere Individuen entftehen als bei Selbftbeftäubung. Aus diefem Grunde können die durch Fremdbeftäubung entftandenen Individuen die übrigen zurückdrängen, fodaß gerade diejenigen Eigentümlichkeiten der Blumen beibehalten werden, welche die Fremdbeftäubung durch Infekten begünftigen. Letztere werden fomit zu eigentlichen Blumenzüchtern. Dabei ift es allerdings noch völlig dunkel, welcher Faktor bei den Infekten den Anftof zur Ausbildung der für den Blumenbefuch fo güntigen Mundwerkzeuge gegeben hat. Jedenfalls fteht felt, das zwilchen Blumen und Infekten innige Beziehungen beftehen, deren Aufklärung fich die logen. Blütenbiologie*) zur Aufgabe geftellt hat. Es kann fich

*) Müller, Herm. Alpenblumen, ihre Befruchtung durch Infekten und ihre Anpaffungen an diefelben. Leipzig. Engelmann 1881. 
hier nur darum handeln, die Hauptergebniffe diefer Disziplin anzudeuten, foweit fie für unfere Zwecke in Betracht kommen.

Da der Blütenftaub nur in einer Blüte der gleichen Art befruchtend wirken kann, wird dadurch noch keine erfolgreiche Beftüubung erreicht, dafs die Infekten Honig oder Blütenftaub fuchend von Blume zu Blume fliegen. Ihre Befuche lind für die Blüten wertlos, fo lange die Infekten nicht öfter's bei folchen von derfelben Art ankehren. Es ift daher vorteilhaft, wenn dafür geforgt wiıd, daf ein beltimmtes Infekt nur einen kleinen Kreis von Blumen befucht, wodureh die Chance einer erfolgreichen Beftäubung erhöht wirrl. Dies erreichen die Blüten durch Geruch und Farbe, indem, wie es fich herausgeftellt hat, jerle Infektengruppe (vielleicht infolge ihrer Blumeilbefuche) ihre Lieblingsfarben und-gerüche hat. So findet man auf grünen, weißen und gelben Blüten vorwiegend Kïfer und Fliegen oder kurzrößßlige Bienen, bei den blauen und violetten befonders Hummeln und langrülßlige Bienen, auf den roten vorwiegend Falter.

Als niederfte Stufe der gegenfeitigen Bezichungen muf aus verfihiedenen Grïnden diejenige betrachtet werden, auf welcher die Infekten den zur Befruchtung beftintmen Blütenftaub wegen feines Reichtums an Nährftoffen verzehren und dabei einen Teil desfellen an ihren Haaren in andere Blüten tragen. So lange der Blütenftaub (oder Pollen) in grofser Menge ausgebildet wird, wie bei den Anemomen (Tifel 4-(i) oder Rosen (Tafel 43), ilt es ohne Belang, wenn auch ein Teil desfelben feiner' urfprünglichen Beftimmung entfremdet und verfpiefen wird. Man bezeichnet diefe an Blütenftaub reichen, honiglofen Blüten als Pollenblumen. Sie find befonders häufig weifs odẹr gelb gefürbt und werden meift von kurzrüfligen Infekten, Käfern und Fliegen befucht, feltener auch von Bienen und Faltern, die hier ihren Bedarf an Blütenftaub decken.

Sind jedoch nur wenige Staubbeutel vorhanden, fo 
könnte das Auffreffen des Blütenftaubes die Befruchtung verhindern. Da find diejenigen Blumen im Vorteil, die den Infekten noch etwas Befferes als Blütenftaub, die ihnen Honig liefern können. Über dem Suchen nach dem köflichen Zucker wird der Blütenftaub vor dem Verfpiefen-werden verfchont, dagegen noch wie bisher am Haarkleide von einer Blüte zur andern transportiert. Es treten alfo die Honigblumen mit wenig Staubblättern als leicht unterfcheidbare Gruppe neben die Pollenblumen.

Obwohl durch das Ausficheiden der Pollenblumen mit ihren Infekten der Kreis von Beftüubern der Honigblumen verringert wurde, blieb ihre Zahl doch noch fo grof, dafs eine weitere Rubrizierung vorteilhaft erfchien. Bei derfelben wurde die verfchiedene Intelligenz der verl'chiedenen Infektengruppen verwertet, indem der Honig in den einen Blüten offen daliegt, fodaf er fchon von den herzufliegenden Infekten erkannt werden kann; in den andern ift er mehr oder weniger gut verfteckt, foclaf ihn der Befucher auffuchen oder feinen Platz kennen nufs, wozu es natürlich mehr. Intelligenz braucht als zum bloken Ablecken. Die Blüten mit ungeborgenem Honig werden daher auch von fchwach begabten Infekten, von Käfern und befonder's von den Fliegen befucht, welche durch die weiken und verfchiedene Nuancen von gelb zeigenden Blüten und deren (uns allerdings zuweilen unangenehmen) Geruch angeluckt werden. Hierher gehören z. B. Ramunculus aronitifolius. (Tafel 2) und Bupleurum longifolium (Tafel 57).

In den Blüten mit verborgenem Honig find die gefcheiteren Infekten, die Hummeln, langrüßßjigen Bienen und Schmetterlinge allein Meifter, da nur fie hier den Honig funden können. Ob, fie ihn auch erreichen, hängt von ihrer Rüffellänge ab. Da der Honig zuweilen im Grunde mehrere Zentimeter langer und enger Röhren aufgefpeichert ift, vermögen ihn \%. B. die Bienen trot\% ihrer Intelligenz nicht hervorzuholen, während er den langrüßligen Faltern zugänglich ift. 
Man kann alfo Bienen- und Hummelblumen einer-, und Falterblumen andrerfeits unterfcheiden. Erftere find vorwiegend blau oder violett gefürbt, wie z. B. das Teilchen, doch treten oft auch andere Farben auf, z. B. weis oder hellgelb, die fonft eher von kurzrüßligen Formen aufgefucht werden. Es tritt da eben ein Zwreites hinzu: Während bei den wenig intelligenten Infekten, den Fliegen und kurzrüßsligen Bienen, nur Geruch und Farbe, die Form der Blüten dagegen nicht in Betracht kommt, erlangt diefelbe bei den von intelligenten Infekten, langrüfligen Schwebefliegen, Bienen und Faltern, befuchten diefelbe Bedeutung wie Geruch und Farbe. So find z. B. die Bienenblumen oft glockenförmig ausgebildet, z. B. Campanula (Tafel 83-88), oder laden fonft zum Hineinkriechen ein, fo z. B. Digitalis (Tafel 115), Aquilegia (Tafel 7) oder die Papilionaceen, z. B. der Klee (Tafel 28-30). Häufig find fie auch dadurch charakterifiert, daßs die Blütenblätter untereinander verfchieden ausgebildet und orientiert find, indem eine obere und eine untere Lippe entfteht. Letztere ift den Infekten als Stützpunkt oft eigentlich auf den Leib gefchnitten ( $\mathrm{Be}$ tonica hirsuta, Tafel 118), während die Oberlippe als weit fichtharer Lockapparat (Fahne der Papilionaceen, Tafel 25 ff.) oder als helmartiges Schutzdach der Staubbeutel dient (Betonica, Tafel 118). Der Honig ift dabei entweder im Grunde der röhrenförmigen Blumenkrone, oder in einer feitlichen Ausftülpung derfelben, dem fogen. „Sporn", enthalten.

Die Falterblumen zeichnen fich durch die langröhrige Geftalt des Honigbehälters aus, wobei es gleichgültig ift, ob die Blüte allfeitig gleichmäßig, wie bei den Nellien (Tafel 17-20), oder zweilippig gebaut ift (Viola ralcarata, Tafel 15). In der Blütenfarbe laffen fich jedoch zwei Gruppen unterfcheiden: die roten, feltener violetten Blumen, die ron den Tagfaltern befucht werden, und die weißen, welche die Nachtfalter, allerdings weniger durch ihre Farbe als durch den ihnen nachts in 
befonderer Stärke entftrömenden Duft auf große Entfernungen (bis 100 Meter) anlocken (Geißblatt).

Die Anpaffung folcher Bienen- und Falterblumen an Körperform und Fähigkeiten ihrer Beftäuber kann fo weit gehen, daf überhaupt nur eine einzige Infektenart die Beftäubung vollziehen kann. Diefe Tatfache trat befonders eklatant zutage, als unfer Wiesenklee in Neufeeland eingeführt wurde. Er gedieh vorzüglich, bildete jedoch keine Samen. Schlieflich kam man auf den Gedanken, dafs vielleicht das Fehlen der ihn beftäubenden Hummeln die Unfruchtbarkeit verurfache. Als diefem Mangel durch die Einfuhr von Hummeln abgeholfen war, trat auch die Fruchtbildung ein.

Gerade diefe Erfahrung zeigt, wie fehr die Blumen auf ihre Beftäuber angewiefen find, fodaßs man aus den Blumenformen einer Flora auf die Zufammenfetzung der dafelbft lebenden Infektenwelt fchließzen kann und umgekehrt von letzterer auf die Blumenformen. Da außserdem die Infekten durch ihre Auslefe diejenigen Blumenformen zu züchten vermögen, die ihrem Bau am beften entfprechen, bildet die Infektenwelt einer Gegend einen die Flora mitbeftimmenden Faktor, fo gut wie die Temperatur oder das Licht. Gerade die in den Alpen beftehenden Verbältniffe erweilen die Richtigkeit diefer Auffaffung.

\section{Beziehungen zwifchen Infekten und Pflanzen in der alpinen Region.}

Die Infektenfauna der Alpen unterfcheidet fich in ihrer Artenzahl, wie folgende Tabelle zeigt, wefentlich von derjenigen der Ebene.

Käfer

Fliegen

Bienen und Hummeln

Schmetterlinge

Aus anderen Klaffen

$\begin{array}{cc}\text { Ebene } & \text { Alpen } \\ 15 \% & 7 \% \\ 30 \% & 43 \% \\ 44 \% & 18 \% \\ 9 \% & 31 \% \\ 2 \% & 1 \% \\ 2 \% & \end{array}$


Die Käfer und Bienen treten alfo in den Alpen, im Vergleich zur Ebene, bedeutend, um mehr als die Hälfte, zurück, während die Zahl der Fliegenarten um mehr als ein Drittel, diejenige der Schmetterlinge um das Dreifache zunimmt. Letzteres ift wohl durch die Abnahme ihrer ïrgften Feinde, der Singvögel, zu erklären. Obiger Tabelle follte nun eine entfprechende mit den Verhältniszahlen der von den genannten Infektenklaffen befuchten Blumen der Ebene und der Alpen gegenübergeftellt werden. Das ift jedoch nicht möglich, da eine Blüte oft von mehreren Infektenklaflen befucht wird, fodaf eine folche Zufammenftellung notwendig an Willkürlichkeit litte.

Aber gerade Blumen mit gemifchtem Befucherkreis geben uns über die Häufigkeit der Befuche einzelıer Infektenklaffen in Alpen und Ebene wichtige Auffohlüfle. Der Thymuran, Thymms Serpyllum, eine Pflanze, die aus der Ebene weit in die Alpen hinaufteigt, erhält im Tieflande $47 \%$ der Befuche von Fliegen und nur $20 \%$ von Schmetterlingen, während die Fliegenbeluche in den Alpen nur $25{ }_{10}$, die Falterbefuche dagegen $53 \%$ betragen; der Befuch von Bienen bleibt fich ungefïhr gleich (21-23\%). Es zeigt fich alfo, dafs entfprechend ihrer grofen Artenzahl die Falter in den $\Lambda$ lpen als Blumenbefucher bedeutend hervortreten.

Daf3 dies auch fchon in frïheren Zeiten der Fall war, geht diuraus hervor, dalis in zahlreichen Galtungen die Arten der Ebene Bienen- ader Hummelblumen befitzen, diejenigen der $A_{\text {pen }}$ dagegen Falterblumen. Diefes Verhältnis katnn nur dadurch erklärt werden, dajs die alpinen Arten als urfjü̈ngliche Bienenblumen atus der Ebene in die Alpen eingewandert und dafelbft durch die Auslefe der Schmetterlinge zu Falterblumen geworden find.

Die Veilchen find in diefer Beziehung befonders intereflant. Diejenigen des Tieflandes find durchwegs an die Bienen angepaßst. Unter den rein alpinen Formen 
find Tiola calcurata (Tafel 15) und cenisia reine Falterblumen mit langem Sporn, die kleinblütige Viola biflora. (Tafel $16 \mathrm{~A}$ ) dagegen eine faft ausfchliefliche Fliegenblume mit kurzem Sporn. Diefe Verhältniffe entfprechen durchaus der Armut der Alpen an Bienen, welche durch Fliegen und Falter erfetzt werden.

In Incylne strintu (Tatel $125 \mathrm{~B}$ alpin) und Inophlone Mezerenm (II. Teil s.' 195 Ebene) haben wir ein Brifpiel dafür, daf.s eine relativ weitröhrige Ebeneublume, die durch Fliegen, Bienen und Falter befucht wird, in den Alpen durch eine engröhrige, reine Falterblume vertreten ilt.

Der umgekehrte Fall fcheint bei Primula farinosa (Tafel 98 B) vorzuliegen, einer urfprïnglich wohl alpinen Art, die in der Eiszeit nach der norddeutfehen Ebene gelaugt ift, und fich dort bis heute behauptet hat. Der Enge des Kronfchlundes entfprechend wurden in den Alpen bisher nur Schmetterlinge auf ihr angetroffen, während Hummelı ihre Blüten verfchmähten. An den norddentfehen Exemplaren dagegen mit ihrem etwas erweiterten Schlundeingange kamen Bienenbefuche zur Beobachtung. Es wäre demnach eine Falterblume der Alpen in der falterarmen Ebene den Bienen zugäuglich geworden.

Die Alpenflora ift fomit durch das Vorwiegen von Falter- und Fliegenblumen und das Zurücktreten der Bienenblumen charakterifiert. Der Grund diefer Erfcheinung liegt in dem, im Vergleich zur Ebene auffallenden Vorwiegen von Faltern und Fliegen, welche fich die ihnen entfprechenden Blumenformen gezïchtel haben, wobei der Anthocyarreichtum der Alpenpflanzen der Entfehung roter Falterblumen befonders günftig war.

\section{Die Feuchtigkeit.}

Gerade wie Wärme und Licht find auch die Fenchtigkeitsverhältniffe von der Dichtigkeit der Luft abhängig, 
indem eine dünne Luft viel weniger Wafferdampf aufnehmen kann als eine dichtere. Dies äufert fich in den Alpen befonders deutlich in der Häufigkeit der Nebelund Wolkenbildung, fobald durch den Wind oder die Temperaturverhältniffe die Luft des Tieflandes zum Auffteigen veranlaßst wird. In einer beftimmten Höhe (im Sommer bei etwa 2000 Metern) lagert daher um die Mittagszeit meiftens ein Wolkengürtel, da hier die auffteigende Luft gerade fo ftark abgekühlt ift, dafs fie ihren Waflerdampf in Form von Nebel abgeben mus. Neben diefen regelmäß̊ig eintretenden, auf lokalen Urfachen beruhenden Niederfchlägen kommen aber in den Alpen noch weit ausgiebigere vor. Da nämlich diefelben zu den Hauptwindrichtungen Europas (von Weft und Südweft) größtenteils fenkrecht verlaufen, fchlagen fich an ihren Hängen bedeutende Feuchtigkeitsmengen nieder (bis $220 \mathrm{~cm}$ ). Von diefer allgemeinen Regel gibt es allerdings Ausnahmen, die befonders durch das Wallis und das Engadin repräfentiert werden. Beide Landfchaften find Täler, die zu den Hauptketten parallel verlaufen und beiderfeits von fchneebedeckten Bergwällen eingefchloffen find. Mag nun ein nordweftlicher oder ein füdöftlicher Wind wehen, feine Feuchtigkeit wird fich gröfstenteils an der äuferen Gebirgslehne niederfchlagen, fodafs nur wenig über den Kamm hinüber ins Tal gelangt. So weift z. B. die den regenreichen Nordweftwinden ausgefetzte Nordfeite der Berneralpen ein Jahresmittel von $150 \mathrm{~cm}$ Regenmenge auf, während ihr dem Wallis zugekehrter Südabhang nur etwa die Hälfte $60-90 \mathrm{~cm}$ erhält.

Die Haupt-Niederfchlagsmenge fällt in Form von Regen, jedoch ift auch der oft tagelang auf den Bergen lagernde Nebel für die Alpenpflanzen von fehr großer Bedeutung, indem daun die Luft den höchften Sättigungsgrad erreicht. Der Schnee, der auch während des Sommers in den Alpen öfters, in feiner Hauptmenge jedoch im Spätherbft fällt, ift für die Alpen und ihre Vegetation 
als Wafferrefervoir von auferordentlicher Bedeutung, um fo mehr als fich dasfelbe auf hohen Bergen nie vollftändig entleert, fodaßs es auch den unteren Lagen, in denen der Schnee fchon längft verfchwunden ift, durch die von oben herab fich ftets erneuernde Bergfeuchtigkeit immer neues Waffer zuführt. Ift jedoch einmal alles oberflächlich abfliefsende Schneewaffer ron den vielen Wafferadern aufgenommen, fo trocknet der Boden rafch aus, fodaß oft fchon im September die höheren Alpenmatten verdorrt find.

Natürlich fpielt dabei die verfchiedene Fähigkeit des Bodens, das Waffer feltzuhalten, eine groß3e Rolle. In den Alpen kommen hauptfächlich folgende Bodenarten in Betracht.

1. Matten- und Weideboden. Derfelbe ift feinkörnig, hinreichend durchlälfig und lufthaltig. In der erften Hälfte des Alpenfommers ift er feucht und trocknet erft im Auguft oder September aus. Zur Not gedeihen auf ihm die meiften in den Alpen vorkommenden Pflanzen. Bei feiner großen Bedeutung für die Alpwirtfchaft und infolgedeflen anch für die Alpenflora muf ich hier auf einige Eigentümlichkeiten des Matten- und Weidebodens aufmerklam machen, die allerdings nicht nur durch die Bodenfeuchtigkeit bedingt find.

Wie die Waldbäume an ihrer oberen Verbreitungsgrenze allmählich niedriger und gedrungener werden, fo auch die Krautpflanzen, welche in der Ebene und in den Tälern die Wiefen bilden, die auf einem Boden von mittlerer Feuchtigkeit gedeihen. Ift letztere von Natur aus nicht in genügender Menge vorhanden, fo wird dem Mangel durch Bewäfferung abgeholfen. Diefe Wiefen find daher von mehrere Dezimeter hohen Kräutern bedeckt, die regelmäßig gemäht werden. Der Salzgehalt des Bodens wird durch Düngung auf gleicher Höhe erhalten.

Weiter oben bleiben diefe Wiefenkräuter infolge der Veränderung von Licht- und Temperaturverhältniffen niedriger, fodaf fich das Mähen kaum lohnt: die Wiefe 
ift in die Matte übergegangen, die weder künftlich bewäflert, noch gedüngt wird. Diefe Malten find fomit die natürliche und für die Alpen charakteriftifche F'or'm der Gras- und Krautvegetation. Ganz rein ift fie nur noch felten vorhanden, nur dort, wo der Menfch und fein Vieh nicht regelmäfig hinkommt. Wo dies der Fall ift, find die Alpenmatten in WVeiden umgewandelt, die fich dadurch von den Matten unterfcheiden, daß lie regelmäfig vom Vieh begangen werden, das die dem Boden anliegenden Blattroletten und niedrigen Gräler abrupft und zugleich den Boden wenigftens ftellenweife durch feinen Mift düngt. Bei guter Alpwirtl'chaft forgt der Senne durch Zerftreuen diefes Miftes für eine gewifle Gleichmäß3igkeit der Düngung. Das Weideland ift allo wie die Wiefe Kulturland (Warming).

Da, wo die Düngung der Alpemmatten durch das Vieh befonder's reichlich und anhaltend ilt, wie in der Nähe von Semmhütten und Stïllen, bei Brumnen oder an gefchiilzten Orten, nach denen fich das Vieh bei Sturm und Regen flüchlet, erhailt die Vegetation ein ron der gewöhnlichen Weide abweichendes Gepräge. $\Lambda$ uf diefen logenamnten Lägern entwickeln fich die Pflanzen äufserft ïppig. Da aber nicht alle Arten eine fo intenlive Dïngung ertragen, beditzen diefe Stellen ihre eigenen Bewohner, die fogeinannte Liigerflora, zu welcher \%. B. das gelbe Aconitum Lyyrortomum (Tafel s), das blauc Aronitum Neppellus, dex senerio cordutus (II. Teil S. 72) und der grofse Alpen-dmpfer, Rumex alpinus, gehören. 2. Moorboden. Derfelle ift reich an verweften Pflanzenreften, vom Waffer durchtränkt und daher luftarm. Sein Waffereichtum wird dadurch hervorgerufen, daf er auf irgendeiner für Waffer undurchlälligen Schicht, z. B. einem feinen Ton, lulıt, der im ganzen Umkreis der Alpen als Reft alter Grundmoränen der Eiszeit-Gletfcher verbreitet ift, indem die Steine durch die Laft des über fie wegrulfchenden Eifes zu feinem Brej zerrieben wurden. Solche glaziale Moore find in den 
Tälern des welfchen Jura und auf der fchweizerifchen und bayerifchen Hochebene hüufig. Kleinere Moore trifft man auch öfters in den Mulden von Felfen, in welchen fich das Regen- und Schneewafler ftaut und die Anfiedelung von Moorpflanzen geftattet.

3. Der in den Alpen fehr häufige Geröllboden ift fehr durchlälfig und daher meift trocken und warm. Allerdings kommen, befonders in der Nähe der Schneegrenze, auch naffe Geröllböden vor, in denen das Schmelzwaffer oder Quellen die Wurzeln der Geröllpflanzen befpülen. Bei Sonnenfchein erwärmen fich aber die Steine fo rafch, daß die Stengel und Blätter der Geröllpflanzen trotz dem Wafferreichtum des Bodens großer Lufttrockenheit ausgefetzt find. Natürlich hängen die Eigenfchaften des Geröllbodens auch von der Größze feiner Beftandteile ab, indem mit zunehmender Kleinheit der Gefteinsfragmente das Geröll in Gefteinsfchult ïbergeht, der wieder durch viele Zwifchenftufen mit dem naffen Tonboden verbunden ift.

4. Der Felsboden endlich beherbergt feine Pflanzen entweder in kleinen, mehr oder weniger flachen Einfenkungen, in welchen Flechten und Moofe znerft einigen Humus gebildet haben - ein Standort, der natürlich dem Austrocknen fehr ausgefetzt ift - oder auf Spalten, welche auch nach Abflufs des Schnee- und Regenwalfer's von der Bergfeuchtigkeit ftets gefpiefen werden, fodaf den Wurzeln immer eine gewifle Waflermenge zur Verfügung fteht.

Die relative Feuchtigkeit der Luft, d. h. der ihrer Dichtigkeit entfprechende Sättigungsgrad mit Wafferdampf, ift in den Alpen im Vergleich zur Ebene grof, wahrfcheinlich infolge der großen Bodenfeuchtigkeit. Folgende Zahlen zeigen dies deutlich:

Theodulpaf $3330 \mathrm{~m} \mathrm{S2 \%}$ rel. Feuchtigkeit,

Simplon

Martigny $2010 \mathrm{~m} 78 \%$ $500 \mathrm{~m} 72 \%$

Neben diefen Durchfchnittszahlen find aber auch die 
Extreme $\mathrm{zu}$ berückfichtigen, indem oft volle Sättigung der Luft mit Waflerdampf und große Trockenheit raf'ch miteinander abwechfeln. So wurde auf dem grofen Plateau des Montblanc $(3930 \mathrm{~m})$ bei einer mittleren Luftfeuchtigkeit von $38 \%$ ein Minimum von $13 \%$ beobachtet, während in Chamounix bei einem Mittel von $82^{\circ} / 0$ das Minimum nur auf $50 \%$ hinabging. Die mitten im Firngebiet gemachten Meffungen find allerdings nur für diejenigen Alpenpflanzen maßggebend, welche gerade dort leben, während die Gewächle der Weiden und Matten unter günftigeren Bedingungen gedeihen, wie mir eigene Meflungen auf einer 1860 Meter hoch gelegenen Alp trotz Sonnenfchein und mäßigem Winde gezeigt haben. Die relative Feuchtigkeit betrug $82 \%$, während fie auf einer Wiele bei 1000 Metern unter fonft gleichen Verhältniffen $60 \%$ betrug.

Außerdem muß man bedenken, daßs die meteorologifchen Meflungen in einer Höhe von 1 Meter über dem Boden gemacht werden, die Alpenpflanzen fich jedoch kaum vom feuchten Boden erheben. In der Tat ergaben bei fchönem Wetter, bei 2000 m Höhe ausgeführte Meflungen in der Nähe eines befonnten, teilweife bewachfenen Felsblockes eine Lufteuchtigkeit von $38 \%$, während fie bei $1 \mathrm{~m}$ Höhe ïber dem Boden nur $29 \%$ betrug. Die meteorologifch feftgeftellte, zeitweilig fo große Lufttrockenheit ïber Firn und Fels wird allo für die Pflanzen des Wiefenbodens bedenteid abgefchwächt. Anders natürlich bei den im belonmen fierölle oder auf exponierten Felfen wachfenden Pflanzen. Da werden allerdings an ihre Widerftandsfähigkeit gegen das Austrocknen zuweilen großse Anforderungen geftellt.

\section{Einfluß der Feuchtigkeitsverhältniffe der Alpenregion auf ihre Pflanzen.}

Die Feuchtigkeitsverhältniffe haben allgemein einen grofen Einfluf auf das Wachstum der Pflanzen, da fich dasfelbe nur dann ungeftört vollziehen kann, wenn eine 
genïgende Waffermenge zur Verfügung fteht. Je trockener die Luft wird, defto mehr Walfer entreist fie der Oberfläche der Pflanze, das Wachstum wird daher verzögert. Diefe Wafferabgabe oder 'Tranfpiration kann von der' Pflanze fo lange ertragen werden, als ihr die Wurzeln in einer beftimmten Zeit mindeftens ebenfoviel Waffer aus dem Boden zuführen, als die in Luft ragenden Organe abgeben. Ift dies nicht der Fall, fo welkt die Pflanze und verdorrt fehlieflich.

Gewächfe verfchiedener Standorte verhalten lich num in diefer Beziehung fehr verfchieden, indem die aus feuchter Luft ftammenden das aufgenommene Waffer rafch abgeben und deshalb auch rafch welken: Feuchtigkeitspflanzen, Hygrophyten, die in trockener Luft gewachfenen dagegen nur felsr langfam: Trockenheitspflanzen, Xerophyten. Man ift nun leicht verfucht, die Verfchiedenheit in Wuchs und Struktur der Xerophyten und Hygrophyten als direkte Folge der verfchiedenen Luftfeuchtigkeit aufzufaffen. Da aber an trockenen Standorten gewöhnlich auch das Licht ftärker ift als an feuchten, ift es nicht erlaubt, alle Eigenfchaften der Xerophyten nur auf die Trockenheit zurückzuführen. Es ift Aufgabe der Phyfiologie, die zahlreichen, in der Natur gleichzeitig fich verändernden Faktoren einzeln wirken zu laffen, was bisher erft in relativ geringem Maßse ausgeführt worden ift.

Wie im Abfchnitt über die Wirkung des Lichts kann ich auch hier nur diejenigen Wachstumsverändelungen behandeln, welche das unbewaffnete Auge feftftellen kann.

Als folche, ohne weiteres fichtbare XerophytenGharaktere gelten:

1. Niedriger Wuchs.

2. Verkleinerung der verdunftenden Oberfläche.

3. Verftopfung der wafferausfcheidenden Organe.

4. Behaarung.

5. Starke Wurzelentwicklung.

G. Senn, Alpenflora. 
Diefe Eigenfchaften kommen nun bei vielen Alpenpflanzen vor; diefelben find deshalb von manchen Forfchern für Xerophyten gehalten worden. Da jedoch erft für wenige Fälle konftatiert ift, dafs wirklich die Trockenleit und nicht etwa die hohe Lichtintenfität den xerophytenartigen Charakter hervorgerufen habe, foll im Folgenden von Fall zu Fall zu entfcheiden verfucht werden, ob die Alpenpflanzen zu den Xero- oder Hygrophyten zu zählen find.

1. Niedriger. W u chs wird tatfächlich durch trockene Luft allein hervorgerufen, wemn Beleuchtungsund Temperaturverhältniffe nicht ver:̈ndert werden, und den Stengeln aus dem Boden genügend Waffer zugeführt wird. So betrug z. B. die Länge der Stengelglieder der in trockener Luft gewachfenen Saubohnen (Vicia Faba) durchfchnittlich nur $59 \%$ von derjenigen in feuchter Luft gewachfener Stengel, während die Länge der halbfeucht gewachfenen $76 \%$ von der Länge der feucht gewachfenen betrug.

Die Alpenpflanzen find bekanntlich niedrig, was (vergl. Seite 14.) auf ftarkes Licht und niedrige Nachttemperatur zurüickgeführt werden kann. Nun kommen aber bei ihnen zuweilen auffallende Größsenunterfchiede vor (z. B. bei Iledysarmm obsrumum, Tafel 32), je nachdem die Pflanze an ihrem Standort exponiert oder gefchützt war. Aber auch da ift es nicht entfchieden, ob diefer Schutz vorwiegend in der Schwächung des Lichtes oder in der Fernhaltung niederer Temperatur oder trockener Luft beftand. Bis genaue Verfuche in der Alpenregion felbft ausgeführt find, wozu es eben eines alpinen Laboratoriums bedarf, das bisher leider noch fehlt, kamn aus dem niedrigen Wuchs der Alpenpflanzen nicht mit Sicherheit auf ihre Xerophyten-Natur gefchloflen werden. Es ift allerdings denkbar, daf die trockene Luft der exponierten Standorte den durch Licht und Temperatur erzeugten Zwergwuchs noch fteigert.

2. Die Oberflächenverkleinerung, die bei 
den Xerophyten in extremen Fiillen bis zu völligem Verluft der Blätter und Annahme der Kugelgeftalt führen kann (Cacteen), erlaubt als folche auch kein ficheres Urteil ïber die Alpenpflanzen, da auch hier das Licht in gleichem Simne wirkt. (Vergl. S. 15.) Dagegen wurde von Brenner*) nachgewiefen, dafs fich $\%$. B. bei den Eichenblättern die Einbuchtungen den Blatherven viel mehr näherten, die Lappen alfo fchmäler wurden, je trockener die umgebende Luft war, was offenbar darauf zurückgeführt werden muß, dafa das in den Nerven durch die Blätter geleitete Waffer in feuchter Luft auf größsere Entfernung vom Blattnerven zur richtigen Bewäferung des Blattgewebes genügt als in trockener Luft. Solche eingefchnittene Blätter find auch in der Alpenflora viel vertreten, befonders bei den Umbelliferen (Tafel 55-59) und Ranunculaceen (Tafel 1-10). Vergleichen wir diefelben mit ihren Verwandten der Ebene, fo zeigt es fich, daß die Blätter der alpinen Pflanzen bald weniger tief geteilt find als die der Ebenenpflanzen (verg]. Ramunculus alpestris und aconitifolius und Anemone alpina, die zwifchen A. Pulsatilla und A. silvestris der Ebene die Mitte hält), oder ähnliche Blattgeftalt zeigen (Romunculus: montams und $R$. arris) oder auch feiner geteilt find (Meum Mutellina II. Teil S. 5(i). Es ergibt fich hieraus, dafs die Blattgeftalt der Alpenpflanzen im Vergleich zu derjenigen ihrer Verwandten der Ebene von ähnlichen Standorten nicht ausgefprochen xerophytifch, fondern zuweilen fogar hygrophytifch ift.

Ausgefprochene Xerophyten find dagegen diejenigen Alpenpflanzen, welche fogenannte Rollblitter befitzen. Durch das Einrollen der Blattränder über die Blattunterleite, die infolge ihres anatomifchen Baues das Waffer befonders leicht abgibt, wird die Verdunftung bedeutend herabgefetzt (Empetrum Tafel 125 A).

*) Brenner, W. Ḱlima und Blatt bei der Gattung Quercus. Flora oder allgemeine botan. Zeitung. 1902. Bd. 90. 
Auch die Rofettenbildung der Blätter kann die verdunftende Oberfläche verkleinern, wenn diefelhen fo dicht beifammen ftehen, daf die ganze Pofette kugelig wird chemperrimum ararhnoideum, Tafel 53, Saxifraga bryoides, Tafel 49 B). Werden aber folche Pflanzen mit kugeligen Roletten ohne Ver:̈inderung der Lichtintenfität in feuchter Luft kultiviert, fo legen fich die Blätter auseinander, die Polette öffnet fich.*) In der Alpenflora treffen wir beides an: kugelige Xerophyten-Pofetten: Sempervimm (Tafel 53), Sarifiaga bryoides (Tafel $49 \mathrm{~B}$ ), wie auch HygrophytenRofetten: Sareifiraga androsacea (II. Teil S. 50), Androsace Chumaejusme (II. Teil S. 100), erftere auf exponierten Felfen, anf denen wir nichts anderes als Xerophyten erwarten können, Jetztere auf Matten oder feuchten Felfen. Es zeigt fich allo auch darin, dafs in der Alpenflora neben ansgefprochenen Xerophyten Formen von hygrophytifchem Charakter vertreten find.

$\mathrm{Zu}$ demfelben Refultat gelangt man bei der Unterfuchung der Blattftruktur der Alpenpflanzen. Ich kann hier nur eine Tatlache erwälnen, die gerade noch mit dem bloß3en Auge beohachtet werden kamm, nämlich

3. Die Verftopfung der wafferausfcheidenden Organe. Von den in den Alpen fo zahlreichen Steinhrecharten (Sarifiageen) find die meiften ausgefprochene Xerophyten, während einige im Schatten der Wälder und Folfen am beften gedeihen, hygrophytifch find (fo befonder's st. rotundifoliu, Tafel 50). Leiztere pflegen aus kleinen öffnungen an den Blattzähnen, den fogenannten IVaflerfpalt en, das überfchülfige Waffer in Form von Tropfen auszufcheiden, die wie große Tautropfen einige Zeit an den Blättern hängen bleiben. Die Funktion diefer Wafferfpalten, die auch den felfenbewohnenden Saxifrageen zukommen, wäre für letztere fehr gefährlich, da fie das einmal aufgenommene W $\mathrm{W}$ afer mög-

*) Brenner, W. Unterfuchungen an einigen Fettpflanzen. Differtation Bafel 1900 (auch in ,Flora" Bd. 87). 
lichft lange behalten follten. Sie haben nun diefe Wafferfpalten dadurch unfchädlich gemacht, daßs fie diefelben durch Kalkablagerung verftopften, welche in Form weißer Schüppchen am Rande oder an der Spitze der Blätter fichtbar ift (Tafel 52 B) und zwar um fo deutlicher, je trockener der Standort. So zeigt die bald in trockenem Gerölle, bald an Quellen lebende Saxifiaya aizoüdes (Tafel 51 A) die Kalkfchüppchen nur am trockenen Standorte deutlich, während man fie an den feucht gewachfenen Pflanzen oft vergeblich fucht.

Es zeigt alfo auch diefes Unterfcheidungsmerkmal, daß3 in den Alpen Xero- und Hygrophyten vertreten find.

4. Beharrung. Daßs eine Schicht von luftführenden Haaren die Pflanze vor Verdunftung fchützt, ift ohne weiteres einzufehen, wurde übrigens auch fchon dadurch feftgeftellt, daß die Waflerabgabe eines rafierten Blattes mit derjenigen eines normal behaarten verglichen wurde. Was die Ausbildung folcher Wollharre veranlast, ift noch nicht einwandfrei nachgewiefen. Obwohl es fcheint, dafs wirklich die Trockenheit der Luft die Haarbildung hervorrufe, ift es doch nicht ausgefchlofien, daf auch ftarkes Licht diefelbe verurfache oder doch fördere. Sicher ift, dafs wollig beharte Pflanzen befonders an trockenen, fonnigen Standorten gedeihen; in grofer Zahl z. B. in den Mittelmeerländern und auch in den Alpen, Leontopodium und Antennaria (Tafel 68), Achillew nun (Tafel $73 \mathrm{~A}$ ), Hievacium lanutum (Tafel S0), Salix glanca (Tafel 126), Androsace imbricata (II. Teil S. 96), u. a.

Den gleichen Dienft wie die Haare fcheinen zuweilen Wachsausfcheidungen $\mathrm{zu}$ verfehen, wie fie bei einigen alpinen Primeln in Form eines weißen, mehlartigen Staubes auftreter. $\mathrm{Ob}$ derfelbe nur in trockener Luft entftehe, oder ob bei feiner Ausfcheidung noch andere Faktoren mafigebend find, ift noch unbekannt.

5. Starke Wurzelentwicklung. Auch die ftarke Entwicklung der Wurzeln wird von Schimper als Xerophytenmerkmal angeführt. Tatfächlich befitzen viele Xero- 
phyten ein fehr ausgebreitetes Wurzelfyftem; ob es aber die Trockenheit der Luft oder des Bodens fei, welche inre Entftehung fördert, wurde noch nicht einwandfrei nachgewiefen. Die gewaltige Wurzelausbildung mancher Alpenpflanzen fcheint viehmehr dadurch hervorgerufen zu fein, daßs die in den Blättern gebildeten Nähıftoffe infolge der ftarken IVachstumshemmung der oherirdifchen Teile nach den in ihrem Wachstum nicht gehemmten Wurzehn geleitet werden, fodaf diefelben der guten Nahrungszufuhr ihre auffallenden Dimenfionen verdanken. Die bei vielen Alpenpflanzen beobachtete ftarke Wurzelentwicklung ift alfo kein untrïgliches Merkmal ihrer Xerophytenftruktur.

Ebenfowenig ift es die reiche Blütenentfaltung der Alpenpflanzen, welche allerdings durch Trockenheit gefördert, aber nur durch ftarkes Licht veranlafst wird.

Bei allen diefen Beobachtungen und Erwägungen kommt man zu dem Schlufs, daf die Alpenflora in den Felfen- und Geröllbewohnern typifche Trockenheitspflanzen, Xerophyten enthält, daß fich aber die vielen alpinen Matten- und IVeidepflanzen von den Wiefenpflanzen des Tieflandes keineswegs durch Einrichtungen zur Herabfetzung der Wafferverdunftung wefentlich unterfcheiden.

\section{Der Boden.}

Daf3 die Befchaffenheit des Bodens anf die ihn bedeckende Flora einen beftimmenden Einflußs ausübe, wurde fchon frühe, befonders in Gebirgsländern beobachtet, wo eben der Untergrund oft nackt zutage tritt. Dabei können aber zwei Eigenfchaften des Bodens in Betracht kommen: die rein chemifche, wobei feine Beftandteile als gelöfte Salze fördernd oder fchädigend auf die Pflanzen einwirken, oder feine phyfikalifchen Eigenfchaften, befonder's Feuchtigkeits- und Wärme- 
verhältniffe, welche allerdings durch feine chemifche $\mathrm{Zu}$ fammenfetzung bedingt find.

Bei den erften Unterfuchungen glaubte man, es könne fich nur um eine Art des Einfluffes lıandeln; es ftand daher in diefer Frage die chemifche der phyfikalifchen Richtung gegenüber, beide auf gewichtige Grïnde geftützt. Der lange dauernde Streit ift heute dahin entfchieden, daßs beide Pichtungen mit gewiffen Befchränkungen recht haben. Es ift eine unbeftreithare Tatfache, dalö das aus Kalkboden entfpringende Waffer iufolge feines Kalkgehaltes oft wie ein Gift wirkt, fo z. B. auf falt alle Pflanzen der Torfmoore, befonders auch auf feine Algen (grüner Schlamm). Bei diefen untergetauchten Organismen kann es fich natïrlich nicht um Trockenheit oder Wärme, fondern allein um die chemifchen Eigenfchaften der im Waffer gelöften Beftandtcile des Bodens handeln. Hier ift allo die chemilche Richtung im Rechte.

Andrerfeits find Fälle bekannt geworden, dafo in einem beftimmten klimatifchen Gebiete gewiffe Pflanzen nur auf Kalk vorkommen, wie z. B. bei uns die Buche, während fie in Südfrankreich nur auf Kiefelborlen Wälder bildet. Es ift kein Zweifel, daß3 hier die phyfikalifehen Eigenfchaften des Bodens ausfchlaggebend find, während der chemifche Einflufs ohne Belang ift: in unferem feuchtkühlen Klima fucht die Buche den relativ warmen und trockenen Kalkboden auf, wähıend ihı derfelbe im warmen Südfrankreich zu trocken wäre, und fie deshalb den relativ feuchten und küilen Kiefelboden bevorzugt.

Sehr häufig kommt es auch vor, dafa der einen von zwei nahe verwandten Arten in einem gewiffen Klima befonders der Kalk, der andern befonders der Kiefelboden zufagt. Sie halten fich deshalb fo ftreng an diefe Bodenarten, dafs man aus ihrer Verbreitung fogar auf die Ausdehnung des Kalk- und Kiefelhodens fchließen kann. Ift jedoch in einem beftimmten, klimatifch vom andern nicht wefentlich verfchiedenen Gebiete nur die eine der beiden Arten vorhanden, fo kommt diefe auch auf dem Geftein 
vor, das fie im andern Gebiete ftreng meidet. Gerade in der Alpenflora werden wir mehrere Beifpiele diefer Art zu verzeichnen haben.

\section{Verteilung von Kalk- und Kiefelgeftein in den Alpen.}

Aus der Entftehungsgefchichte der Alpen ift die jetzige Verteilung von Kalk- und Kiefel- oder Urgeftein (Gneis und Granit) leicht zu verftehen. Die Kalke lagerten fich in dem Meere ab, das vor und während der fogenannten Tertiärperiode, die der Eiszeit voranging, auch die jetzige Alpengegend hedeckte. Infolge der durch die allmähliche Abkühlung verurfachten Verkleinerung des Erdinnern wurde die Rinde zu groß, fie legte lich deshalb wie die Haut eines austrocknenden Apfels in Falten. Wo diefe Faltung fehr ftark war, brachen die oberften, am ftärkften gedehnten Schichten auf, fodaf darunter die erfte Erftarrungskrufte, der feinkörnige, kiefelreiche Gneis zutage trat. Ift auch feine Lagerung fehr ftark geftört, fo kommt der darunter liegende Granit zum Vorfchein. Da derfeibe ungefähr die gleiche Zufammenfetzung hat wie der Gneis, müffen wir uns denfelben aus der gleichen feurig-flüffigen Maffe entftanden denken, aber nicht wie der Gneis unter relativ rafcher Ahkühlung, fondern allmählich, in großser 'Tiefe und daher' unter grofzem Drucke, forlaß fich einzelne Beftandteile zu fchönen Kriftallen (Feldfpat) ausbilden konnten.

So finden wir in den Alpen die Randketten, den Jura inhegriffen, aus Kalk beftehend, auf wejche nach dem Innern die Gneile, und in den höchften zentralen Ketten die Granite folgen.

Diefe Angaben haben allerdings nur im grofen und ganzen Gültigkeit, während im einzelnen manche Ausnahmen zu verzeichnen find. So treten in den zentralen Gneis- und Granitketten an verfchiedenen Stellen Piefte der urfprüuglichen Kalkdecke zutage und im reinen Kalkgebirge, z. B. im Jura, Torfmoore, für welche Kalkwaffer reines Gift ift. Dicfelben verdanken, wie wir 
gefehen haben, ihre Exiftenz der Tätigkeit der großen Gletfcher der Eiszeit, indem die von ihnen hinterlalfenen tonigen Grundmoränen nicht nur die Moorbildung durch Schaffung eines für Waffer undurchläffigen Untergrundes ermöglichten, fondern das Moor faft hermetifch gegen die kalkhaltigen Gewäffer der Umgebung abfchliefen.

Der. Urgefteinsboden ift in den Alpen im allgemeinen von derfelben Befchaffenheit, mit Ausnahme der lokal vorkommenden Serpentine und Bafalte, die im Gegenfatz zu Granit und Gneis fehr langfam verwittern und daher eine trockene und warme Unterlage bilden wie der Kalk. Diefer zeigt in feinen verfchiedenen Schichten und in den verfchiedenen Partieen der Alpen eine fehr verfchiedene Konfiftenz. Letzterer Unterfchied tritt befonders ftark bei der Vergleichung von Jura und Alpen hervor. Der Jurakalk verwittert im allgemeinen fchwer, der Boden ift daher meift trocken und warm. Der Alpenkalk dagegen widerfteht der Verwitterung im allgemeinen weniger lange. Er zerfällt daher oft in feinen Schutt, der fogar zuweilen eine tonige Befchaffenheit annimmt, fodafs er auch feuchtigkeitsliebende Pflanzen (Hygrophyten) beherbergen kann. Anders in den füdöftlichen Alpen, in denen eine fchwerer verwitternde Magnefiumverbindung, der Dolomit, den Kalk vertritt.

\section{Kiefel- und Kalkpflanzen der Alpen.}

Die ausfchließlich an Kalk- oder Kiefelgeftein gebundenen Arten find, wie allgemein, auch in den Alpen nicht zahlreich. Kalkfliehend find $u$. a. einige Farme, z. B. Asplenium septentrionale (Tafel $143 \mathrm{~B}$ ) und Blecthmum spicant, die allerdings mitten im Kalkgebirge auftreten können, dann aber nur auf erratifchen, von den Gletfchern dorthin transportierten Granitblöcken. Auserdem Saxifraga Cotyledom, Sempervium arachnoideum (Tafel 53) und Antrosare cornea (Tafel 100B), während Androsace lactea (Tafel 100 A) eine ausgefprochene Kalkpflanze ift. 
Viel häufiger find die nur in einem beftimmten Gebiet an eine fpezielle Bodenart gebundenen Pflanzen. So befiedelt z. B. Erica carnea in der Schweiz Kalk und Kiefel, während fie in Bayern, wohl wegen größserer Rauheit des Klimas, das Urgeftein vollftändig meidet.

Verhältnismäfig oft kommt es in den Alpen vor, daß zwei nahverwandte in demfelben Gebiete verbreitete Arten fich ftreng an das eine Geftein halten und fich daher gegenfeitig ausfchliefsen, während lie, fobald die Konkurrenz der andern Art fehlt, in der Bodenart nicht wählerifch find. Hieher gehören Anemone alpina und sulfurea: letztere in den Alpen nur auf Kiefelboden, während ulpina den Kalk bewohnt. Diefe wächft aber in den Vogefen auf Kiefelboden, wohin fie aus dem Jura gelangt ift, dem Anemone sulfuren fehlt. Daslelbe Verhalten zeigen die beiden Alpenrofen: Rhododendron ferrugineum und hirsutum (Tafel 91). Erftere liebt feuchten, moorigen Boden und kommt daher in den Alpen auf Urgeftein vor, Rhododendron hirsutum dagegen auf dem trockenen, warmen Kalk. Ihre Konkurrenz ift in dem von ihnen gemeinfam befiedelten Engadin befonder's auffallend. Auf dem Urgeftein ift Rhorlordendron ferrugineum als Unterholz des Lärchenwaldes und auf Weiden gemein. Rhododendron hirsutum dagegen ift hier felten und nur auf den wenigen zutage tretenden Kalkbändern zu finden, fo z. B. am Eingang ins Val Fex. Daf3 aber auch hier nur die Konkurrenz beider Formen ausfehlaggebend ift, beweift Rhorlodent.ron fermuineum, das aus den Weftaljen, denen Rhododention. hirsutum fehlt, lïngs den Höhenzügen des Jura in diefes, ja ausfchlief3lich aus trockenem, warmem Kalk beftehende Gebirge eingewandert ift und fich offenbar nur dank der Abwefenheit der andern Art darin erhalten hat. Ähnlich verhalten fich

Achillen atratu (Kalk) und mosrhatu (Kiefel), Primula Aurirula (Kalk) und hirsute (Kiefel), Androsace pubesrens (Kalk) und glacialis (Kiefel). 
Infolge diefer Konkurrenz fiedelt fich auf chemifch fehr abwechslungsreichem Boden auch eine abwechslungsrefp. artenreiche Flora an. Beim Vergleich einer geologifchen Karte mit einer folchen, auf welcher die Gebiete mit verfchiedenem Artenreichtum eingezeichnet find, fällt es daher auf, daf die Gebiete gröfsten Reichtums meift diefelben find, in denen zahlreiche Gefteinsarten auf kieinem Raume zufammenkommen, wie z. B. in den Wallifer und Engadiner Alpen, während andrerfeits geologifch einheitliche Gebiete, wie z. B. das Graubündner Oberland, auch einheitliche, relativ artenarme Floren befitzen.

Daß3 aber die Armut oder der Reichtum an Pflanzenarten in den Alpen nur teilweife durch die geologifche Unterlage hervorgerufen wird, geht aus dem nächften Abfchnitt hervor.

\section{Der Wind.}

Als klimatifcher Faktor ift der Wind auch für die Pflanzen von großer Bedeutung. Es ift daher notwendig, die

\section{Windverhältniffe in den Alpen}

kennen zu lernen, wobei Richtung und Stärke der Winde gefondert $\mathrm{zu}$ behandeln find.

Die Pichtung hängt von lokalen und von allgemein geographifchen Faktoren ab.

Lokale Winde von beftimmter Richtung find in den Alpen fehr verbreitet, indem die Luft während der Nacht infolge der Abkühlung und der damit verbundenen Gewichtszunahme finkt, was fich an den Berglehnen in einem nach dem Tal fich bewegenden B e rgw ind äußert. Am Tage dagegen fteigt die Luft infolge der Erwärmung, durch die fie Jeichter wird, in die Höhe. 
Es entwickelt fich daraus ein an den Berglehnen aufwärts ftreichender Talwind.

Als lokaler Wind ift auch der Föhn zu bezeichnen, der in allen fenkrecht zur Hauptrichtung der Alpen verlaufenden Tälern dann herrfcht, wenn große Luftdruckunterfchiede zwifchen Süd- und Nordfeite der Alpen ausgeglichen werden. Die Luft fließst aus dem Gebiete mit hohem Barometerftand, allo hohem Stand des Luftmeeres ïber den Kamm der Alpen in das Gebiet des Tiefftandes der Luft. Diefe herabltrömende kalte und dünne Luft verdichtet fich in den tieferen Lagen, wodurch ihre Temperatur und damit ihre Fähigkeit zur Aufnahme von Wafferdampf erhöht wird. Die Föhnwinde, die auf der Süd- wie auf der Nordfeite der Alpen vorkommen, find daher warm und trocken, was befonders bei der Schneefchmelze von großem Wert ift.

Die vorherrfchende Windrichtung in Mitteleuropa und infolgedeffen auch auf der nördlichen und nordweftlichen Seite der Alpen ift diejenige von Weft nach Oft und Südweft nach Nordoft. Der Südfuf der Alpen ift, wenigftens während des Sommers, auch nördlichen und nordweftlichen Winden ausgefetzt, während im Herbft die füdöftlichen vorherrfchen.

Die Stärke der Winde ift in den Alpen bedeutend gröfser als in der Ebene, da fich die Luft(trömungen, weder durch Hügel noch liohe Vegetation gehemmt, fortbewegen können. Folgende Werte für die gröften, in Zürich $(493 \mathrm{~m})$ und auf dem Süntis (2500 m), im Jahre 1897 gemeffenen Windfärken illultrieren diefe Tallache am beften. (Angegeben in $\mathrm{m}$ während einer Sekunde.) Zürich Säntis Differenz
Jahresmaximum
22
38
16
Maximum für Juli-Oktober
14
35
21.

Die größste Windfärke fällt alfo bei 2500 in auf die Monate Juli-Oktober, in welchen fich die Entwicklung der Alpenpflanzen abfpielt; lie ift daun mehr als doppelt 
fo grof als in der Ebene. Dabei ift zu bemerken, daß ein Wind, der mit einer Gefchwindigkeit von $30 \mathrm{~m}$ in der Sekunde daherftürmt, alle kleineren Gegenftände, die nicht niet- und nagelfeft find, fogar kleinere Steine, mit fich fortzutragen vermag.

\section{Einfluß der alpinen Winde auf die Pflanzen.}

Holzpflanzen, die einem ftets von der gleichen Seite wehenden Winde ausgefetzt find, bilden fogenannte Win dformen aus, die dadurch entftehen, dafs die gegen den Wind wachfenden Äfte ahgeknickt oder gezwungen werden, in demfelben Sinne zu wachfen, wie fich der Wind bewegt. Es kommen dadurch merkwïrdig einfeitige Formen zuftande, die, wenn es Gebüfche find, wie abgefchoren aussehen. Solche Windformen von Bäumen kommen in den Alpen an der oberen Grenze des Bergwaldes auch etwa vor, ohne jedoch für die Waldgrenze charakteriftifch zu fein. In der eigentlichen baumlofen Alpenregion wurden ähnliche Erfcheinungen noch nicht beobachtet. Es ift allerdings möglich, dafs die Polfterform mancher Alpenpflanzen, wie die der nordifchen Kugelpflanzen, auf die mechanifche Wirkung des Windes zurïckzuführen ift. Genaue Beobachtungen, gelchweige demn Verfuche, fehlen jedoch noch vollftändig.

Der Einflufs des Windes auf die Fortpflanzungsverhältniffe äußert fich in der Art der Beftäubung und in der Art der Samenverbreitung.

Neben den früher befprochenen, durch Infekten beftäubten Pflanzen gibt es eine grobe Anzahl folcher, deren Blütenftaub durch den Wind von einer Blüte in die andere transportiert wird. Und wie die Häufigkeit gewiffer Blumenformen in einer Flora der Häufigkeit ihrer Beftäuber entfpricht, fo ift auch das Verhältnis von Windblütlern zu Infektenblütlern eines Gebietes durch die Wind- und Infektenverhältniffe bedingt. Am klarften tritt uns dies auf den Külteninfeln der Nordfee entgegen. 
Während in ganz Deutfchland die Windblütler $22 \%$ der Gefamtartenzahl betragen, befitzt

\section{Schleswig-Holftein $27 \%$, \\ Röm, Sylt \\ nur $1 \mathrm{~m}$ hohen Halligen $47 \%$.}

Auf Helgoland beherbergt die rom Wind etwas gefchützte Oftfeite zalilreiche Infektenblütler, während fonft auf diefer Infel faft nur Windblütler vorkommen. Diefe Verhältnilfe find leicht begreiflich, da die fliegenden Infekten den ftarken Wind meiden, der fie as leichte Beute mitnehmen kömnte. Den auf ausgefetzten Standorten angefiedelten Infektenblütlern fehlt es deshalb an Beftäubern, fodaß fie vor den Windblütigen das Feld räumen müffen.

Obwohl die Alpen ein fehr windreiches Gebiet find, beträgt die Zah] der windblïtigen Arten nur $16^{\circ} \%_{0}$ (iu ganz Deutfchland $22^{\circ}$ ), was davon herrührt, daf der Blätenftaub bei den grofen Windfïrken nicht nur über die Abhänge hinfliegt, wo Individuen der gleichen Art ftehen, fondern gerade fo leicht ïher Täler und Kämme limüher; und wenn er dann glücklich wieder den Boden erreicht, fo ift er vielleicht in ein ganz anderes Florengehiet gelangt, hat allo feinen Zweck verfehlt.

Während fomit die Windbeftiubung auf ebenem Standorte gute Dienfte leiftet, weil dort der Blütenftaub auf Blüten derfelben Art gelangen muß, ift fie in den Alpen unpraktifch, fodaf3 die Infektenblütler, die ihren Pollen einem intelligenten Transportmittel anvertrauen, die Windblütigen im Konkurrenzkampf bedeutend zurüickgedrängt haben.

Der Einfluf des Windes auf die Ausfäungsvorrichtungen macht fich dadurch geltend, daß an den dem Wind ausgefetzten Standorten die Pflanzen folche Samen oder Früchte befitzen, die rom Winde leicht fortgeführt werden können, was durch Kleinheit der Samen, Herabletzung ihres Gewichtes, Flügel- und Haarbildungen 
erreicht wird. Die für die Verbreitung durch Tiere eingerichteten Früchte und Samen befitzen entweder nahrhaftes Fleifch, das befonders die Vögel auffuchen, oder find mit Widerhaken ausgerüftet, die fich im Haarkleid der Sïugetiere fefthalten, und darin weiterbefördert werden. Über die Ausfïungsvorrichtungen der Alpenpflanzen, fpeziell der fchweizerifchen, lind wir durch die Arbeit von $\mathrm{Vogler}$ *) gut unterrichtet. Es geht darans hervor, dafs 6/10 der alpinen Arten durch den Wind ausgefät werden, womit fie den Durchfchnitt aller fchweizerifchen Arten (einfchlieflich der alpinen) un $18 \%$ ïberfteigen. Die durch Tiere verbreiteten Samenarten ftehen um $10 \%$ hinter dem Mittel der ganzen Schweiz zurück, was bei der geringen Zahl von alpinen Säugetieren und Vogelarten begreiflich ift. Auch der Prozentfatz der durch Waffer oder auffpringende Früchte verbreiteten Samen ift in den Alpen geringer als in der ganzen Schweiz. Somit bildet der Wind in der alpinen Region das wirkfamfte Transportmittel für die Samen.

Befonders wichtig find dabei die an fchönen Tagen über die Hänge ftreichenden Talwinde; bei der dann herrfchenden Lufthockenheit werden die Früchte und Samen frei, fodafs fie der Talwind an die Hänge hinauftragen, und fo diefelben befiedeln kann.

Demgegenüber fpielt der Föhn als Samen-Transportmittel nicht die grofse Rolle, die man ihm frülıer zufchrieb, da er verhältnismäßsig felten weht und, weil abfteigend, ebenfowenig wie die nächtlichen Bergwinde Samen über die Kämme hinüberträgt.

Die Erfolge des Samentransportes durch fehwache Luftftrömungèn machen fich bei dem fchrittweifen Vordringen der Pflanzen geltend, fehr deutlich befonder's da, wo frifche Standorte eröffnet werden, z. B. durch Erd-

*) Vogler, P. Üher die Verbreitungsmittel der fchweizerifchen Alpenpflanzen. Differtation Zürich 1901. (Auch „Flora“ 1901. Bd. 89. Ergänzungsband.) 
rutfche oder bei dem Rückgang eines Gletfchers. An dem feit 1874 beobachteten Rhonegletfcher wurde z. B. feftgefteilt, daß, je jünger eine Flora ift, defto größser ihr Prozentfatz an Arten mit Windverbreitung.

Wenn fomit die fchwachen Winde für die Verbreilung der Alpenpflanzen von Bedeutung find, wird dies für die ftarken Stürme noch eher zutreffen, die ja fchon Salzkriftalle von einem halben Gramm bis zum Gotthard befördert haben, welche nur aus einem, mindeftens $250 \mathrm{~km}$ entfernten Salzgarten der Mittelmeerküfte ftammen konnten. Daßs da auch die viel leichteren Samen mitzufliegen imftande find, liegt auf der Hand.

Solchen ftarken Winden haben auch die einer gewiflen Windrichtung ausgefetzten Gegenden ihren Artenreichtum teilweife zu verdanken, wïhrend benachbarte, aber gegen den Wind abgefchloflene Täler durch ihre Artenarmut auffallen. Befonders deutlich ift dies im Wallis zu beobachten, wo die bis zum füdlichen Kamme reichenden Täler (Einfifch- und Zermattertal) viele füdliche und füdweftliche Arten befitzen, die von den ftarken Süd- und Sïdweftwinden aus den piemontefifchen Alpen zugetragen wurden, während das tief eingefchnittene, befonders auch gegen Süden durch mächtige Eiskümme abgefchloffene Turtmanntal eine fehr arme Alpenflora beherbergt, der füdliche Arten fehlen.

Der Wind fpielt fomit in den Alpen als Transportmittel der Samen eine hervorragende Rolle, während er als Beftäubungsmittel zurücktritt.

\section{Zufammenfaffung.}

So find alfo fchon jetzt die hauptfächlichften Eigentümlichkeiten der Alpenpflanzen in Bau und Lebensweife auf die in den Alpen herrfchenden, klimatifchen und biologifchen Verhältniffe zurückzuführen: 
der niedrige, gedrungene Wuchs auf tiefe Nachttemperatur und hohe Lichtintenfitait während des Tages, die ftarke Wurzelentwicklung auf die Wärme des Bodens, die Abwefenheit des Lichts und die kräftige Ernährung durch die Blätter,

der Reichtum gewiffer Familien an roten Blüten auf das ftarke Höhenlicht und die durch dasfelbe gefteigerte Zuckerbildung,

das Vorwiegen von Fliegen- und Falterblumen auf den Reichtum der Alpen an entfprechenden Infekten, wodurch die windblütigen Arten zurückgedrängt wurden, fehlieflich

der Reichtum an Arten, deren Früchte und Samen durch den Wind rerbreitet werden, auf die hohen Windintenfitäten.

Außser den Felfen- und Geröllbewohnern, die deutliche Anpaffungen an ihre trockenen Standorte zeigen, ift die Alpenflora an halbfeuchte Standorte angepafst.

Die Alpenflora kann fomit wohl als Kailte- und Lichtflora, in gewiffem Sinne auch als Windflora, nicht dagegen als 'Trockenflora bezeichnet werden.

Weit davon entfernt, den von den Alpenpflanzen ausgehenden Zauber zu zerftören, locken die bisher gewomnenen Kenntniffe vielmehr dazu, immer tiefer in die ungezählten Gebeimnifle einzudringen, die diefe liebenswürdigen Wefen uns noch verbergen.

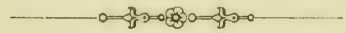



II. Teil.

T a f e l n. 
Die Hahnenfußgewiohfe oder Ranunculaceen find durch den Befitz von fcharfen, oft giftigen Stoffen und befonder's durch die großse 'Zahl von Staubblätter'n und Fruchtknoten ausgezeichnet.

Die Gattung Ranunculus hat eine doppelte, aus je fünf Blätter'n beftehende Blütenhülle. Die äußsere ift als grüner Kelch, die innere als lebhaft gefïrbte Krone ausgebildet; die Blätter der letzteren tragen am Grunde eine Honigdrüle.

Ranunculus pyrenaeus. - Tafol 1. - Stengel $8-25 \mathrm{~cm}$ hoch, unverzweigt, aufrecht, mit wenigen, schmalen, kahlen, blaugrünen Blättern, welche mit ihrer Basis den Stengel umfassen. Blüten weif, meist einzelı. Bau und Geftalt der Pflanze, befonder's der Stengel und Blätter, erinnern auffallend an gewifle Liliengewächfe.

Mehrjährig.

Blüht Juni Juli, bald nach der Schneefchmelze.

Befucher: Fliegen.

Früchtchen ohne Verbreitungsmittel.

Alpen, Pyrenäen.

Ranunculus parnassifolius. - Herzblätriger Hahnenfuß. - Stengel zuerft nieder-

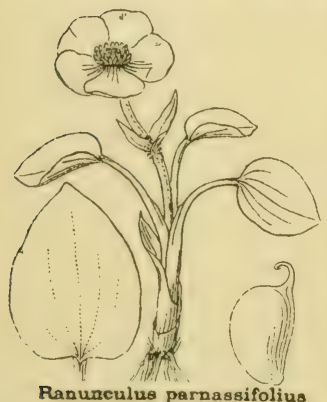

Alpen, Pyrenäen. liegend, dann aufteigend, leidig behaart; $5-15 \mathrm{~cm}$ hoch. Die meiften Blätter grundftändig, lang geftielt, fpitzeiförmig, die oberen l'chmal, den Stengel umfaffend. Blüten weik, $1 \mathrm{~cm}$ groß, zu $1-3$ auf einem Stengel. Kelch rötlich, behaart.

Mehrjährig. Blüht Juni bis Auguft. Belucher: Fliegen.

Früchtchen ohne Verbreitungsmittel.

Kalkgerölle, Schiefer, Moränenfchutt, $2300-2900 \mathrm{~m}$. 


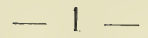

Feuchte Matten 1800-2700 Meter.

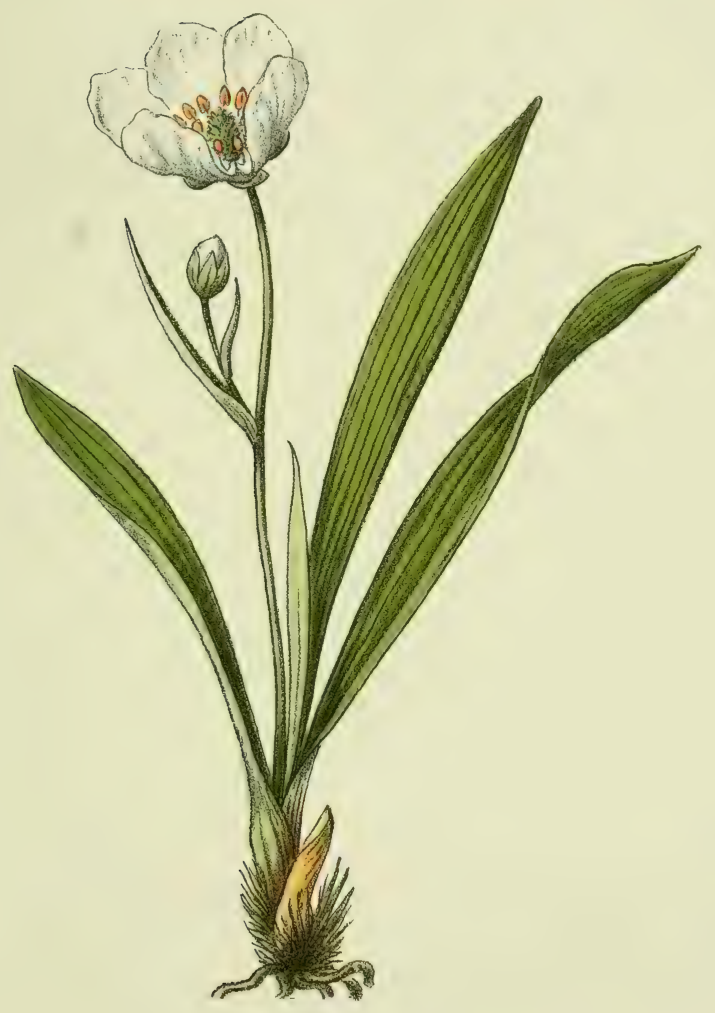

Ranunculus pyrenaeus. Renoncule des Pyrénées. Pyrenean Crowfoot. 


\section{$-2$}

Nasse Wiesen, Bachufer, Läger 500-2900 Meter.

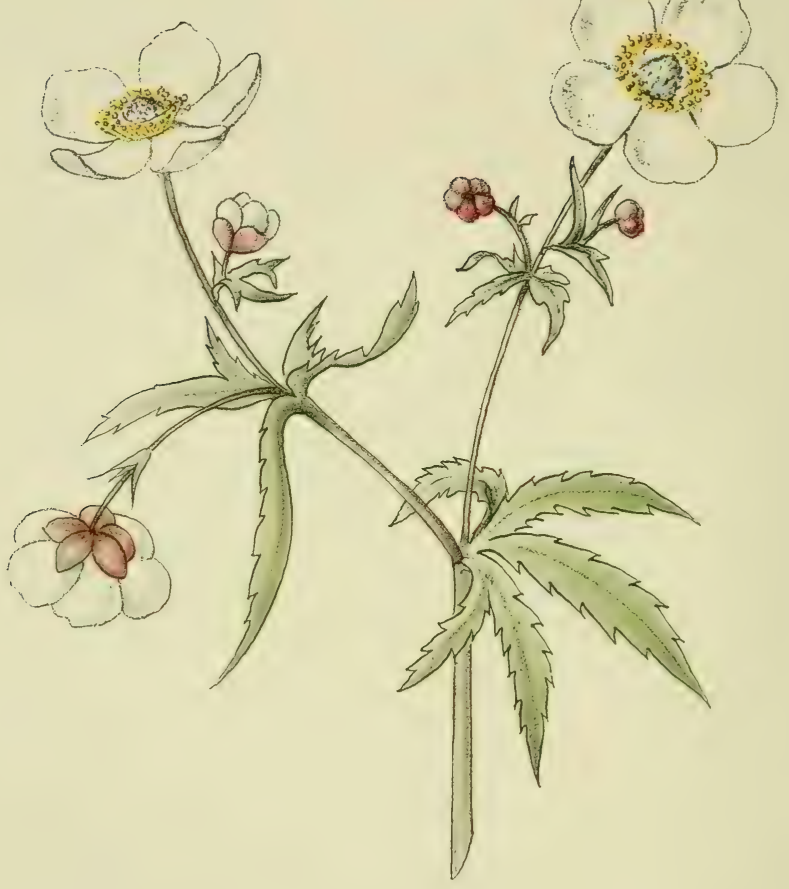

Ranunculus aconitifolius. Eisenhutblättriger Hahnenfuss. Renoncule à feuilles d'aconit. Fair maid of France. 
Ranunculus aconitifolins. - Tafel 2. $-30-90 \mathrm{~cm}$ hoch, mit verzweigtem, vielhlütigem Stengel. Blätter tief handförmig eingel'chnitten mit 3-7 zugespitzten Abl'chnitten. Blüten weißs, Kelchblätter lehwach behaart.

Mehrjährig. Blüht April bis Juli. Befucher: Fliegen.

Früchtchen ohne Verbreitungsmittel.

Ebene bis $2900 \mathrm{~m}$.

Mitteleuropa, Alpen, Pyrenäen.

Ranuneulus alpestris. - Alpen-Hahuenfuf. - Bis $10 \mathrm{~cm}$ hoch, kahl, mit glänzenden Blättern; die grundftändigen im Umrifs rund, fchwach 3 -5fpaltig, die stengelftändigen lichmal. Blüten weifs, $1^{1 / 2}$ cm grof, meift einzehn.

Mehrjähıjg. Blüht während und bald nach der Schneefchmelze. Befucher: Fliegen.

Früchtchen ohne Verbreitungsmittel.

Feuchte Matten; Beftandteil der fogenamnten Schneetälchen-Flora, $1500-2700 \mathrm{~m}$.

Alpen, Pyrenäen, Karpathen.

Ranunculus montanus. - Berg-Hahnenfufs. - 6 bis $25 \mathrm{~cm}$ hoch. Stengel fteif, aufrecht, nicht oder wenig verzweigt. Grundftändige Blätter handförmig geteilt, mit fünf, meilt dreifpitzigen Lappen; gewöhnlich nur ein ftengelftändiges, l'chmal 5-teiliges Blatt. Blüten gelb, 1-2 cm grof, meilt einzeln. Kelchblätter fchwach behaart.

Mehrjährig.

Blüht Mai bis Auguft.

Befucher: Fliegen, Falter.

Früchtchen mit Flügelrand:

Windverbreitung.

Kühle Matten, waldige Wei-

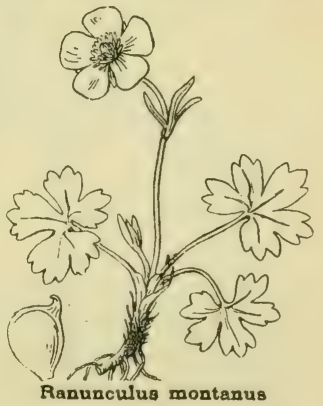
den $1000-2900 \mathrm{~m}$.

Alpen, Jura, Pyrenäen; Karpathen, Kaukafus. 
Ranunculus glacialis. - Tafel $3 .-8-15 \mathrm{~cm}$ hoch, mit dick fleifchigen, niederliegenden bis aufsteigenden Stengeln. Blätter ebenfalls fleifchig; die grundftändigen tief eingelchnitten, mit ftumpfen Lappen, die ftengelftïndigen klein, einfach oder dreiteilig. Blüten einzeln, $1-3 \mathrm{~cm}$ groß. Blumenkronblätter weif oder, hefonders aufsen, rofirot, bleiben nach dem Blühen an den Früchten. Kelchblätter mit dunkeln Haaren.

Mehrjährig. Blüht Juli Auguft, im kurzen Sommer der nivalen Region.

Befucher: Fliegen, kleine Falter.

Friichtchen berandet: Windverbreitung.

Oft im Schneefchmelzwaffer. In der Schweiz am Gipfel des Finfteraarhorns bei $4275 \mathrm{~m}$ gefunden. Alpen, Pyrenäen; nordpolare Länder, Altai, Himalaya.

Ranunculus Thora. - Gift-Hahnenfuß. - Mit Büfchel fpindelförmig verdickter Wurzeln.

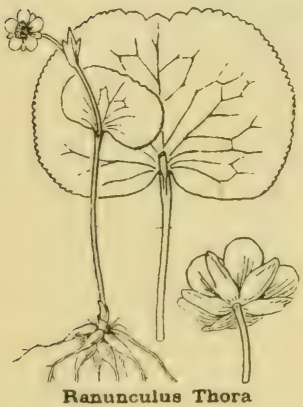
Stengel 10-25 $\mathrm{cm}$ hoch, ohne grundftändige Blätter. Oberhalb der Stengelmitte ein großes, rundliches, ungeftieltes, blaugrün glänzendes Blatt. Oberfte Blätter klein, fchmal. Blüten meift einzeln, gelb, kaum $1 \mathrm{~cm}$ grof. Kelchblätter kahl, faft fo lang wie die Krone.

Mehrjährig. Blüht Mai bis Juni. Befucher? Früchtchen ohne Verbreitungsmittel. In magerem Rafen, befonders auf Kalk, $1500-2000 \mathrm{~m}$. Alpen, Jura, Pyrenäen, Karpathen.

Ranunculus Seguieri. - Seguier's Hahnenfuß. $10-20 \mathrm{~cm}$ hoch, mit auffeigendem, kaum verzweigtem, oberwärts behaartem Stengel. Blätter tief handförmig eingefclinitten, fpitzlappig. Blüten weif, $1-2 \mathrm{~cm}$ grof.

Mehrjährig. Blüht Juni bis Juli.

Befucher: wahrfcheinlich Fliegen.

Gerölle der höchften Kalkalpen von Italien, Dauphiné, Südtirol (fehlt der Schweiz). 
Gerölle, Felsspalten 2300-4000 Meter.

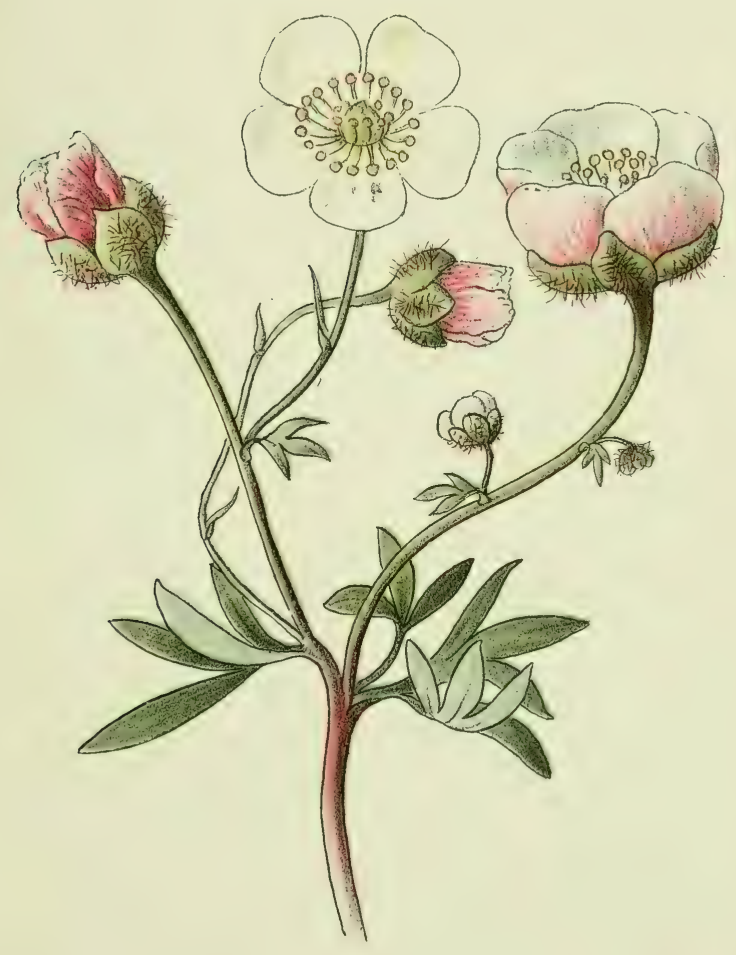

Ranunculus glacialis. Renoncule des glaciers.

Gletscher Hahnenfuss, Gamskress. Glacier's Crowfoot. 
Gerölle, über I 800 Meter.

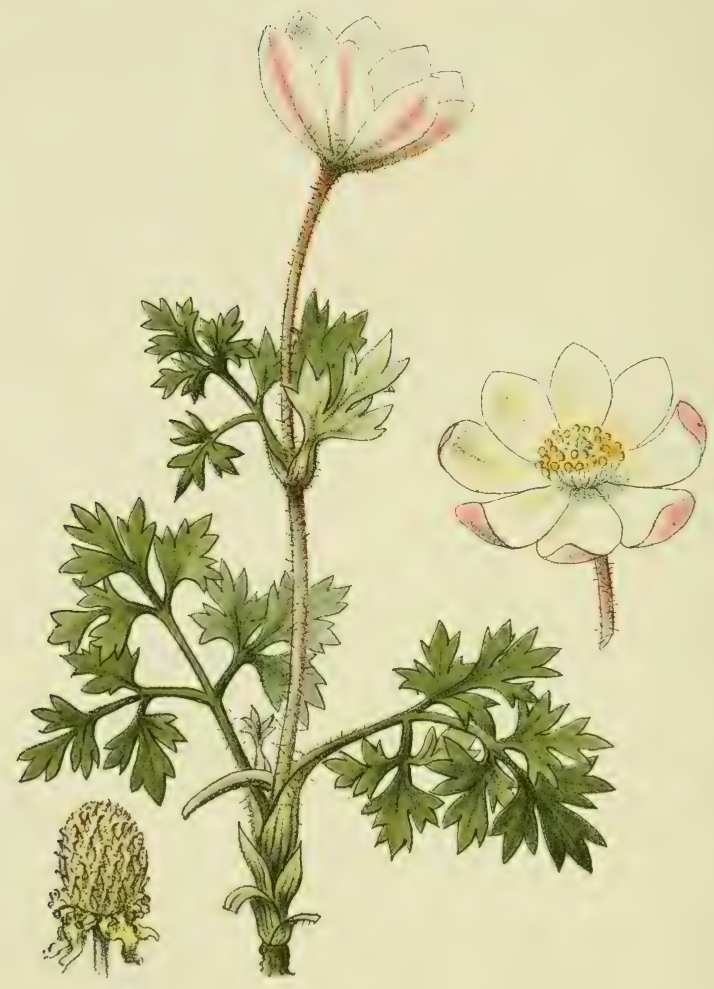

Anemone baldensis.

Anémone fraise.
Windröschen vom Monte Baldo (Garda-See). Windflower of Monte Baldo (Tirol). 
Die Anemonen lıaben nur eine einzige, mehrblättrige Blütenhülle, unter welcher drei größzere oder kleinere Hochblätter ftehen. Die Blüten find honiglos und werden von den Infekten nur wegen des Blïtenftaubes befucht: Pollenblumen.

Anemone baldensis. - Tafel 4. - Pflanze mit langem, verzweigtem Wurzelftock. Stengel $5-10 \mathrm{~cm}$ hoch, aufrecht, behaart. Blätter in Umrif rundlich, Blattablechnitte keilförmig, gezähnt. Hochblätter wie die grundftindigen ansgebildet.

Blüten einzeln, weifs, mit $5-8$ aufen rötlichen unı behaarten Blättern. Früchte wollig hehaart, in dichten Köpfchen.

Mehrjährig. Blüht Juli bis Auguft.

Befucher:?

Frïchtchen mit Wollhaaren: Windrerbreitung.

Gerölle, Gefteinsfchutt, 1800--3000 m.

Alpen, Pyrenäen, Karpathen.

Anemone verualis. - Frïhlings-Anemone. - Seidig behaart, $4-12 \mathrm{~cm}$ hoch, mit einem einzigen Blütenfchaft. Blätter unpaarig gefiedert mit fïnf breiten dreilpaltigen Abfchnitten. Hochblätter bis zur Bafis in fchmale Zipfel geteilt.

Blüte grof, aufrecht, mit fechs Blütenblättern, die innen weiß, außen hell violett oder rola gefärbt und mit goldgelben Haaren bekleidet find. Früchtchen zu federigem Köpfchen vereinigt.

Mehrjährig.

Blüht Mai Juni, fofort nach

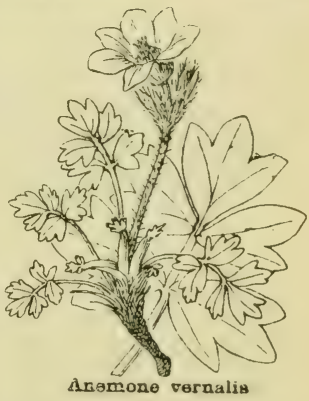
der Schneefchmelze.

Befucher: Fliegen, feltener Bienen und Falter.

Früchtchen mit Haarfchweif: Windverbreitung.

In kurzem, noch naffem Rafen, $1800-3600 \mathrm{~m}$.

Alpen, Auvergne, Pyrenäen. 
Anemone alpina. - Tafel 5. - Ein bis mehrere, $10-20 \mathrm{~cm}$ hohe Blütenfchäfte, die fich nach dem Blühen zuweilen bis zu 40 (cm ftrecken. Blätter im Umrif dreieckig, dreifach geteilt, mit gezïlnnten Abfchnitten. Die Hochblätter gleichen den grundftändigen.

Blüten mit fechs innen weifsen, aufen bläulichen und etwas hehıarten Blütenblättern. Früchtchen zu federigen Köpffchen vereinigt (fiehe Titelbild).

Mehrjährig. Blüht Mai bis Juli.

Befucher: Fliegen, feltener Käfer.

Früchtchen mit Haarfchweif: Windverbreitung.

Weiden, Rafenbänder, Gerölle, 1200-2800 m.

Alpen, Jura, Vogefen; Auvergne, Pyrenäen; Karpathen, Harz, Nordafien.

Anemone sulfurea - Schwefelgelbe Kiichenfchelle unterfcheidet fich von voriger durch die fchwefelgelben Blüten und kleineren Früchtchen (nur 3-4,5 mm ftatt $5-7 \mathrm{~mm}$ lang).

Wird vielfach nur als Varietiit von Anemone alpina aufgefafist, die auf kiefelreichem Boden (Granit) eine andere Farbe angenommen. Dagegen fpricht die Tatfache, dafs Anemome alprima in den Vogefen trotz dem Granitboclen weifs hlühl. Anemone sulfurea ift deshalb als befondere Art zu behandeln.

Mehrjährig. Blüht Juni bis Juli.

Befucher?

Früchtchen mit Haarfohweif: Windrerbeitung.

Auf kiefelreichem Boden, WVeiden, Rafenbänder, Gerölle, $1300-2800 \mathrm{~m}$.

Alpen, Pyrenäen, Piefengebirge, Kaukafus. 
Steinige Weiden, Rasenbänder, Gerollhalden, I200-2800 Meter.

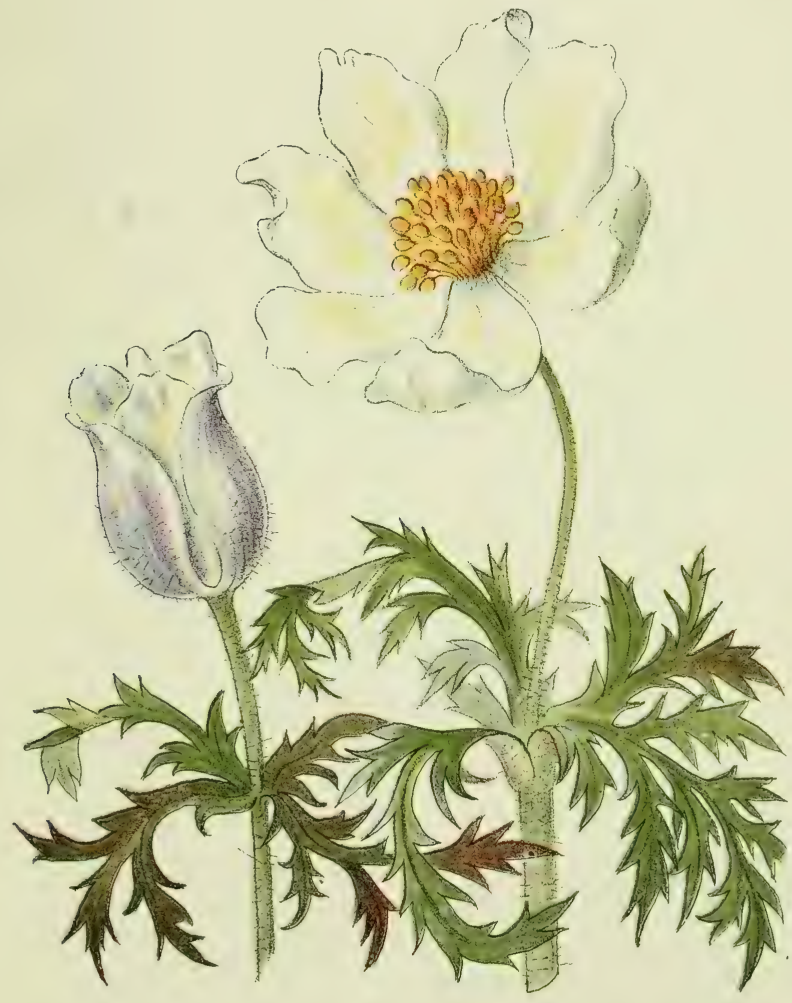

Anemone alpina.

Alpen-Windröschen.

Anémone des Alpes. Alpine Flaw flower. 
Matten, Weiden, Wildheuplanken I300-2800 Meter.

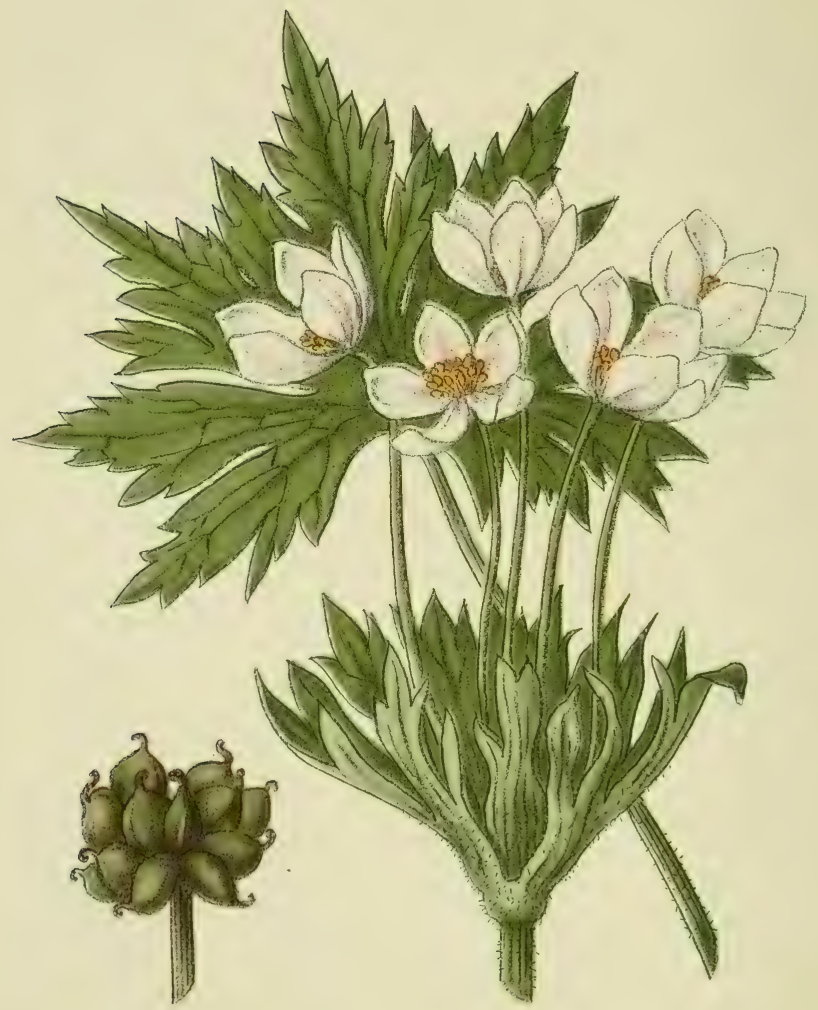

Anemone narcissiflora. Narcissblumiges Windröschen. Anémone à fleurs de narcisse. Narcissus-flowered Anemony. 
Anemone narcissiflora. - Tufel 6. - Kurzhaarig, 30-40 cm hoch; grundftändige Blätter langgeftielt, fünfteilig, Abfchnitte mit lchmalen Zipfeln. Hochblätter ungeftielt, ebenfalls mit fichmalen Zipfeln.

Blüten etwa $1 \mathrm{~cm}$ grof, zu $2-6$ in einer Dolde, innen weiß, außen rötlich angelaufen.

Mehrjährig. Blüht Mai bis Juli.

Befucher: Fliegen.

Früchte mit Flügelrand: Windverbreitung.

Weiden, Rafenbänder, 1300--2800 m.

Alpen, Jura, Vogelen; Pyrenäen; Karpathen, Kaukafus, afiatifche Polarländer und Hochgebirge.

\section{Anemone Halleri - Haller's Anemone - gleicht} der Anemone vernalis, unterfcheidet fich aber von derfelben durch die fchmäleren Blattabfchnitte und die dunklere Färbung der Blüten.

Mehrjährig.

Blüht Juni bis Juli, erft einige Zeitnach der Schneefchmelze.

Befucher?

Frïchtchen mit Haarfchweif: Windverbreitung.

Sonnige Hügel, Weiden bis $3000 \mathrm{~m}$.

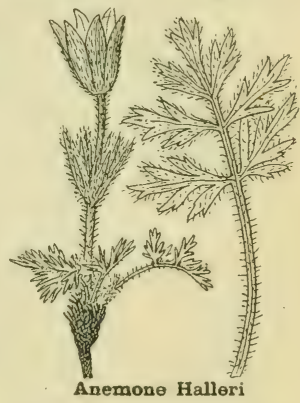

Alpen von Frankreich, Italien, Schweiz (nur im Gebiet von Zermatt), Öfterreich, Böhmen. 
Ranunculaceen.

Acpuilegia alpina. - Tafel \% - Stengel aufrecht, $30-4()$ (an hoch, oberwärts klehrig. Blätter dreiteilig, mit tief dreifpaltigen Ablchnitten.

Blüten etwa 5 cm grof. hellblau, an zartem Stiele hängend. Blumenkronblätter in Forın langer fpitzer . Tüten (Honighehälter) gegen den Sticl zurückgefchlagen. Äufsere Blïtenblïtter flach, abftehend, ebenfalls blau.

Mehrjährig. Blüht Juni bis Juli.

Befucher: vermutlich Hummeln.

Samen ohne Verbreitungsmittel.

Alpen.

Afnilegia vulgaris. - Gewöhnliche Akelei oder Narrenkappe - mit zahlreichen, nur etwa 2 cm grofen, dunkelblauen oder violetten Blüten.

Mehrjährig. Blüht Mai bis Juli.

Befucher: Gartenhummel.

Samen ohne Verbreitungsmittel.

Auf fteinigen Weiden und Heiden bis zur Baumgrenze (um $2000 \mathrm{~m}$ ).

Delphinium elatum. - Hoher Ritterfporn. - Stengel

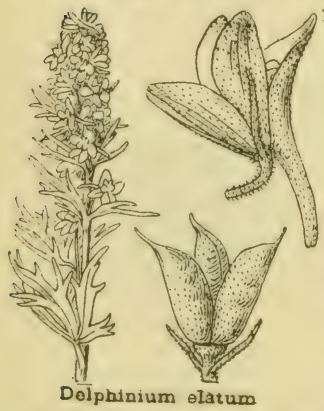
aufrecht, 1-2 $\mathrm{m}$ hoch. Zahlreiche, auf dem Stengel gleichmäßig verteilte Blätter mit 5-7 dreiteiligen Abfchnitten. Blüten zu langer Ähre vereinigt, blau, mit fpitzem Sporn (Honigbehälter). Früchte ohne Granne (fiehe Zeichnung rechts unten).

Mehrjährig. Blüht Juni bis Sept. Befucher: Gartenbummel.

Samen geflügelt: Windverbreitung. Kühle Matten, Bachufer.

1500 bis $2000 \mathrm{~m}$.

Alpen von Frankreich und der Schweiz (felten), öftliche Pyrenäen, Mitteleuropa, Kleinafien. 
Blockbesäte Weiden, Waldlichtungen I600-2400 Meter.

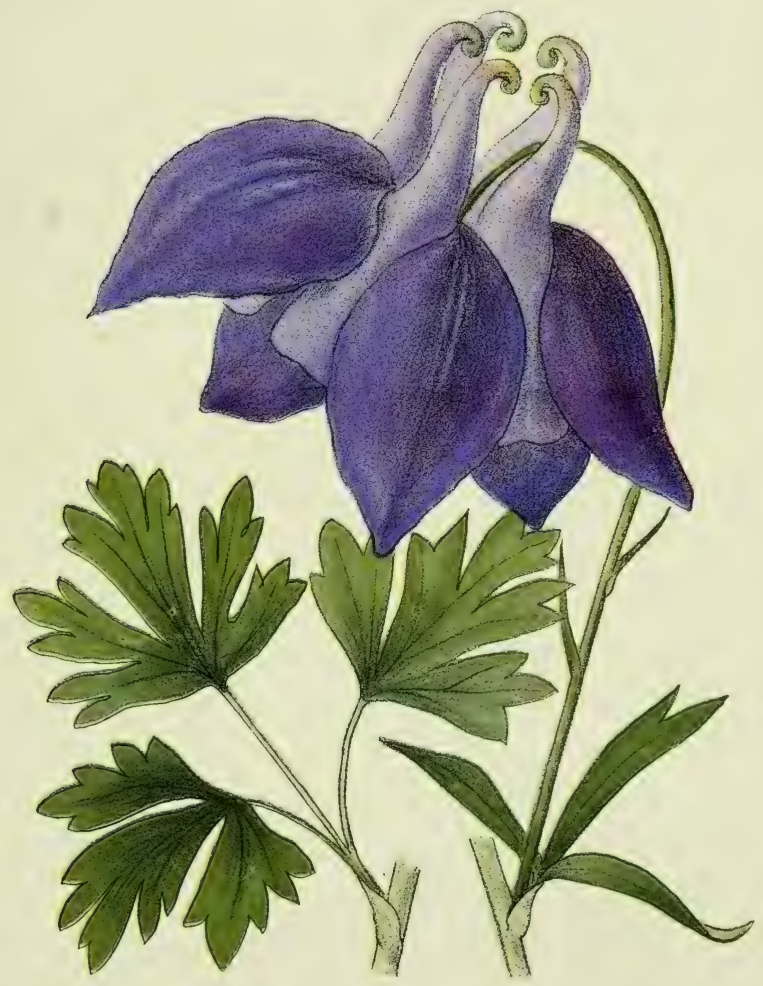

Aquilegia alpina.

Ancolie des Alpes.
Alpen-Ackelei. Alpine Columbine. 
Wälder, blockbesäte Weiden, Läger bis 2400 Meter.

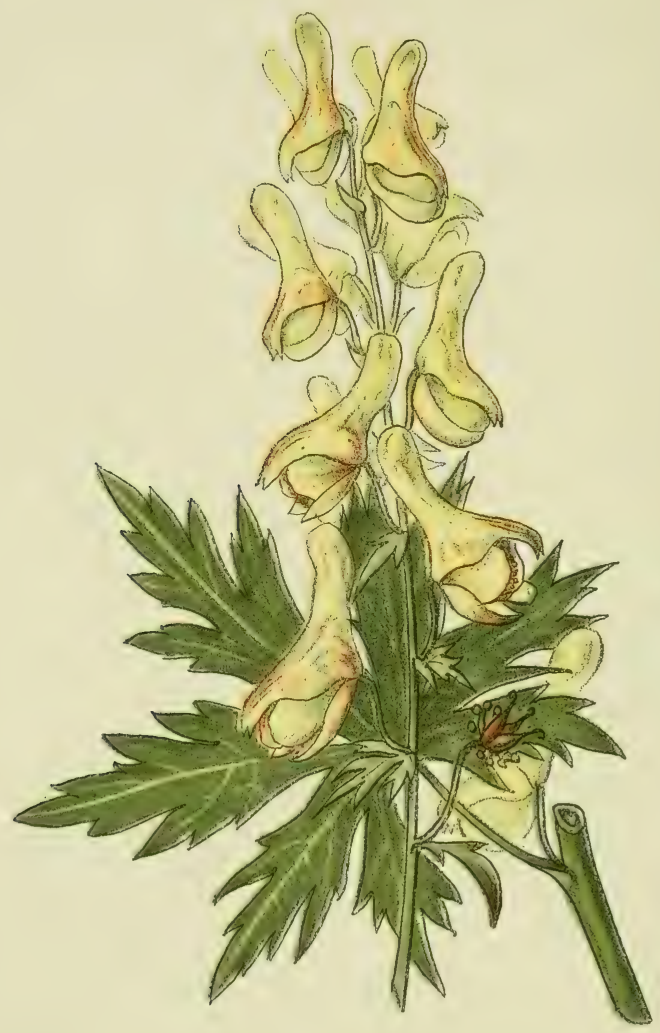

Aconitum Lycoctonum.

Aconit tue-loup.
Wolfs-Eisenhut.

Yellow Wolf's-bane. 
Die Gattung Aconitum unterfcheidet fich wie Delphinium von den übrigen Remunrulureen dadurch, dafs die einzelnen Blätenblätter untereinander verfchieden find, was auf hochgradige Anpaflung an Infekten hinweift. Das obere, helmförmig gewölbte beherbergt zwei rührenförmige Honigbehälter, welche nur von den Hummeln richtig entleert werden können, deren Verhreitungsgebiet fich faft genau mit demjenigen von Aconitum deckt.

Frifche Pflauzen giftig, vom Vieh nicht gefreffen; trocken unfchädlich. Das befonders in den Wurzeln enthaltene Aconitin wird in der Merlizin verwendet.

Aconitum Lycoctonum. - Tafel 8. - Stengel gerade, aufrecht, bis $1 \mathrm{~m}$ hoch, schwach behaart. Blätter handförmig 5-7teilig. Blüten blaßsgelb, in Trauben.

Mehrjährig. Blüht Juni bis Auguft.

Befucher: Hummeln.

Samen ohne Verbreitungsmittel.

Blockbefäte Wälder, Weiden, Läger, bis $2400 \mathrm{~m}$.

Alpen, Mitteleuropa.

Aconitum paniculatum.

Stengel hin und her gebogen, bis 1 in hoch. Blätter handförmig geteilt. Blüten blauviolett in kurzen lockeren Trauben.

Mehrjährig.

Blüht Juli bis September.

Befucher: Hummeln.

Samen mit Flügelrand: Windverbreitung.

Waldlichtungen, Gebüfche, kühle Weiden.

1200-2400 m.

Weftalpen, Jura.
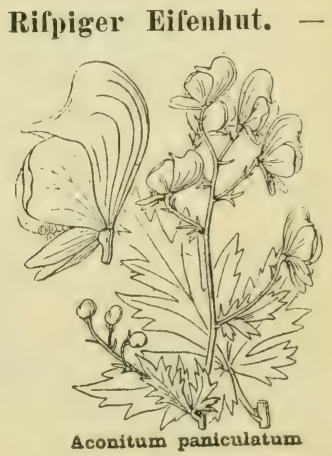
Trollius europaeus. - Tafel 9. - Stengel $20-40 \mathrm{~cm}$ hoch, aufrecht, kahl. Blätter dunkelgrrün glänzend, handförmig fünfteilig. Blüte einzeln, kugelig, goldgelb. In Immern auferhalb der staubblätter lange, fchmale, dunkelgelbe Honigblätter.

Mehrjährig. Blüht Mai bis Juli.

Befucher: Käfer, Fliegen.

Samen ohne Verbreitungsmittel.

Laubwaldzone bis $2100 \mathrm{~m}$.

In den Gebirgen (Alpen, Jura, Vogelen, Schwarzwald, Auvergne, Gevennen, Pyrenäen) und im Norden Europas.

Caltha palustris. - Sumpf-Dotterblume. - Stengel

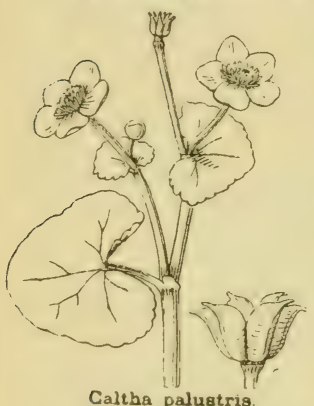
dick fleifchig, hohl, $20-40 \mathrm{~cm}$ hoch. Blätter rundlich-herzförmig, dunkelgrün; obere ungeftielt.

Blüten etwa $2 \mathrm{~cm}$ groß, weit geöffnet, mit 5 dottergelben Blütenblättern ohne Honigdrülen. Honig am Grunde des Fruchitknotens ausgefchieden.

Mehrjährig.

Blüht April bis Juli.

Befucher: Fliegen, Käfer, Bienen. Samen fchwirnmfähig: Wafferverbreitung.

Feuchte, torfige Matten, Bachufer. Ebene bis $2300 \mathrm{~m}$. Europa, Afien, öftliches Nordamerika. 
Feuchte Matten bis 2100 Meter.

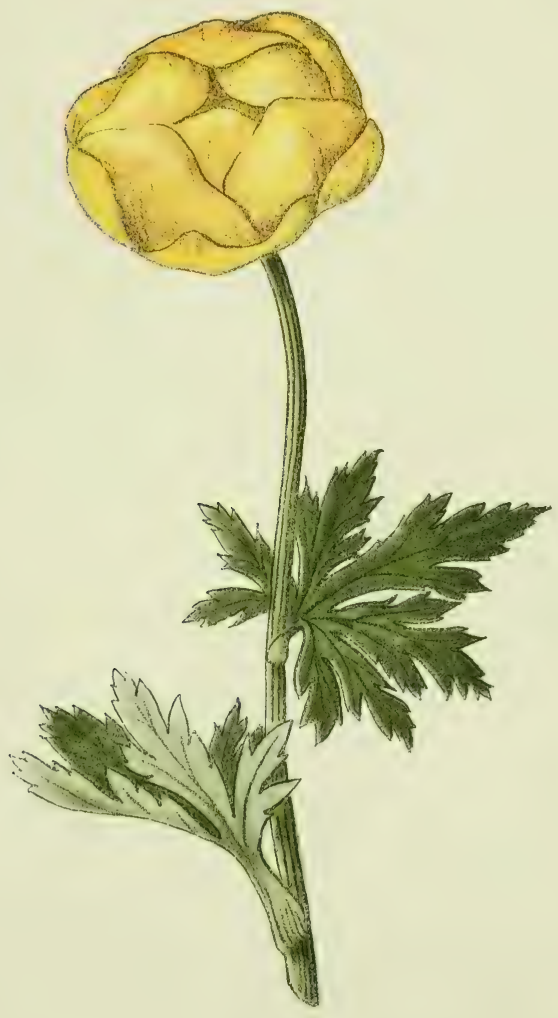

Trollius europaeus. Boule d'or.
Europacische Trollblume. Globeflower. 
Gebüsche, Waldlichtungen über rooo Meter.

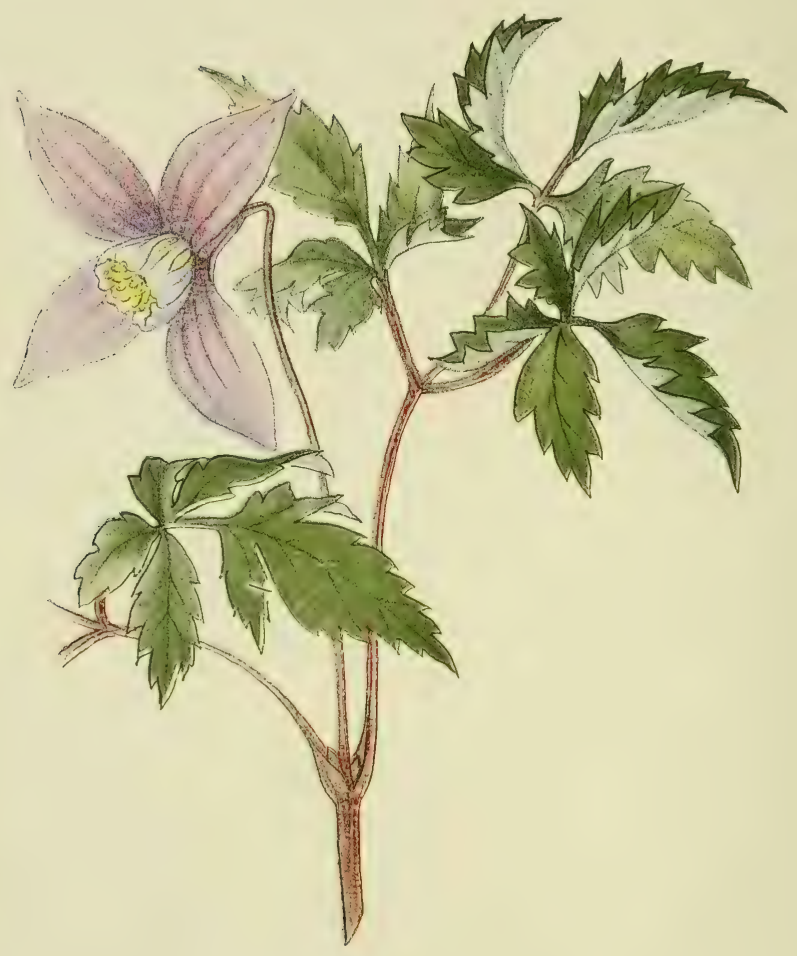

Glematis (Atragene) alpina.

Apenrebe.

Clématite des Alpes. Alpine Virgin's bower. 
Clematis (Atragene) alpina. - Tafel 10. - Schlingender, holziger Stengel mit je zu zweien einander gegenüberftehenden (gegenftïndigen) doppelt dreizähligen Blättern.

Blüten grofs, nickend. Die vier äuferen Blütenblätter grofs, violett, die 10-12 innern klein, fpatelförmig, mit Honigdrüle. Früchtchen zu federigen Köpfchen vereinigl.

Mehrjährig. Blüht Mai bis Juli.

Befucher: Bienen, Hummeln.

Früchtchen mit Haarfchweif: Windverbreitung.

Gebüfche, Waldlichtungen, über $1000 \mathrm{~m}$.

Alpen, Pyrenäen, Karpathen.

\section{Thalictrum aquilegifolium. - Akeleiblättrige} Wiefenraute. - Stengel aufrecht, bis $1 \mathrm{~m}$ hoch, kahl. Blätter zufammengeletzt, mit dünnen fteifen Stielchen. Blättchen breit, unterfeits bläulichgrün.

Blüten in dichten Büfcheln. Da die vier Blütenblätter fehr früh $a b-$ fallen, verdanken die Blüten ihre zart violette Fürbung ausfchließlich den zahlheichen Staubgefüßsen.

Mehrjährig. Blöht Mai bis Juli. Befucher : Küfer, Fliegen (Pollenblume ohne Honig).

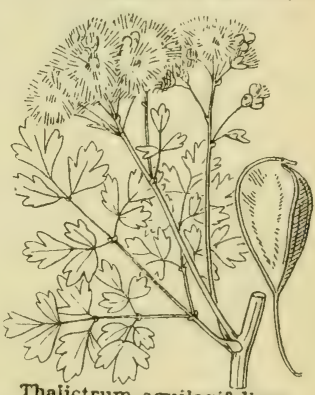

Thalictrum aquilegifolium

Früchtchen dreikantig (fiehe Skizze): Windverbreilung. Waldlichtungen, Gebülche, frifche Wiefen, zwifchen Felsblöcken, $700-2000 \mathrm{~m}$.

Alpen, Jura; Pyrenäen, Auvergne, C'evennen; Mitteleuropa, Nordafien. 
Die Papaveraceen und Nymphaeaceen find durch ihren Blätenbaı und den Befitz von Milchgefäfsen verwandt. Befonder's reichlich laflen alle Mohngewächfe bei der geringften Verletzung einen Milchfaft ausfließen, der das giftige Morphium enthält, welches die Medizin in kleinen Dofen als Beruhigungsmittel anwendet.

Papaver alpinum. - Tafel 11. - 4-15 cm hohe, etwas bläulich angelaufene Pflanze. Blüten einzeln, mit zwei grünen, fchwarzborftigen, beim Aufblühen abfallenden Kelchblättern und vier anfangs zerknitterten, feidenglänzenden, weißzen, feltener rötlichen Kronblättern.

Mehrjährig. Blüht Auguft.

Befucher: Fliegen (Pollenblume ohme Honig).

Samen ohne Verbreitungsmittel.

Alpen, Pyrenäen, Karpathen, Nordpolarländer, Altai, Himalaya.

Papaver rhaeticum - Bündner-Mohn -- mit goldgelben Blüten und breiteren, behaarten Blattzipfeln.

Engadin (Bernina) und Tirol, 1800-2900 in.

Nuphar pumilum.

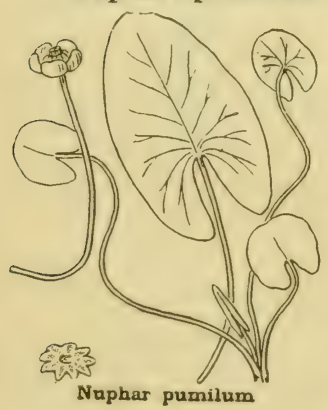

Kleine gelbe Seerofe. - Der Wurzelftock trägt die langgeftielten, herz-eiförmigen, höchftens $15 \mathrm{~cm}$ langen Blätter, die auf der Wafferoberfläche fchwimmen. Blüten etwa $3 \mathrm{~cm}$ grof 3 , mit j grofen und zahl. reichen kleinen gelben Blütenblättern mit Honigdrülen.

Mehrjährig. Blüht Juni bis Juli. Befucher: vermutlich Käfer und Fliegen.

Früchte fchwimmend: Wafferverbreitung.

Berg- und Alpenfeen von Mittelund Nordeuropa (Alpen, Jura, Vogefen, Schwarzwald). 
Gerölle der Kalkalpen I 200-2900 Meter.

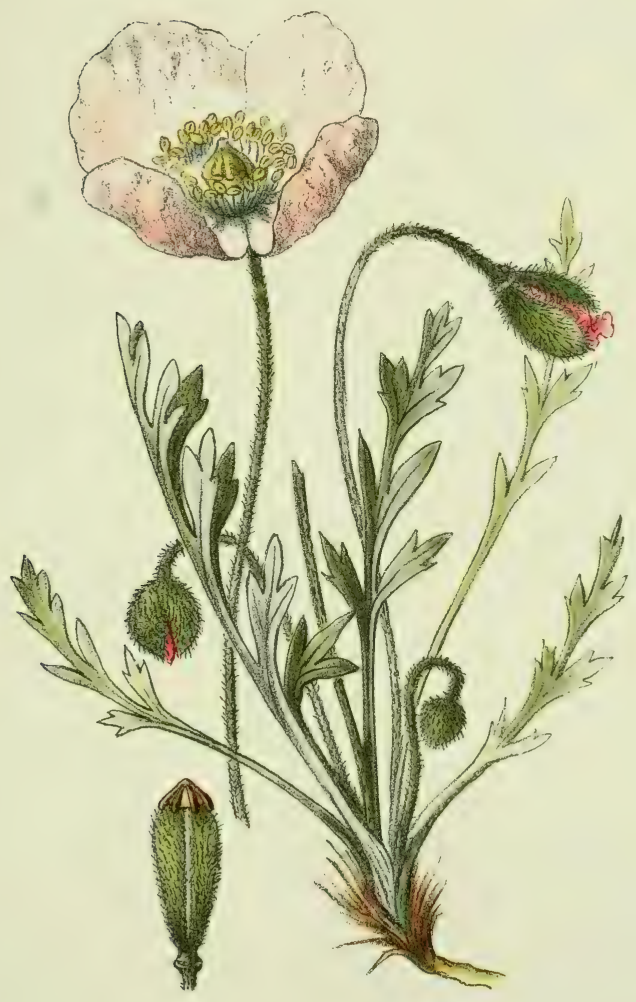

Papaver alpinum.

Pavot des Alpes.

Alpen-Mohn. Alpine Poppy. 
Felsen, steinige Halden 1000-2200 Meter.

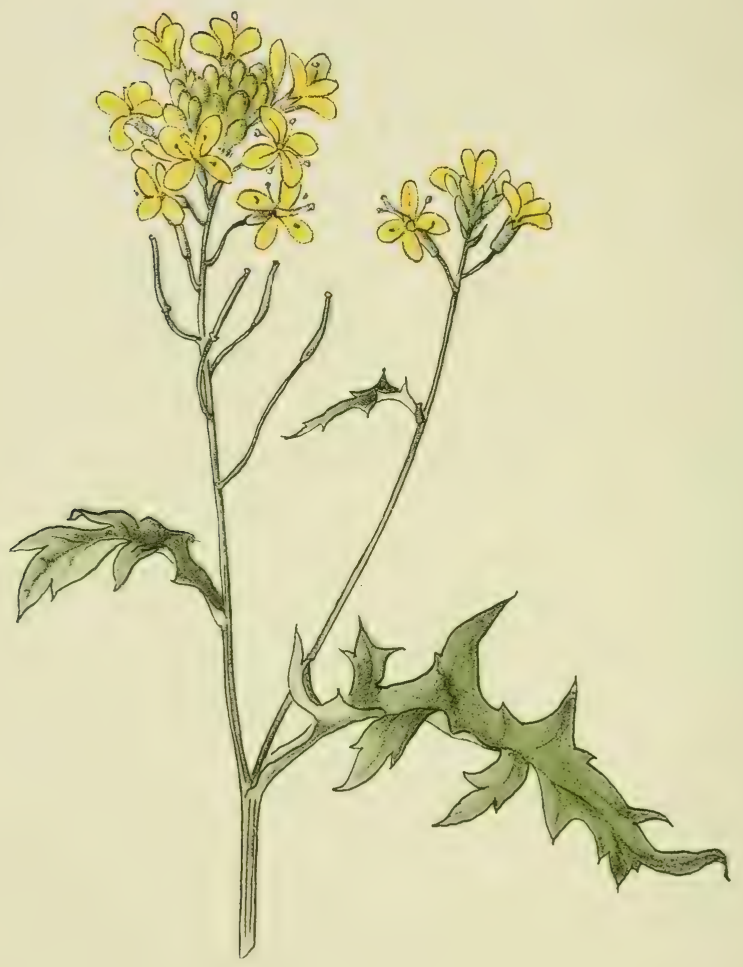

Sisymbrium austriacum. Roquette autrichienne.
Oesterreichische Rauke. Austrian Rocket. 
Die Kreuzbliitler oder Cruciferen fchliefsen fich eng an die Mohngewächfe an. Ihren Namen hahen fie von den vier kreuzweife geftellten Blumenkronblättern. Honigdrüfen im Grunde der Blüten; Beftäubung durch Infekten, im Notfalle Selbftbeftäubung.

Sisymbrium austriacum. - Tafel 12. - 20-60 cm hohe, aufrechte, verzweigte Pflanze. Blätler geftielt, denjenigen des Löwenzahns ähnlich. Blüten in langen Trauben.

Zweijährig. Blüht im Mai. Befucher: Fliegen, Bienen.

Samen ohne Verbreitungsmittel.

Alpen, Jura, Mitteleuropa, Pyrenäen.

Dentaria digitata. - Gefingerte Zahuwurz. Weifer fchuppiger Wurzelftock, mit 2-4 handförmig fünfteiligen Blättern. Blüten groß, violett oder rötlich.

Mehrjährig. Blüht Mai bis Juni. Befucher?

Samen beim Auffpringen der Früchte herausgefchleudert. Humusreicher Boden des BergLaubwaldes.
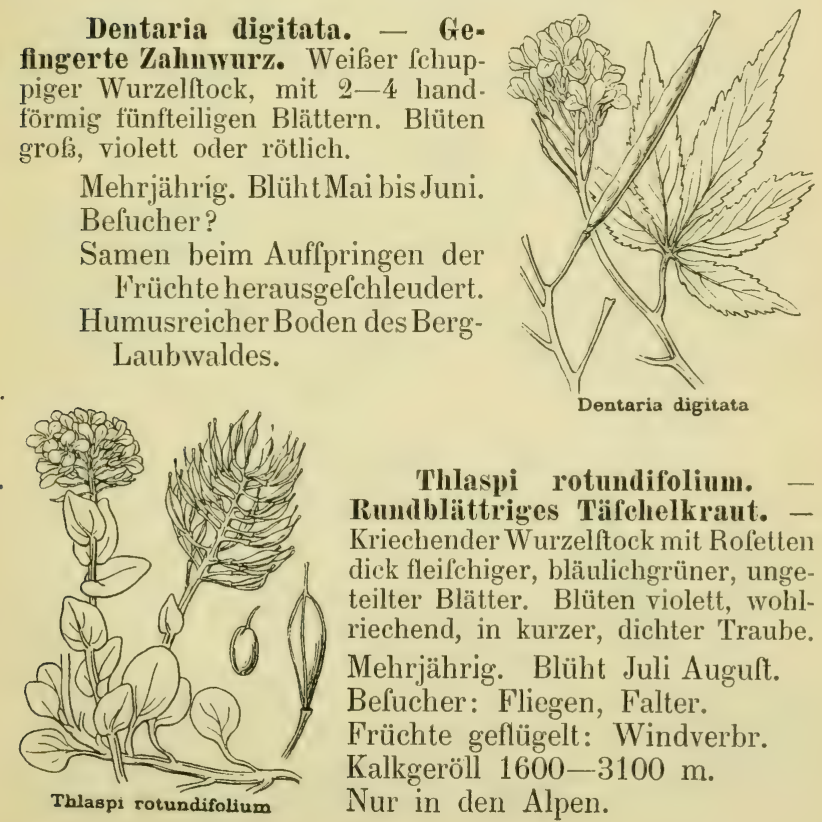

Thlaspi rotundifolium. -
Rumdblättriges Täfchelkraut. Kriechender Wurzelftock mit Rofetten dick fleifchiger, bläulichgrüner, ungeteilter Blätter. Blüten violett, wohlriechend, in kurzer, dichter Traube. Mehrjährig. Blüht Juli Auguft. Befucher: Fliegen, Falter. Früchte geflügelt: Windverbr. Kalkgeröll 1600-3100 m. Nur in den Alpen. 
Sisymbrium (Hugueninia) tanacetifolium. - Tafel 13. Schwach behaart, mit zahlreichen, $30-80 \mathrm{~cm}$ hohen, aufrechten, oberwärts verzweigten, dicht beblätterten Stengeln. Blätter hellgrün, gefiedert, Abfchnitte eingefchnitten-gefägt. Blüten klein, gelb, lang geftielt, mit Honiggeruch.

Mehrjährig. Blüht Juli.

Befucher: Fliegen, Bienen, Falter.

Samen ohne Verbreitungsmittel.

Schweiz (Wallis), nördliche Alpen von Frankreich und Italien; Pyrenäen.

\section{Arabis alpina. --}

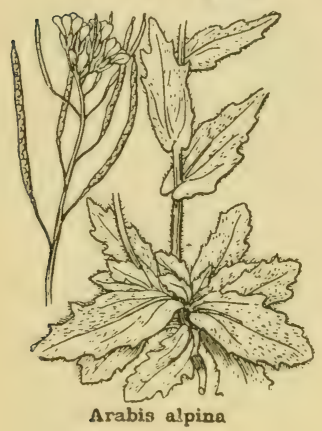

A1pen-Gäulekreffe. - $10-30 \mathrm{~cm}$ hoch, behaart. Stengel beblättert, oft mit grundfündiger Blattrofette. Blätter fpitz-eiförmig, grob gezähnt. Blüten weiß, in Trauben.

Mehrjährig.

Blüht Mai bis Auguft.

Befucher: Fliegen, feltener Falter. Samen berandet: Windverbreitung. Felsfpalten, Gerölle, 500-3000 m. Alpen, Jura, Pyrenäen, Karpathen, Kaukafus, Nordpolarländer, Himalaya.

Arabis caerulea. - Blaue Gänfekreffe. - Meifte

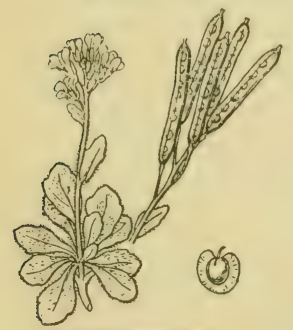

Arabis crerulea.

Blätter in grundftändiger Rolette; 1 bis

3 kleinere Blätter auf dem 5-10 cm hohen Slengel. Blüten bläulich.

Mehrjährig.

Blüht Juli bis Auguft.

Befucher?

Samen mit breitem Flügel (fiehe Skizze rechts unten): Windverbreitung.

Felsblöcke, feuchte Felfen.

Alpen. 2000-3000 m. 
Felsen, Gerölle, Rasenbänder 1500-2300 Meter.

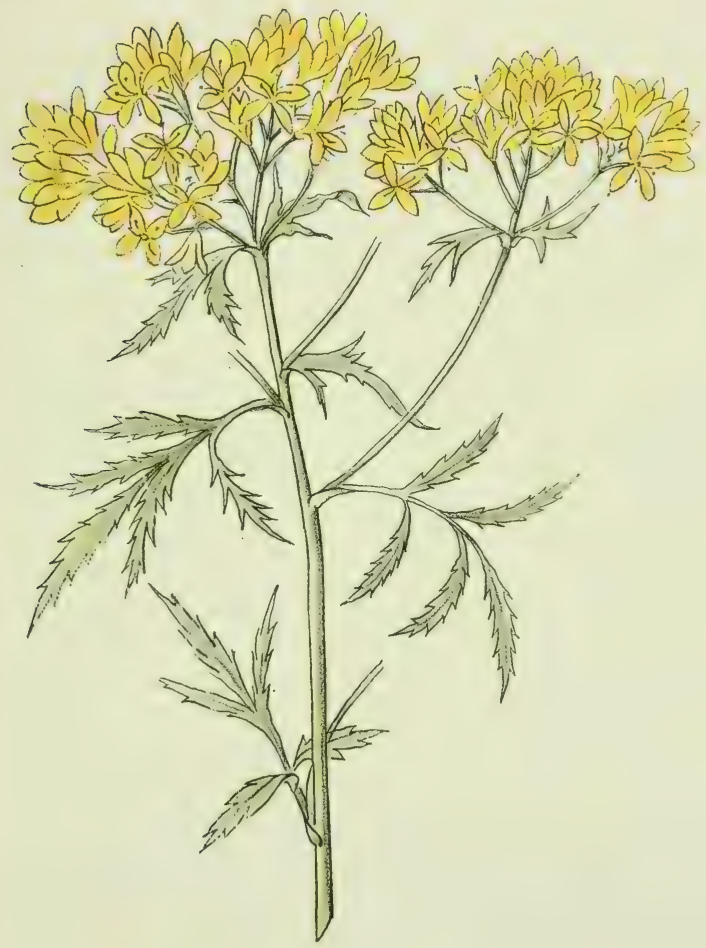

Sisymbrium tanacetifolium. Roquette a feuilles de tanaisie.

Rainfarnblätrige Rauke. Tansy-leaved Rocket. 
Felsen, Gesteinsschutt. Bis 2800 Meter.

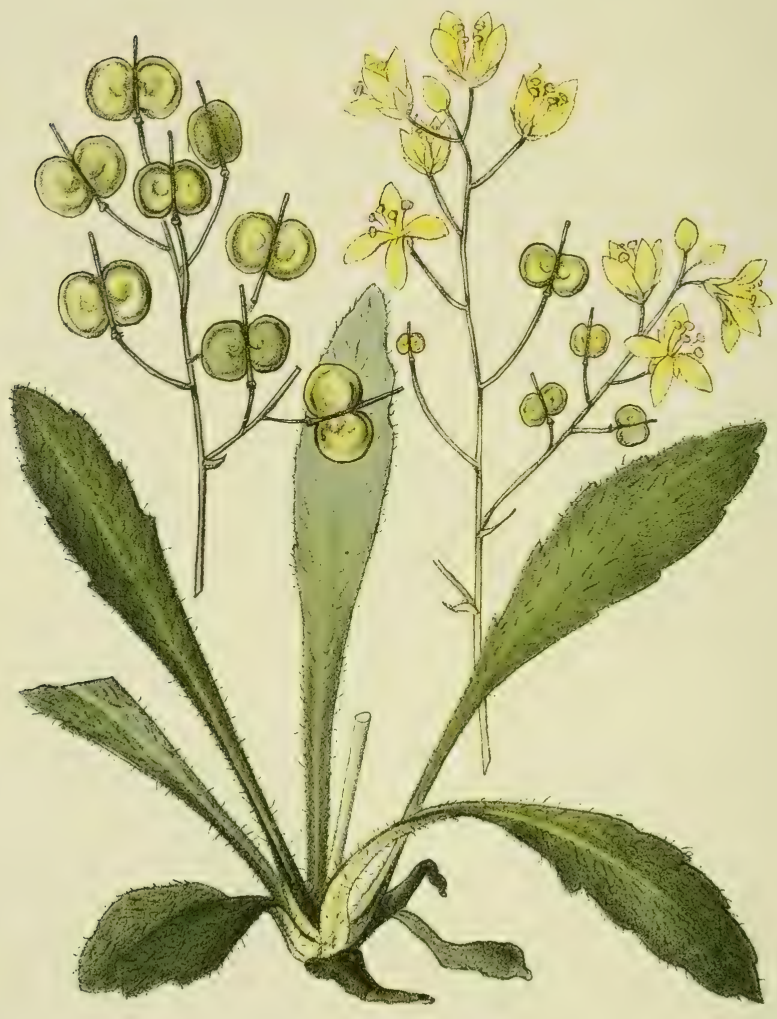

Biscutella laevigata. Lunetière.

Brillenschötchen. Biscutella. 
Biscutella laerigata. - Tafel 1́. - Stengel verzweigt, dünn, brüchig, $10-40 \mathrm{~cm}$ hoch, fchwach beblättert. Meifte Blätter in grundftändiger Rofette, ungeteilt, fchwach sezähnt, fteifhaarig. Blüten hellgelb, in Trauben.

Mehrjährig. Blüht Juli bis Auguft.

Befucher: Fliegen, Bienen, Falter.

Früchte 5-10 $\mathrm{mm}$ breit, brillenförmig: Windverbr.

Felfen, Gefteinsfchutt, fteinige Orte, bis $2000 \mathrm{~m}$.

Alpen, Pyrenäen, Karpathen, warme Täler von Deutfchland und Frankreich.

Hutchinsia alpina. - Alpen-Gemskrefle. $-3-8 \mathrm{~cm}$ hoch, 'Blätter gefiedert, meilt mit fünf Abfchnitten. Blüten fchneeweif, in Trauben.

Mehrjährig. Blüht April bis Auguft.

Befucher: Fliegen.

Samen ohne Verbreitungsmittel. Häufig in Geröllen und Gefteinsfchutt, Fellen, $1700-3300 \mathrm{~m}$. Steigt oft mit den Bächen ins Tal.

Alpen, Jura, Pyrenäen, Karpathen.

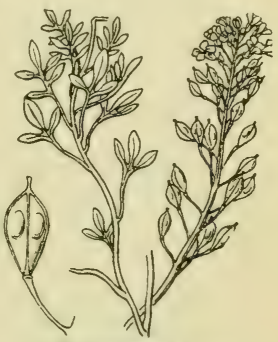

Hutchinsia alpina

Draba aizoides. - Mauerpfeffer-Hungerblume. Blütenichäfte $4-10 \mathrm{~cm}$ hoch, aufrecht, unverzweigt, kahl. Blätter in dichter, grundltändiger Rofette, fchmal, fpitz, fteifhaarig. Blüten gelb, in kurzen Trauben.

Mehrjährig. Blüht März bis Juli.

Befucher: Fliegen, Faiter.

Samen fehr klein: Windverbreitung.

Felfen, befonders auf Kalk. $1000-3400 \mathrm{~m}$.

Alpen, Jura, Cevennen, Pyrenäen; Karpathen.

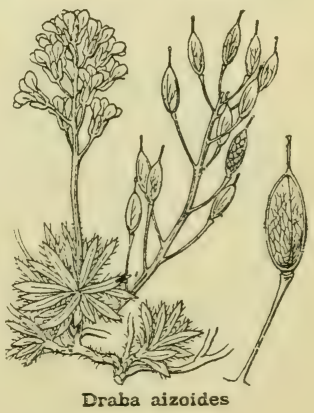

5 
Die Violaceen find durch die Ungleichheit ihrer fünf Blumenblätter und den Befitz eines rïckwärts gerichteten fchlauchartigen Honigbehälters, eines „Sporns“, ausgezeichnet. Ihre hauptfächlichften Befucher find in der Ebene die Bienen. Samen beim Auffpringen der Früchte herausgefchleudert.

Viola calcarata. - Tafel 15. - Pflanze kahl, 2-10 cm hoch. Stengel zart. Blätter lang eiförmig, gekerbt, zu lockerer, grundfändiger Rofette vereinigt. Blume grof, riolett, beim Schlundeingang gelb. Sporn 13-25 mm lang.

Mehrjährig. Blüht Juli bis Auguft.

Befucher: Falter; bei den längftfpornigen Blüten kann nur der Tambenfchwanz den Honig erreichen.

Schleuderfiucht.

Alpen, Jura, Kaukafus.

Viola cenisia. - Veilchen des Mont-Cenis. - Dent vorigen ähnlich, jedoch die Blitter kurzeiförmig, nicht gekerbt, in Rofette. Blüte wrof, violett: Sporn nur fo lang als die Kelchblätter.

Mehrjährig. Blüht Juli bis Auguft.

Befucher: wahrl'cheinlich Falter. Schleuderfrucht.

Kalkgerölle, 1600 - 2500 m. Alpen, Pyrenäen.

Viola pimnata. - Fiederblättriges Veilchen. - Ohne

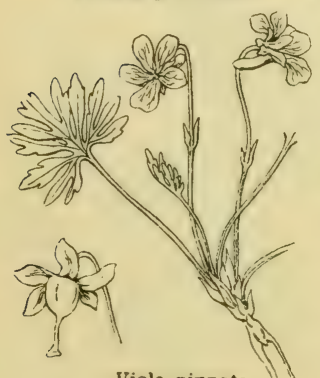

Viola pincata unterirdifchen Stengel. Alle Blätter grundftändig, im Umrif rundlich, handförmig in 3-5 Lappen mit fchmalen Abfechnitten geteilt. Blüten klein, violett oder hellblau, fehwach duftend.

Mehrjährig. Blüht Juni bis Juli. Befucher: wahrfcheinlich Bienen. Schleuderfrucht.

Sonnige Felfen, 1000-1900 m.

Weft- und Oftalpen, Altai. 
Matten, Gerölle IRoo-3000 Meter.

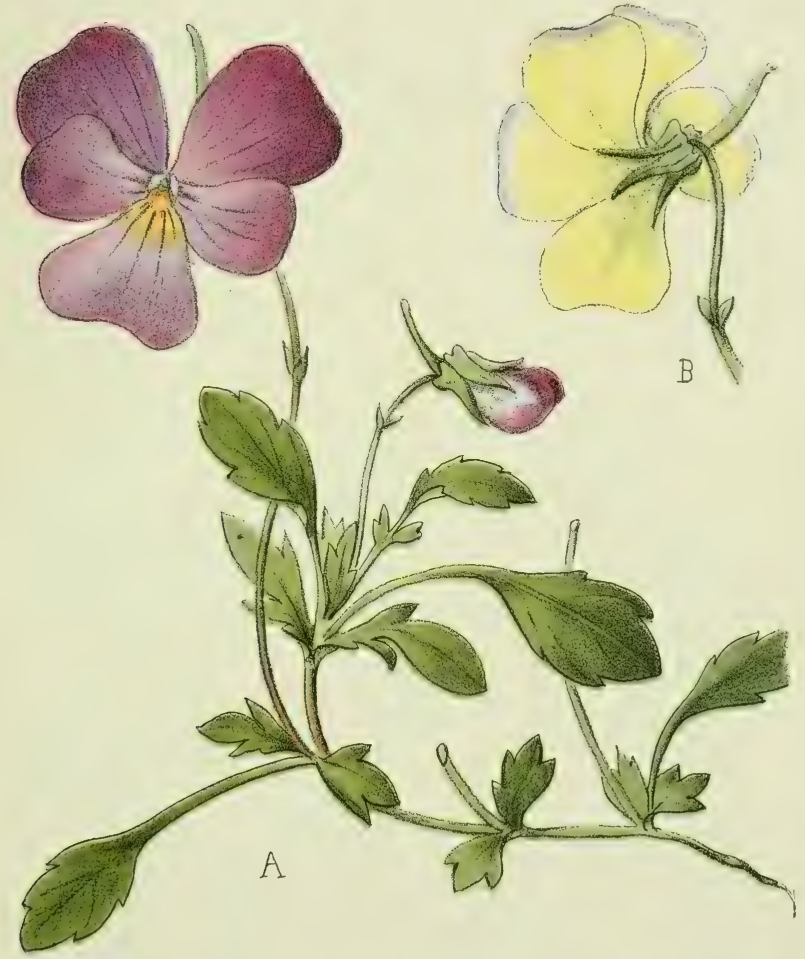

Viola calcarata.

Violette éperonnée.
Langsporniges Veilchen. Alpine Pansy. 
Schattige, feuchte Orte 1000-3000 Meter.
Feuchte Matten

bis 2600 Meter.

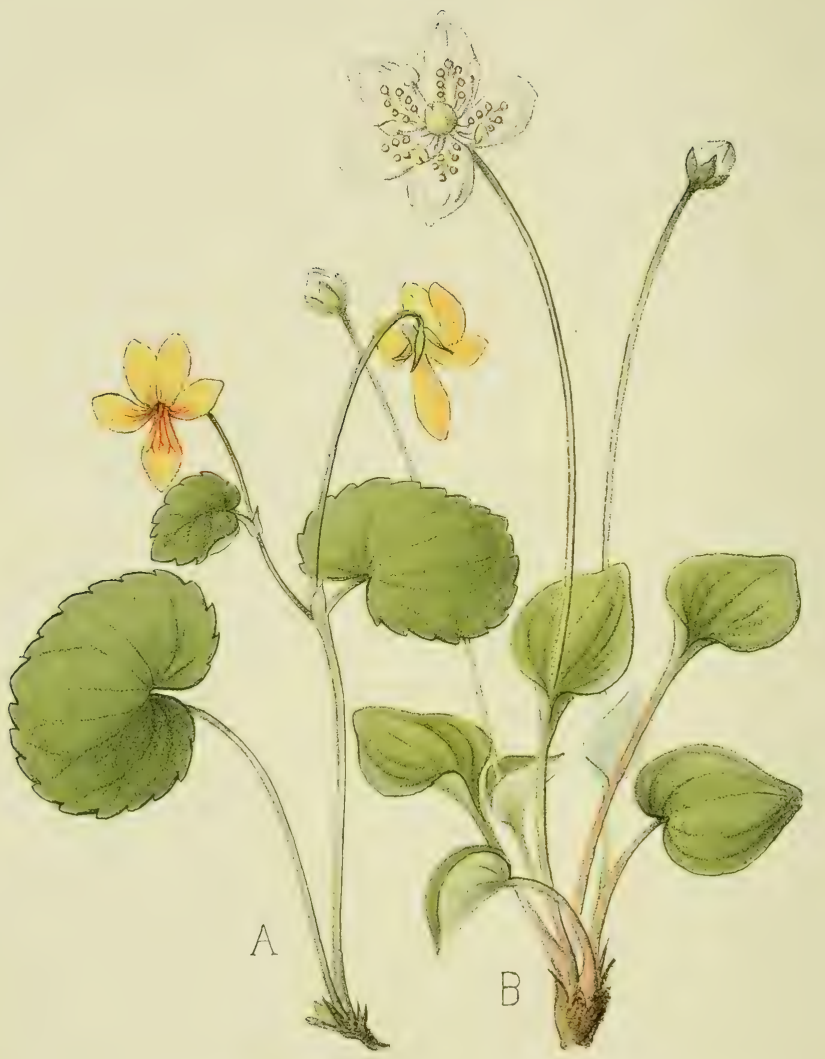

A. - Viola biflora.

Zweiblütiges Veilchen.

Violette à deux fleurs.

Two-flowered Violette.
B. - Parnassia palustris. Sumpfherzblatt. Parnassie des marais. Grass of Parnassus. 
Viola biflora. - Tafel $16 \mathrm{~A}$. - Stengel dünn, 5-10 $\mathrm{cm}$ hoch. Blätter rundlich, lchwach gekerbt, hellgrïn, die unteren lang geftielt. Blüten meift zu zweien, klein, gelh mit brauner Zeichnung. Sporn kurz.

Mehrjährig. Blüht Mai bis Augult.

Befucher: Fliegen. Schleuderfrucht.

Alpen, Vogefen, Auvergne, Cevennen, Pyrenäen, Nordpolarländer, afiatifche Hochgebirge.

Viola palustris. - Sumpf-Veilchen. - Niedrige Pflanze. Blätter grundftändig, rundlich, hellgrün. Blüten klein, hellviolett, geruchlos, mit kurzem, dickem Sporn.

Mehrjährig. Blüht Maibis Juni. Befucher? Schleuderfrucht. Feuchte, torfige Matten. $1000-2100 \mathrm{~m}$.

Mitteleuropa, Alpen, Jura, Auvergne, Cevennen, Pyrenäen.

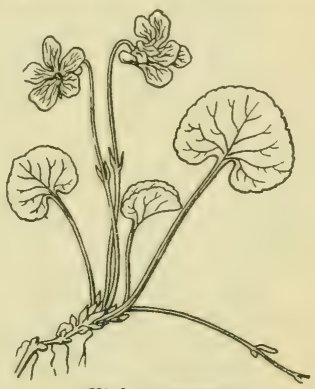

Viola palustris

\section{Droseraceen.}

Parnassia palustris. - Tafel $16 \mathrm{~B}$. - Stengel gerarle, aufrecht, $8-30 \mathrm{~cm}$ hoch. Blätter herzförmig, blafggrün, die meiften in grundftändiger Rofette, geftielt; das ftengelftändige ungeftielt.

Blüten weif, in der Ebene $2^{1} / 2 \mathrm{~cm}$, in den Alpen $1^{1} / 2 \mathrm{~cm}$ grof. Innerhalb der fünf Kronblätter fünf merkwürdig gefranfte Organe, an deren Grund je eine Honigdrüfe liegt.

Mehrjährig. Blüht Juli bis Auguft.

Befucher: Fliegen, werden durch die glänzenden Knöpfchen der Franfen angelockt.

Samen klein, berandet: Windverbreitung.

Sehr weit verbreitet: Mitteleuropa, Alpen, Pyrenäen, Nordpolarländer, afiatifche Hochgebirge. 
Die Sileneen oder Nelkengewächfe befitzen fchmale Blätter, die je zu zweien einander gegenüberftehen (gegenftändig find). Blüten mit radförmig ausgebreiteter Krone über tief röhrenförmigem Kelche, in deflen Grunde der Honig liegt, nur langrüßßligen Infekten zugänglich.

Dianthus silvestris. - Tafel 17 A. - Pflanze kahl, oft b) lüulichgrïn, 5-25 em hoch. Stengel fchwach beblättert, mit ein bis drei geruchlofen Blüten. Unter dem Kelche kurze, dreieckige Schuppen. Kronblätter hellrofa, kahl.

Mehrjährig. Blüht Juli bis Auguft.

Befucher: Tagfalter.

Samen mit Flügehand: Windverbreitung.

Alpen, Jura, Pyrenäen.

Dianthus neglectus. - Tufel 17 B. -- Pflanze kahl, ralig, höchftens $10 \mathrm{~cm}$ hoch. Blätter flach, in Rofette. Stengel aufrecht. Unter dem Kelche lange lpitze Schuppen. Blüten grof, rot, Kronblättẻr oberfeits etwas behaart.

Mehrjährig. Blüht Juli.

Befucher: wahrfcheinlich Tagfalter.

Halden, trockene Felfen, bis $2500 \mathrm{~m}$.

Südalpen (Dauphiné, Provence), Pyrenäen.

Dianthus Seguieri. - Seguier's Nelke. - Der vorigen

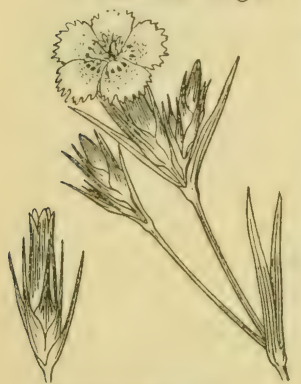

ähmlich, aber 20-40 cm hoch, mit verzweigtem stengel. Sichuppen des Kielches fpitz, fo lang als er felbft.

Blüten grof, rot, mit purpurnem Ring in der Mitte; am Schlundeingang behaart.

Mehrjährig. Blüht Juni.

Befucher: vermutlich Tagfalter.

Trockene Matten.

$1000-1600 \mathrm{~m}$.

Südliche Alpen, Pyrenäen.

Dianthus Seguieri 
Weiden und steinige Abhänge bis 2500 Meter.

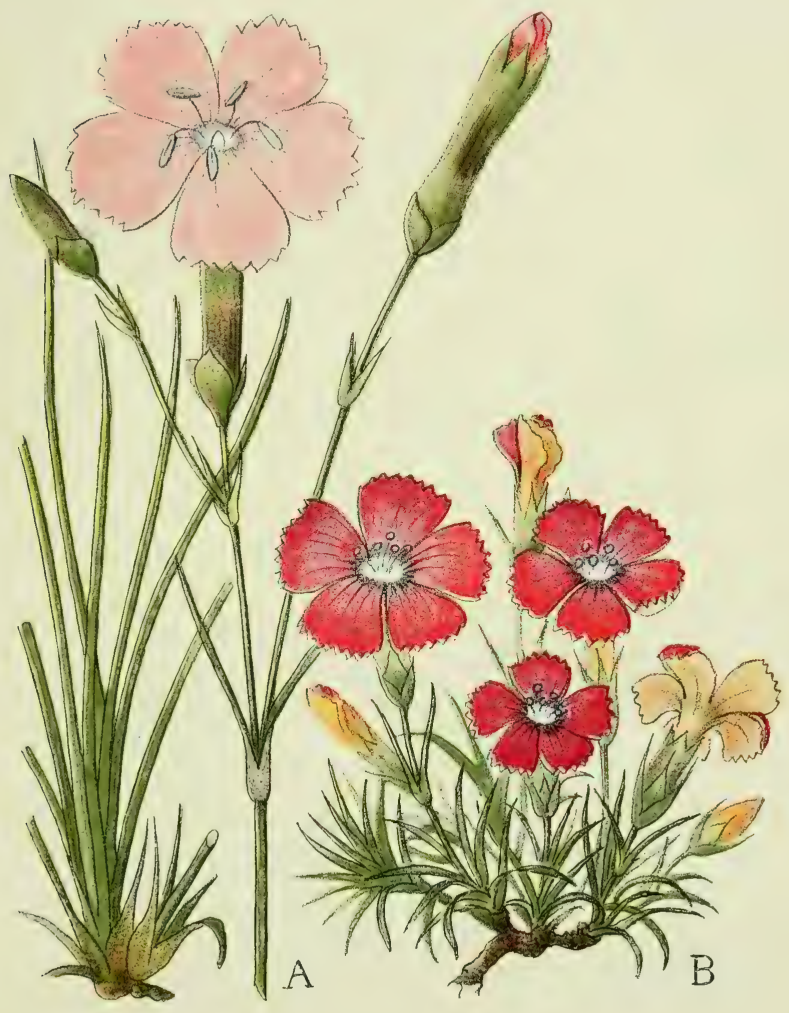

A. - Dianthus silvestris.

Waldnelke.

Eillet des forêts.

Wood-Pink.
B. - Dianthus neglectus.

Lange übersehene Nelke.

Eillet du Lautaret.

A long time not observed Pink. 
Steinige Matten

I000-I800 Meter.
Matten und Grasbänder 2300-2900 Meter.

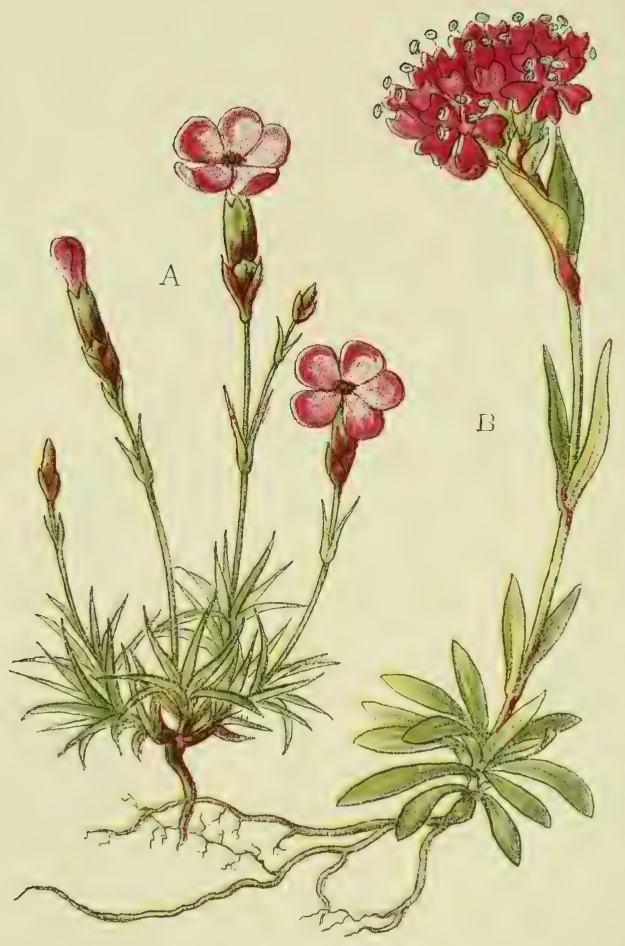

A. - Dianthus subacaulis.

Kurzstengelige Nelke.

Eillet a courte tige.

Nearly acaulous Pink.
B. - Lychnis alpina.

Alpen-Lichtnelke.

Lycnide des Alpes. Alpine Ragged Robin. 
Dianthus subacaulis. - Tafel $18 \mathrm{~A}$. - Pflanze kahl, rafig, mit nur $3-15 \mathrm{~cm}$ hohen Stengeln. Diele mit zwei bis drei Paaren kurzer, fteifer, blangrüner Blätter. Blüten einzeln, rot, geruchlos. Kelch kurz, bauchig; leine schuppen halb fo lang als er felbft. Kronblätter kahl.

Mehrjährig. Blüht Mai bis Auguft.

Befucher: vermutlich Tagfalter.

Samen flach: Windverbreitung. Befonders auf Kalk. Siidliche Alpen (Dauphiné, Provence), Cevenmen, Pyrenäen.

Dianthus caesius. - Blangriine Nelke. - Ganze Pflanze deutlich blaugrün, dicht rafig; $5-20 \mathrm{~cm}$ hoch. Blätter flach, am Rande rauh.

Blüten groß, meift einzeln, wohlriechend. Schuppen unter dem Kelche kurz. Kronblätter purpurrot, am Schlundeingang behaart.

Mehrjährig. Blüht Juli.

Befucher: vermutlich Falter.

Samen flach: Windverbreitung.

Felfen, Rafenbänder.

Alpen, Jura, Auvergne.

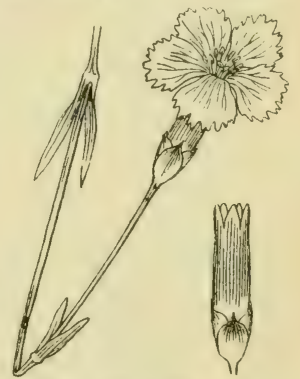

Dianthus casius

Lychuis alpina. - Tafel $18 \mathrm{~B}$ - - Pllanze kahl, rafig, mit grundfändigen Blattrofetten. Stengel aufrecht, $5-15 \mathrm{~cm}$ hoch, unverzweigt, mit drei bis vier Blattpaaren und einem dichten Straufs lebhaft roter, kurzgeltielter Blüten. Kelch bauchig erweitert.

Mehrjährig. Blüht Juli bis Auguft.

Befucher: Tagfalter.

Samen flach: Windverbreitung; auf Urgeftein.

Alpen, Pyrenäen, Nordpolarländer, Altai. 
Iychnis Flos Jovis. - Tufel 19 A - Ganze Pflanze weifs wollig hehaart. Stengel 20-40 $\mathrm{cm}$ hoch, aufrecht, unverzweigh. Blïtter lïnglich eiförmig. l3lüten hellot, in flachem Strauf.

Mehrjährig. Blüht Juli.

Befucher: Tagfalter.

Samen ohne Verbreitungsmittel.

Alpen der füdlichen Schweiz, Piemont, Dauphiné.

Silene acaulis. - Tafel $19 \mathrm{~B}$. - Polfterpflanze mit zahlleichen, kurzen Stengeln, die bis $30 \mathrm{~cm}$ grofe Rafen bilden. Blitter kurz fpitz, fehr dicht ftehend. Die purpurnen Blüten erheben fich kaum über die Blätter. Kelch kurz, glockenförmig.

Mehrjährig. Blüht Juni bis Auguft.

Befucher: Falter, feltener Bienen, Fliegen und Käler. Samen ohne Verbreitungsmittel.

Nlpen, Pyrenïien, Karpathen, Nordpolarländer, Ural.

silene vallesia.

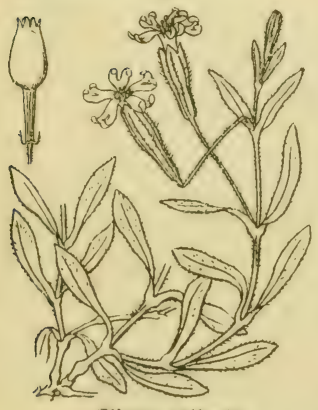

Silene vallesia
- Wallifer Leimkraut. - Klehrig drüfenhaarig, rafenbildend. Stengel $5-15 \mathrm{~cm}$ hoch, zuerlt niederliegend, dann aufrecht. Blaitter nicht in Rofetten. Blïten einzeln, entfpringen auf langen Stielen aus den Achfeln der oberen Blätter. Kelch keulenförmig. Kronblätter einwärts gerollt, innen rein rola, aufien l'chmutzig rot, ziveifpaltig.

Mehrjährig. Blüht Juli.

Befucher: vermutlich Falter und Humneln.

Samen ohne Verbreitungsmittel. Felfen, Gerölle der Nadelholzregion. Wallis, franzöfifche und italienifche Alpen. 
Sonnige Weiden 1000-1500 Meter.
Matten, Rasenbänder, Gerölle I600-3600 Meter.

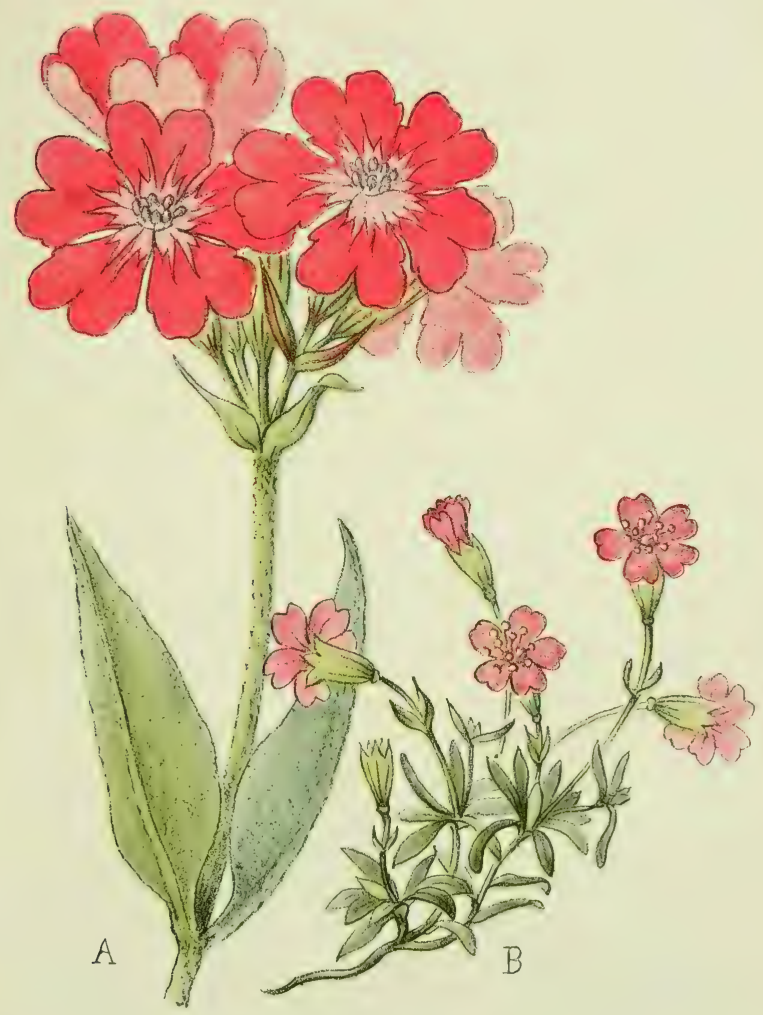

A. Lychnis Flos-Jovis. Jupiters Lichtnelke.

Lycnide fleur de Jupiter.

Ragged Robin of Jupiter.
1). - Silene acaulis.

Stengelloses Leimkraut. Silène sans tige. Cushion Pink. 
Weiden, steinige Abhänge der Alpen bis 1800 Meter.
Steinige Abhänge, Felsen bis 2400 Meter.

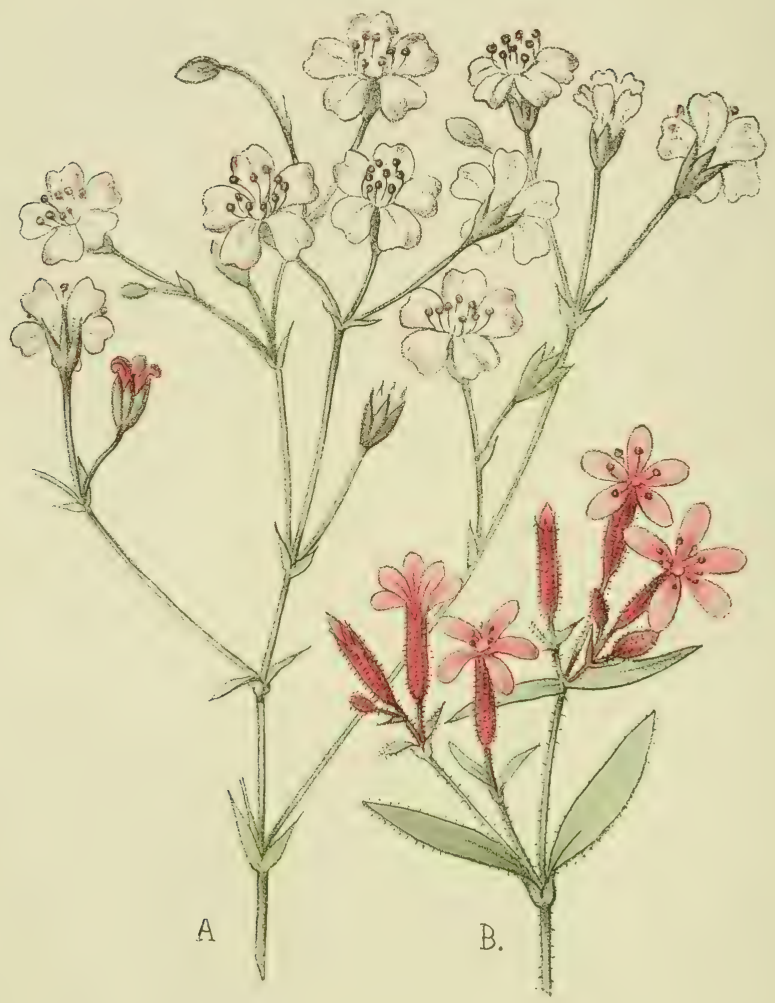

A. - Gypsophila repens. Kriechendes Gypskraut. Gypsophile rampante. Creeping Gypsophila.
B. - Saponaria ocymoides. Basilienartiges Scifenkraut. Saponaire faux-basilic. Trailing Soapwort. 
Cyypsophila repens. - Tafel $20 \mathrm{~A}$ - Pflinze kahl, rafenbililend. Stengel $10-25$ cm hoch, zuer't niederliegend, dann aufrecht, fchwach beblättert. Blätter dick, bläulichgrün. Blüten innen weifs, aufsen rofa, in aufrechten Trauben.

Mehrjährig. Blüht Mai bis Juli.

Befucher: vorwiegend Fliegen, daneben auch Hummeln und Falter.

Samen klein: Windverbreitung.

Weiden, Gerölle, 400-2700 m.

Alpen, Jura, Pyrenäen, Karpathen.

Saponaria ocymoides. - Tafel 20 B. - Niederliegend, bis $15 \mathrm{~cm}$ hohe, grofse Teppiche bildend, belıart. Stengel oherwärls klebrig, bis oben beblattert. Blüten leblıft rot, in Trauben.

Mehrjährig. Blüht Mai bis Juli.

Befucher: Falter, feltener Hummeln.

Samen ohne Verbreitungsmittel.

Gelteinsfchut, Gerölle, hefonder's auf Kalk.

Voralpen bis $2400 \mathrm{~m}$; fteigt zuweilen mit den Bächen ins Tal.

Alpen, Jura, Auvergne, Cevennen, Pyrenäen.

Saponaria lutea. - Gelbes Seifenkrant. - Stengel aufrecht, unverzweigt, dichte Ralen bildend, $5-10 \mathrm{~cm}$ hoch, belonders unterwärts dicht beblättert. Untere Blätter kahl, obere kurzhaarig.

Blüten in dichtem Straufe, l'chwefelgelb, am Schlundeingang l'chwarzviolett.

Mehrjährig. Blüht Juli Auguft. Befucher?

Samen ohne Verbreitungsmittel.

Sonnige Felfen der füdlichen Alpen (Dauphiné, Italien).

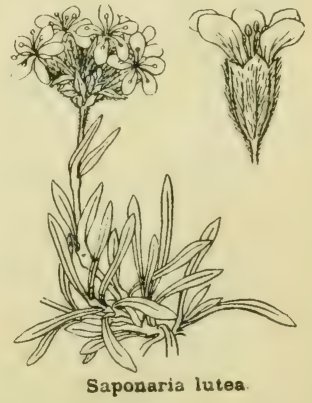


Die Hypericaceen oder Hartheugewächfe find durch den Befitz von Ölbehältern ausgezeichnet, die in den Blättern oft als durchlcheinende Punkte fichtbar find. Die Blätter ftehen fich paarweile gegenüber. Blüten mit zahlreichen staulgefäßsen, ohne Honig: Pollenblumen.

Hypericum Richeri. - Tufel 21. - Pflanze kahl, mit holzigem Wurzelftock. Stengel aufrecht, $20-40 \mathrm{~cm}$ hoch, rund. Blätter ungeftielt, eiförmig, am Rande mit f'chwarzen Punkten. Blüten grof, in einer Traube. Kelchblätter gefranft, fchwarz punktiert, ebenfo die gezähnten, goldgelben Kronblätter.

Mehrjährig. Blüht Juli.

Befucher: wahrfcheinlich Fliegen, Bienen und Hummeln, Falter.

Samen ohne Verbreitungsmittel.

Weiden und Bergwälder 1200-1700 m.

Pyrenïen, Weftalpen, Jura, Oftalpen, Kaukafus.

\section{Hypericum фuыdrangulum. - Vierkantiges Johannis-}

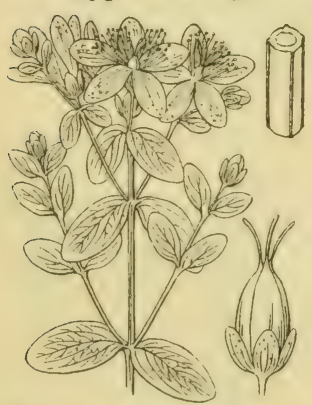

Hypericum quadrangulum kraut. - Pflanze kahl, 20-60 cm hoch. Stengel aufrecht, fchwach verzweigt, vierkantig. Blattrand mit fchwarzen Punkten. Blüten goldgelb in lockerem Strauf. Kelchblätter nicht gefranlt. Kelch- und Kronblätter fchwarz punktiert.

Mehrjährig. Blüht Juni bis Auguft. Befucher: Fliegen, Bienen, Hummeln.

Samen ohne Verbreitungsmittel. Gebülche und Weiden. Ebene bis $2100 \mathrm{~m}$. Alpen, Jura, Vogefen. 


\section{$-21-$}

Weiden, Bergwälder I200-I700 Meter.

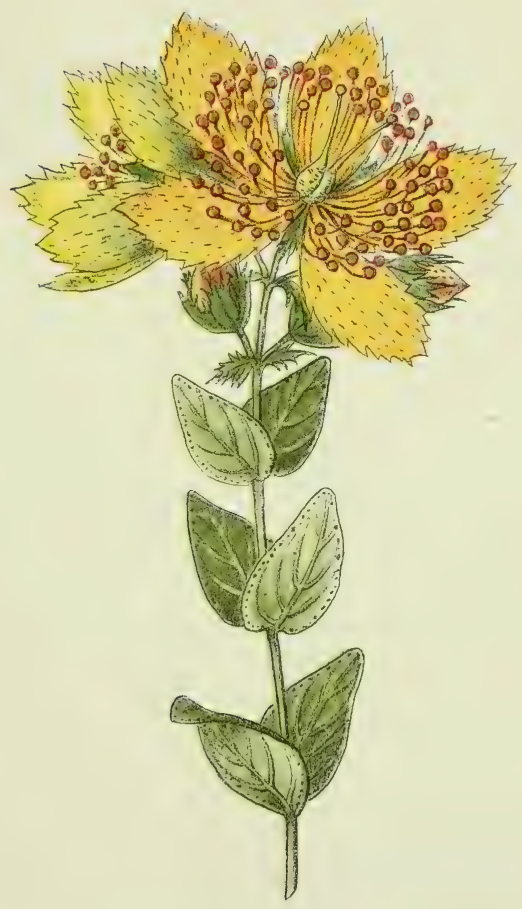

Hypericum Richeri. Millepertuis de Richer.

Richers Johanniskraut. Richer's Tutsan. 
Bachufer, feuchte Matten bis 2500 Meter.

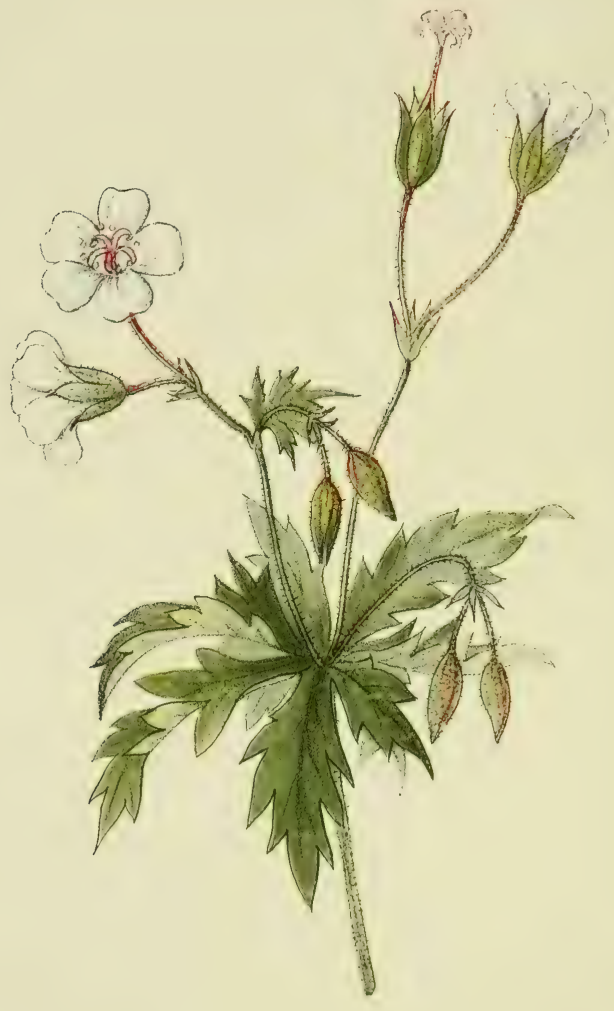

Geranium rivulare.

Bach-Storchschnabel.

Géranium des ruisseaux.

IVater-Cranesbill. 
Die Storchfchuabelgewächfe haben ihren Namen von den lang l'chnahelartigen Früchten; diefelben fjuringen bei der Reife plötzlich auf und lchleudern dabei die Samen einige Neter weit heraus: Schleuderfrüchte.

Geranium rivulare. - Tafel 22. - Dicht weichhaarig, $15-40 \mathrm{~cm}$ hoch mit anfangs nierlerliegenden, dann aufrechten Stengeln. Blätter tief handförmig in fünf bis fieben fchmale Abfchnitte geteilt. Blüten weißs, mit violetten Adern, je zu zweien in lockerem Stande.

Mehrjährig. Blüht Juli.

Befucher: Fliegen, Bienen und Hummeln, Falter.

Schleuderfrüchte.

Alpen der Schweiz, Frankreich, Italien, Südtirol; in den Pyrenäen fehr felten.

\section{Geranium argenteum. - Silber-Storchfchnabel. -} Kleine, filberweifs behaarte Pflanze. Faft alle Blätter grundftändig, mit kreisförmigem Umriß, handförmig in fünf bis fieben dreiteilige Ablchnitte geteilt. Blüten grof, blafrrofa. Blütenltiele zart, länger als die Blätter, mit je zwei Blüten. Kronbiätter nach unten allmählich verjüngt, oben etwas ausgebuchtet.

Mehrjährig.

Blüht Juli bis Auguft.

Belucher?

Schleuderfrüchte.

Felsfpalten der Alpenregion.

Alpen, fehlt den Seealpen.

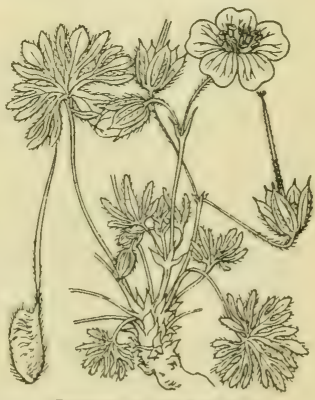

Geranum argenteum

Geranium cinereum - Afchgrauer Storchfchnabel gleicht dem vorigen, jedoch graugrün und Blumenkronblätter an der Balis plötzlich verfchmälert.

Wie voriger. Befucher: Fliegen, Bienen, Falter.

Pyrenäen. 
Geranium silvaticum. - Tafel 23. - Dicht weichhaarige, oherwärts klebrige Pflanze. Stengel kräftig, $30-60 \mathrm{~cm}$ hoch, aufrecht. Blätter handförmig faft bis zum Blattftiel in 5-7 lang gezähnte Abfchnitte gefpalten. Blüten rotviolett, in lockerem Stande. Blütenftiele lang, klebrig, mit je zwei Blüten. Kronblätter an der Bafis behaart.

Mehrjährig. Blüht Juni bis Juli.

Befucher: Fliegen, Bienen und Hummeln, Falter.

Schleuderfrucht.

Mähwiefen, Wälder, feuchte 'Täler, befonders auf Kiefelboden.

Von der Buchenregion bis über $2000 \mathrm{~m}$.

Alpen, Jura, Vogelen, in Deutfchland zerftreut, Cievennen, Pyrenäen.

Geranium macrorrhizum. - Dickwurzliger Storch-

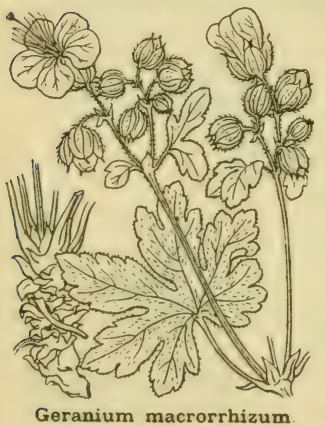

und Hummeln. fchmabel. - Pflanze dicht weichhaarig, mit dick fleifchigem Wurzelftock. Stengel $10-30 \mathrm{~cm}$ hoch, aufrecht, oberhalb der Blattinfertionen knotig verdickt. Blätter geftielt, handförmig 5-7 fpaltig, mit gezähnten Abfehnitten.

Blüten groß, rot, in lockeren Trauben. Blütenftiele mit je zwei Blüten. Kelchblätter abftehend, rötlich. Kronblïtter an der Bafis behaart, kürzer als dlie Staubgefäfe.

Mehrjährig. Blüht April bis Juni. Befucher: wahrfcheinlich Bienen Schleuderfrucht.

Wälder, Felfen, 800-1400 m.

Südliche Alpen (Seealpen, Italien), Schwarzwald, Süitirol, Krain. 
Kühle Wiesen, Wälder bis 2300 Meter.

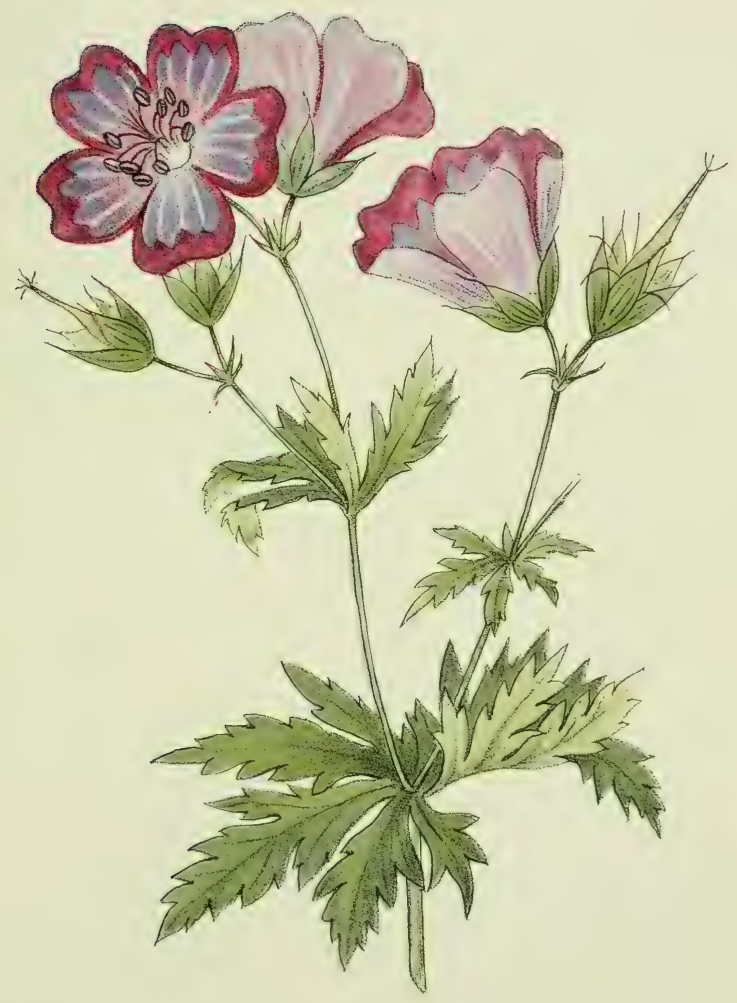

Geranium silvaticum.

Géranium des forèts.

Wald-Storchschnabel.

Wood Cranesbill. 
Trockene Matten, steinige Abhänge bis 2200 Meter.

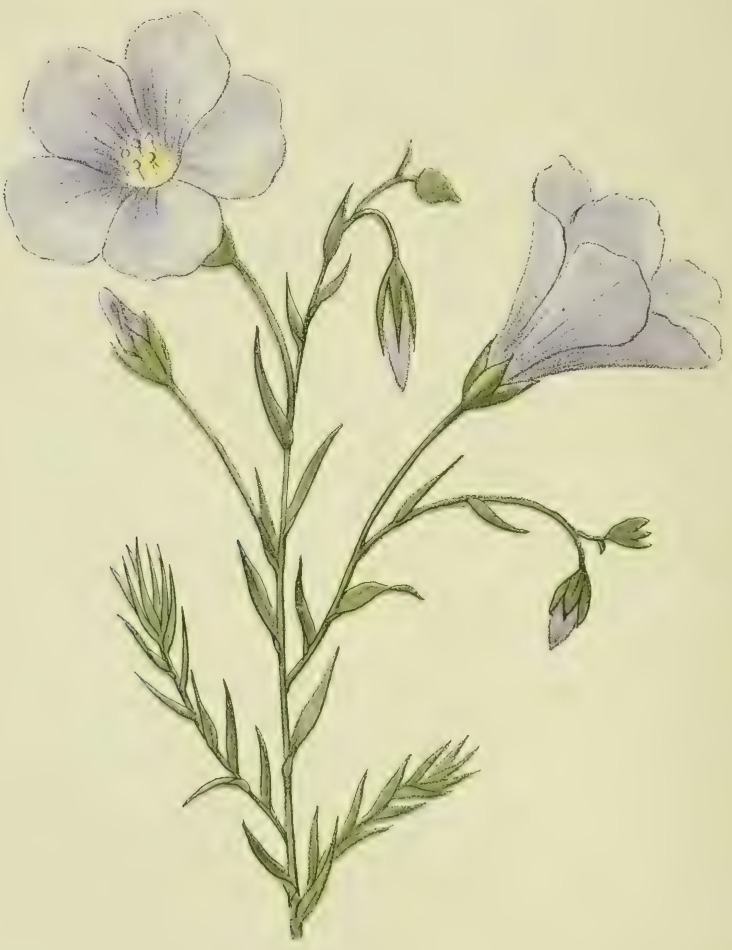

Linum alpinum.

Lin des Alpes.

Alpen-Lein. Alpine Flax. 
Linum alpinum. - Tafel 2t. - Der Alpenlein treibt aus l'einem harten Wurzelftock zahlreiche zarte, $10-50 \mathrm{~cm}$ hohe Stengel, die oft niederliegen. Blätter lchmal, fpitz, in grofer Zahl gleichmäßrigg aul dem Stengel verteilt.

Blüten etwa \&ै cm grof, zu wenigblütigen, lockeren Trauben vereinigt. Kronblätter blau, fallen lehr leicht ab.

Mehrjährig. Blüht Mai bis Auguft.

Belucher: vermutlich Fliegen.

Samen geflügelt: Windverbreitung.

Trockene Matten, fteinige Abhänge der Voralpen bis $2200 \mathrm{~m}$; auf Kalk.

Alpen, Jura, Pyrenäen.

Rhamnus alpina. - Alpen-Wegdorn. - Kräftige, $1-3 \mathrm{~m}$ hohe Holzpflanze. Äfte knorrig, in der Jugend weichhaarig, dicht beblättert. Blätter dunkelgrün, eiförmig zugefpitzt, lehr fein gezähnt, mit ftark hervortretenden Nerven. Staubgefäfre und Fruchtknoten in verfchiedenen Blüten und diele auf verfchiedenen Stöcken, grünlich, in kleinen dichten Bülcheln in den Achleln der Blätter.

Mehrjährig. Blüht Mai bis Juni.

Befucher: vermutlich Käfer, Fliegen, Bienen, Hummeln. Frucht eine fleifchige, kugelige,

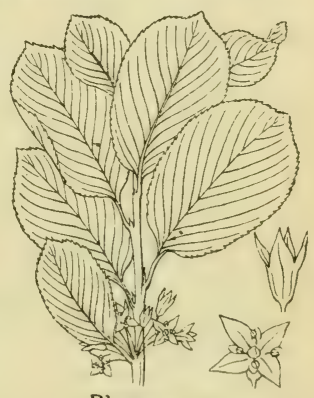

Rhamnus alpina.

bei der Reife lichwarze Beere: durch Vögel verbreitet.

Fellen, Gerölle der Kalkhügel, bis $2500 \mathrm{~m}$.

Gebirge von Mittel- und Südeuropa (Alpen, Jura),

von Nordafrika, Kaukafus, vielleicht Himalaya. 
Die Papilionaceen find durch die auffallend geftalteten, fogen. Schmetterlingsblüten ausgezeichnet. Von den fünf Kronblättern ift das obere als „Fahne“ breit, aufgerichtet, während die vier übrigen gerade vorgeftreckt die Staubgefäße und den Fruchtknoten umfchließen. Befucher vorwiegend Bienen und Hummeln. Eine meift mit zwei Klappen auffpringende Hülfenfrucht.

Anthyllis Vulneraria affinis. - Alpen-Wundklee. Vulnéraire des Alpes. - Alpine Kidney Vetch. - Tafel 25. Alpenform unferes Wiefenklees, Anthyllis Vulneraria mugaris, mit kräftigem Wurzelftock und aufrechten, krautigen Stengeln. Diefe jedoch niedriger und Blätter mit größserem End- und kleineren Seitenblättchen. Außerdem Kronblätter weiflich (Itatt gelb) und, befonders die beiden untern (das Schiffchen), rot geftreift.

Mehrjährig (Ebenen-Form einjährig).

Blüht Juni Juli.

Befucher: Hummeln.

Hülfe im aufgeblafenen Kelch: Windverbreitung.

Magere Wiefen, Felfen. 1000-2500 m.

Südliche Ketten der Alpen.

Anthyllis montana. -- Stark verzweigte, auf dem Boden niederliegende, $10-15 \mathrm{~cm}$ dicke Teppiche bildende Pflanze, die weifs behaart ift. Bläter mit 8-15 Paaren feitlicher Blätchen und einem Endblättchen. Blïten lebhaft rot, wohlriechend, in kugeligen Köpfchen.

Mehrjährig. Blüht Mai bis Juli.

Befucher: Bienen, Hummeln, Schmetterlinge.

Hülfe im aufgeblafenen Kelch vom Wind verbreitet. Felfen, trockene Rafenbänder, $600-1800 \mathrm{~m}$.

Alpen, Jura, Cievennen, Pyrenäen, Gebirge der Mittelmeerländer. 


\section{$-25-$}

Felsen, trockene Rasenbänder 600-I800 Meter.

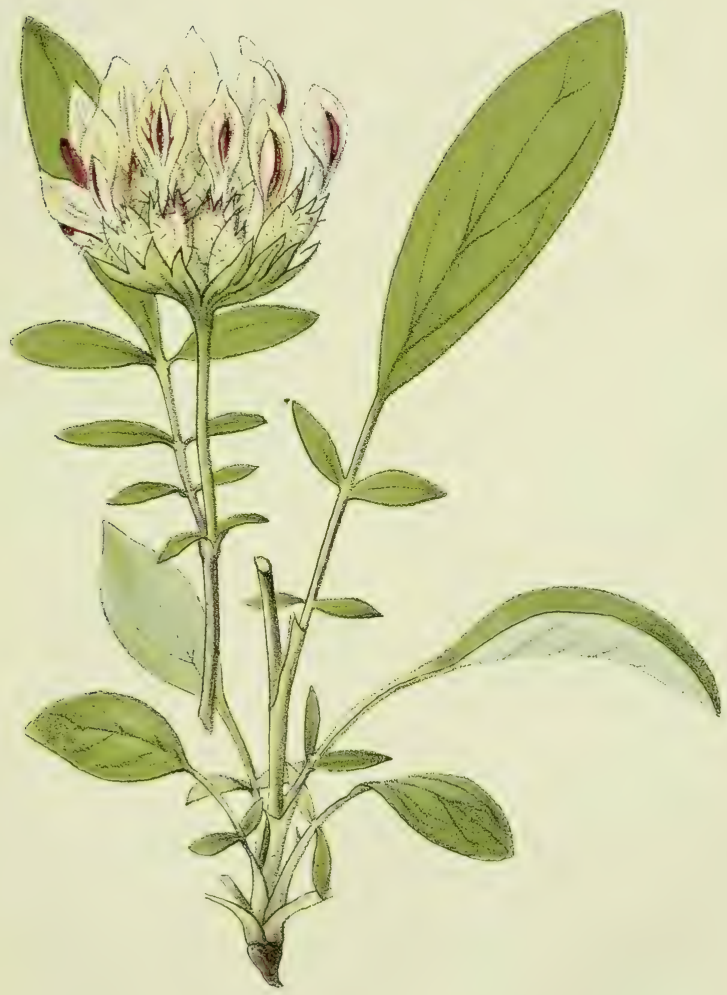

Anthyllis Vulneraria affinis.

Vulnéraire des Alpes.

Alpen-IVundklee. Alpine Kidney Vetch. 


\section{$-26$}

Magere, steinige Weiden I600-2700 Meter.

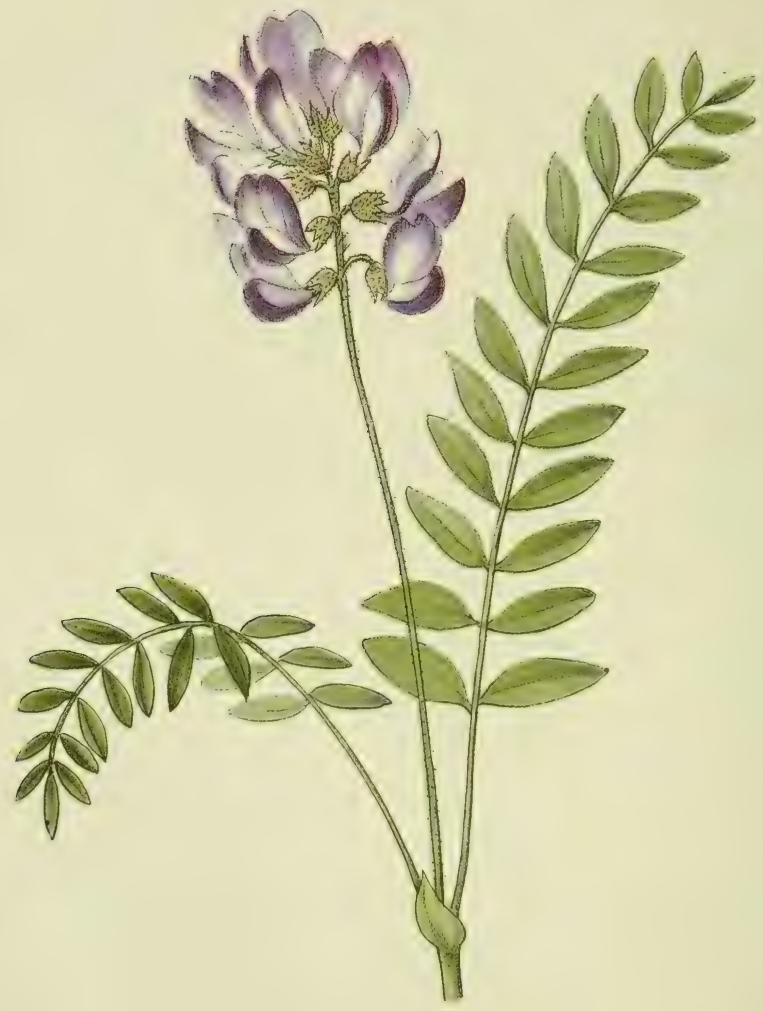

Phaca astragalina. Phaque astragale.
Tragantartige Berglinse. Astragalus bastard Vetch. 
Phaca astragalina (Astragalus alpinus). - Tafel 26. -Zarte $8-15 \mathrm{~cm}$ hohe Pflanze mit zuerft nicderliegenden, dann auffeigenden, dünnen Stengeln. Blätter unpaarig gefiedert, mit 8-12 Paaren länglich ovaler Blättchen.

Blüten violett oder hlafshlau mil weifser Zeichnung, in kurzer kugeliger Traube, auf hohem, zartem schaft.

- Mehrjährig. Blüht Juli bis Auguft.

Befucher: Hummeln, Falter.

Frucht aufgeblafen: Windverbreitung.

Magere Weiden, Felfen, 1600-2700 m.

Alpen, Pyrenäen, Karpathen, Kaukafus, Nordpolarländer, Ural, Altai, Himalaya.

Phaca frigida. - Kälteliebende Berglinfe. - Grofe Pflanze mit dickem Wurzelltock, der oft lange, unterirdifche Ausläufer treibt. Stengel gleichmäfig beblättert, 20-60 cm hoch. Blätter unpaarig gefiedert, mit 3-8 Blätterpaaren; an der Blattbafis zivei blaf3gelbe Nebenblättchen.

Blüten in einer Traube. Kelch faft kahl, Kronblätter weifgelb.

Mehrjährig.

Vorzügliches Gemfenfutter.

Blüht Juli bis Auguft.

Befucher: vermutlich Hummeln.

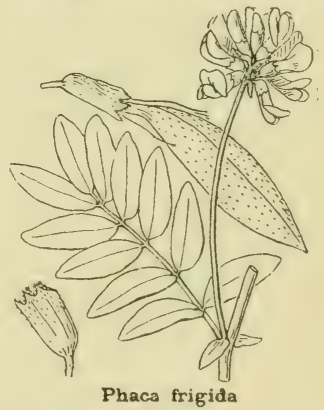

Frucht aufgeblafen: Windverbreitung.

Im Schatten von Felsblöcken, befonder's auf. Kalk. $1500-2700 \mathrm{~m}$.

Alpen, Karpathen, Nordpolarłänder, Ural, Altai. 
Phaca alpina. - Tafel 2\%. - Behaarte, ftark beblätterte Pflanze mit aufrechten, fteifen, verzweigten Stengeln. Blätter unpaarig gefiedert, mit $8-15$ Paaren länglich eiförmiger, ziemlich kleiner Blättchen. An der Blatthafis zwei fchmale abftehende Nebenblätter.

Blüten zu 6-12 in einer einfeitigen Traube, auf langem, dünnem Stiel. Kelch behaart. Krone gelh.

Mehrjährig. Blüht Juli his Auguft.

Befucher: Hummeln, Falter.

Hülfe aufgeblafen: Windverbreitung.

Felfen und Weiden.

Alpen, Pyrenäen.

Phaca australis. -- Siidländifche Berglinfe. - Nieder-

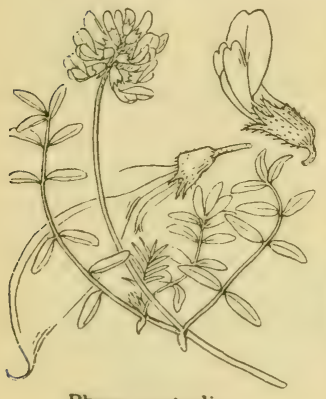

Phaca australis liegende, zarte Pflanze mit ausgehreiteten Älten. Blätter unpaarig gefiedert, mit 4-8 Paaren länglich eiförmiger Blättchen und kleinen l'chmalen Nebenblättern.

Blüten fchmutzig-weif; zu 8 bis 16 in dichten eiförmigen Trauben. Die beiden untern, das fogenannte Schiffchen bildenden Kronblïtter l'chwarz-violett. Kelch behaart.

Mehrjühırig. Blüht Juli Auguft. Befucher?

Hülfe ftark aufgeblafen: Windverbreitung.

Felfen, fteinige Weiden, $1600-2300 \mathrm{~m}$. Alpen, Pyrenäen; Karpaltıen, Nordpolar]änder. 
Weiden, zwischen Felsblöcken der alpinen Region.

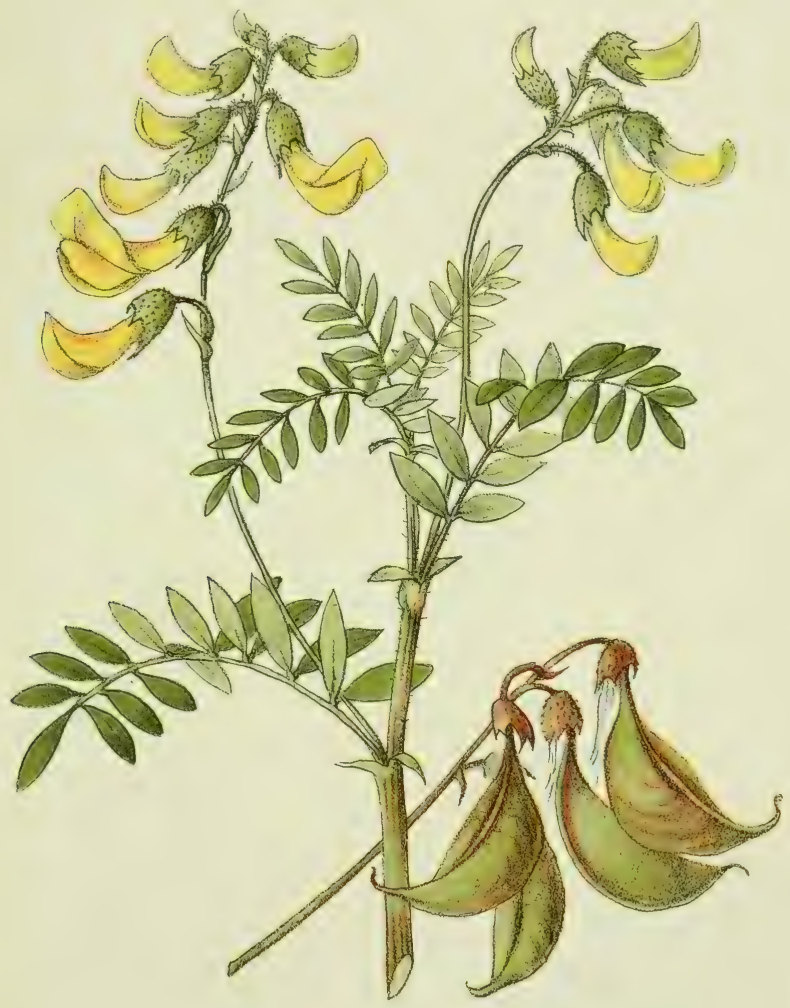

Phaca alpina.

Phaque des Alpes.

Alpen-Berglinse. Alpine bastard Vetch. 
Trockene Weiden. Hügelbis untere alpine Region.

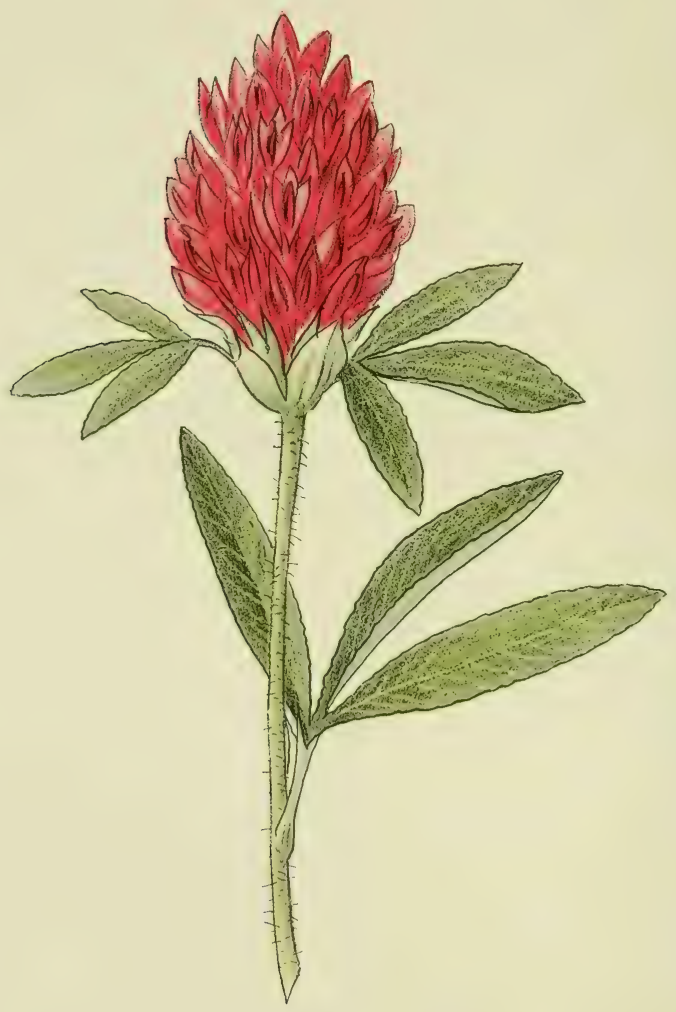

Trifolium alpestre.

Alpen-Klee. Trèfle alpestre. Alpine Trefoil. 
Trifolium alpestre. - Tafel 28. - Stengel fteif, aufrecht, unverzweigt, behaart. Blätter kurz geftielt, oberwärts gegenftänlig, mit je drei länglich eiförmigen, fein gezülmten und behaarten Blittchen, deren Nerven sehr deutlich hervortreten. Blülen purpurot, in kugeligen Köpfchen.

Mehrjährig. Blüht Juni bis Augult.

Belucher: vorwiegend Falter.

Hülle im zottig bewimperten Kelch: Windverbreitung. Alpen, im öltichen Frankreich bis in die Hügelregion, Jura, Auvergne, Cevennen, Pyrenäen.

Trifolium repens. - Kriechender Klee. - Ralenbildend, mit niederliegenden, wurzelnden Stengeln, aus denen die langen, aufrechten Blatt- und Blütenftandltiele entfpringen. Blüten weifs, in kugeligen Dolden.

Mehrjährig. Blüht Mai bis Okt.

Befucher: Bienen, Hummeln, daneben Falter.

Früchte ohne Verbr.-Mittel. Ebene (Wiefen, Wegränder), Alpen bis $2500 \mathrm{~m}$, Pyrenäen bis $2000 \mathrm{~m}$.

Europa bis Sibirien.

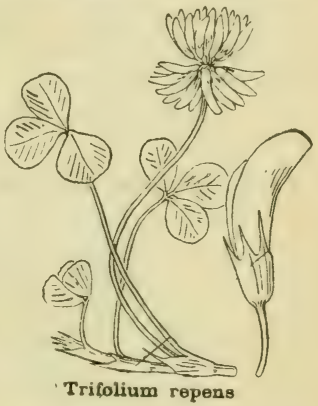

Trifolium pallescens. - Bleicher Klee. - Vorigem ähnlich, aber die Stiele der Blütenköpfchen entfpringen am Ende des erft niederliegenden, dann auffteigenden, nie wurzelnden Stengels.

Mehrjährig. Blüht Juli bis Sept.

Befucher: Bienen, Hummeln, Schmetterlinge.

Früchte ohne Verbreitungsmittel.

Trockene Matten, Moränen,

Kies der Bergbäche; fteigt mit denfelben oft ins Tal. Alpen.

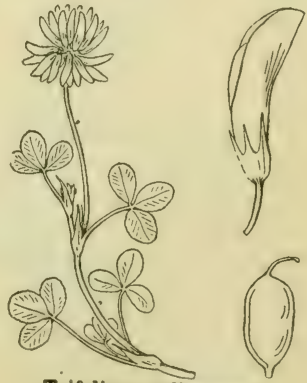

Trifolium pallescens 
Trifolium alpinum. - Tafel 29. - Rafenbildend, mit ftarkem, füßfchmeckendem Wurzelftock (Alpen/üfiholz!). Zahlreiche, 5-25 $\mathrm{cm}$ hohe, aufrechte Stengel. Blattfcheiden ftark entwickelt. Die drei Blättchen lang, eiförmig, kahl.

Blüten leicht duftend, über $2 \mathrm{~cm}$ lang, zu $6-12$ in lockeren Trauben. Krone purpurrot.

Mehrjährig. Vorzügliche, befonders bei den Schafen beliebte Futterpflanze.

Blüht Juni bis Auguft.

Befucher: Hummeln, Falter.

Früchte durch die bleibende Blumenkrone geflügelt: Windverbreitung.

Felfige, trockene Weiden, $1300-3000 \mathrm{~m}$.

Alpen, Auvergne, Cevennen, Pyrenäen, Sierra Newada; Karpathen.

Trifolium montanum. - Bergklee. - 20-40 cm

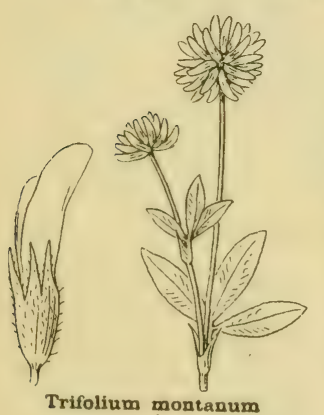

Ebene bis $2600 \mathrm{~m}$.

hoch, weißlich behaart. Stengel meift aufrecht. Blättchen fchmal elliptifch, lpitz, unterfeits behaart, oberfeits kahl. Blüten weif, in kugeliger Dolde, auf langem, geradem Schaft.

Mehrjährig.

Gefchätzte Futterpflanze.

Blüht Mai bis Juli.

Befucher: Bienen, Falter.

Früchte ohne Verbreitungsmittel. Magere Wiefen, trockene Matten, Felfen.

Alpen, Jura, Auvergue, Gevennen, Pyrenäen. 
Trockene Weiden I300-3000 Meter.

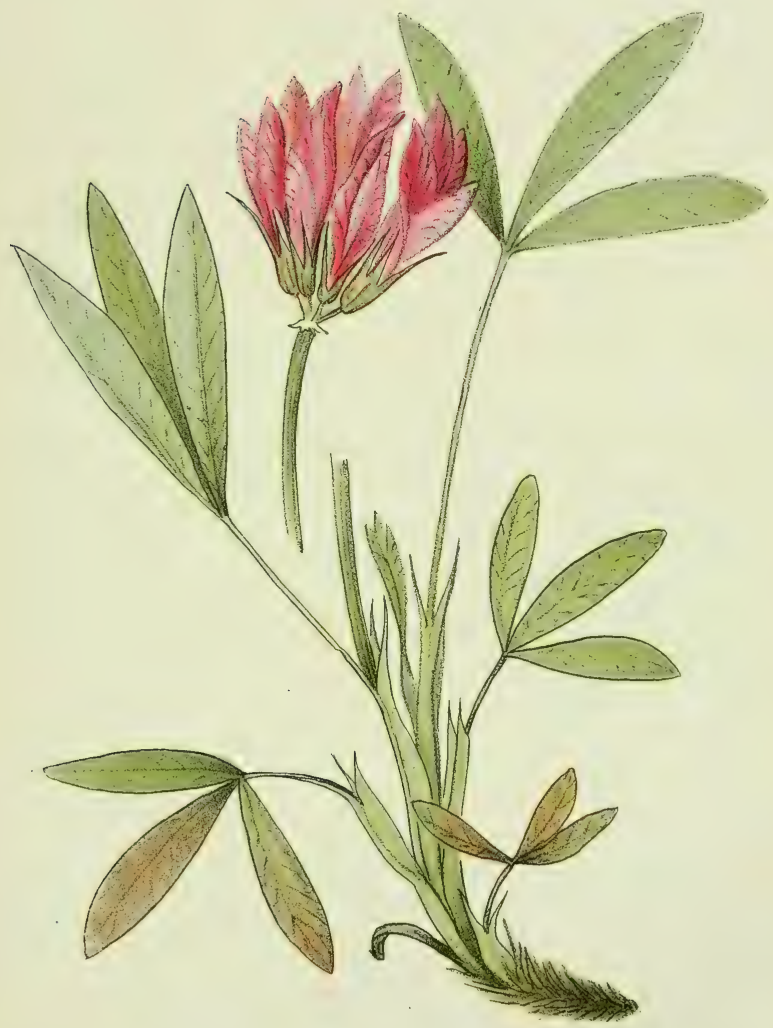

Trifolium alpinum.

Trèfle des Alpes, Réglisse des Alpes.

Alpen-Klee. Alpine Clover. 


\section{$-30-$}

Trockene Weiden, Gerölle ז300-2700 Meter.

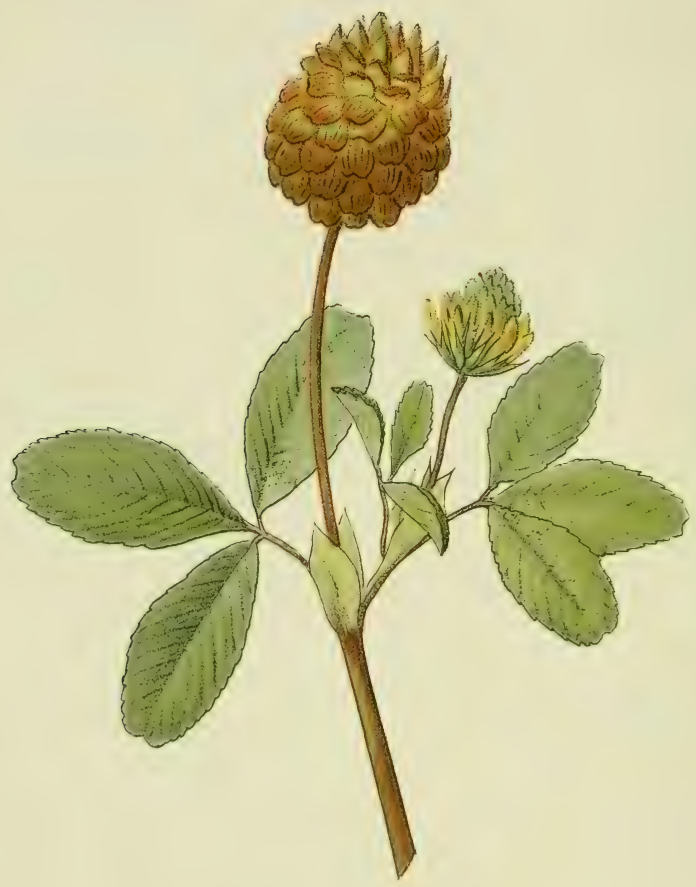

Trifolium badium.

Braunklee.

Trèfle brun.

Brown Clover. 
Trifolium badium. - Tafel 30. - Stengel 5-20 $\mathrm{cm}$ hoch, aufrecht, anliegend behart. Blätchen elliptifeh, fift kahl. Nebenblätter lang. Blüten in dichtem kugeligem, lang geftieltem Köpfchen; während des Blühens goldgelb, abftehend, nachher herabhängend, hellbraun. Später fällt der ganze Blütenftand wie ein Tannenzäpfchen $a b$.

Zweijährig. Gute Futterpflanze des mageren Bodens. Blïht Juli Auguft. Befucher: Hummeln, Falter.

Früchte mit bleibender Krone: Windverbreitung.

Alpen, Jura, Auvergne, Pyrenäen, Karpathen, Kaukafus.

Trifolium spadiceum. - Kolbiger Klee. - Wie voriger, aber Fruchtftände länglich oval; Blüten kleiner, nach dem Blühen dunkelbraun, faft fchwarz.

Meift nur einjährig.

Blüht Juni bis September.

Befucher und Frïchte wie bei vorigem.

Feuchte Wiefen mit Binfenbeftänden, Torfboden, befonders auf Urgeftein. Alpen, Jura, Auvergne, Cevennen, Pyrenïien.

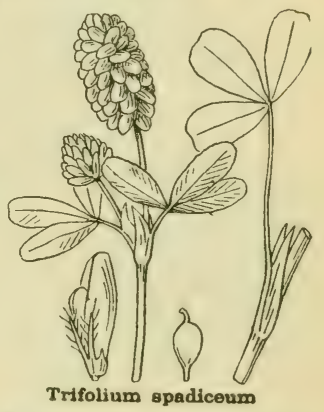

Trifolium saxatile. - Felfenklee. - Grauharig, mit erft niederliegenden, dann aufteigenden Stengehn. Blätter kurz geftielt mit lïnglichen, vorn eingebuchteten Blättchen. Blüten weißlich, klein, in kugeligen Dolden, die von den Nebenblättern der oberften Blätter eingehüllt werden.

Einjährig. Blüht Juli bis Auguft. Befucher? Hülfe im zottig behaarten Kelch: Windverbr. Gerölle, Granitfand.

Weftalpen bis Graubünden.

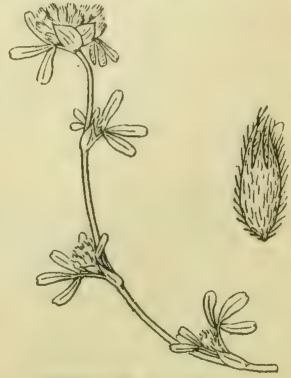

Trifolium saxatile 
Lathyrus luteus. - Tafel 31. - Pflanze mit unterirdifchem, wagrechtem Wurzelftock, der $20-50 \mathrm{~cm}$ hohe, krautige, aufrechte und bis oben heblätterte Stengel trägt. Blätter gefiedert, mit 2 --5 Paaren breit ovaler, oberleits hellgrüner, unterfeits blaugrüner Blättchen. Statt des Endblättchens eine kurze Spitze. Nebenblïtter folmal, fpitz.

Blüten gelb, 16-25 mm lang, zu drei bis zehn in einer Traube, die nicht viel länger ift als das darunter ftehende Blatt. Fahne aufrecht, etwas ausgebuchtet.

Mehrjährig. Blüht Mai bis Auguft.

Befucher: Hummeln.

Die gerade, 6-7 cm lange, bei der Reife fchwarze Hülfe fchleudert die Samen beim Auffpringen weg. Lichtungen des Bergwaldes.

Alpen (Schweiz, Frankreich), Jura, Karpathen ; Pyrenäen.

\section{Lathyrus heterophyllus. - Verfehiedenblättrige}

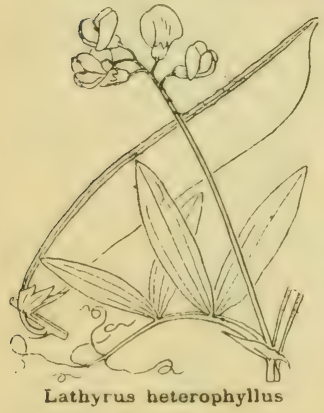

Lathyrus heterophyllus

Platterbfe. - Bis $1 \mathrm{~m}$ langer Rankenkletterer. Stengel und Blattftiele grün geflügelt. Obere Blattpartie als äftige Ranke ausgebildet, untere mit 1-2 Paaren fehmalelliptifcher Blättchen.

Blüten rofa, grof, zu vier bis acht in lockeren Trauben, deren Stiel viel länger ift als das darunter ftehende Blatt.

Mehrjährig. Blüht Juni bis Auguft. Befucher: Hummeln.

Die 7-8 cm langen, cylindrifchen Hüllen fchleudern bein Auffpringen die Samen weg.

Wälder und Gebüfche der Bergregion. Alpen (Frankreich und Schweiz), Jura. 
Lichtungen des Bergwaldes.

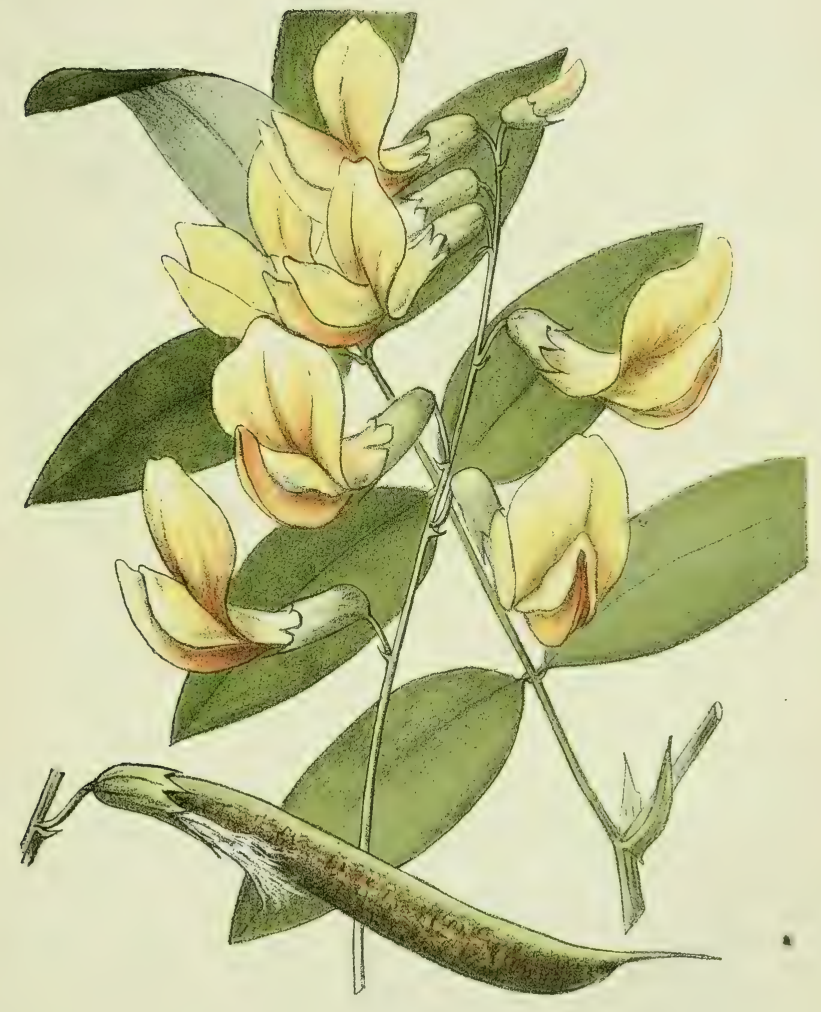

Lathyrus luteus.

Gesse jaune.

Gelbe Platterbse. Yellow Pea. 
Felsen, steile Weiden 1700-2800 Meter.

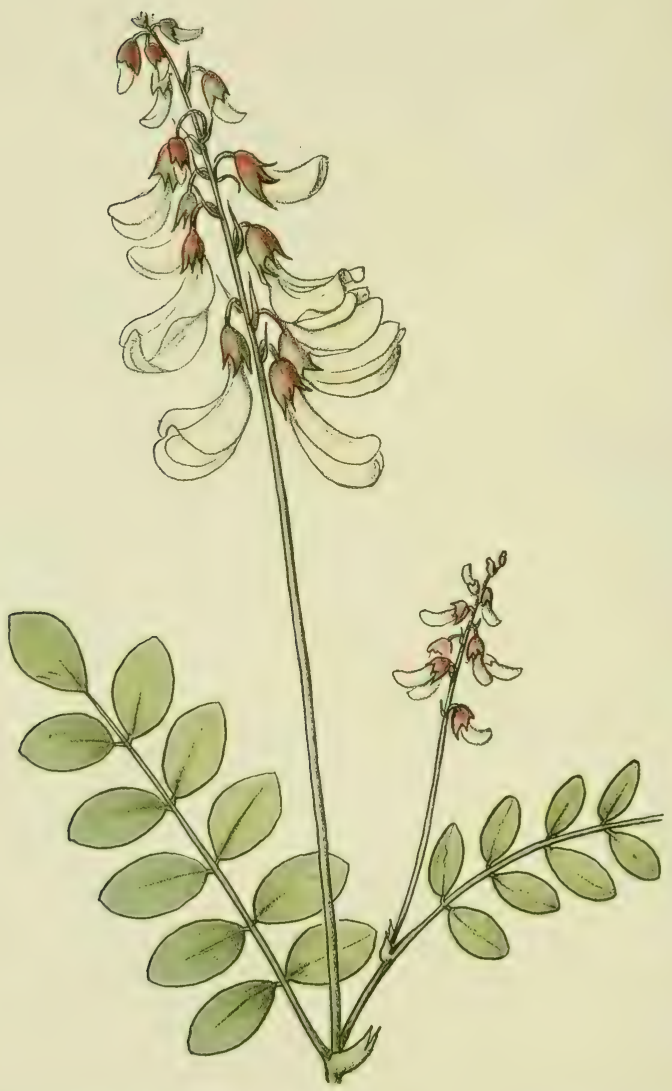

Hedysarum obscurum.

Dunkler Süssklee. Sainfoin des Alpes. Alpine Honeysuckle. 
Herlysarum obscurum. - Tafel 32. - Wurzelftock lang, verzweigt. Oberirdifche Stengel zahlreich, aufrecht, 20-50 cm hoch, kahl, unterwärts verzweigt, bis oben beblättert, fterben nach der Fruchtreife ah. Blälter mit 5-9 eiförmigen, kahlen blättchen. Nebenblätter zu einer zweifpitzigen Scheide verwachfen.

Blüten dunkelpurpurrot, etwas hängend, zu $10-50$ in grofer, einfeitiger 'Traube.

Mehrjährige, vorzügliche Futterpflanze.

Blüht Juli bis Auguft.

Befucher: Hummeln, Falter.

Samen durch den Wind verbreitet.

Steile Weiden, Rafenbänder, Grünerlengebülche.

1700 bis $2800 \mathrm{~m}$.

Alpen, Pyrenäen, Karpathen, Kaukafus, nordpolare Länder, Ural, Altai.

Onobrychis montana. - Berg-Efparfette. - Stengel lang, meift niederliegend, mit wenig Blättern, die 5-7 Paare lang-ovaler Blättchen tragen.

Blüten hellrola, rot geadert. In langen, langgeftielten Trauben.

Mehrjährig. Blüht Juni bis Auguft.

Befucher: mehrere Bienenarten.

Frucht mit kurzen Borften häkelnd: durch Säugetiere verbreitet.

Steinige Hänge, magere Wiefen, auf Kalk.

1500 bis $2300 \mathrm{~m}$.

Alpen, Jura, Pyrenäen. 
Astragalns aristatus. - Tafel 33. - Wenig verzweigter, dorniger, 10-30 cm hoher, graubehaarter Strauch. Blitter lang, dicht ftehend. mit ihrer verbreiterten Bafis den Stengel umfaffend. Blattftiele fteif. An Stelle des Endblättchens bildet die Blattfpindel eine harte Spitze. 6-10 Paare lang ovaler, fein weif̧haariger Blättchen. Nebenblätter lang, fpitz, dem Blattftiel angewachfen.

Blüten weißs oder lila, zu $3-8$ in Trauben, die kürzer find als die Blätter.

Mehrjährig. Blüht Mai bis Juni.

Befucher: Hummeln.

Samen ohne Verbreitungsmittel.

Matten und Felfen der Narlelholzregion.

Befonders auf Kalk.

Weftalpen (Weftchweiz, Frankreich, Italien).

Astragalus alopecuroides. - Fuchsfchwanz-Tragant. Kräftige, $1 / 2$ bis $1 \mathrm{~m}$ hohe Kraut-

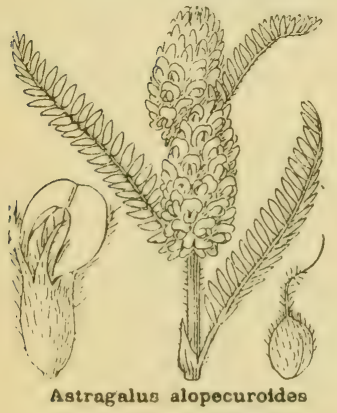
pflanze mit langen Wollhaaren. Stengel zahlreich, aufrecht, unverzweigt, dick. Blätter lang, weiflich, mit 20-40 Paaren fchmal eiförmiger Blättchen. Nebenblätter oval fpitz, nicht verwachfen.

Blüten blafgelb, fehr zahlreich in dichten eiförmigen Trauben.

Mehrjährig.

Blüht Juli bis Auguft.

Befucher: Gartenhummel.

Früchte kurz (fiehe Skizze rechts unten!) häkelnd?

Felfige Weiden der Nadelholzregion. Weltalpen (Frankreich und Italien). 
Steinige Matten und Felsen der Nadelholzregion.

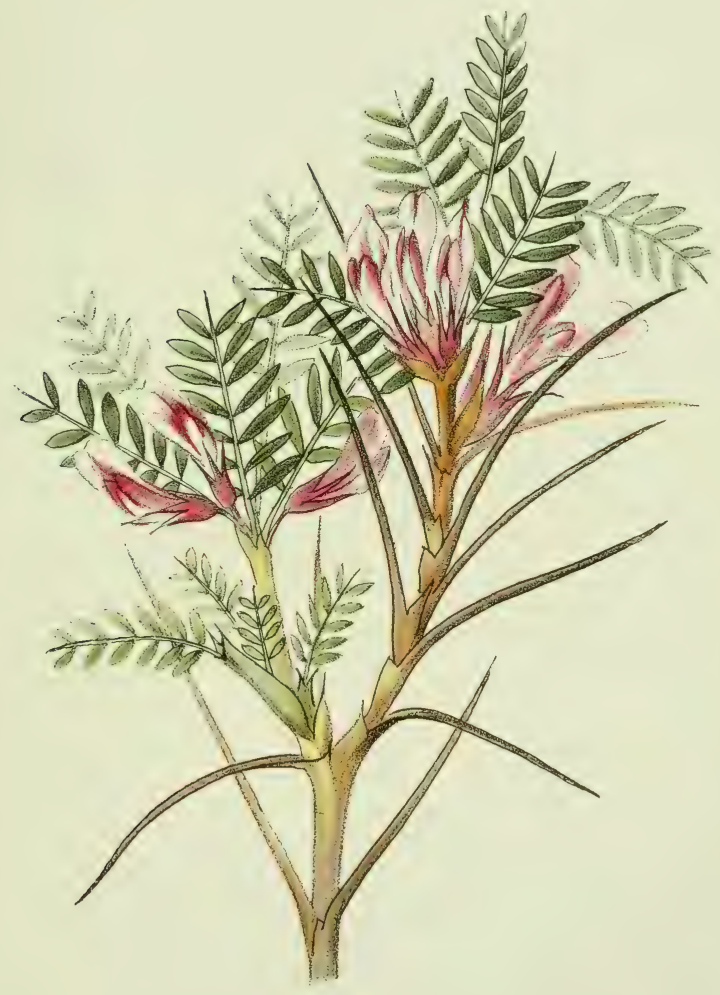

Astragalus aristatus. Astragale épineux.

Stachel-Tragant. Thorny Vetch. 
Steinige, sonnige Weiden und Felsen bis 1400 Meter.

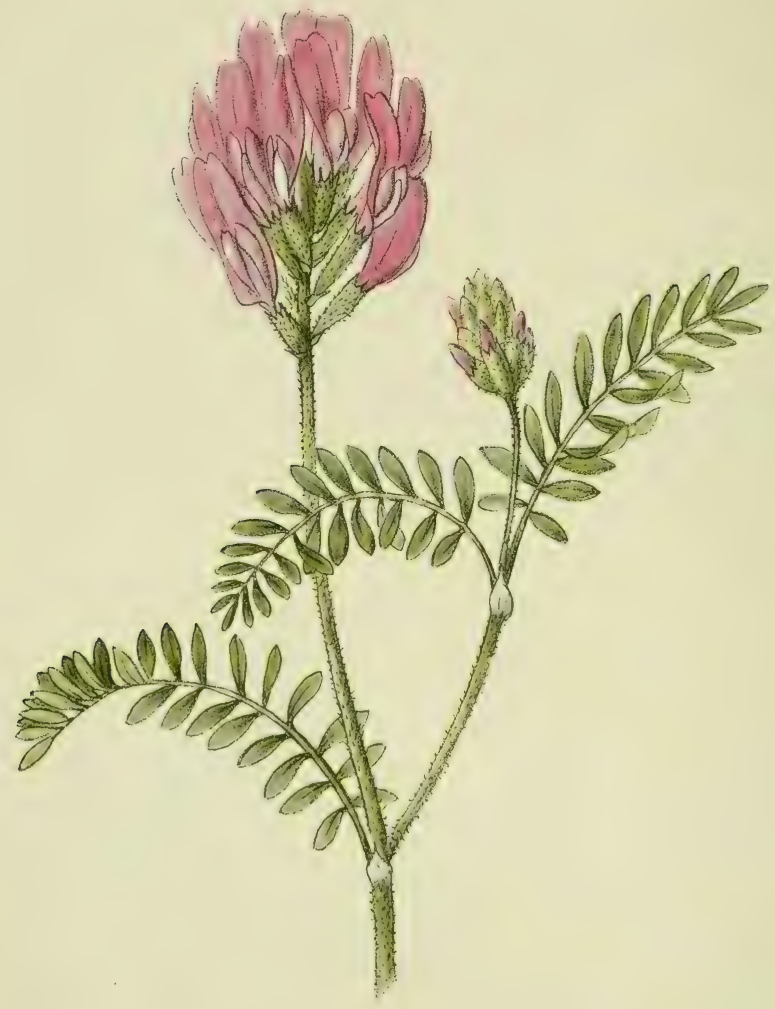

Astragalus Onobrychis. Astragale-sainfoin.
Esparsetten-Tragant. Sainfoin Vetch. 
Astragalns Onobrychis. - Tafel 34. - Bildet lockere, 20 bis $50 \mathrm{~cm}$ hohe, dornlofe Büfche. Stengel feft, weichhaarig. Blätter mit $8-12$ Paaren länglicher, ovaler Blättchen und einem Endblättchen.

Blüten blïulichpurpurn, zu 10-20 in aufrechten, eiförmigen Dolden, deren stiele die Blätter überragen. Das obere Kronblatt (Fahne) lang, vorn abgeftutzt.

Mehrjährig. Blüht Mai bis Juli.

Befucher: Bienen, Hummeln.

Hülfe kurz, rauhaarig, häkelnd (?).

Sonnige Fellen, magere Weiden.

Alpen der Provence, Dauphiné, Savoyen, füdliche Schweiz, Tirol bis Böhmen, Südrußland.

Coronilla coronata (montana). - Kronwicke. - Unbehaart, mit holzigem Wurzelftock. Stengel krautig, aufrecht, $30-60 \mathrm{~cm}$ hoch. Blätter bläulichgrün, mit 3-6 Paaren eiförmiger Blättchen; die unterften dem Stengel anliegend. Nebenblätter miteinander verwachfen, zweifpitzig, fallen frühzeitig ab. Blüten gelb, übelriechend, zu 15 bis 20 in kugeliger Dolde auf langem Stiel. Hülle 25-30 cm lang.

Mehrjährig. Blüht Juni.

Befucher: Hummeln.

Samen ohne Verbr.--Mittel.

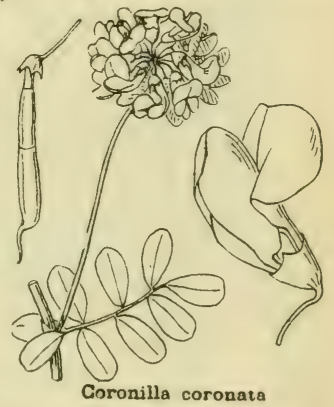

Wälder, Waldlichtungen, fteinige Halden der Hügelund Bergregion; auf Kalk.

Alpen, Jura, in Süd- und Mitteldeutfchland zerftreut, bis Steiermark, Krain und dem Littorale. 
Ononis rotundifolia. - Tafel 35. - Pflanze mit holzigem Wurzelftock, fchwach beharrt, etwas klebrig (Drül'enhatare!). Stengel krautig, $30-50 \mathrm{~cm}$ lioch. Blätter abftehend mit je :) rundlichen, fchwach gezähnten Blättchen. Nebenb]ätter kurz, eiförmig, zugefpitzı. Blüten grof, lebhaft rofenrot, zu 22-:3 auf gemeinlamem Stiel. Oberes Kronblatt (Fahne) aufgerichtet.

Mehrjährig. Blüht Mai bis Auguft.

Befucher: Bienen und Hummeln, Schmetterlinge.

Hïlfe $3 \mathrm{~cm}$ lang, aufgeblafen, aber fich ülfnend: Samen ohne Verbreitungsmittel.

Felfen, trockene Halden, auf Kalk.

Südliche Alpentïler (Frukreich, Schweiz, Tirol), Cievennen, Pyrenäen.

\section{Ononis fruticosa.}

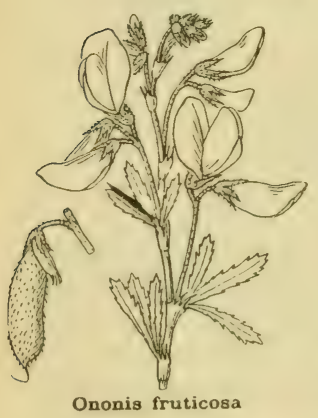

- Stranch-Hauhechel. - Stark verzweigter, dornlofer, 30 bis $100 \mathrm{~cm}$ hoher Stratich; kahl, mit Ausnahme der jungen 'Triebe, der Blattftiele und Früchte, die drüfig behaart find. Blätter klein, kaum geftielt, mit drei länglichen Blättchen mit gelägtem Rande. Nebenblätter gezähnt, den Stengel umfaffend. Blüten grof, rofenrot, zu 2-3 auf langen Stielen, bilden zufammen einen hohen traubenartigen Stand. Mehrjährig. Blüht Auguft. Befucher: wahrfcheinlich Bienen und Hummeln.

Samen ohne Verbreitungsmittel.

Felfen, Gebüfche der Hügel- und Bergregion.

Nördliche Alpen von Frankreich und Italien, Pyrenïen. 


\section{5}

Steinige ()re, Felsen. Hügel bis in die Nadelholzregion.

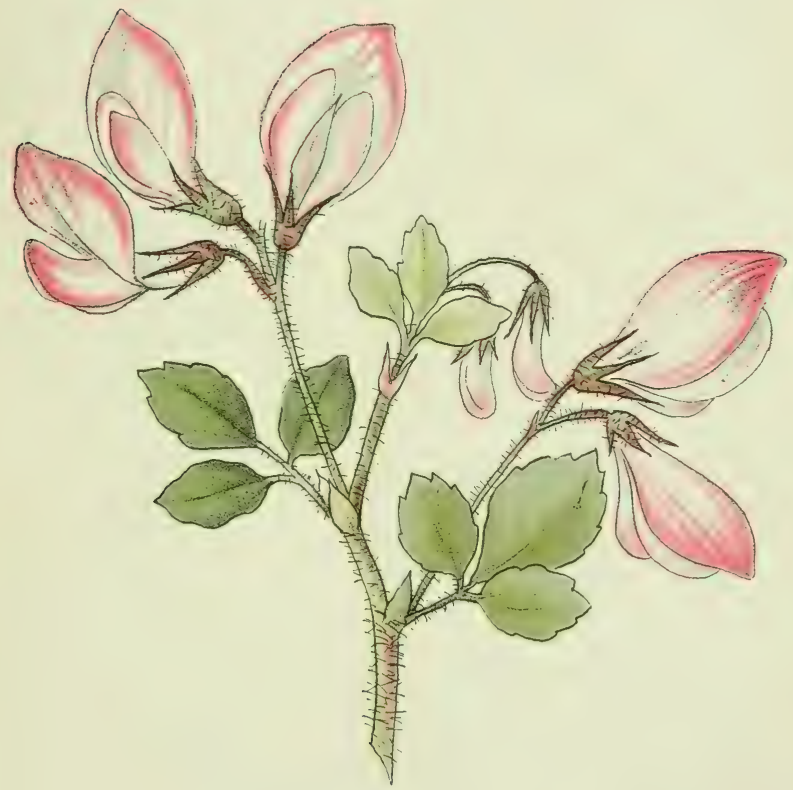

Ononis rotundifolia. Bugrane à feuilles rondes.
Rundblättriger Hauhechel. Alpine Rest-Harrow. 
Steinige Orte und Weiden der Nadelholzregion.

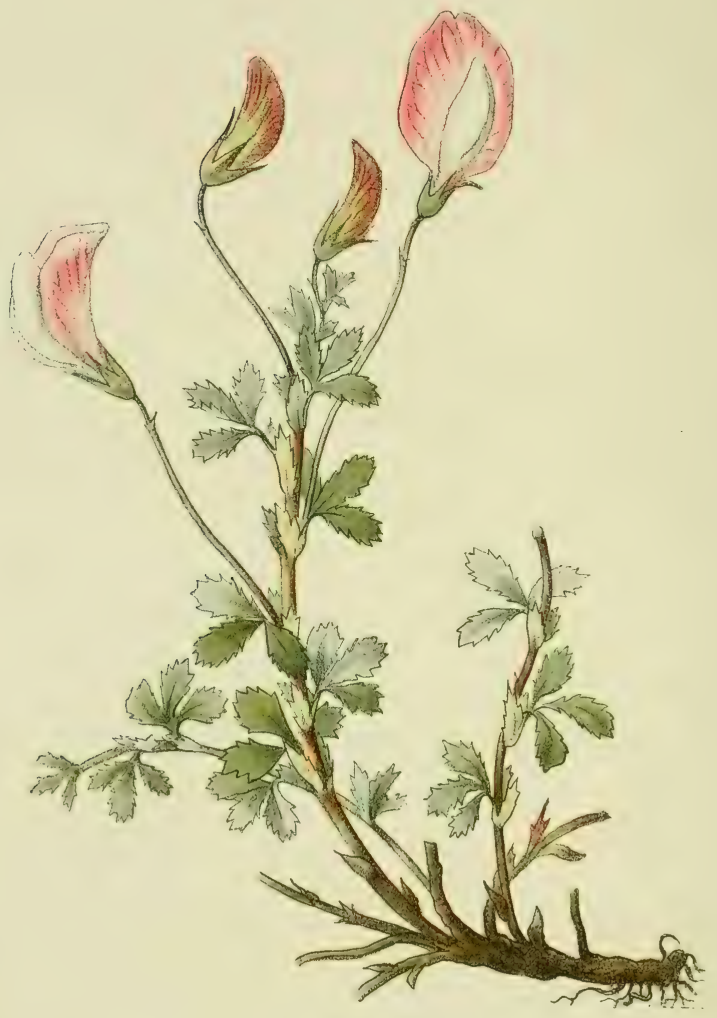

Ononis cenisia.

Bugrane du Mont-Cenis.
Hauhechel des Mont-Cenis. Rest-harrow of Mont-Cenis. 
Ononis cenisia. - Tafel 36. - Niedere Pflanze mit kriechendem Wurzelftock und niederliegenden, an der Bafis lchwach verholzten Stengeln, die $5-25 \mathrm{~cm}$ holıe Büfche bilden. Blätter klein, kurz geftielt, mit drei eiförmigen, ftark grezähnten, kahlen Blättchen. Nebenblätter lo grof wie die Blättchen, den Stengel umfaffend. Blüten rola, einzeln auf Jangen, zarten Stielen.

Mehrjährig. Blüht Juli.

Befucher: wahrlcheinlich Bienen und Hummeln.

Fellen, Weiden der Nadelholzregion.

Nördliche Alpen von Frankreich und Italien, Pyrenäen.

Cytisus alpinus. - Alpen-fxoldregen. - Dem Goldregen unferer Gärten fehr ähnlicher, 7-8 $\mathrm{m}$ hoher Baum. Blätter lang geftielt, mit drei lang elliptilchen, fpitzen, fchwach behaarten Blättchen. Blüten fattgelb, in langen hängenden Trauben.

Mehrjährig. Blüht Mai bis Juli. Befucher: vermutlich Bienen, Hummeln und Falter.

Samen ohne Verbreitungsmittel.

Buchen- und Tannenwälder. Alpen von Frankreich, Italien,

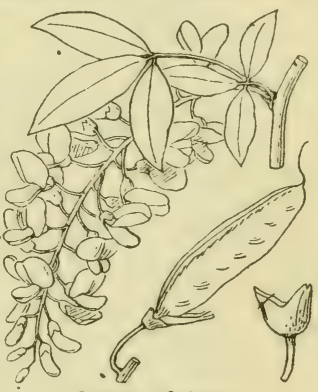

Cytisus alpinus der füdlichen Schweiz, Jura, Tirol, Krain. 
Vicia silvatica. - Tafel $3 \%$ - Bis $1 \mathrm{~m}$ langer Rankenkletterer mit kahlen Stengeln. Blätter mit 5-10 Paaren länglich ovaler Blättchen. Nebenblätter halbmondförmig, grob gezähnt. Blüten weiß, blau odler violett geadert, zu 10-15 in lockerer Traube.

Mehrjährig. Blüht Juni bis Juli. Schleuderfrucht. Befucher: Vermutlich Bienen, Hummeln.

Alpen der Schweiz, Frankreich; Jura; in Deutfchland zerftreut.

Lotus corniculatus. - Hornklee. - Kahl, Stengel

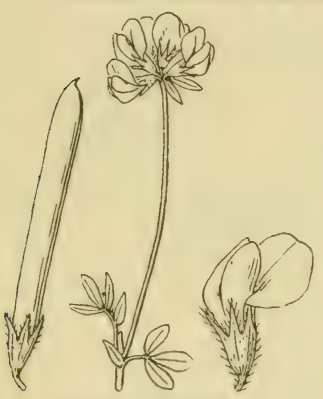

$10-40 \mathrm{~cm}$ lang, in dichtem Rafen aufrecht, fonft niederliegend. Blätter mit drei eiförmigen Blättchen. Blüten gelb, zu 3-6 in Dolden auf hohem Stiel. Kronblätter gelb, in den Bergen oft orange- oder purpurrot.

Mehrjährige, gute Futterpflanze.

Blüht Mai bis Herbft.

Befucher: Bienen, Hummeln.

Schleuderfiucht.

In ganz Mitteleuropa; in den Alpen bis $2900 \mathrm{~m}$.

Lotus corniculatus

Oxytropis lapponica. - Lapplïndifcher Spitzkiel. -

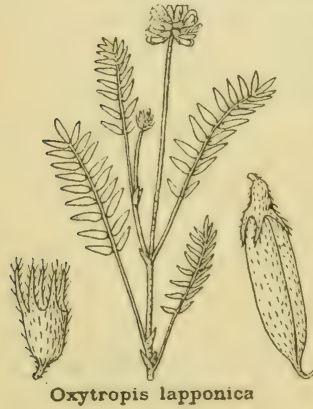

Dünnftengelige, $10-25 \mathrm{~cm}$ hohe, drei bis fünfblättrige Pflanze. Blätter mit. 8-12 Paaren fchmal-eiförmiger, fpitzer Blättchen und einem Endblättchen. Blüten hellrötlich, in kurzer, faft kugeliger Traube.

Mehrjährig. Blüht Juli.

Befucher: Falter, auch Hummeln. Samen ohne Verbr.-Mittel.

Felfen und Rafenbänder; auf Urgeftein.

Weftalpen, europäifche Polarländer, Himalaya. 


\section{- 37 -}

\section{Bergwälder.}

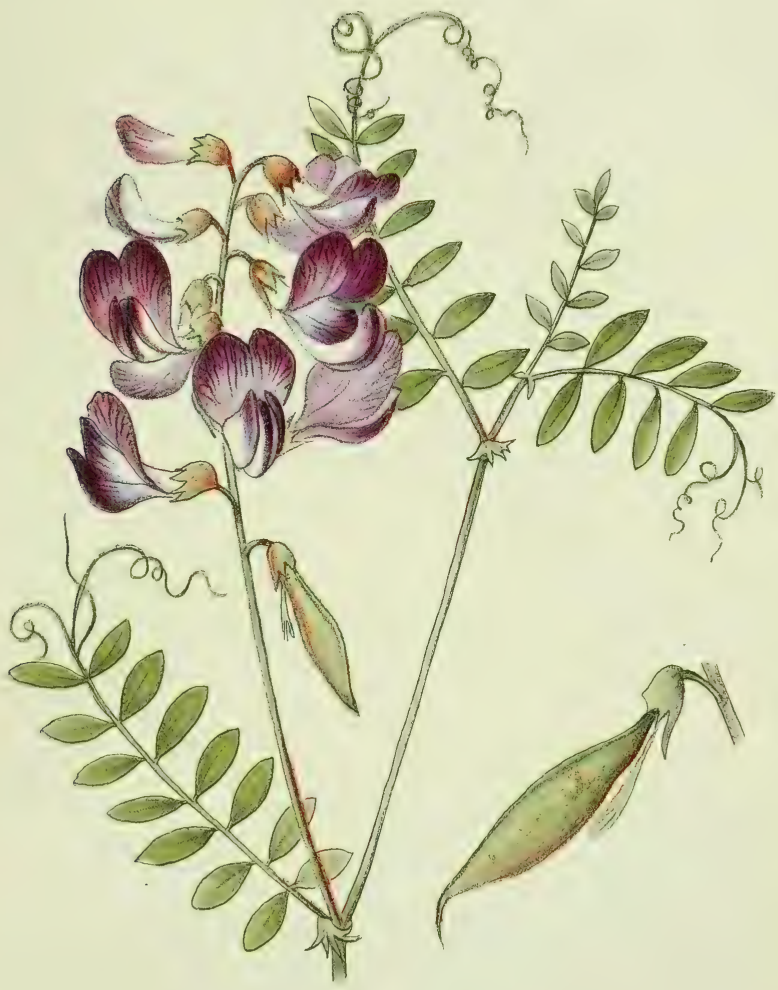

Vicia silvatica.

Vesce des bois.

Waldwicke.

Wood-Vetch. 
Steinige Weiden 1700-3000 Meter.
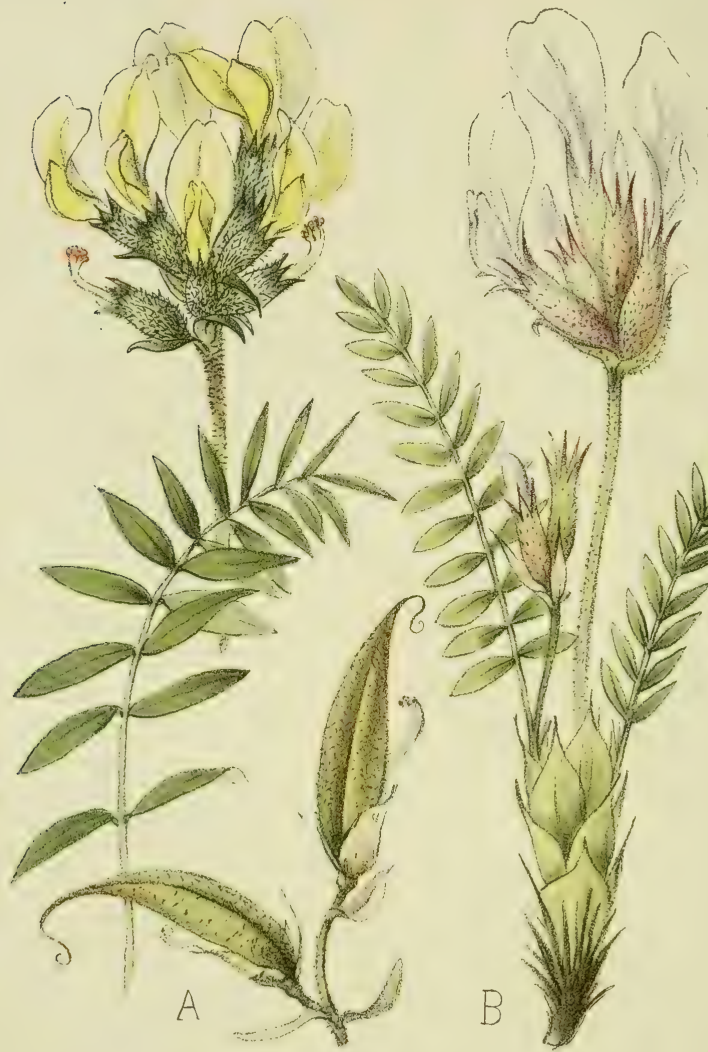
Oxytropis campestris. - Tafel 38 A. - Kräftiger Wurzelftock mit zahlreichen, graugrünen Blättern; jedes mit 7-14 Paaren fchmal eiförmiger, zugefpitzter Blättchen und einem Endblättchen. Bläten zu 5-10 in eiförmiger Traube auf 5-10 cm hohem Stiel. Kronblätter hellgelb, die beiden unterften (Schiffehen) mit violettem Fleck.

Mehrjährige, vorzügliche Futterpflanze.

Blüht Juli Augult. Befucher: Hummeln, Falter.

Hülfe behart, aufgeblafen: Windverbreitumg.

Steigt zuweilen mit den Bächen bis $450 \mathrm{~m}$ hinab.

Alpen, Pyrenäen, Karpathen, nordpolare Länder, Ural, Altai.

Oxytrop is foetida. - Tafel $38 \mathrm{~B}$. - Wie vorige, aber nit unangenehm riechenden Drüfenhaaren. Blätter mit 15-95 Paaren fehr l'chmaler Blättchen. Blüten gelblich, in Trauben.

Mehrjährig. Blüht Juli bis Auguft.

Befucher: vermutlich Hummeln, Falter.

Hülfen etwas gebogen, aufgeblafen: Windverbreitung.

Felfen und magere Weiden.

Weftalpen (Schweiz, Frankreich, Italien).

Oxytrop is montana. - Berg-Spitzkiel. - Stengel 5 bis $10 \mathrm{~cm}$ hoch, mit 3-4 Blättern; diele weiflich behaart, mit 10-15 Paaren fchmal eiförmiger, fpitzer Blättchen und einem Endblättchen. Bläten rotviolett, zu 5-15 in eiförmigen, langgeftielten Trauben.

Mehrjährig. Blüht Juli Aug. Befucher: Hummeln, Falter. Samen ohne Verbr.-Mittel.

Magere Matten, fteinige Weiden, Felfen, $1800-3000 \mathrm{~m}$. Alpen, Jura, Pyrenäen, Karpathen.

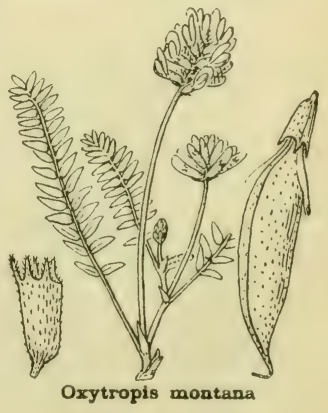


Die Pirolaceen verdanken ihren Namen der Ähnlichkeit ihrer Blätter und Blüten mit denjenigen des Birnbaums (Pirus), welche aber nur oberflächlich ift. Tatfiichlich find fie mit den Heidekrïutern (Ericaceen) und Primelgewächfen verwandt.

Pirola minor. - Tafel 39. - Stengel 10-25 $\mathrm{cm}$ hoch, aufrerht. Blätter eiförmig oder elliptilch, etwas länger als in Stiel. Bläten klein, weifs his rolis, fich nur halb öftnend; in dichten endltändigen Trauben.

Mehrjährig. Blüht Juni bis Auguft.

Befucher : Käfer, Fliegen.

Samen fehr klein: Windverbreitung.

Mooshoden fchattiger W:ilder, Ebene bis $2400 \mathrm{~m}$.

Pyrenäen, Alpen, Mitteleuropa, Sibirien, Kanada, Rocky Mountains, Neumexiko.

Pirola uniflora. - Einbliitiges Wintergriin. - Kleine
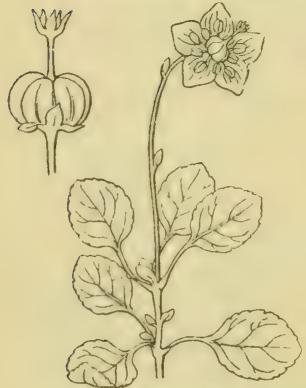

Pirola uniflora Pflanze mit unterixdifchem, zartem Stengel. Oberirdilche Triebe aufrecht, 5-10 $\mathrm{cm}$ hoch, am Grunde mit kleinen, rundlichen, f'chwach gezähnten Blättern, die blafgrün gefärbt find. Unterhalb der Blüte 2-3 grüne Schuppenblätter. Blüten einzeln, bis $2^{1 / 2} \mathrm{~cm}$ grof, wohlriechend, mit fünf weifsen, weitgeöffneten Blumenkronzipfeln, auf welchen die Staubblätter ausgebreitet find. Stempel aufrecht, mit fünf Narben (fiehe Skizze links oben).

Mehrjährig. Blüht Juni bis Juli.

Blüten honiglos, Befucher?

Samen fehr klein: Windverbreitung.

Moosboden fehr fchattiger Wälder. $800-1800 \mathrm{~m}$. Alpen, Vogefen, Gevennen, Pyrenäen ; Sibirien, Nordamerika bis Colorado. 
Monsboden schattiger Bergwalder bis 2400 Meter.

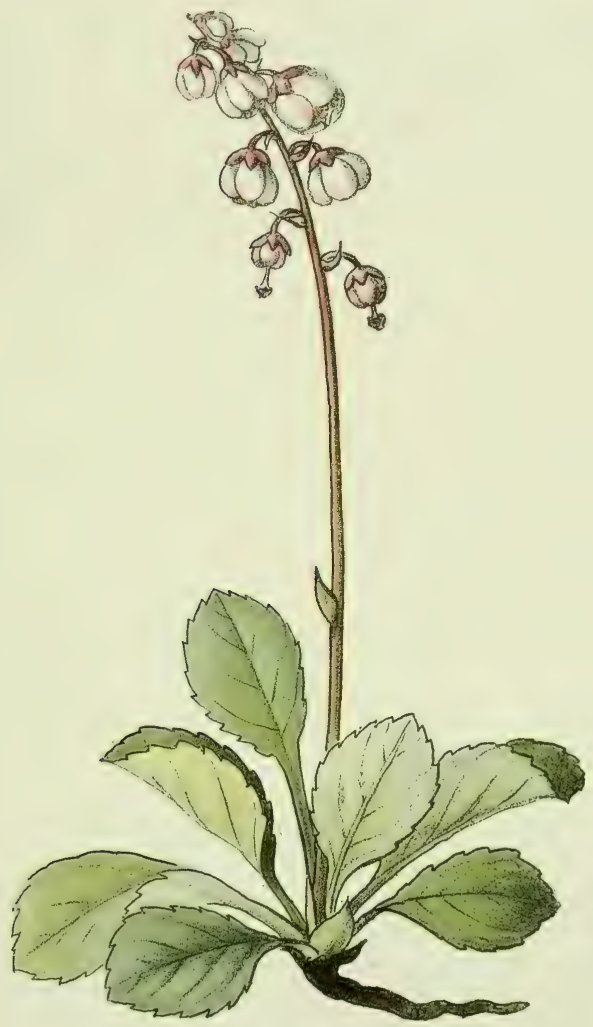

Pirola minor.

Kleines Wintergrün.

Petite Pirole.

Lesser Wintergreen. 


\section{$-40-$}

Moosboden schattiger Wälder 1000-2000 Meter.

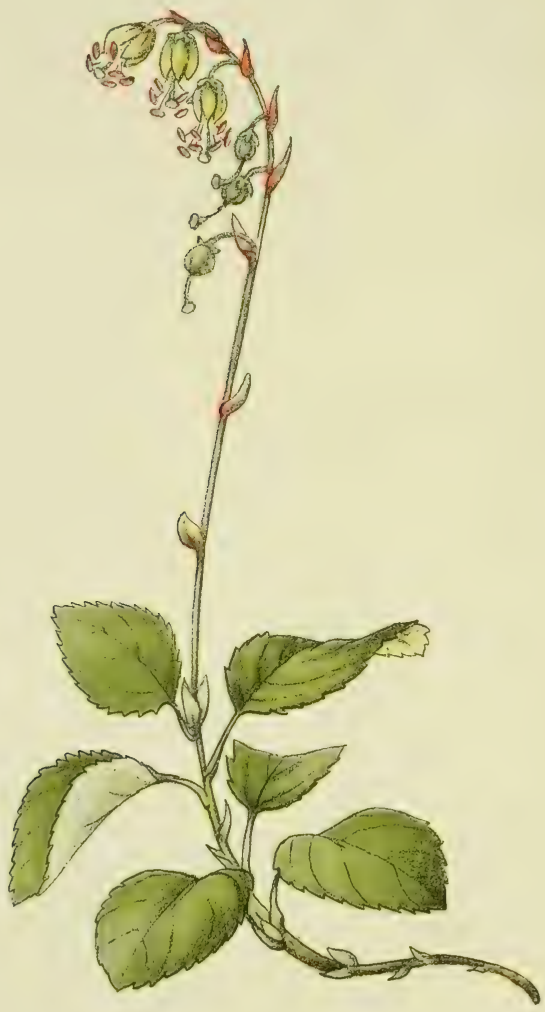

Pirola secunda. Pirole unilatérale.
Einseitswendiges Wintergrün. Yevering Bells. 
Pirola secunda. - Tafel 40. - Pflanze mit zarten, unterirdifchen, im Moofe kriechenden Stengehn. Obeririffche Triebe 8-2.5 cm hoch, unterwärts nit einigen eiförmigen, lichwarh gezähnten Blättern, deren stiele kürzer find als die Spreite. Unterhalb der Bläten einige Schuppenblätter. Blüten rrünlich-weifs, liøh nur halb öffnend, in endftändiger, einleitiger Traube.

Mehrjäırig. Blülıt Juni bis Auguft. Befucher?

Samen fehr klein: Windverbreitung.

Moosboden fehattiger Wälder. 1000-_ogo m.

Alpen, Jura, Vogefen, Auvergne, Cevennen, Pyrenïen, nürdliches Afien, Nordamerika bis Mexiko.

Die Familie der Rofengewiichfe oder Rosifloren umfaßst eine grofse 'Zahl fehı' verfchieden ausfehender' Pflanzen. Sie find bald als Bäume (Apfel-, Birn-, Kirfchbaum etc.), bald als Sträucher (Rolen, Brombeeren), bald als niedere Krautpflanzen (Erdbeeren, Fingerkraut) entwickelt. Ihr gemeinfames Merkmal befteht befonders im Bau der Blüten, die meift durch eine grofse Zahl ron Staub- und Fruchtblätlern ausgezeichnet lind, wie diejenigen der Runumrulureen, jedoch ltets eine doppelte Blütenhülle befitzen.

In die Alpenregion fteigen nur die niedrigen, krautigen Arten hinauf, während die Obfthäume von einer beftimmten Höhe ah ihre Früchte nicht mehr reifen. Nicht einmal als Futterpflanzen fpielen die Rosifloren in den Alpen eine Rolle, dagegen erfreuen fie das Auge durch ihre meift farbenprächtigen Blüten. 
Alchemilla alpina. - Tafel 41. $-10-30 \mathrm{~cm}$ hoch. Untere Blätter handförmig geteilt, mit 5-7 länglich-ovalen gezähnten Blättern, die oberleits kahı, unterfeits weif feidenhaarig find. Blütentragende Sproffe aufrecht, fchwach beblättert. 'Zahlreiche, unleheinbare, grünliche Blüten in aufrechten, lockeren Trauben.

Mehrjährig. Blüht Juni bis Auguft.

Befucher: Käfer, Fliegen, Ameifen, Schlupfwefpen. Früchte mit Fallfchirm: Windverbreitung.

Alpen, Vogefen, Auvergne, Cievennen, Pyreuäen, Karpathen, Kaukafus, Gebirge v. Nordeuropa u. Nordamerika.

\section{Alchemilla valgaris. - Gewöhnlicher Franenmantel.}

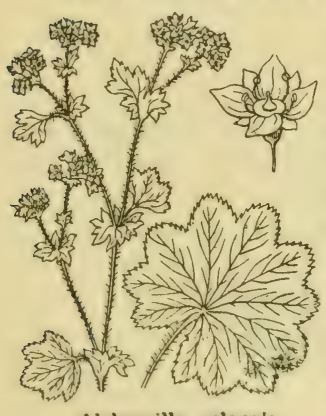

Alchemilla vulgaris

Wie voriger, jedoch die blühenden Sproffe anfangs niederliegend, dann aufgerichtet. Blätter beiderfeits grün, mit 7 - 11 feichten, gezähnten Lappen. Blühende Triebe $10-40 \mathrm{~cm}$ hoch. Blüten in dichten, endfändigen Sträufchen.

Mehrjährig. Blüht Mai bis Juli. Befucher: Vorwiegend Fliegen. Früchte wie beim vorigen. Mähwiefen, Bachufer, Läger.

Ebene bis $2700 \mathrm{~m}$.

Mitteleuropa, Nordafien.

Alchemilla pentaphyllea. - Finflöittriger Sinau. Faft kahl, mit auffeigenden $5-15 \mathrm{~cm}$

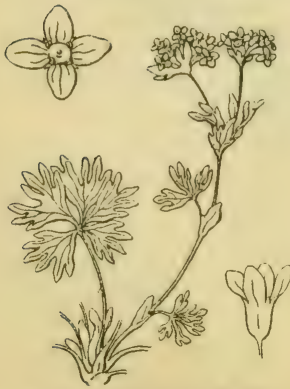
hohen Stengeln. Wenige, beiderfeits kahle, handförmig う-teilige Blätter. Mehrjährig. Blüht Juli Aug. Befucher: Käfer, Fliegen, Ameifen. Früchte mit Fallfchirm: Windverbreitung.

Im kurzen Rafen feuchter Hänge;

Beftandteil der Schneetälchen-

Flora. $1900-3000 \mathrm{~m}$.

Alpen, Pyrenäen. 
Magere Weiden, Felsen, Gerölle 700-2700 Meter.

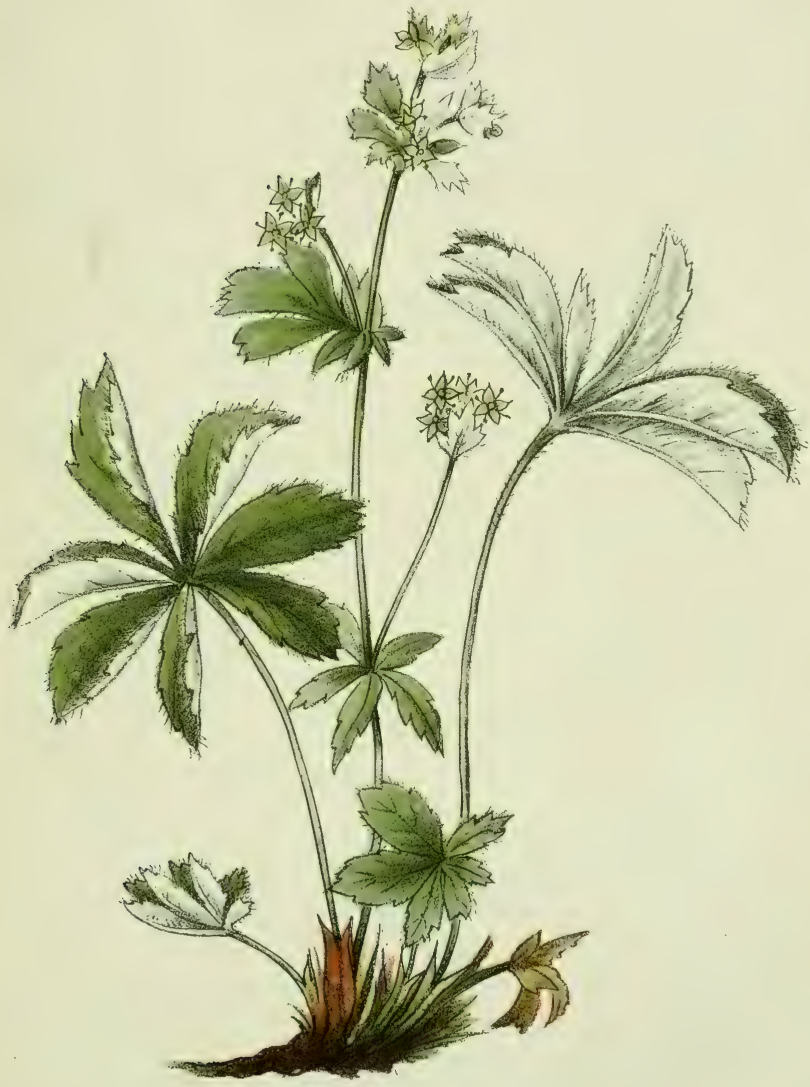

Alchemilla alpina. Alchémille des Alpes.
Alpen-Frauenmantel. Alpine Lady's mantle. 
Magere Weiden, Felsen ז5̄oo-2900 Meter.

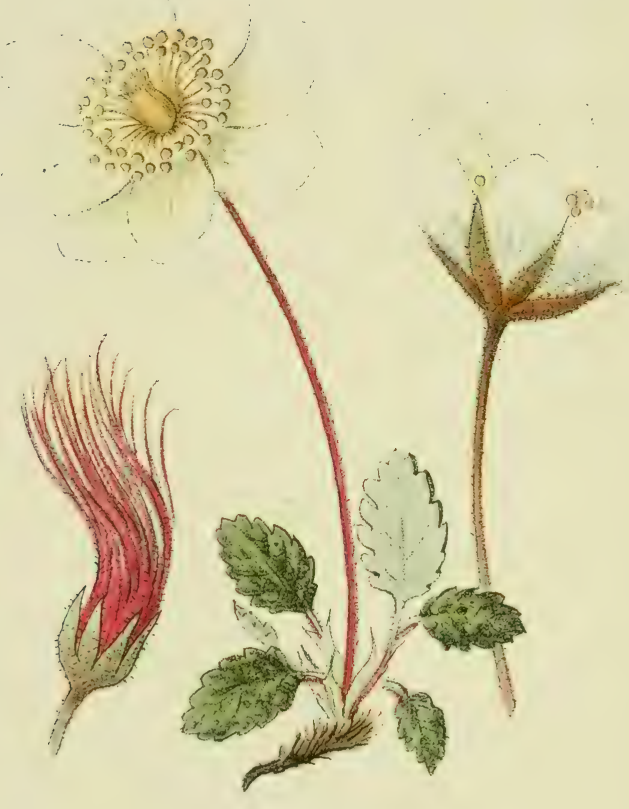

Dryas octopetala.

Silberwurz.

Dryade a huit pétales.

Mountain Avens. 
Dryas octopetala. - T'ufel f: - Niederliegende, fpalierbildende Pflanze mit kriechenden, ftark verzweigten und verholzten Stengeln. Blätter oval, oberfeits glänzend, dunkelgrün, unterfeits weif behaart. Rand gekerbt, etwas nach unten umgerollt.

Blüten weißs, grof, einzeln auf dem j-10 cm hohen Stiel. Je 7-9 Kelch- und Kronblätter. Die Griffel der zahlreichen Fruchtknoten ftrecken lich nach dem Verblühen zu federigen Grannen, fodafs das Fruchtköpfchen demjenigen mancher Anemonen lehr ähnlich ift.

Mehrjährig. Blüht Juli bis Auguft.

Befucher: Vorwiegend Fliegen und Bienen.

Früchte mit Haarfchweif: Windverbreitung.

Magere Weiden, Felsblöcke, in kurzem Ralen.

1500 bis $2800 \mathrm{~m}$, befonders auf Kalk.

Alpen, Jura, Auvergne, Pyrenäen, Karpathen, Kaukafus, nordpolare Länder, Ural, Altai.

Cotoneaster tomentosil. - Wollige Steinmifpel. Höchftens $1 \mathrm{~m}$ hoch. Äfte behaart, an fonnigem Standort knorrig, im Schatten lang, gerade, ohne Dornen. Blätter oval, oberfeits fchwach behaart, unterleits weiffilzig.

Blüten weifs oder rötlicb, zu $3-5$ in aufrechten Trauben, mit filzigem Stiel und Kelch.

Mehrjähırig.

Blüht April bis Mai.

Befucher: Wefpen.

Fleifchige, bei der Reife rote Apfelfrucht: durch Vögel verbreitet.

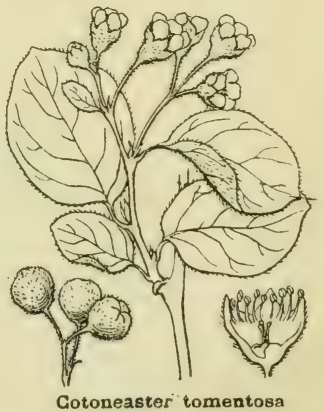

Felfen, feltener bei Baumgruppen, $800-2000$ m. Alpen, Jura, Cievennen, Pyrenäen. 
Rosa alpina. - Tafel 43. - Strauch selten höher als $1 / 2$ 111 , ohne Stacheln, aufer einigen fehr fichwachen am Blütenftiel. Blïtter mit 7-11 länglich-ovalen Blïttchen. Blüten einzeln an den Zweigenden, lelten zu zivei oder drei vereinigt. Kronblätter rot.

Mehrjährig. Blüht Juni bis Juli. Pollenblume.

Befucher: vermutlich Käfer und Bienen.

Hagebutte länglich, orangerot: durch Vögel verbreitet. Alpen, Jura, Vogefen, Auvergne, Cievennen, Pyrenäen.

Rosa glauca. - Rofe mit blaugriinen Bliattern. Kräftiger, 1-2 Meter hoher Stranch mit wenigen, aber ftarken, gekrümmten Stacheln. Blätter blïulichgrün, kahl, mit j-7 ovalen gezähnten Blättchen. Blüten rot, meilt einzeln.

Mehrjährig. Blüht Juni bis Auguft.

Befucher: vermutlich Käfer und Bienen.

Hagebutte kugelig, meift kahl, durch Vügel verbreitet. Waldlichtungen der Berge, l'ttener der Högelregion. Alpen, Jura, Vogefen, Auvergne, Cevennen, Pyrenäen.

Rubus saxatilis. - Fellen-Himbeere. - Stengel

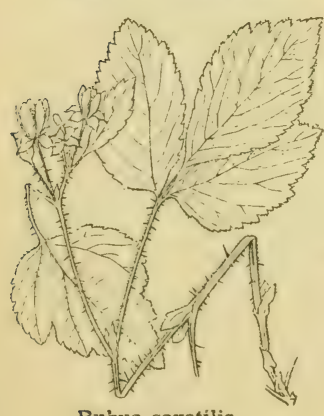

krautig, $20 \mathrm{~cm}$ hoch, nicht verholzt (im Gegensatz zu den Pubus der Ehene), lchwach behaart, mit lehr fchwarhen stachehn befetzt. Blätter dümn, hellgrün, mit drei gezähnten Blättchen. Blüten zu 5-8 in endltändiger Traube. Kronblätter weif, fchmal-eiförmig.

Oberirdifeher Stengel einjährig.

Blüht Mai bis Juni.

Befucher: Fliegen, Bienen.

Früchte fleifchig, rot, lauer, durch

Vögel verbreitet.

Waldlichtungen, Eelfen.

$1000-2000 \mathrm{~m}$.

Apen, Jura, Vogefen, Auvergue, Cievennen, Pyrenäen; Nordeuropa, Nordalien. 
IValdränder, Gebüsche 1000-2600 Meter.

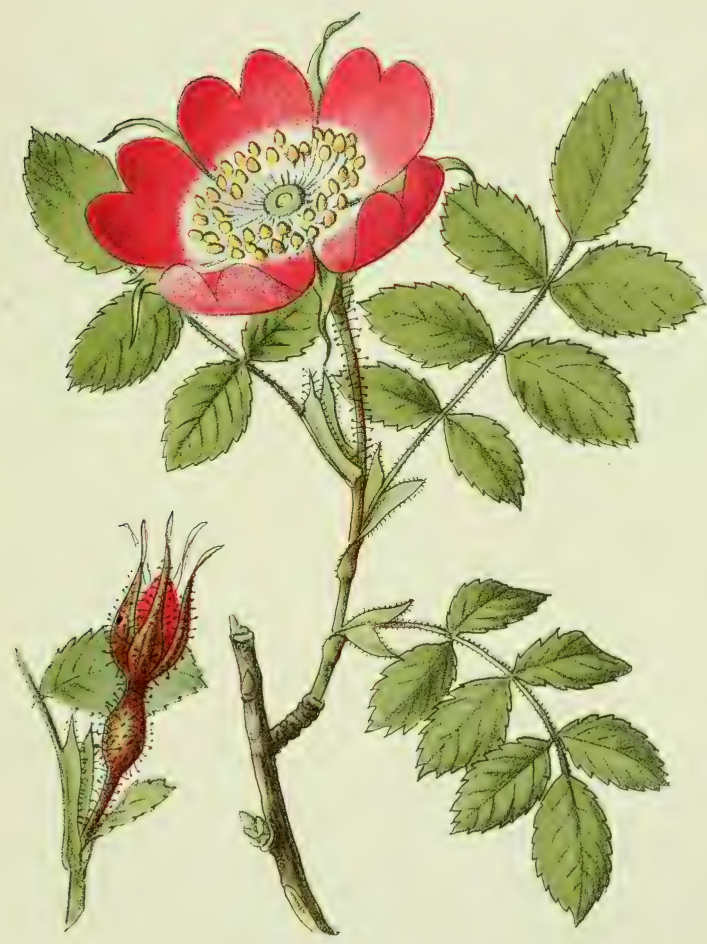

Rosa alpina.

Églantier des Alpes.
Alpen Hag-Rose. Alpine Rose. 
Weiden, Rasenbänder 1000-2700 Meter.

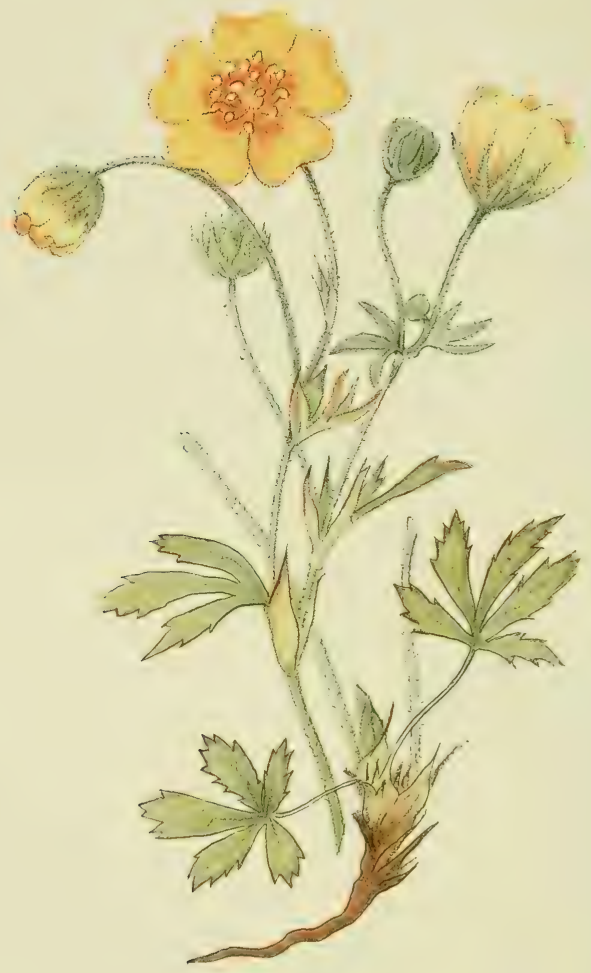

Potentilla aurea.

Potentille dorée.
Goldgelbes Fingerkraut. Golden Cinquefoil. 
Potentilla aurea. - Tafel it. - Kriechender Wurzelftock mit zuerft niederliegenden, dimn auffeigenden, $5--25 \mathrm{~cm}$ hohen, wenigblütigen Sproßsen. Blätter handförmig zulammengefełzt, mit fünf lïnglich ovalen, gezähnten Blättchen, die oberleits kahl, unterleits auf Nerven und Rand leidig behaart find. Kronblätter goldgelb, an Grunde mit orangerotem Fleck.

Mehrjährig. Blüht Juni bis Auguft. Befucher: Fliegen, Bienen, Falter. Früchte ohne Verbreitungsmittel. Alpen, Jura, Auvergne, Cevennen, Pyrenäen ; Karpathen, Nordeuropa.

Potentilla multifida. - Schlitzblïtriges Fingerkraut. - 5-25 $\mathrm{cm}$ hohe, weiß̧behaarte Pflanze, mit fiederförmig in schmale Ablchnitte geteilten Blättern. Kronblätter 'gelb, fchwach ausgerandet.

Mehrjährig. Blüht Juli.

Befucher: vermutlich Fliegen, Bienen.

Früchte ohne Verbr.-Mittel. Weiden, auf Urgeftein.

Weftalpen, Kaukafus, Nordpolarländer, Ural, Altai, Himalaya.

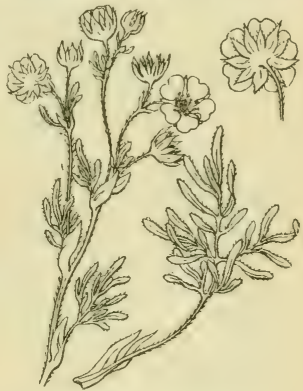

Potentilla multifida

Potentilla frigida. - Kälteliebendes Fingerkraut. Würzige, 2-10 $\mathrm{cm}$ hohe, drüfig behaarte Pflanze. Die Stengel überragen die Blätter kaum. Diefe mit je drei ovalen, beiderleits ftark behaarten, grobgezähnten Blättchen. Blüten gelb, meift einzeln, l'eltener zu 2-5 an Ende des Stengels.

Mehrjährig. Blüht Juli Aug.

Befucher: vermutlich Fliegen und Bienen.

Früchte ohne Verbr.-Mittel.

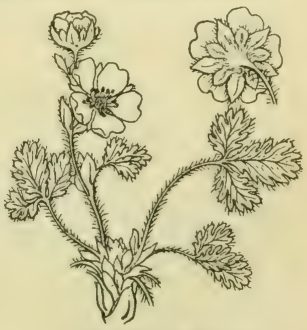

Potentilla frigida

Steinige Weiden, Felfen bis $3000 \mathrm{~m}$.

Alpen, Nordpolarländer, Altai. 
Potentilla grandiflora. - Tufel 45. -- Ganze Pflanze hehatart. Stengel aufrecht, $10-20 \mathrm{~cm}$ hoch, nicht alle blühend. Blitter dreiteilig, beiderleits grün. Blättchen eiförmig, mit wenigen grofsen Zähnen. Blüten gelh, etwa 21/2 cm grof3.

Mehrjährig. Blüht Juli bis Auguft.

Befucher: Fliegen, Bienen, Falter.

Früchtchen ohne Verbreitungsmittel.

Alpen, Pyrenäen, polares Alien und Nordanerika.

Potentilla Tormentilla (silvestris). - Tormentill. -

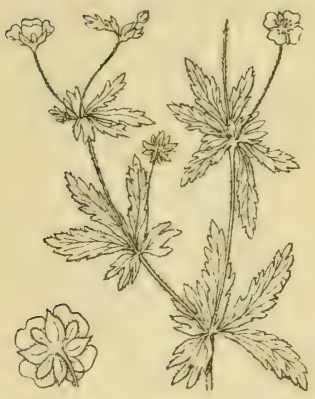

Potentilla Tormentilla

Einzige alpine Potentilla mit vierzähligen Blüten. $15-40 \mathrm{~cm}$ hoch. Blätter tief dreilpaltig, wie die beiden grofen Nebenblätter ftark gezähnt. Blüten klein, gelb.

Mehrjährig. Blüht Mai bis Aug. Befucher: Fliegen, Bienen, Falter. Früchtchen ohne Verbr.-Mittel. Heiden, feuchte torfige Wiefen, Weiden, Waldlichtungen. Ebene bis $2200 \mathrm{~m}$.

Mittel- und Nordeuropa bis Sibirien.

Potentilla nitida. -- Seidenglänendes Fingerkrant.

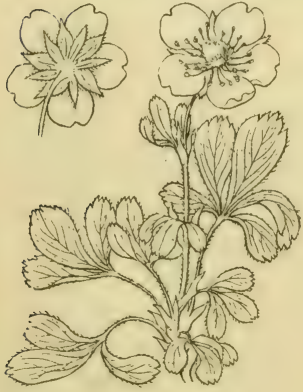

Potentilla nitida

$5-15 \mathrm{~cm}$ hohe, weif feidenhaarige Pflanze. Die Stengel überragen kaum die Blätter. Diefe mit 3-5 länglich eiförmigen, am Grunde verfchmälerten Blättchen, die vorn gezähnt lind. Blüten rofenrot, groß, meilt einzeln.

Mehrjährig. Blüht Juli bis Auguft. Befucher?

Kalkfelfen, felten.

Hochalpen von Frankreich, Italien, Tirol, Kärnten, Krain, Steiermark. 
Felsen, steinige IV iden 1500-3000 Meter.

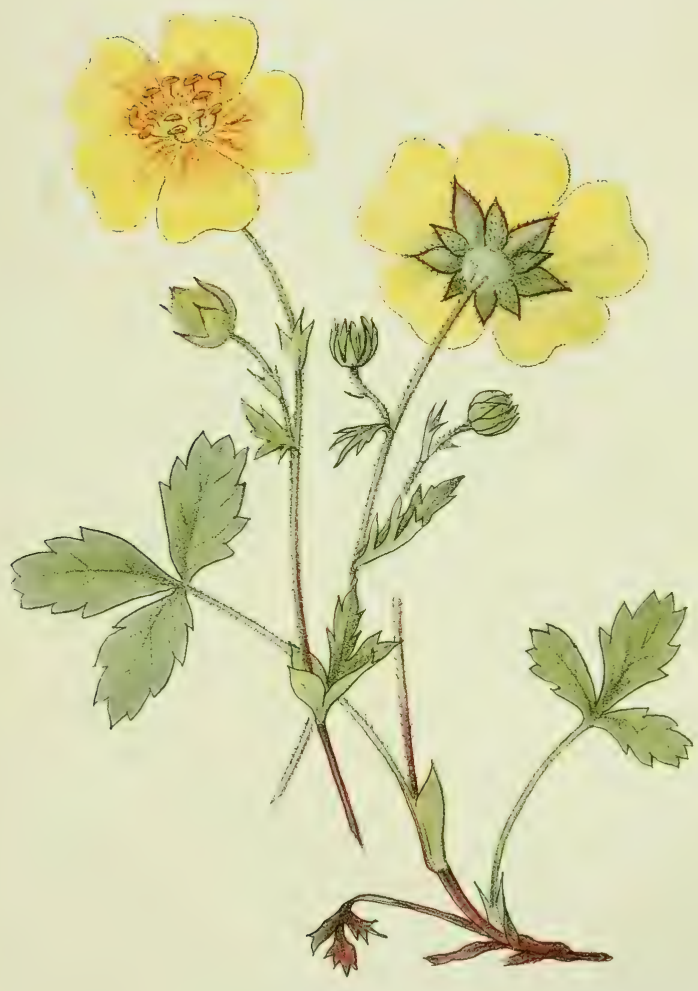

Potentilla grandiflora. Potentille à grandes fleurs. (jrossblumiges Fingerkraut. Large flowered Cinquefoil. 


\section{6}

Feuchte, torfige Wiesen bis 2600 Meter.

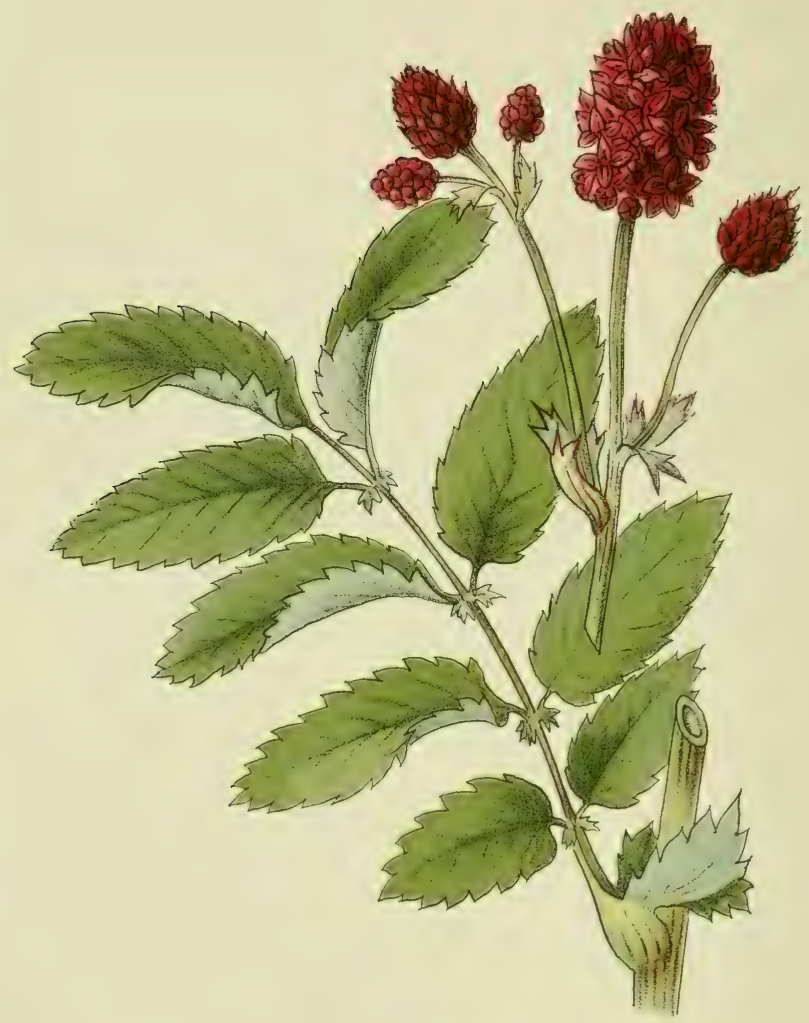

Sanguisorba officinalis. Sanguisorbe officinale.
Offizineller Wiesenkopf. Great Burnet. 
Sanguisorba officinalis. - Tafel $46 .-80 \mathrm{~cm}$ bis $1 \mathrm{~m}$ hoch, mit ftarkem, kriechendem Wurzelltock. Stengel verziveigt, aufrecht, l'chwach beblïtert. Blatter fiederteilig, mit 7-15 Paaren ovaler, gezïhnter, unterleits bläulicher Blättchen. Blüten dunkel purpurn, zu $50-100$ in eiförmigem Köpfchen.

Mehrjährig. Blüht Juni bis Auguft.

Befucher: Fliegen, Falter. Früchte ohne Verbr.--Mittel. Mitteleuropa bis Sibirien.

Potentilla nivalis. - Schnee-Fingerkrant (V'arietät von $P$. caulescens). - Lang feidenhaarige, $10-30 \mathrm{~cm}$ hohe Pllanze. Grundltändige Blätter handförmig geteilt, mit 5-7 eiförmigen, am Grunde verfchmälerten, vorn gezähnten Blättchen. Blüten in lockerer Traube. Kronblätter weif, kürzer als die Kelchblätter.

Mehrjährig. Blüht Juni Juli. Befucher: Bienen, Hummeln. Früchtchen zottig behaart: Windverbreitung.

Felfen, Rafenbänder, Gerölle. Südweft-Alpen, Pyreriäen.

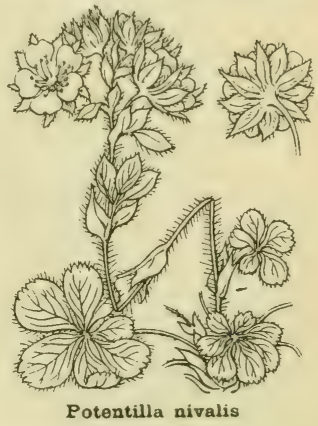

Sorbus Chamaemespilus. - Zwerg-Eberefehe. - Bis $1 \mathrm{~m}$ hoher Strauch mit beiderfeits grünen, kahlen, elliptifchen, vorn gezähnten Blättern. Blüten rofa, in kurzen Trauben. Kronblätter aufrecht, nicht ausgebreitet.

Mehrjährig. Blüht Juni Juli. Befucher: Fliegen, Bienen, Wefpen.

Frucht apfelartig, orangerot, durch Vögel verbreitet.

Felfen, zwilchen Felsblöcken bis $2300 \mathrm{~m}$.

Alpen, Jura, Vogefen; Auvergne, Pyrenäen.

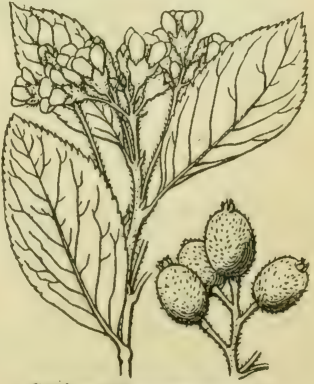

Sorbus Ghamæmespilus 
Geum (Sieversia) reptans. - Tafel 47. - Der Wurzelftrck bildet oberirdifche $10-30 \mathrm{~cm}$ lange, zarte, beblätterte Auslïufer. Stengel aufrecht 5-20) (mo hoch. Grundfändige Blätter tief fiederlchnittig, mit wezühnten Abfchnitten. Blüten einzeln, nit meift lechs gelben Kronblättern. Die Früchtchen bilden wie diejenigen der Anemonen ein federiges Köpfchen.

Mehrjährig.

Bläht Juni bis Auguft.

Befucher: vermutlich diefelben wie bei folgender Art. Früchtchen mit verlängertem, federförnnigem Griffel: Windverbreitung.

Spalten fchattiger Felfen, feuchter Gefteinsfchutt, Moränen 2100-3400 m.

Alpen, Karpathen.

Geum montauum.

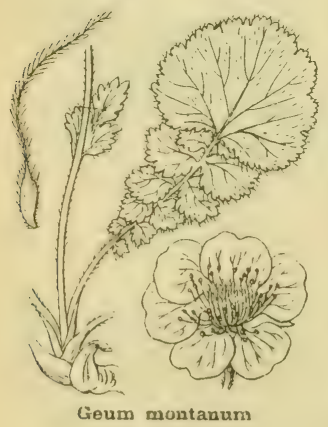

Geum montanum
- Berg-Nelkenwur\%. - Unterfcheidet fich von voriger durch das Fehlen von Ausläufern und durch das Endblättchen, das viel gröfer als die parrigen Blättchen und kaum gelappt ilt.

Mehrjährig.

Blüht Juli bis Auguft.

Befucher: vorwiegend Fliegen, daneben auch Käfer, Bienen, Falter.

Früchtchen mit Haarfchweif (fiehe Skizze links oben): Windverbreitung.

Matten, felfige Weiden, Rafenbänder. $1600-2700 \mathrm{~m}$.

Alpen, Auvergne, Pyrenäen, Karpathen. 
Felsen, Gesteinsschutt, Gerölle 2100-3400 Meter.

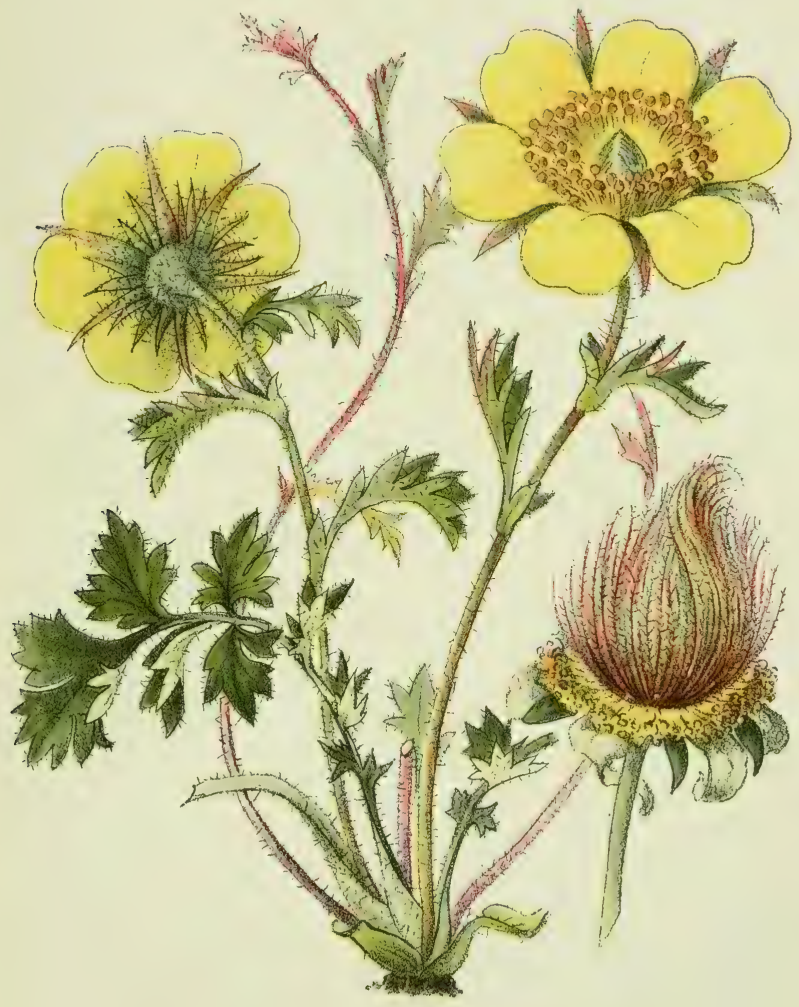

Geum reptans.

Benoite rampante.
Kriechende Nelkenwurz.

Creeping Avens. 
Flusskies, Gerölle 700-2200 Meter.

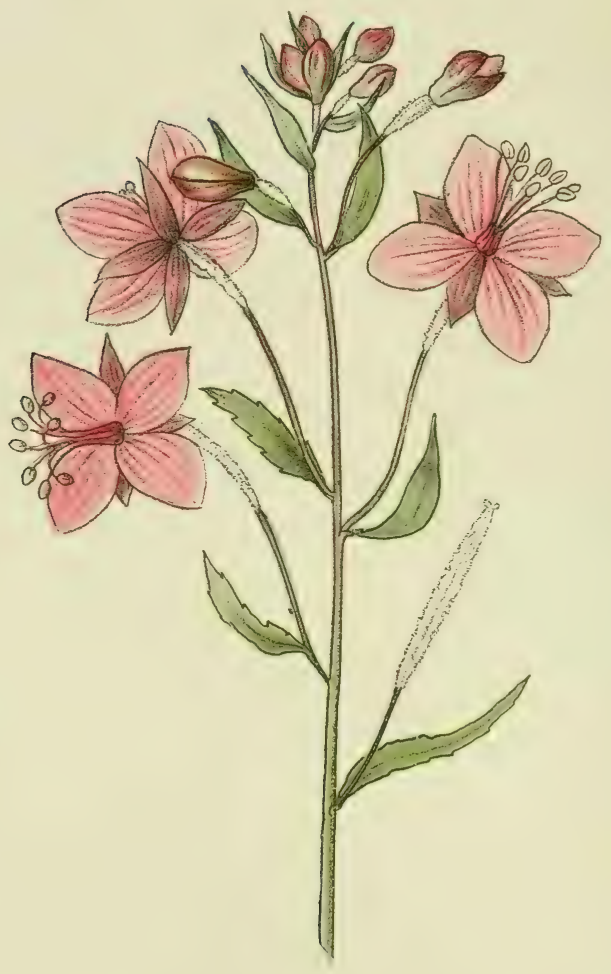

Epilobium Fleischeri. Epilobe de Fleischer.

Fleischers Weidenröschen. Fleischer's Willow-herb. 
Epilobium Fleischeri. - Tafel 48. - Krautpflanze mit unterwärts etwas verholzten, $10-40 \mathrm{~cm}$ hohen, fchwach verzweigten Stengeln. Alte vierkantig, ftark beblättert. Blätter :3 c'm lang, fchmal. Blüten vierzählig, lang geftielt, zu 5-10 in Trauben. Kelchblitter fchmal, dunkel purpurn, Kronblätter oval, violettrola. Griffel an der Spitze vierteilig.

Mehrjährig.

Blüht Juli bis Auguft.

Befucher: Bienen, Falter.

Samen mit Haarfchopf: Windrerbreitung.

Gerölle, Kies der Gebirgsbäche, fteigt mit diefen oft ins Tal. $700-2200 \mathrm{~m}$.

Alpen, Jura.

Circaea alpina. - Alpen-Hexenkraut. - Zarte, 5 bis $15 \mathrm{~cm}$ hohe Pflanze, mit langen, unterirdifch kriechenden Stengeln. Oberirdifcher Stengel aufrecht, kahl, mit zwei bis drei Paaren dünner, durchf'cheinender, hellgrüner Blätter, die herzförmig, zugefpitzt und grob gezähnt find. Blüten weiß, in aufrechter Traube. Kelchblätter fchmal zurückgefchlagen. Kronblätter zweilappig. Zwei lange Staubgefäßse.

Mehrjährige Schattenpflanze. Blüht Juni bis Juli.

Befucher: Schwebefliegen. Früchte borftig, häkelnd,

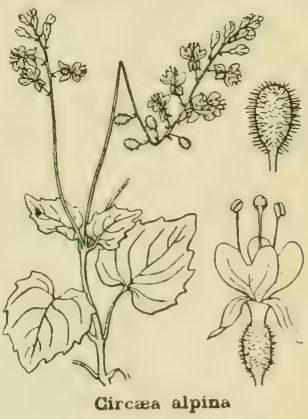
durch Säugetiere verbreitet.

Wälder bis $2000 \mathrm{~m}$.

Mitteleuropa, Alpen, Jura, Vogefen etc., nördliches Afien und Amerika, aber nicht in der polaren Zone. 
Die Saxifragaceen find durch ihre fünfzähligen Blüten mit zweigriffligem Fruchtknoten ausgezeichnet, der bei der Reife zwifchen den Griffeln mit eincm Loch auffpringt. An den Blattzïhnen finden fich häufig fogen. Wafferfpalten (vgl. I. Teil Seite 3(j), die zuweilen durch Kalkablagerungen verftopft find.

Saxifraga cuneifolia. - Tufel $49 \mathrm{~A}$. - Locker rafig mit offenen Blattroletten. Blätter lederartig, kahl, am Grunde keilförmig verl'chmïlert, vorn gezähnt. Blähende Stengel aufrecht, verzweigt, wenig beblïltert, drülenhaarig. Blüten in lockeren Trauben. Kronblätter weifs nit gelben Punkten.

Mehrjährig. Blüht Juni Juli. Befucher: Schwebefliegen. Samen mit Hervorragungen: Windverbreitung.

Alpen, Cievennen, Pyrenäen; Karpathen.

Saxifraga bryoïles. - Tafcl $49 \mathrm{~B}$. - Rafenbildende Pflanze mit vielen nicht blühenden, dicht kugeligen Blattrofetten. Blätter fchmal, nur $\check{-}-7 \mathrm{~mm}$ lang, lebhaft grün, nicht oder nur wenig behaart. Blühende Triebe $3-8 \mathrm{~cm}$ hoch, aufrecht, mit kleinen, anliegenden Blättern. Blüten einzeln, weifggelh.

Mehrjährig. Blüht Juli bis Auguft. Befucher: Fliegen. Samenoberfläche durch Hervorragungen vergröfert:

Windverbreitung. Auf Urgeftein.

Pyrenäen, Auvergne, Alpen, Riefengebirge, Karpathen.

Saxifraga aspera. - Rauher Steinbrech. - Mit voriger

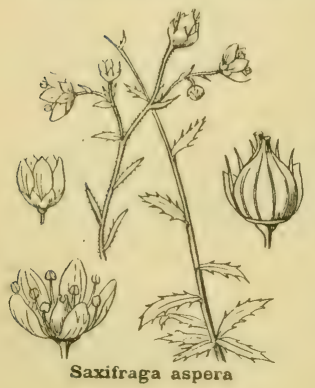
nächlt verwandt. Stengel fteif, beblättert, $8-15 \mathrm{~cm}$ hoch, mit lelsmalen, lpitzen, Iteifhaarigen Blättern. Blüten zu 1-5, gelblich weißs. Kronblätter am Grunde mit gelben Punkten.

Mehrjährig. Blüht Juli bis Auguft. Befucher: Schwebefliegen.

Samenoberfläche durch Hervorragungen vergrößsert: Windverbr. Feuchte Fellen in der Nähe von Bächen, befonders auf Urgeftein. $1000-3000 \mathrm{~m}$. Alpen, Pyrenäen, Banat. 
Schattige, feuchte Felsen des Bergwaldes.
Steinige IVeiden, Felsblöche 2000-4000 Meter.

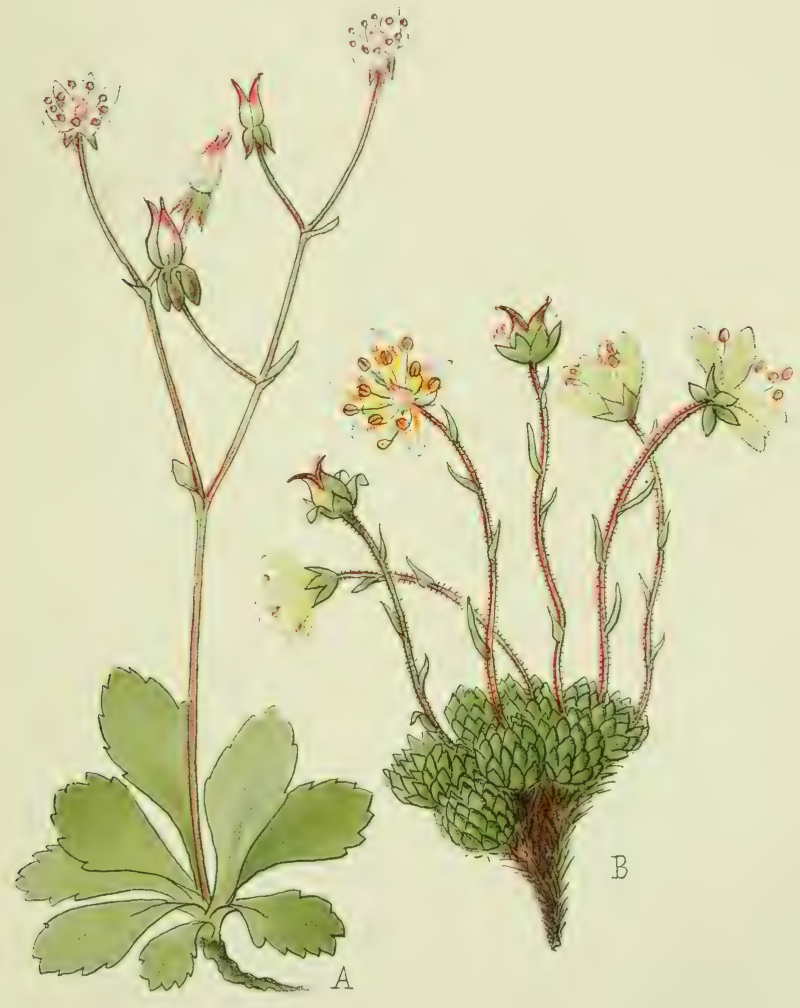

\section{1. - Saxifraga cuneifolia.}

Keilblättriger Steinbrech. Saxifrage à feuilles en coin. Wedge-leaved Stonebreak.
B. - Saxifraga bryoides.

Birnmoos-artiger Steinbrech. Saxifrage mousse. Mosslike Saxifrage. 
Feuchte Bergwälder 800-2200 Meter.

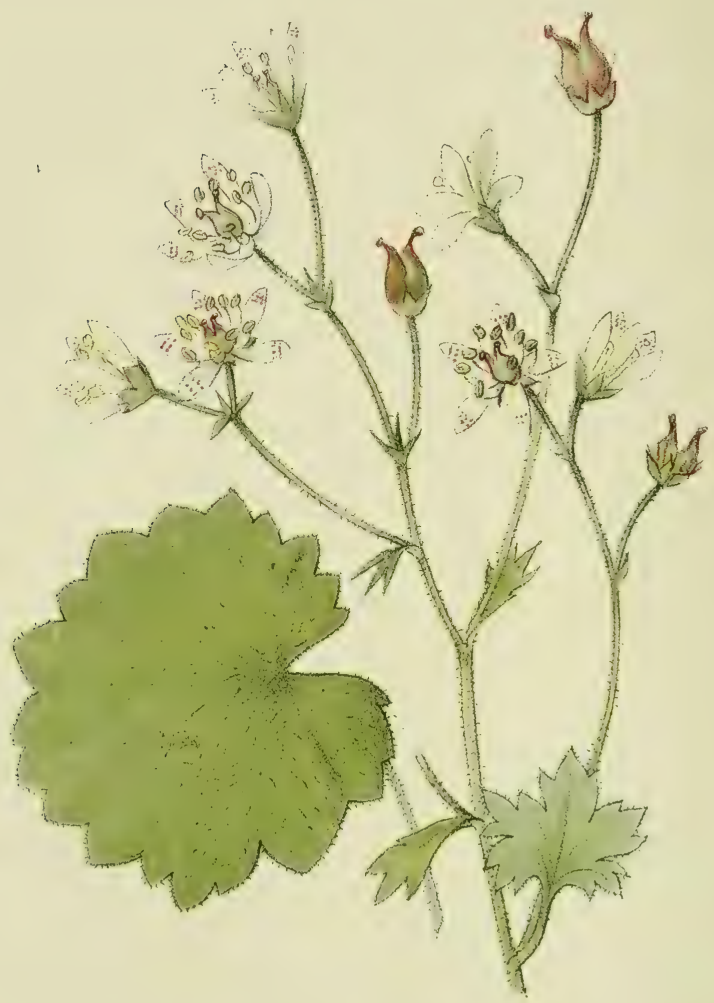

Saxifraga rotundifolia.

Rundblättriger Steinbrech. Saxifragre à feuilles rondes. Round-leaved Stonebreak. 
Saxifraga rotundifolia. - Tafel 50. - Stengel 10 bis (j) $\mathrm{cm}$ hoch, aufrecht, etwas behaart und oberwärts verzweigt; trägt einige lang geftielte, runde oder nierenförmige, gezähnte und lang behaarte Blätter. Blüten klein, in lockerer Traube. Kronblätter weif;, rot oder gelb punktiert.

Mehrjährig. Blüht Juni bis Auguft.

Befucher: Schwebefliegen.

Samen mit Hervorragungen: Windverbreitung.

Alpen, Jura, Auvergne, Cevennen, Pyrenäen; Appennin, Gebirge von Sizilien, Balkanhalbinfel, bis Kaukafus.

Saxifraga stellaris. - Stern-Steinbrech. $-5-15 \mathrm{~cm}$ hoch; Blätter in ausgebreiteter Rolette, lang oval, glänzend, am Grunde verfchmälert, grob gezähnt. Blüten in lockerer Traube. Kronblätter fchmal, ausgebreitet, weifs mit je zwei gelben Punkten.

Mehrjährig. Blüht Juli Auguft. Befucher und Samenverbreitung wie bei vorigem. Bachufer, feuchte Felfen. $1200-3000 \mathrm{~m}$.

Alpen, Auvergne, Gevennen, Pyrenäen; Karpathen, nordpolare Länder, Ural, Altai, Himalaya.

\section{Saxifraga androsacea. - Mannsfchild-Steinbrech. -} Rofettenbildende, $2-10 \mathrm{~cm}$ hohe Pflanze. Blätter lanzettlich, weich. Blütenftiele drüfig behaart, mit ein bis drei milchweifaen Blüten.

Mehrjährig. Blüht Juli Auguft. Befucher: Fliegen.

Samen fehr klein: Windverbr. Feuchte Fellen, Tonboden. $1600-3000 \mathrm{~m}$.

Alpen, Auvergne, Pyrenäen; Karpathen, polares Europa, Ural, Altai.

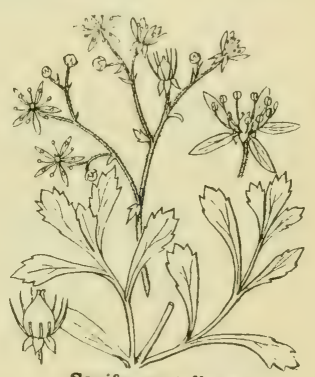

Saxifraga stellaris

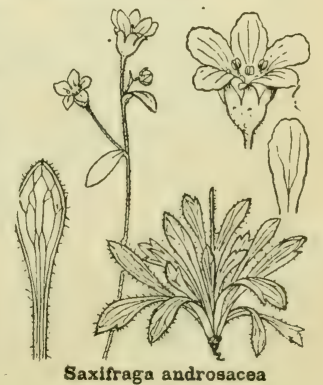

Saxifraga androsacea

G. Senn, Alpenflora. 
Saxifraga aizoïles. - Tafel $51 \mathrm{~A}$. - Verzweigte, $15 \mathrm{~cm}$ holie, lockere Rafen bildende Pflanze. Stengel unten ftark, oben lchwach beblïttert. Blätter fchmal, dickfleilchig, faft walzenförmig, l'pitz, ähnlich denen des Mauerpfeffer's, Sechum acie. Blüten hellgelb, mit orangeroten Punkten oder dunkelgelb mit rotbraunen Punkten.

Mehrjährig. Blüht Juli Auguft.

Befucher: vorwiegend Fliegen, dancben auch Bienen und Falter.

Samenoberfläche durch Hervorragungen vergrößsert:

Windverbreitung.

Steigt oft mit den Bächen in die Ebene hinab.

Alpen, Jura, Pyrenäen; Karpathen, nordpolare Länder.

Saxifraga exarata. - Tufel $51 \mathrm{~B}$. - Bulchige, rafenbildende Pflanze mit unterwïrts dicht ftehenden Blättern. Diefe am Grunde verfchmälert, ungeteilt, oder vorn mit drei ungleichen, fpitzen Zipfeln. Blütenftiele drüfig hehaart. Blüten klein, in lockerer 3-10blütiger Traube. Kronblätler weifsgelb.

Mehrjährig. Blüht Juni Juli.

Befucher: Fliegen.

Samen fehr klein: Windverbreitung.

Meift nur auf Urgeftein.

Alpen, Auvergne, Pyrenïen, Kaukafus, nordpolare Länder.

Saxifraga muscoides. - Moosartiger Steinbrech. -

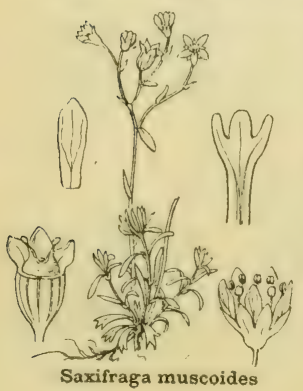

Nur 2-12 cm hohe, der vorigen ähnliche Pflanze, mit zahlreichen Blattroletten, die runde Polfter bilden. Sonft wie voriger, nur alles etwas kleiner. Blüten gelblich.

Mehrjährig.

Blüht Juni Juli

Befucher: Fliegen.

Samen fehr klein: Windverbreitung. Felfen, Gerölle. $1600-3500 \mathrm{~m}$. AJpen, Jura, Pyrenäen, Hohe Sudeten. 


\section{$-51$}

Nasse Felsen, Gerölle r500-3100 Meter.

Felsen

bis 3000 Meter.

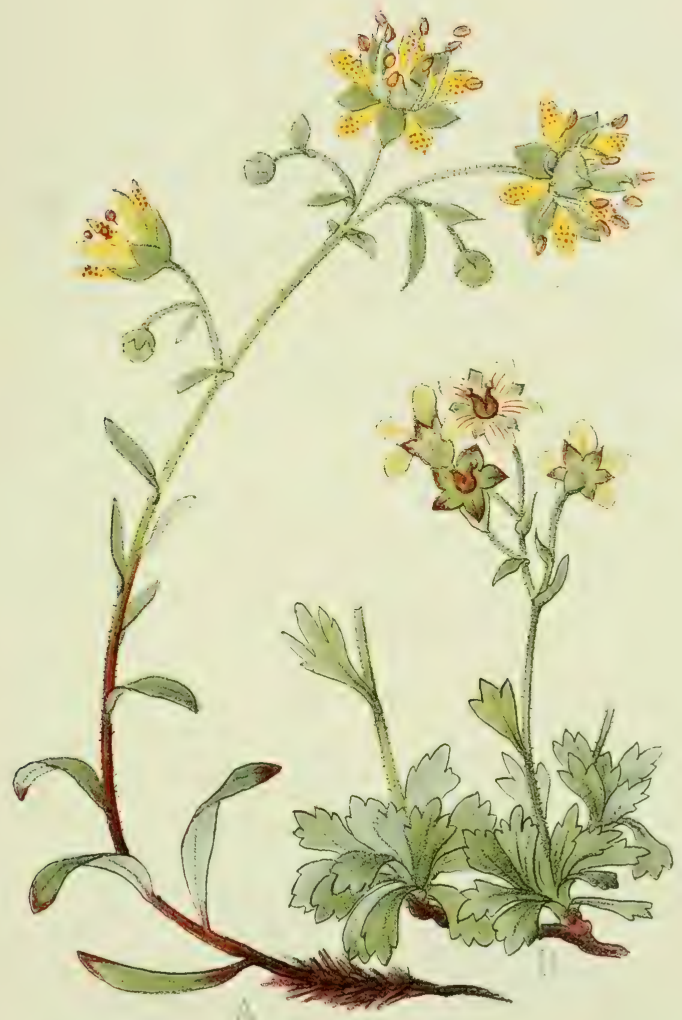

A. - Saxifraga aizoides.

Mauerpfeffer-Steinbrech.

Saxifrage pain doiseau.

Stone-crop Saxifrage.
B. - Saxifraga exarata. Gefurchter Steinbrech. Saxifrage sillonnée. Furrowed Stonebreak. 
Felsen, Gerölle

Felsen

I $500-3400$ Meter.

I 100-3000 Meter.

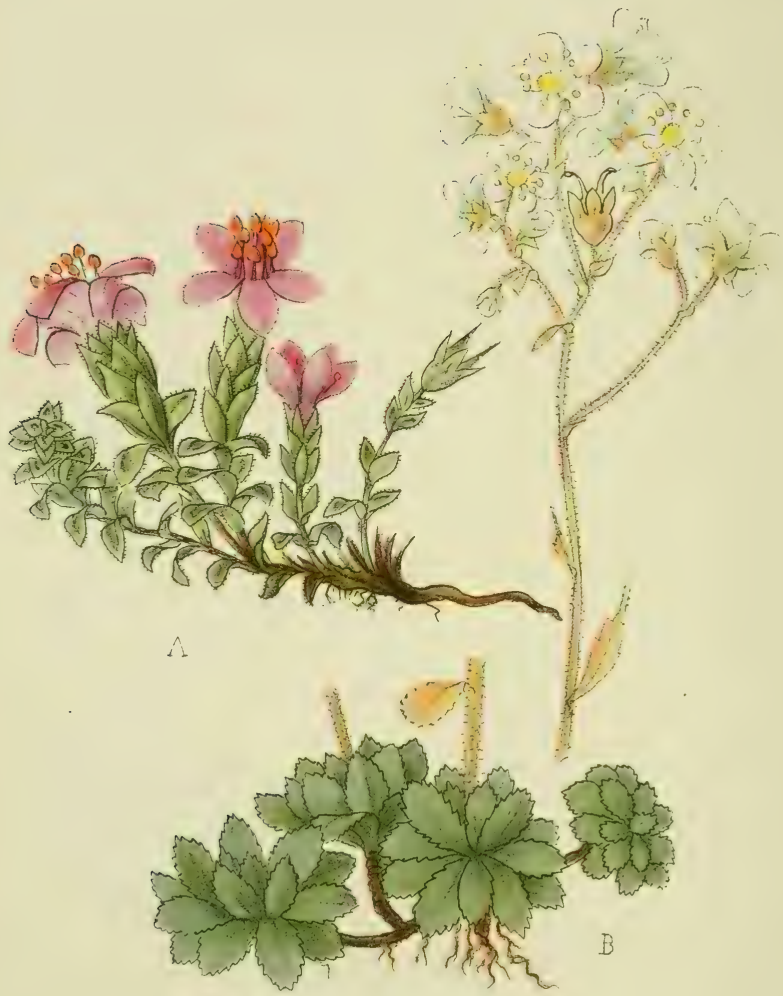

A. - Saxifraga oppositifolia. Gegenblättriger Steinbrech. Saxifrage à feuilles offosies. Opposite-leaved Saxifrage.
13. - Saxifraga Aizoon. Immergrüner Steinbrech. Saxifrage toujours verte. Evergren Stonebreak. 
Saxifraga oppositifolia. - Tafel 52 A. - Niederliegend, reich verzweigt, teppichbildend. Stengel dicht beblättert, mit dunkelgrünen, derben, ungeftielten, eiförmigen, gegenftändigen, am Rande behaarten Blättern, die an der Spitze ein Kalklichüppchen tragen. Abgreltorbene Blätter bleiben am Stengel. Blüten einzeln, wein- oder violettrot.

Mehrjährig. Blüht Mai bis Auguft.

Befucher: Fliegen, Falter.

Samen mit Hervorragungen: Windverbreitung.

Steigt oft mit den Bïchen ins Tal (z. B. am Boclenfee). Alpen, Jura, Auvergne, Pyrenäen; Karpathen, nordpolare Länder, Ural, Altai, Himalaya.

\section{Saxifraga biflora. - Zweibliitiger Steinbrech. -} Dem vorigen ähnlich, aber weniger gedrungen. Blüten zu zweien.

Mehrjährig.

Blüht Juli Auguft.

Befucher: Fliegen, Falter.

Samen ohne Verbr.-Mittel.

Felfen, Gefteinslchutt.

2000-2900 m.

Pyrenäen, Alpen, Transfilvanifche Alpen (zwifchen Siebenbürgen und $\mathrm{Ru}-$ mänien).

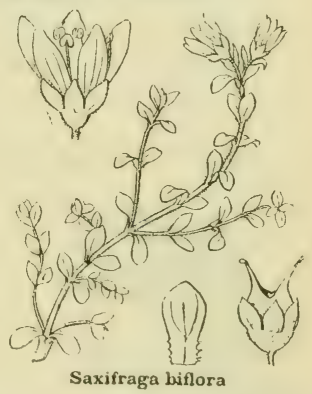

Saxifraga Aizoon. - Tafel $52 \mathrm{~B}$. - Grundftändige Blätter in regelmäßigen Roletten, fpatelförmig, $1-5 \mathrm{~cm}$ lang, lederartig, gezïhnt. Auf jedem Zahn ein Kalkfehüppchen. Stengel $10-30 \mathrm{~cm}$ hoch, aufrecht, nur oberwärts verzweigt, fchwach drüfig behaart. Blüten in kurzer zufammengefetzter Traube, mit 1-2-blütigen Zweigen. Kronblätter gelhlichweif, zuweilen mit roten Punkten.

Mehrjährig. Blüht Juni bis Augult.

Befucher: Schwebefliegen, Bienen.

Samen mit Hervorragungen: Windverbreitung.

Alpen, Jura, Auvergne, Gevennen, Pyrenäen; Vogefen, Schwarzwald, fchwäbifche Alp etc., Karpathen, Kaukafus, polares Europa. 
Die Crassulaceen oder Fettpflanzen tragen ihren Namen wegen der fleifchigen Konfiftenz ihrer stengel und Blätter. Ihre Blüten find durch den Befitz mehrerer in Kreile angeordneter Fruchtknoten mit einem kurzen Griffel ausgezeichnet.

Sempervivum arachnoidenm. - Tafel 53. - Rofettenhildend. Blätter lanzettlich, dick, fleifchig, fpitz, gegenleitig durch fpinnwebeartig ausgelpannte, weifse Haare niteinander verbunden. Blütentragende Stengel $5-10 \mathrm{~cm}$ hoch, rot, fleifchig, mit kleinen Blättern. Bläten lebhaft rot, in wenigblütigen Trauben. Mindeltens 10 Kelch- und Kronblätter; doppelt fo viele Staubgefäfe.

Mehrjährig. Blüht Juli Auguft.

Befucher: Fliegen, Bienen, Falter.

Samen fehr klein: Windverbreitung.

Sonnige Urgefteinsfelfen. $1300-3000 \mathrm{~m}$.

Alpen, Auvergne, Gevemnen, Pyrenäen.

Sempervivum tectorum. - Dach-Hauswurz. - Blatt-

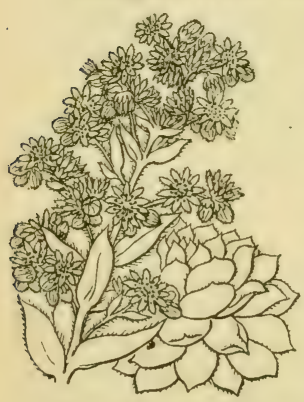

roletten 5-8 cm grof, oft in grofer Zahl zu Kiffen vereinigt. Blätter länglich oval, dick, aber flach; beiderfeits kahl, am Rande hewimpert, lpitz, graugrün und am Vorderende oft braunrot. Blühende Stengel kräftig, 20 bis $45 \mathrm{~cm}$ hoch, beblättert und drüfig behaart. Blütenftand ftark verzweigt, reichblütig. Blüten hellrofa, weit geöffnet.

Mehrjährig. Bläht Juli Auguft. Befucher: Bienen, Hummeln, Falter. Samen fehr klein: Windverbreitung. Trockene, fonnige Felfen, bis $2400 \mathrm{~m}$. Oft auf Dächern kultiviert.

Alpen, Jura, Vogefen, Auvergne, Cevennen, Pyrenäen. 
Sonnige Felsen r300-3000 Meter.

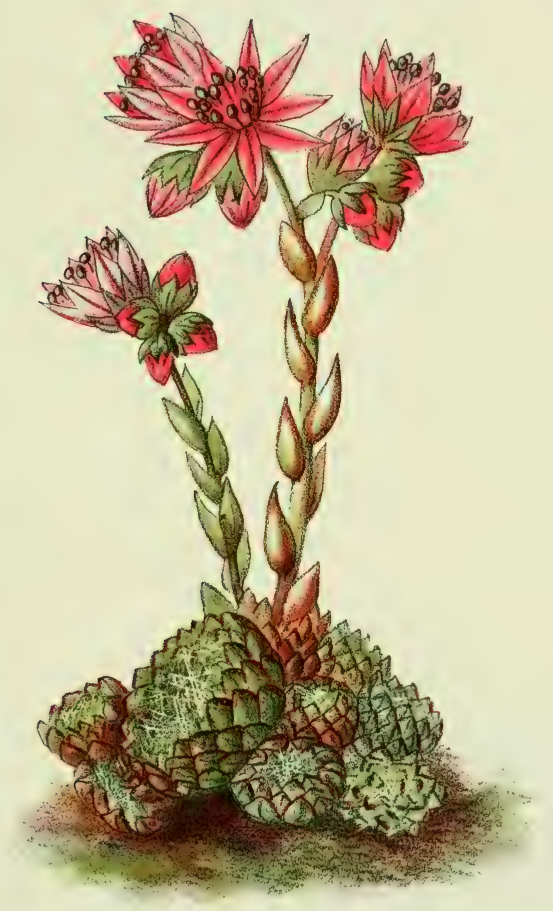

Sempervivum arachnoideum. Joubarbe toile d'araignée.
Spinnwebe-llauswurz.

Cobweb Houseleek. 
Sonnige Felsen 1200-2800 Meter.

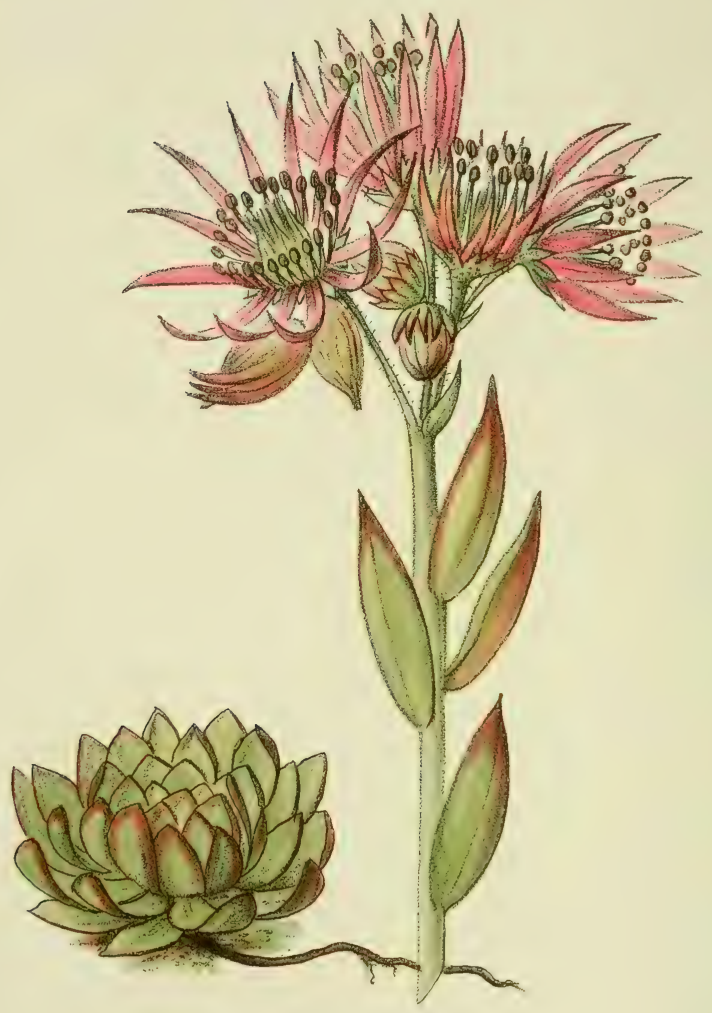

Sempervivum montanum. Joubarbe des montagnes.

Berg-Hauswurz. Mountain Houseleek. 
Sempervivum montanum. - Tafel 54. - Blattroletten bis $4 \mathrm{~cm}$ grof. Blätter faft walzenförmig, ftumpf. Haare kurz, drülentragend, nie miteinander verflochten. Blüten leuchtend rot, mit mehr als zehn Kelch- und Kronblättern und doppelt fo vielen Staubgefäßsen.

Mehrjährig.

Blüht Juli bis Auguft.

Befucher: Bienen, Falter.

Samen klein: Windverbreitung.

Sonnige Felfen.

1200 -2800 m, fteigt zuweilen bis $600 \mathrm{~m}$ hinab.

Pyrenäen, Alpen, Karpathen, Kaukafus.

Sedum Rhodiola (roseum). - Rofenwurz. - Pflanze $10-20 \mathrm{~cm}$ hoch, mit mehreren aufrechten, kräftigen, dicht beblätterten Stengeln. Blätter flach, lanzettlich, mit fpitzen Zähnen. Blüten rötlich, am Ende der Triebe in kurzer, dichter Traube, vierzählig: mit je vier Kelch- und Kronblättern, acht Staubgefären und vier Stempeln. Oft nur Staubgefäß3e oder nur Stempel in einer Blüte.

Mehrjährig.

Blüht Juli bis Auguft.

Befucher: Fliegen, Ameilen.

Samen klein, flach: Wind-

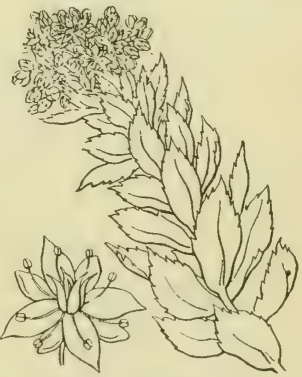

Sedum Rhodiola verbreitung.

Trockener, fteiniger Boden, Felfen, bis über $2000 \mathrm{~m}$.

Pyrenäen, Alpen, Vogefen, Karpathen, nordpolare Länder, Ural, Altai, Himalaya. 
Die Umbelliferen oder Doldengewächfe verdanken ilnren Namen der Anordnung ihrer Blüten, deren Stiele alle aus einem Punkte des Stengels entfpringen: Dolde, Umbella. Neiltens trägt jeder Doldenzweig wieder eine Dolde; alle zulammen bilden einen breiten Schirm dichtgedrängter Blüten. Diefelben befitzen eigentlich nur die gefïrbten Kronblätter, während der Kelch faft ganz verfchwunden ift; aufserdem fünf Staubgefäfse und einen zweiteiligen Fruchtknoten.

Erynginm alpinum. - Tafel 5.5. - Diftelartige, 30 bis $70 \mathrm{~cm}$ hohe Pflanze mit lichwarlı verzweigtem Stengel. Grundftändige Blätter eiförmig, relativ weich, jedoch lcharf gezähnt. Stengelftändige Blätter lederartig, bläulichgrün, handförmig drei- bis fünflpaltig, mit ftachellpitzisen Zäbnen. Blüten weil3, in 1-3 einfachen, kopfö̈migen, langgeftielten Dolden, die von einem abftehenden Kragen von 10-20 ftahlblauen, feinborftigen Hüllblättern umgeben find.

Mehrjährig. Blüht Juli bis Augult. Befucher?

Früchte flach: Windverbreitung.

Tiefgründige Mähwieleı, Alpenrofen- und Erlengebüfche, Rafenbänder, zerftreut.

Alpen, Bosnien, Montenegro.

Athamanta cretensis. - Kretifche Angenwur\%. -

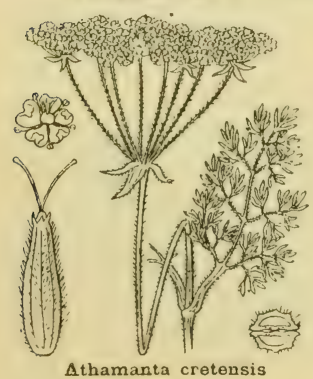

Graubehaarte, $10-40 \mathrm{~cm}$ hohe Pflanze mit feingerilltem Stengel, der meift nur eine einzige, zufammengeletzte Dolde trägt. Blätter dreifach fiederteilig, mit fehmalen Abfchnitten. Am Grunde der grofien Dolde eine Hülle von z.vei bis drei hinfälligen Blättchen; an den kleinen Dolden vier bis acht Hüllblättchen. Blüten weif.

Mehrjährig.

Blüht Mai bis Juli. Befucher? Samen ohne Verbreitungsmittel. Felfen, Felsfchutt, meift auf Kalk.

1500-2600 m.

Pyrenäen, Cevennen, Alpen, Jura, Dalmatien, aber nicht auf Kreta!! 
Mähwiesen, Gebüsche, Grasbänder der alpinen Region.

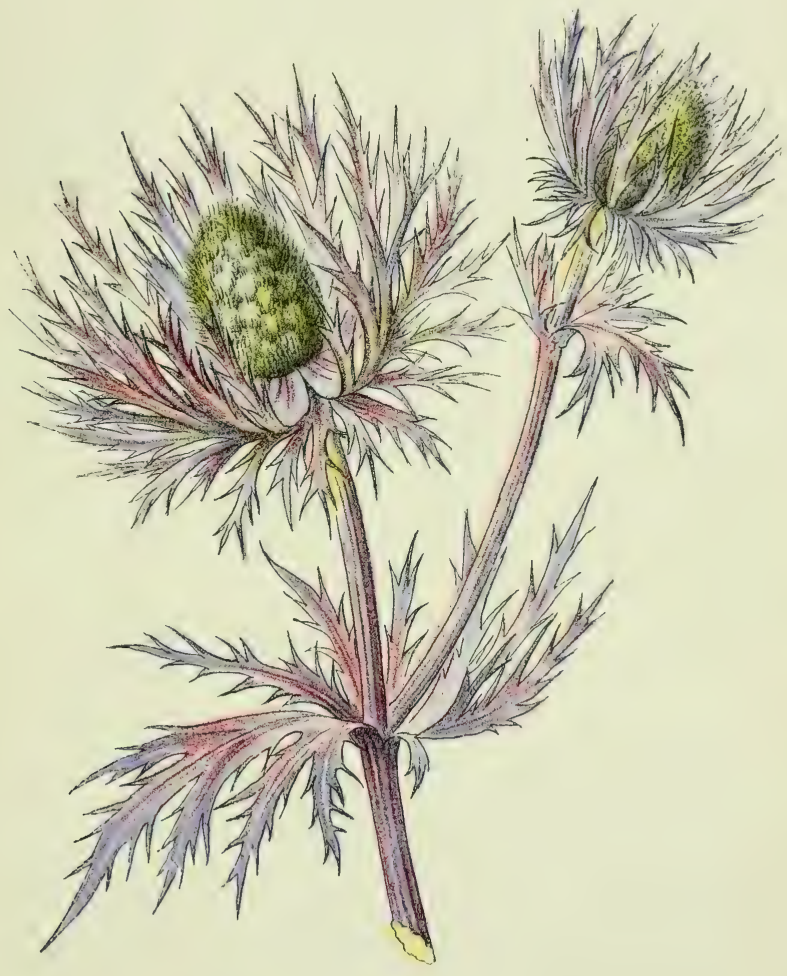

Eryngium alpinum.

Panicaut des Alpes, Chardon bleu.
Alpen-Mannstreu. Alpine Eryngo. 
Mähwiesen 1000-2600 Meter.

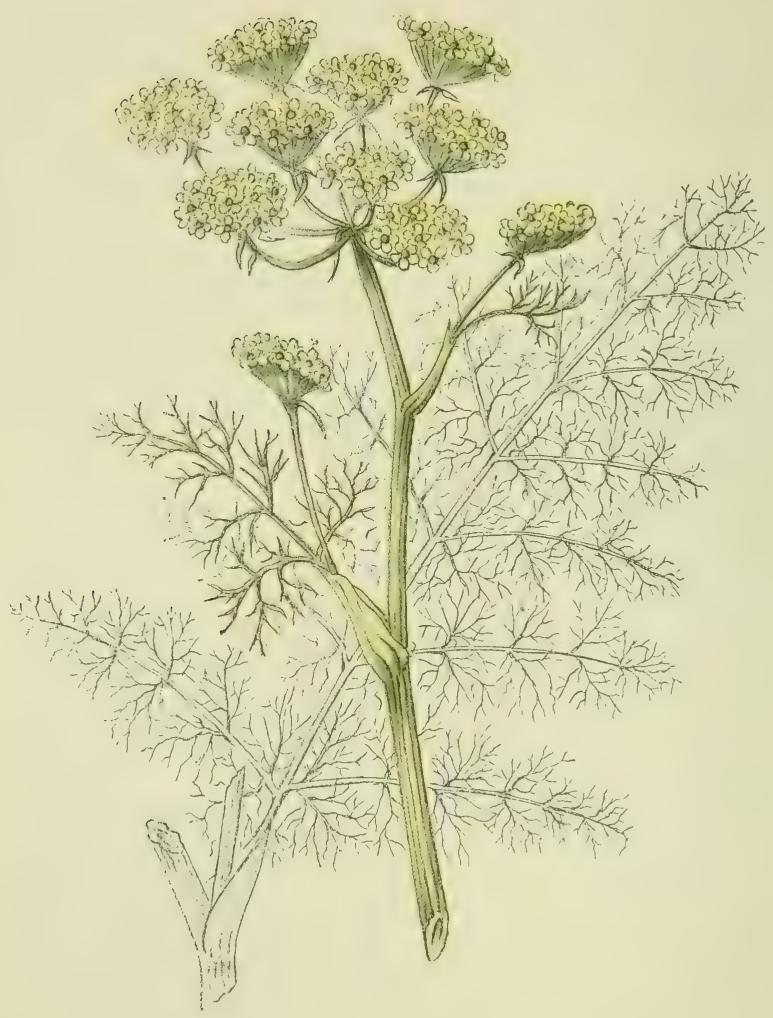

IMeum athamanticum.

Bärenwurz.

Fenouil des Alpes. 
Meum athamanticum. - Tafel 56. - Unbehaart, 20 bis $50 \mathrm{~cm}$ hoch. Stengel gerillt, lehwach verzweigt. Blätter dreifach fiederteilig mit l'chnalen, dunkelgrünen Ablchnitten. An Grunde der grofsen Dolde nur ein, an den kleinen trei bis acht fchmale Hüllblättchen. Blüten weißs.

Mehrjährige, ftark aromatifche Pflanze.

Blüht Juli bis Auguft.

Befucher?

Früchtchen ftark gerippt: Windverbreitung.

Mähwiefen, Weiden, 1000-2600 m.

Alpen, Jura, Vogefen, Auvergne, Cevennen, Pyrenäen; in Deutfchland zerftreut.

Menm (Ligusticum) Mutellina. - Mutteru. - Stengel gerillt, einfach oder fchwach verzweigt. Wenige grundftändige, mit der Bafis den Stengel umfaffende, dreifach fiederteilige Blätter mit unregelmäßsigen, lipitzen Abfichnitten. Blüten weifs oder rola, in zulammengefetzter Dolde. Nur am Grunde der kleinen Dolden drei bis acht Hüllblätter.

Mehrjährige, vorzïgliche Alpen-Futterpflanze.

Blüht Juni bis Auguft.

Befucher: Fliegen, Bienen,

Schmetterlinge.

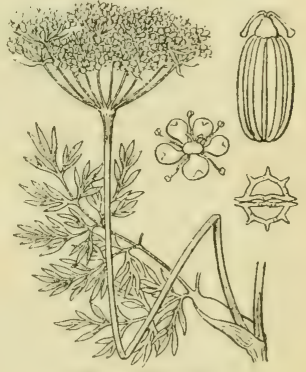

Moun Mutellina

Früchtchen gerippt: Windyerbreitung.

Mähwiefen, magere Weiden, Rafenbänder.

$1300-2700 \mathrm{~m}$.

Alpen, Karpathen. 
Buplenrum longifolium. - T'afel 5\%. - Stengel 30 his $60 \mathrm{~cm}$ hoch, aufrecht, oberwärts fchwach verzweigt, gleichmäßsig aber locker beblättert. Blätter lang eiförmig, ungeteilt. Am Grunde der grofen und der kleinen Dolden fünf bis acht kleine, eiförmige Hüllblätter von weclłlelnder Geftalt und Farbe. Blüten gelb.

Mehrjährig.

Blüht Juli bis Auguft.

Befucher: wahrfcheinlich Fliegen.

Früchte ohne Verbreitungsmittel.

Waldlichtungen, fteinige Weiden, Felfen, Hügel.

Bis $1500 \mathrm{~m}$.

Mitteleuropa, Alpen.

\section{Bupleurum stellatum. - Stern-Hafenohr. - Stengel}

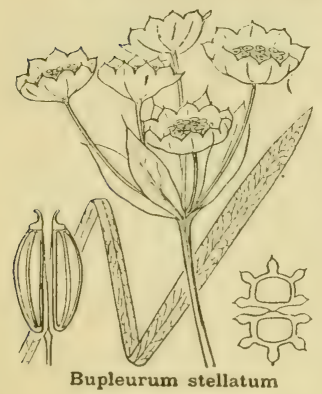

$10-40 \mathrm{~cm}$ hoch, nicht oder wenig verzweigt, bläulichgrün. Blätter f́chmal, bandförmig, fpitz. Blüten gelb bis braun, in zulammengefetzter Dolde. Am Grunde der grofen Dolde zwei bis fünf lang ovale, zugefpitzte Hüllblätter. Diejenigen der kleinen Dolden länger als die Blüten, gegenfeitig zu einheitlicher, mehrzipfliger Schale verwachfen.

Mehrjährig.

Blüht Juli bis Auguft.

Befucher: Fliegen.

Früchte mit geflügelten Rippen

(fiehe Skizzen): Windverbreitung.

Trockene Matten, felfige Weiden, Rafenbänder.

$1800-2700 \mathrm{~m}$.

Alpen. 


\section{$-57$}

Lichte Wälder, steinige Weiden bis r 500 Neter.

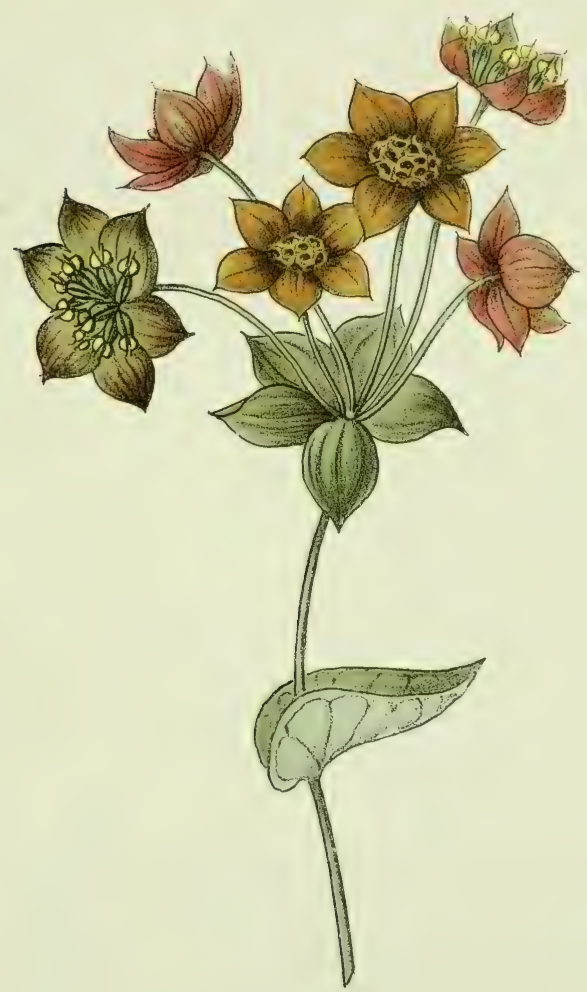

Bupleurum longifolium.

Langblättriges Hasenohr.

Buplève à longues feuilles.

Long leaved Thorowax. 
Magere Wiesen, Gebüsche bis 1900 Meter.

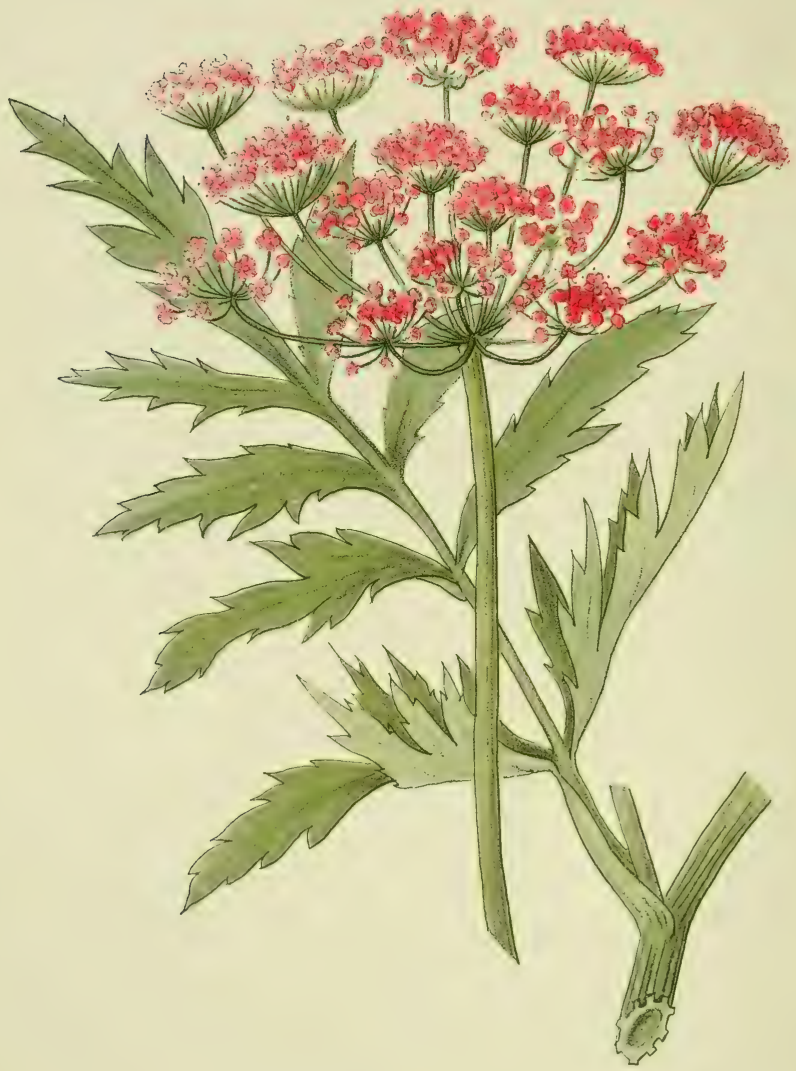

Pimpinella magna.

Grande Pimprenelle, Grand Boucage.
Grosser Bibernell.

Large Pimpinell. 
Pimpinella magna. - Tafel 58. - Stengel dick, gefurcht. Blïtter nur einfach gefiedert; die grundftändigen mit fünf lis neun eiförmigen, grob gezühnten und fpitzen Ablchnitten. Dolden zulammengeletzt. Blüten weifs bis rofa.

Mehrjährig.

Blüht Mai bis Juli.

Befucher : Käfer, l'liegen.

Früchte ohne Verbreitungsmittel.

Magere Wiefen, Gebüfche, Waldlirhtungen, Weiden. Ebene bis $1900 \mathrm{~m}$. Im Tiefland bis $1 \mathrm{~m}$ hoch mit weißsen Blüten, in den Alpen nur 30 cm hoch mit roten Blïten.

Mittel- und Wefteuropa.

Myrrhis odorata. - Duftende Siibdolde. - jo his $150 \mathrm{~cm}$ hoch, lang behaart. Stengel dick, gefurcht. Blätter grof, im Umrifo dreieckig, weich, zwei- bis dreifach fiederlchnittig. Ablchnitte fpitz. Blüten weils, in zulammengeletzter Dolde. Am Grunde der grofen Dolde keine Hüllblätter, am Grunde der hleinen fïnf bis acht fpitzeiförmige, heruntergefchlagene Blättchen.

Mehrjährige, nach Anis duftende Pflanze.

Blïht Juni bis Juli.

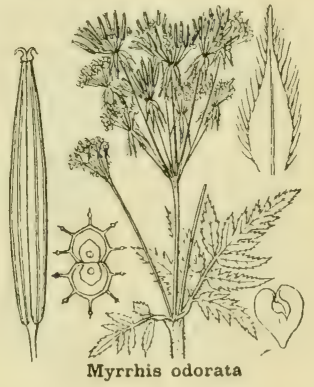

Befucher: Käfer, Fliegen.

Früchte mit geflügelten Rippen (fiehe Skizzen links): Windverbreitung.

Kühle Wiefen, Waldränder, Bachufer.

Buchenregion bis $2400 \mathrm{~m}$.

Mitteleuropa, Alpen, Jura, Vogefen, Auvergne, Cevennen, Pyrenäen, Karpathen, Bosnien, Macedonien, Kaukafus, Chile. 
Astrantia major. - Tafel 59. - Unbehaarte, 20 bis 50) ('m hohe Pflanze. Stengel l'chwach verzweigt, mit gegenftändigen (einander gegenüber auf gleicher Höhe entlpringenden) X̃ften. Blätter glänzend; grundftändige lang geftielt, lıandförmig drei bis fiebenlpaltig, unregelmäßrig gezähnt; ftengelftïndige faft ungeftielt. Blüten in einfacher Dolde mit zahlreichen grofen, die Blüten überragenden, lpitzen, rolit angehauchten Hüllblättern mit grünem Ailernetz.

Mehrjährige, gute Futterpflanze.

Blüht Juli bis Auguft.

Befucher: Käfer, Fliegen.

Früchte mit blafigen Schuppen: Windverbreitung.

Magere WViefen, fenchte Felfen, 500-2000 m.

Pyrenäen, Auvergne, Italien, Apen, Jura, falt ganz Mittelenropa, Mittel- und Südrußłand, Montenegro.

\section{Astrantia minor. - Kleine Sterndolde. - Wie}

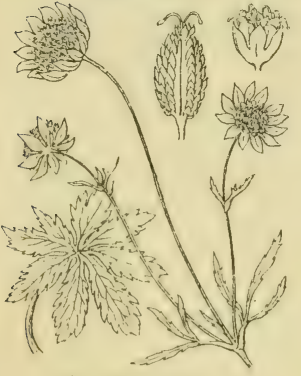

Astrantia minor vorige, aber in allen Teilen kleiner und zarter. Stengel $15-30 \mathrm{~cm}$ hoch, dünn. Stengelitändige Blätter mit fechmalen Zipfeln. Hüllblätter der' Dolden weiß.

Mehrjährig.

Blüht Juli bis Auguft.

Befucher: Fliegen.

Früchte mit blafigen Schuppen (fiehe Skizze): Windverbreitung. Magere, fteinige Weiden. $1000-2300 \mathrm{~m}$. Alpen, Auvergne, Pyrenäen. 
Weiden, magere Wiesen 500-2000 Meter.

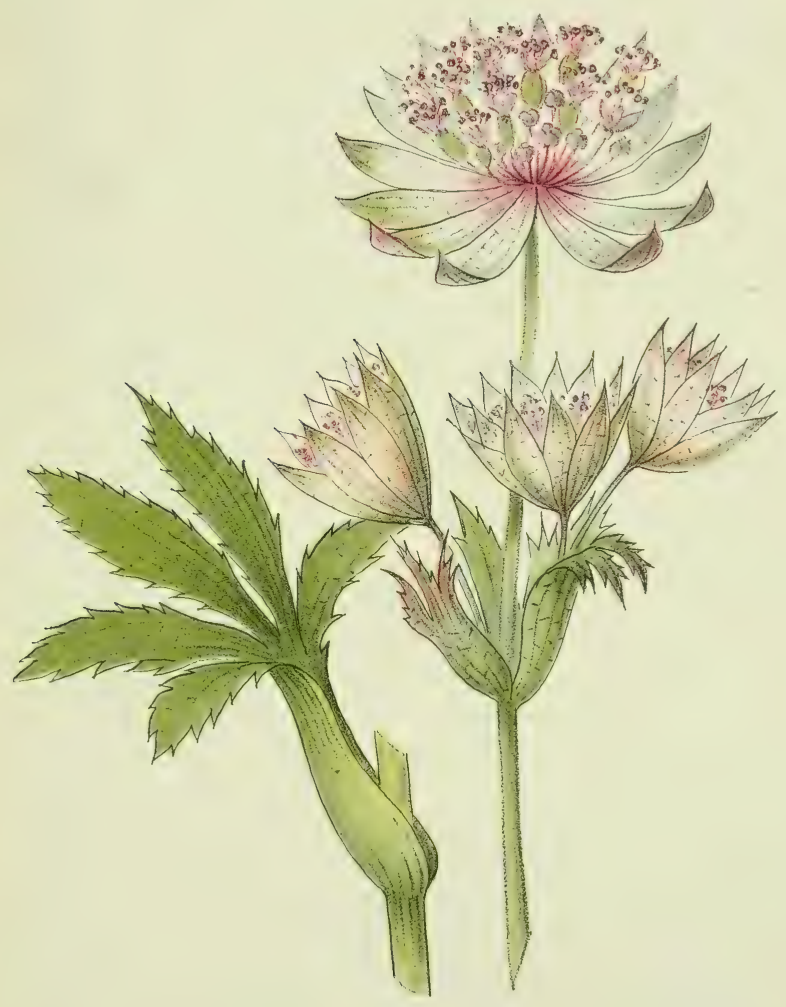

Astrantia major.

Grande astrance, Radiaire.
Grosse Sterndolde.

Greater master-wort. 
Lichte Wälder, an feuchten Felsen bis 2000 Meter.

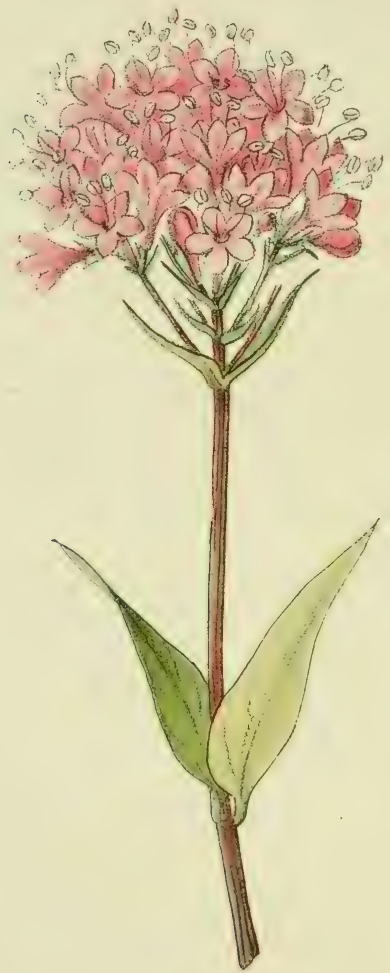

Valeriana montana.

Valériane des montagnes.

Berg-Baldrian.

Mountain Valerian. 
Die Valerianaceen und Dipsaceen lind durch den allgemeinen Blütenbau nahe niteinander verwandt, während ihre an die Compositen (Tafel 62 fit.) erimmemde Köpfchenbildung nicht auf direkter Verwandtlchaft mit jener Familie beruht.

Valeriana montana. - Tafel 60. - P'flanze $20-50 \mathrm{~cm}$ hoch, mit zahlreichen Stengeln. Blätter hellgrün, glänzend, lang" geftielt, on den nicht blühenden Trieben rundicht-ıval, an den blühenden länglich, mit zuweilen gezähntem Rande. Blüten in dichten sträufsen. Blumenkrone hellrot, trichterförınig, mit fünf Zipfeln.

Mehrjärig, mit holzigem, ftark nach Baldrian riechendem Wurzelftock.

Blüht Mai bis Juli.

Befucher: Fliegen.

Früchte mit Haar-Fallfehirm: Windverbreitung.

Waldlichtungen, feuchte Felfen, bis $2000 \mathrm{~m}$.

Südliches und weftliches Mitteleuropa: Alpen, Jura, Pyrenäen.

\section{Cephalaria alpina. - Alpen-Schuppenkopf. - Bis} $1 \mathrm{~m}$ hoch. Stengel hohl, glatt. Blätter flaumig behaart; gefiedert, mit gezähnten, lipitzen Abl'chnitten. Blüten gelb, zu kugeligen Köpfchen vereinigt; diele am Grunde von einem Kranz l'chmaler, f'pitzer Hochblätter umgeben.

Mehrjährig.

Blüht Juni bis Juli.

Befucher: Hummeln.

Früchte ohne Verbreitungsmittel.

Trockene Weiden, Felfen.

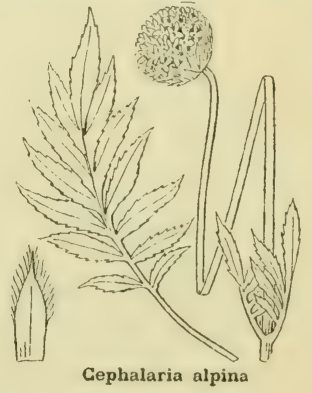

Alpen der Schweiz, Frankreich und Italien, Jura. 
Valeriana saliunca. - Tafel 61. - Kahl, 5-15 cm hoch, mit holzigem, verzweigtem Wurzelftock, der mehrere, iufrechte, gerillte Blütenl'chäfte trägt. Grundftändige Blätter lanzettlich, am Grunde allmählich verlchmälert. Nur ein bis zwei Paare ftengelftändiger, fehr fchmaler Blätter. Blüten hellrot, in kleinen dichten Ständen.

Mehrjährig.

Wurzelftock mit fehr ftarkem Baldriangeruch.

Blüht Juli bis Auguft.

Befucher: vermutlich Fliegen.

Früchte mit Haar-Fallfchirm: Windverbreitung.

Felfen, Gerölle, 1500 bis $2200 \mathrm{~m}$.

Alpen, Pyrenäen.

Die Caprifoliaceen oder Geißblattgewächfe find durch ihren Blütenhau und die gegenftändigen Blätter mit den Valerianareen und Dipsaceen nahe verwandt.

Limnaca borealis.

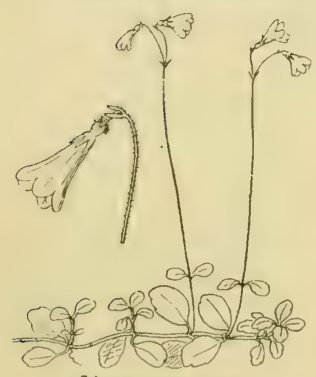

Linnæa borealis
Nordilche Linnse. - Zarte Pflanze mit kriechendem, beblättertem Stengel und aufrechten, dünnen, höchftens $10 \mathrm{~cm}$ hohen Blütenfchäften, die in ihrem unteren Teil ein Paar kurzgeftielter, rundlicher Blätter tragen. Blüten weif bis rolia, glockenförmig, hängend, zu 1-4 auf gemeinfamem Schaft. Krone fünfzipflig; zwei lange und zwei kurze Staubgefäße.

Mehrjährig.

Blüht Juli.

Befucher: Fliegen und Falter.

Klettfrïchte im Fell von Sïugetieren verbreitet.

Im Moos des Alpenwaldes, befonders in Arven- und Lärchenbeftänden.

Savoyen, Wallis, Graubünden, Tirol, Salzburg, Nähren bis Laufitz, nordpolare Länder. 
Felsen, Gerölle i500-2200 Meter.

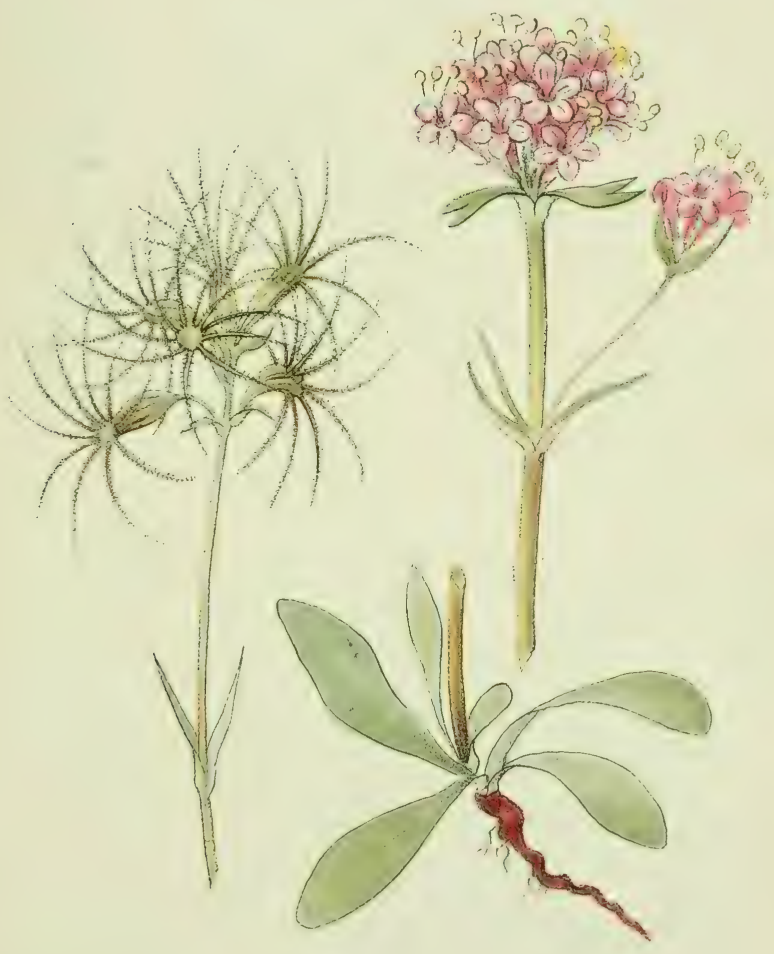

Valeriana saliunca.

Valériane à feuilles de saule.

Weidenblättriger Baldrian.

Willow-leaved Valerian. 
Felsen, Rasenbänder 800-3000 Meter.

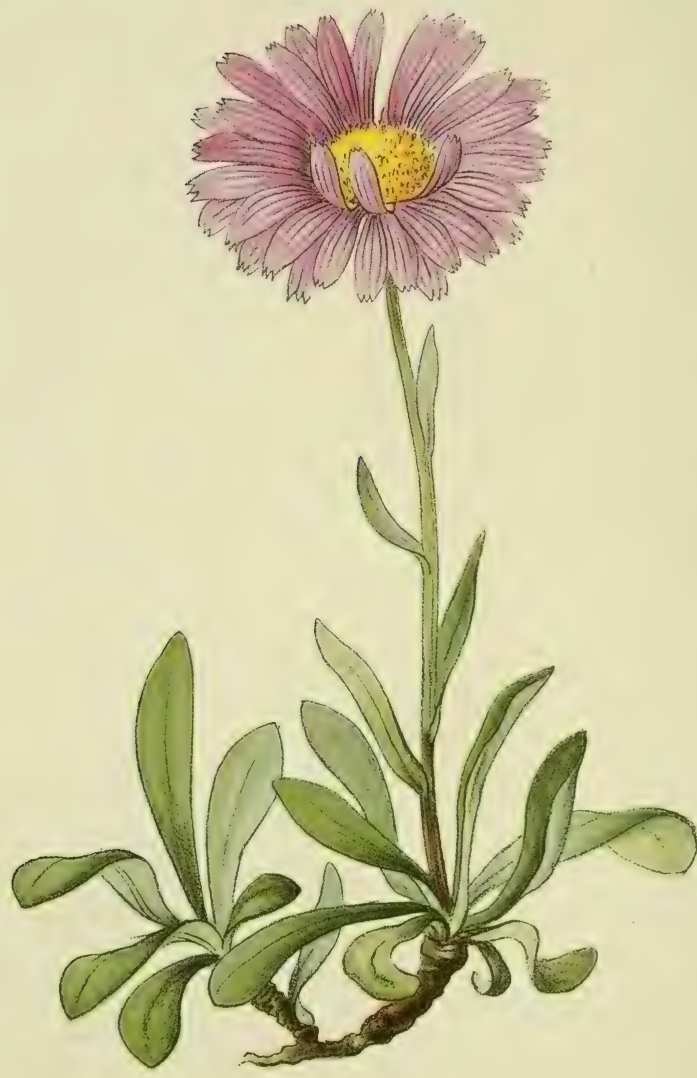

Aster alpinus.

Alpen-Aster. Aster des Alpes. Alpine Starmort. 
Die Familie der Compositen oder Körbchenbliiller, zu welcher z. B. der Löıenzahn und die Margerite gehören, ift durch die Anhäufung der Blüten in einem Köpfchen, das man gewöhnlich als Blume bezeichnet, charakterifiert. Von andern Familien mit ähnlichen Blütenftänden (z. B. Dipsaceen) unterfcheiden fich die Compositen durch den Blütenbau, der fie als nahe Verwandte der Campanulaceen (Tafel $83 \mathrm{ff}$.) verrät; der Kelch fehlt jedoch oder ift in Form eines Haarkranzes ausgebildet, der zur Verbreitung der Früchtchen dient.

Aster alpinus. - T'afel 62. - Schwach behaarte, 3-60 $\mathrm{cm}$ hohe Pflanze mit aufrechtem, einköpfigem Stengel. Blätter lanzettlich, Köpfchen bis $4,5 \mathrm{~cm}$ im Durchmeffer, mit mehrreihiger Hülle fchmaler Hochblättchen. Randblüten violett, zungenförmig, Scheibenblüten gelb, röhrig.

Mehrjährig. Blüht Juli Auguft.

Befucher: vorwiegend Falter.

Früchtchen mit Haar-Fallfchirm: Windverbreitung.

Trockene Weiden, Felsblöcke, befonders auf Kalk.

$800-3000 \mathrm{~m}$.

AJpen, Jura, Cevennen, Pyrenäen; Karpathen, Kaukafus, nordpolare Länder, Ural, Altai, Himalaya.

Petasites niveus. - Schneeweifse Peftilenzwurz. Stengel aufrecht, mit am Grunde breiten, vorn zugefpitzten, fchuppenförmigen Blättern und $20-30 \mathrm{~cm}$ langen, dichten Trauben weifer oder blauroter Blütenköpfchen. Grundftändige Blätter geftielt, groß, dreieckig, grob gezähnt, unterfeits weißwollig behaart.

Mehrjährig. Blüht April, vor dem Erfcheinen der grundftändigen Blätter.

Befucher: vermutlich Fliegen und Falter.

Früchte mit Haar-Fallfchirm:

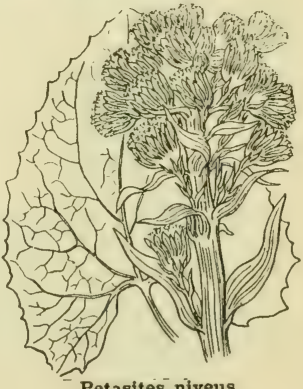

Windverbreitung.

Bachufer, feuchte Felfen der Nadelholzregion.

Alpen, Jura.

G. Senn, Alpenflora, 
Compositen.

Arnica montana - Tafel 63. - 20-60 $\mathrm{cm}$ hoch. Grundtandige Rofette von ovalen, gegenftändigen, etwas drülig hehıarten Blättern, aus denen fich ein gerader Stengel mit 1-2 Blattpaaren uml meitt einem einzigen, $5-8$ cm grofsen Blütenköpfchen erhebt. Randblüten zungenförmig, latt orangegelb.

Mehrjährige Giftpflanze, deren alkoholifcher Auszug befonders frïher zu Kompreflen verwendet wurde.

Blüht Juni Juli.

Befucher: Tagfalter.

Früchte mit Haar-Fallfchirm: Windverbreitung.

Alpen, Vogefen, Auvergne, Gevennen, Pyrenïen; Karpathen, nordpolare Länder, Altai.

Doronicum cordatum. - Herzblätrige Gemswur\%, $40-60 \mathrm{~cm}$ hoch, l'chwach behaarl.

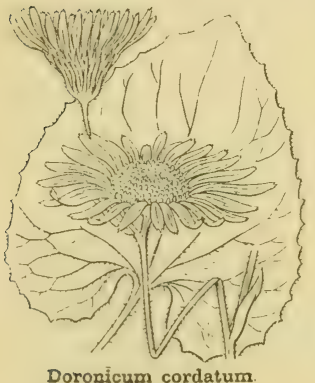
Stengel verzweigt. Blätter leicht gezähnt, die grundltändigen herzförmig, lang geftielt, die ltengelfändigen am Grunde plötzlich verfchmälert, den Stengel umfaffend. $1-8$ Blütenköpfchen auf f'chwachen Stie. len. Randblüten hellgelb.

Mehrjährig. Blüht Juni bis Auguft. Befucher: vermutlich Fliegen und Bienen.

Früchtchen mit Haar-Fallichirm:

Windverbreitung.

Bergwälder, Bachufer.

Ebene bis etwa $2200 \mathrm{~m}$.

Alpen, Jura, Vogefen, Auvergne, Cievemnen, Pyrenäen. 
Matten bis $2800 \mathrm{~m}$.

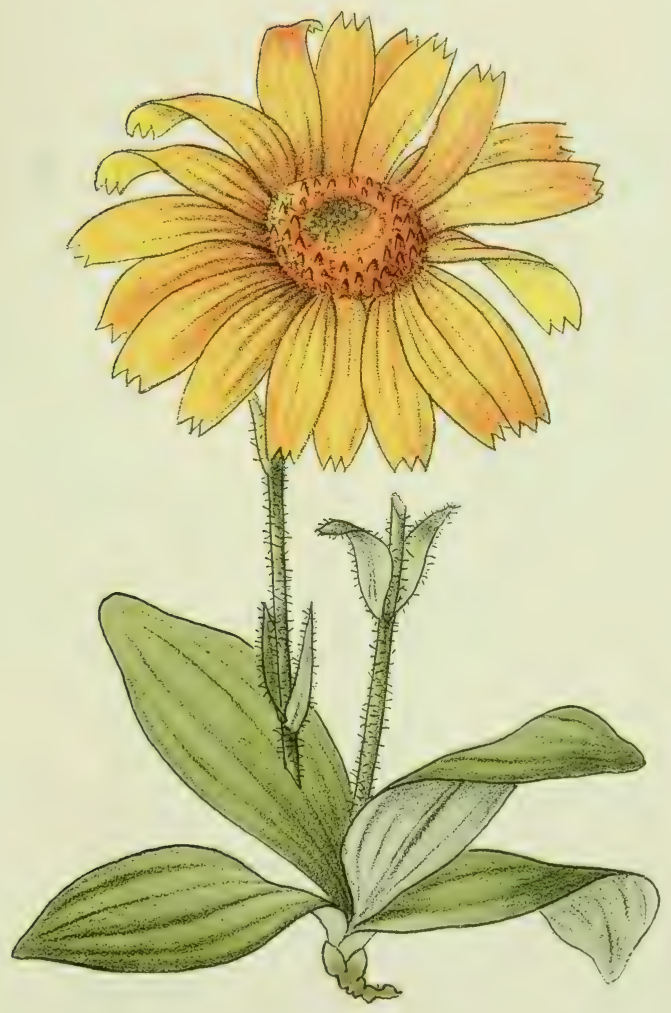

Arnica montana. Arnica.

Wohlverleih. Arnica. 


\section{$-64-$}

Gerölle, zwischen Felsblöcken 1400-2800 Meter.

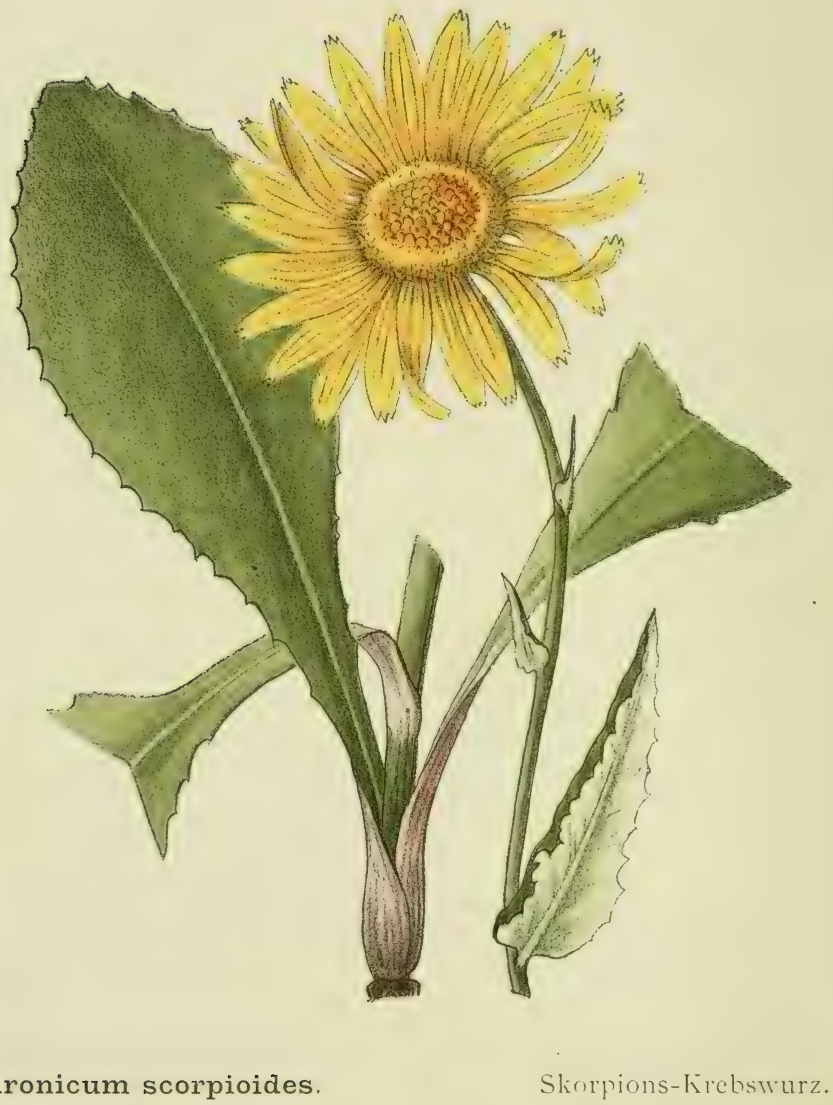


Aronicum scorpioides. - Tafel 6x. - Stengel 10 bis $35 \mathrm{~cm}$ hoch, aufrecht, oberwärts behaarl, verzweigt, mit wenigen, zerftreuten, gezähnten Blättern; die grmolfändigen geftielt, eiförmig; die ltengelftändigen l'hmal-eiförmig, kaum abftehend, den Stengel teilweile unfaflend. 1-3 grofie, gelbe Blütenköpfchen.

Mehrjährig. Blüht Juli Auguft.

Befucher: vermutlich Fliegen und Falter.

Früchtchen mit Haar-Fallichirm: Windverbreilung. Gerölle, Fe]fen, befonder's auf Kalk, $1600-2500 \mathrm{~m}$. Alpen, Pyrenäen, Karpathen.

Aronicum CInsii. -- Krebswurz des Clusius. - Der vorigen ähnlich, unterlcheidet fich von ihr durch den unverzweigten, einköpfigen Stengel, die l'chwach gezähnten und am Grunde allmählich verl'chmälerten Blätter.

Mehrjährig. Blüht Juli Auguft. Befucher: Fliegen, Tagfalter. Früchtchen mit Haar-Fallfchirm: Windverbreitung. Felsblöcke, Gerölle der Hochalp.

Alpen, Karpathen, polares Europa.

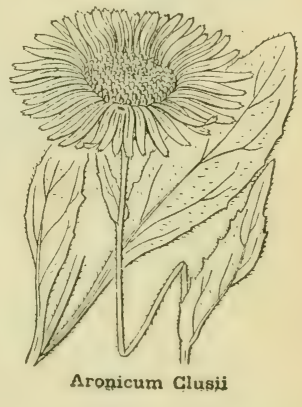


Erigeron alpinus. - Tafel $65 \mathrm{~A}$ - Pflanze $10-30 \mathrm{~cm}$ hoch, flaumig behaart. Stengel aufrecht, 1- bis 4köpfig. Blätter lang lanzett, fpitz. Randhlüten zungenförmigg, rotviolett.

Mehrjährig. Blüht Juli Auguft.

Befucher: vorwiegend Falter.

Früchtchen mit Haar-Fallfchirm: Windverbreitung. Alpen, Jura, Auvergne, Pyrenäen; Karpathen, Kaukalus, nordpolare Länder, Altai, Himalaya.

\section{Erigeron uniflorus. - Einköpfiges Berufkraut. -}

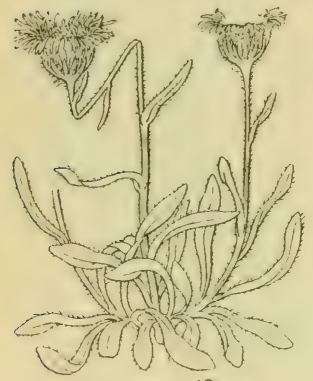

Erigoron uniforus

Unterlcheidet fich von voriger Art durch die wollige Behaarung der Köpfehenhülle, die ftumpfen Blätter und die ftets einzeln ftehenden Köpfchen mit weißen Randblüten.

Mehrjährig.

Blüht Juli bis September.

Befucher: Falter.

Früchtchen mit Haar-Fallfchirm:

Windverbreitung.

Ralenbänder, Felfen bis $2700 \mathrm{~m}$. Alpen, Karpathen, Kaukafus, nordpolare Länder, Altai, Himalaya.

Homogyne alpina. - T'ufel bij B. - Grundltändige Rofette nierenförmiger, his 4 cm grofier, geftielter Blätter, die dick, lederartig, runzelig, gezähnt :und unterfeits behaart find. Aus ihrer Mitte erhebt fich ein 20 - :30 (m hoher, faft unbeblätterter, einköpfiger Blülenlichaft. Köpfchen falt cylindrifch, mit rotbraunen Hüllblättern. Alle Blüten rölrenförmig, hellrot.

Mehrjührig. Blüht Juni Juli.

Befucher: vorwiegend Falter, dineben anch Fliegen. Frïchtchen mit Haar-Fallfchirm: Windverbreitung. Alpen, Jura, Pyrenäen; Karpathen. 
Steinige Weiden I500-2700 Meter.
Matten

I ioo-2300 Meter.

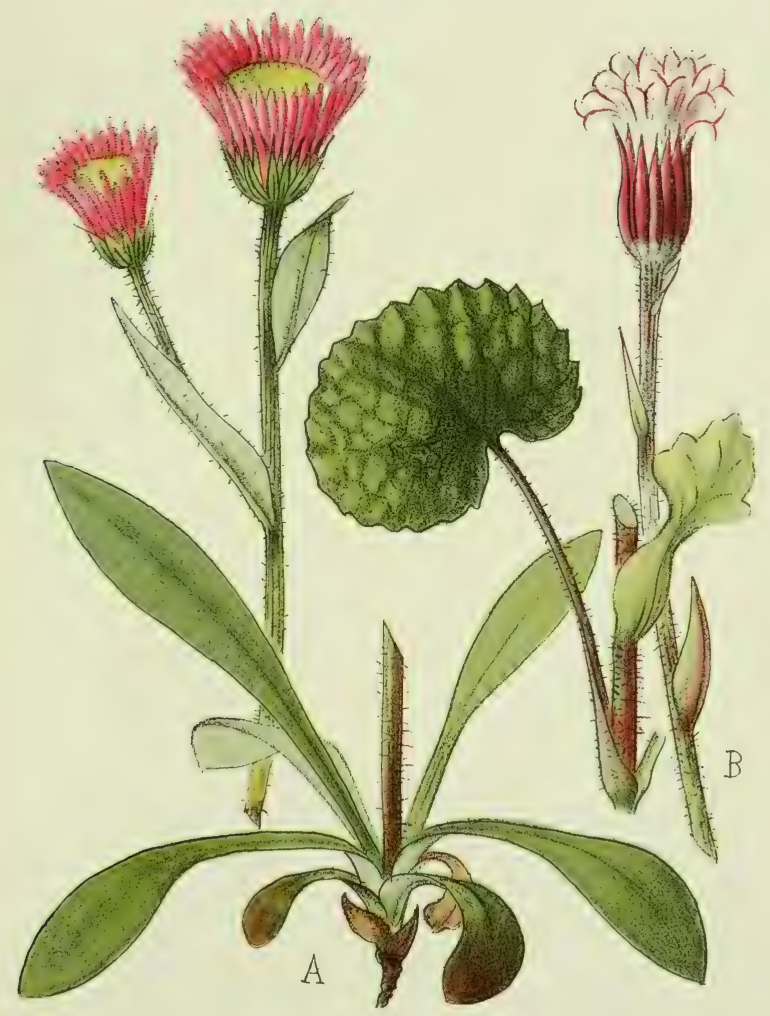

A. - Erigeron alpinus. Alpen-Berufkraut. Vergerette des Alpes. Alpine Fleabane.
B. - Homogyne alpina.

Alpenlattich. Tussilage des Alpes. Alpine Coltsfoot. 
Weiden, Rasenbänder 1700-3600 Meter.

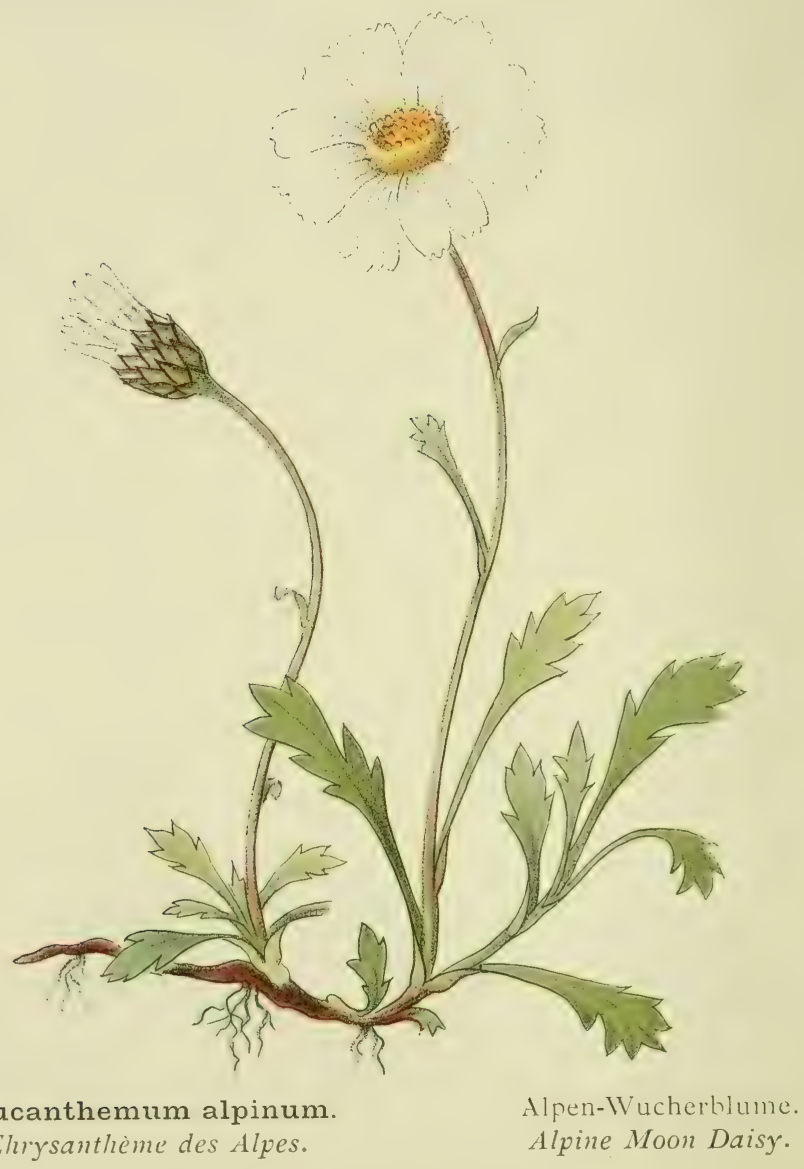


Lencanthemum alpinum. - Trafel 66. - Irurzelftock mit zahlireichen Stengeln, die 5-15 cmı hohe Bülche bilden. Stengel aufrecht, unverzweigh, helsart. Blätter zahlreich, geftielt, die srmolftündigen fiederteilig mit lichnalen $A b$ lichnitten, die ftengelftändigen fichmal, nicht gezähnt. Blütenköpfchen his 3 cm im Durchmeffer, von breiten, lichwarzgeränderten schuppen eingehüllt. Zaungen der Randblüten weifs oder rötlich-weif́s.

Mehrjährig. Blüht Juli.

Befucher: Fliegen, Falter.

Früchte klein, mit Reften der Blumenkrone: Windverbreitung.

Felsblöcke, fteinige Halden, magere Weiden.

$1700-3600 \mathrm{~m}$.

Alpen, Pyrenäen, Karpathen.

\section{Lencanthemum coronopifolium. - Krähenfu(b)lätt-} rige Wucherblume. - Wenig ftengelig, $6-30 \mathrm{~cm}$ hoch, nicht oder nur wenig verzweigt. Die grundltändigen Blätter in den Stiel verl'chmälert, die ftengelftändigen ungeftielt, alle mit grofien, l'chmalen Zühnen. Blütenköpfchen $3-4 \mathrm{~cm}$ im Durchmefler, von breiten, braungeränderten Schuppen umgeben. Zungen der Randblüten weif.

Mehrjährig. Blüht Juli.

Befucher: Fliegen, vorwiegend Falter.

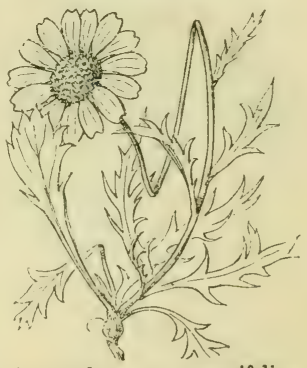

Leucanthemum coronopifolium

Früchte klein, mit Reften der Blumenkrone: Windverbreitung.

Felsblöcke, Gerölle der Hochalpen.

Alpen, Pyrenäen. 
Compositen.

Adenostyles albifrons. - Tafel $6 \%$ - Bis $1 \mathrm{~m}$ hoch, mit aufrechten, oberwärts verzweigten, kurzhaarigen Stengeln. Grundftändige Blätter rundlich, 30-40 cm breit, unterfeits weifwollig, ungleich grob gezälınt: die ftengelftändigen am Grunde mit ohrläppchenartigen Zipfeln. Blütenköpfchen klein, 5- bis 8blütig, zu rundlichem, lockerem Strauf vereinigt. Alle Blüten röhrenförmig, gleichmäfsig 5zipflig, hellrofa.

Mehrjährig. Blüht Juli Auguft.

Befucher: Fliegen.

Früchte mit Haar-l'allfchirm: Windverbreitung.

Waldlichtungen, im Knieholz, felfige Bachufer.

Bis $2500 \mathrm{~m}$.

Alpen, Jura, Vogelen, Schwarzwald, Sudeten; Auvergne, Cevennen, Pyrenäen.

Adenostyles leucophylla. - Weißbättriger Wafferdoft. - Höchftens $50 \mathrm{~cm}$ hoch.

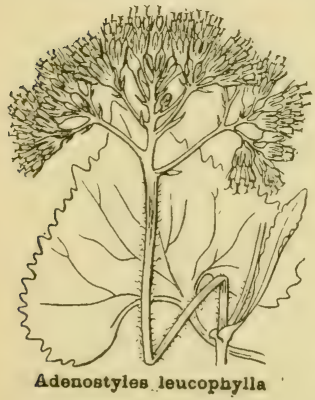
Blätter auf beiden Seiten, befonders unterfeits weißfilzig. Blütenköpfchen in dichten Ständen; jedes mit 12 bis 30 kleinen, hell - rolafarbenen Röhrenblüten.

Mehrjährig. Blüht Juli.

Befucher : vermutlich Fliegen und Falter.

Früchtchen mit Haar-Fallfchirm:

Windverbreitung.

Felfen der Hochalpen.

Weft- und Oftalpen.

Adenostyles alpina. - Alpendoft. - Der vorigen ähnlich, jedoch noch kleiner und Blätter beiderfeits grün und gleichmäßrig gezähnt. Blütenköpfchen nur 4- - jblütig.

Mehrjährig. Blüht Juli Auguft.

Befucher: Fliegen und Falter.

Früchtchen mit Haar-Fallfchirm.

Lichte Wälder, Felfen, Gerölle der Berge.

Alpen, Jura. 
Waldlichtungen, felsige Bachufer bis 2500 Meter.

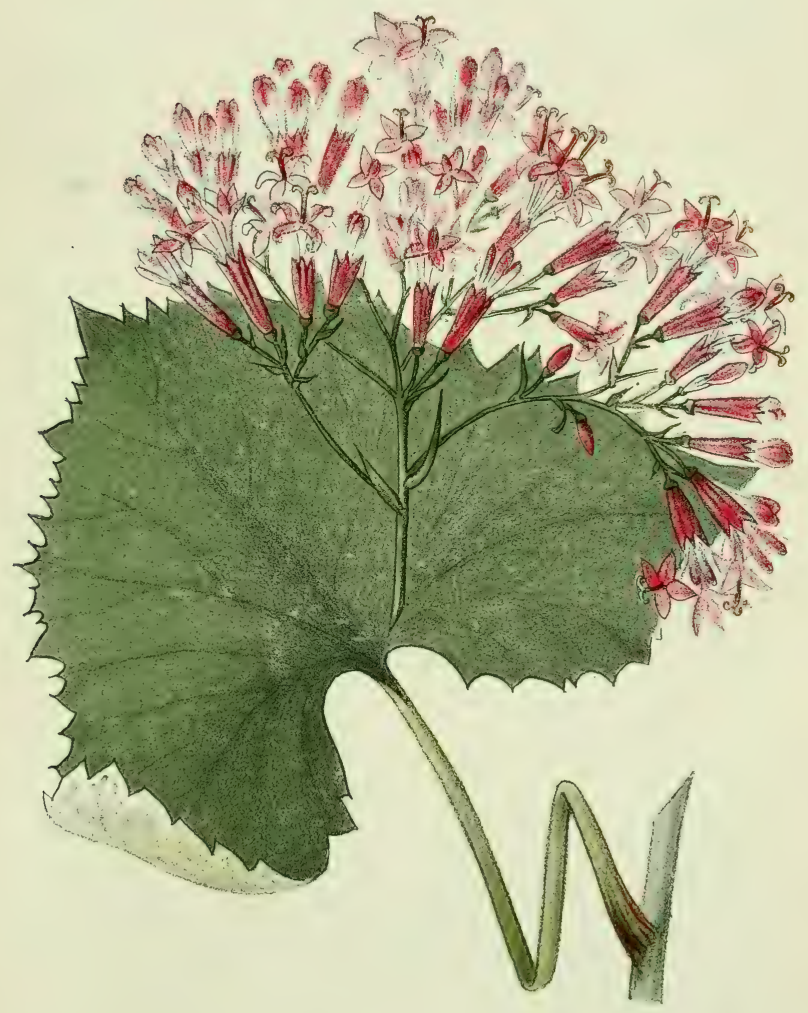

Adenostyles albifrons.

Weissblättriger Alpendost Cacalie à fenilles blanches.

White-leaved Butterbur. 
Steinige Weiden, Rasenbänder I800-3400 Meter.
Weiden, sonnige Orte bis 2800 Meter.

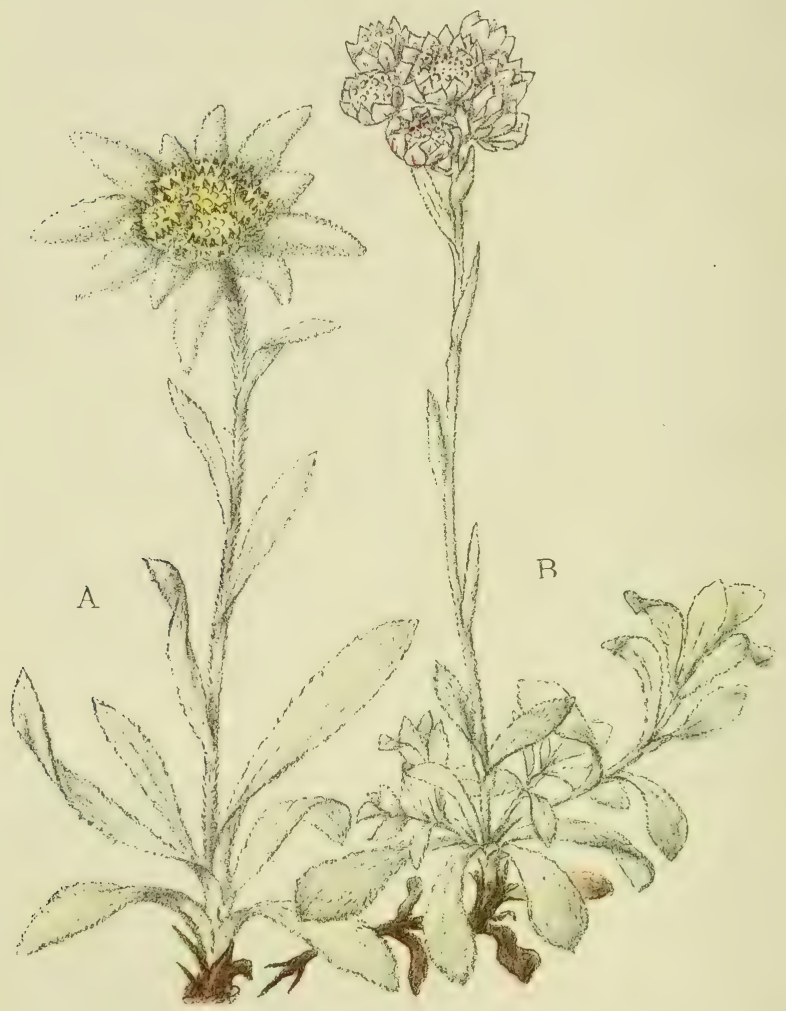

1. - Leontopodium alpinum. B. - Antennaria dioica.

Edelweiss.

Pied de lion.

Edelweiss.
Katzenpfötchen.

Pied de chat.

Chast-veed. 
Leontopodium alpinum. - Tafel $68 \mathrm{~A}$. - Pflanze 5 bis $20 \mathrm{~cm}$ hoch, mit weißen Wollhaaren dicht beletzt. Blätter fchmal lanzettlich. Stengel aufrecht, unverzweigt, mit dichtem, ein einziges Köpfchen vortäufchendem Stand von Köpfchen mit gelben Röhrenblüten. Der Köpfchenftand von weiffilzigen, fternförmig ausgebreiteten Hüllblïttern umgeben.

Mehrjührig. Blïht Juli Auguft. Befonders auf Kalk. Befucher: Fliegen, Käfer.

Früchtchen mit Haar-Fallfchirm: Windverbreitung. Alpen, Jura, Pyrenïen, Karpathen, Altai, Himalaya.

Antennaria dioica. - Tafel $68 \mathrm{~B}$. - Weiffilzig, mit niederliegenden, wurzelnden Stengeln, die Rofetten eiförmiger, befonders unterleits ftark filziger Blätter tragen. Blütenl'chäfte aufrecht, $5-25 \mathrm{~cm}$ hoch. Männliche Blüten (nur mit Staubgefä(3en) und weibliche Bläten (nur mit Stempel) auf verfchiedenen Stöcken: Pflanze zweihäufig, dioecifch. Alle Blüten röhrenförmig. weifs; Köpfchen von weif̧en oder rötlichen Hüllblättern umgeben.

Mehrjährig. Blüht Mai bis Juli. Befucher: Falter. Früchte mit Haar-Fallfchirm: Windverbreitung.

Alpen, Pyrenäen ; Karpathen, Kaukafus, nordpolare Länder, Ural, Altai.

\section{Antenuaria carpathica. - Katzenpfötchen der} Karpathen. - Ohne niederliegende Stengel, Blätter dicht wollig behaart, fchmal. Köpfchen von braunen Hüllblättchen umgeben.

Mehrjährig.

Blüht Juli Auguft.

Befucher: vermutlich Fliegen.

Früchtchen mit Haar-Fallfchirm: Windverbreitung. Felfige. Weiden, magere Matten, $1800-3100 \mathrm{~m}$. Alpen, Pyrenäen; Kar-

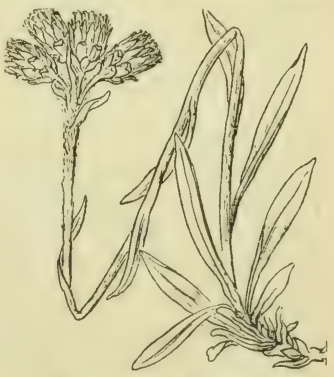

Antennaria carpathica pathen, nordpolare Länder, Ural. 
Die alpinen Artemisia-Arten find durch ihre feidenglänzende Behaarung und den Reichtum an aromatifchen Stoffen ausgezeichnet, weshalb fie zur Bereitung f'hweiftreibender Aufgüffe verwendet werden. Blüten honiglos: Pollenblumen, im Übergang zur Windbeftüubung begriffen.

Artemisia Mutellina. - Tafel 69 A. - Dicht, filberglïnzend behaart, $6-20$ (m hoch. Blätter 3- bis viellpaltig nit lchmalen Ablchnitten. Blühende Triebe aufrecht, unverzweigt, mit kugeligen Köpfchen gelber Bläten in lockerer Traube.

Mehrjährig. Blüht Juli Auguft. Windbeftäubung?

Früchtchen ohne Verbreitungsmittel.

Alpen, Pyrenäen, Appennin.

\section{Artemisia glacialis. - Gletfcher-Edelrante.}

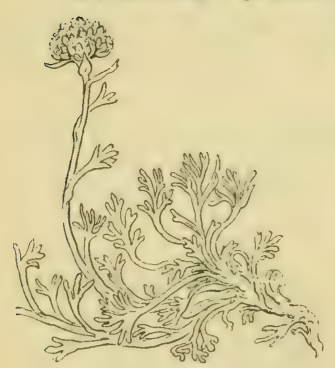

Der vorigen ähnlich, aber Blütenköpfchen in dichter, faft kugeliger Traube. Bläten lebhaft gelb gefärbt.

Mehrjährig.

Blüht Juli Augult.

Befucher? Windbeftäubung?

Felsipalten.

Weft- und Oftalpen.

\section{Artemisia glacialis}

Artemisia atrata. - Tafel (j9) B. - Stengel $20-40 \mathrm{~cm}$ hoch, fteif, kahl. Blätter fiederfpaltig, mit lehr lchmalen Abl'chnitten, mehr oder weniger weif behaart. Köpfchen kugelig, von braun berandeten Schuppen umgeben, in lïnglicher Traube.

Mehrjährig. Blüht Juli Auguft. Windbeftäubung?

Früchtchen ohne Verbreitungsmittel.

Felsblöcke, Rafenbänder der Hochalpen.

Weft- und Südalpen, fehlt der Schweiz. 
Sonnige Felsen $1600-3500$ Meter.
Steinige Matten, Rasenbänder der alpinen Region.

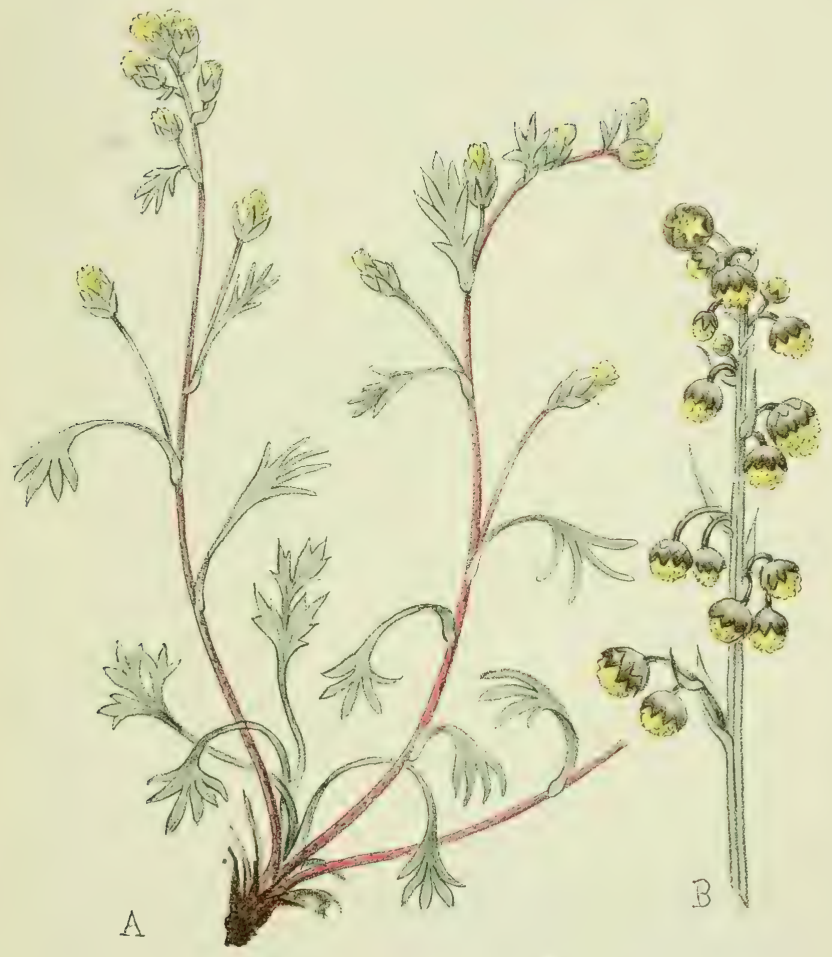
A. - Artemisia Mutellina.
1). Artemisia atrata.
Edelraute.
Génépi.
Schwärzlicher Beifuss. Armoise noirâtre.
Mutellina Wormuod. Black Wormuood. 


\section{$-7()$}

Waldlichtungen, schattige Weiden und Felsen bis 2000 Meter.

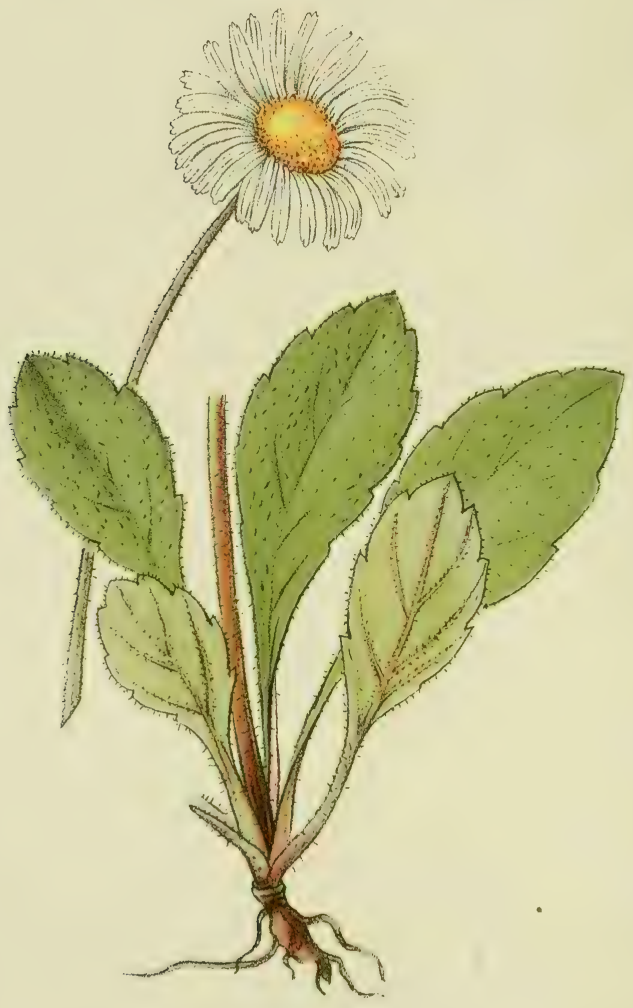

Bellidiastrum Michelii.

Michelis Sternliebe.

Bellidiastrum de Micheli.

Micheli's Bellidiastrum. 
Bellidiastrum Michelii. - Tafel 7o. - Gleicht fehr unlerem gemeinen Gänfe- oder Mattenblümchen (Bellis perennis), ift jedoch in all’n Teilen gröfser, auch bébitzen die Blüten einen Haarkelch, der bei Bellis felslt. Mittlere Blülen des Köpfchens (Scheibenblüten) röhrenförmig, gelb, Randblüten zungenförmig, weißs.

Mehrjährig. Blüht Juni Juli.

Befucher: Fliegen, Schmetterlinge.

Früchtchen mit Haar-Fallichirm: Windverbreitung.

Schattige Weiden, fenchte Felfen, Berge bis $2000 \mathrm{~m}$. Alpen, Jura, Schwarzwald, Vogefen, Karpathen.

Buphthalmum grandiflorum. - Grobes Rindsauge. Stengel Iteif, verzweigt, $30-50 \mathrm{~cm}$ hoch, gleichmäßrig beblättert. Blätter ungeteilt, lanzettlich, mit feiner Spitze, fein gezähnt. Blütenköpfchen $\tilde{5} \mathrm{~cm}$ im Durchmeffer. Randblüten zungenförmig, vorn abgeftutzt, dreizähnig, wie die röhrenförmigen Scheibenblüten lebhaft gelb.

Mehrjährig.

Blïht Juni bis Juli.

Befucher: Fliegen, Bienen, Schmelterlinge.

Früchtchen ohne Verbrei-

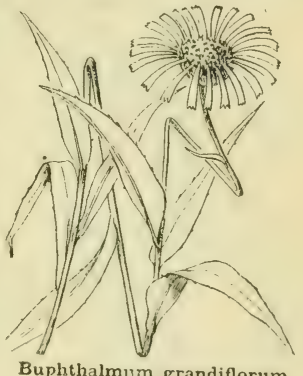
tungsmittel.

Waldlichtungen, Felfen, auf Kalk. Alpen, Jura, Cevennen. 
Senecio incanus. - Tafel \%1. - Niedrige Pflanze mit kriechenden Wurzelfock und Rolette kleiner, wollig bebatrter, fiederlichittiger Blïtler, mit Ichmalen, gleichartigen Abl'chnitten. Blütenköpfchen klein, in kurzer Traube. Jedes enthält nur $6-8$ orangegelbe Blüten, wovon $2-4$ zungenförmig lind.

Mehrjährig. Blüht Juli Auguft.

Befucher: vermutlich Fliegen, Falter.

Früchtchen mit Haar-Fallichirm: Windverbreitung.

Steinige Weiden, trockener Urgefteinsl'chutt.

$1800-3000 \mathrm{~m}$.

Nur in den Alpen.

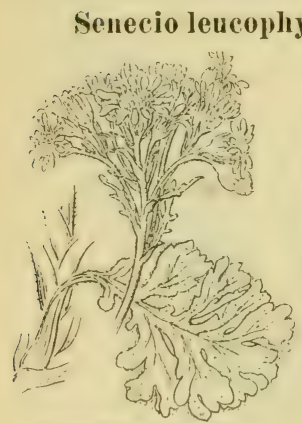

Sonecio leucaphyllus

Windverbreitung.

Dem vorigen ähnlich, jedoch die in dichten Bülchen am Stengelgrunde ftehenden Blätter derb, beidfeitig dicht wollhaarig, tief fiederl'chnittig, mit breiten, abgerundeten Abfchnitten. Köpfchen zahlreich, jedes mit 5 bis 7 gelben Zungenblüten, in breitem Straufe.

Mehrjährig.

Blüht Auguft bis September.

Belucher: vermutlich Fliegen und Falter.

Frïchtchen mit Haar-Fallfchirm:

Felshlöcke, Gerölle, auf Urgeftein, befonders auf den Bergkämmen. $1800-2650 \mathrm{~m}$.

Cevennen, Oft-Pyrenäen.

Senecio Cineraria. - Die Cinerarie ift eine der vorigen ähnliche, befonders frühler heliebte, weiffilzige Zierpflanze mit fiederfchnittigen Blättern. Wild kommt fie auf den Fellenufern des Mittelmeeres vor. 
Steinige trockene Orte 1800-3000 Meter.

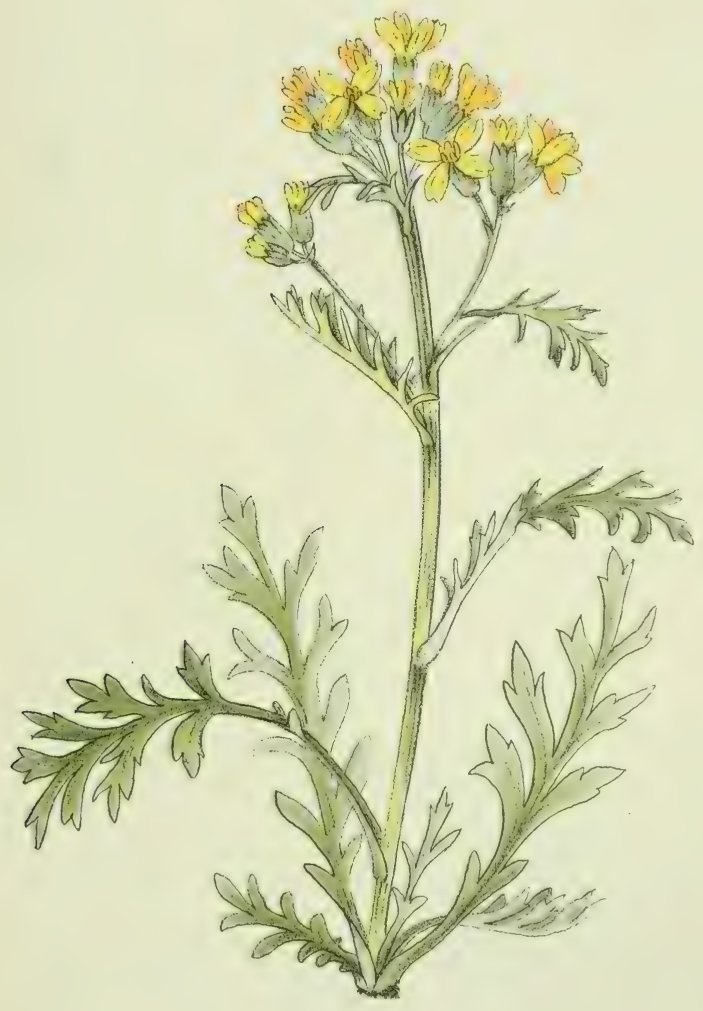

Senecio incanus.

Graues Kreuzkraut.

Senecon blanchâtre. 
Gerölle, steinige Weiden 1500-2500 Meter.

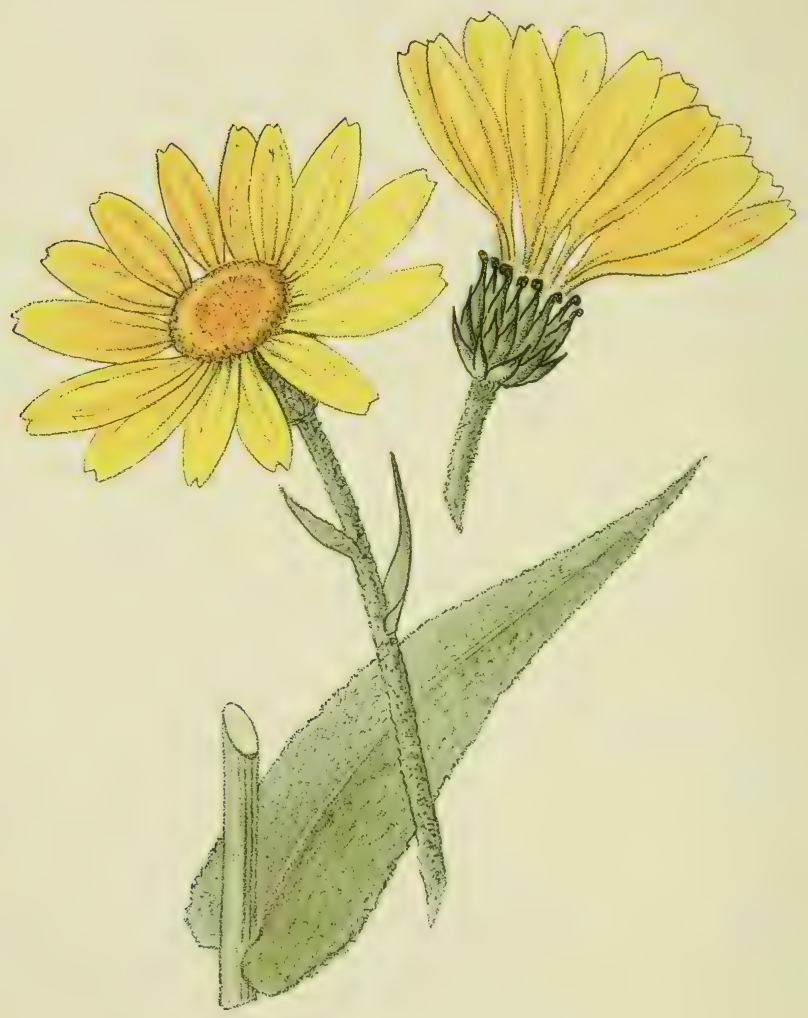

Senecio Doronicum. Senecon Doronic.
Gemswurz-ähnliches Kreuzkraut. Leopard's bane Groundsel. 
Senecio Doronicum. - Tafel 7\% - Stengel kräftig, aufrecht, 20-40 cm hoch, fein finnwebeartig weishaarig. Blätter lederartig dick, kahl, oder belonder's unterleits weils lpimmeheartig behaurt; die Itengelländigen Blitter an Rande etwas umgerollt. Stengel 1-3köptig. Ramlblüten zahılreich, zungenförmig, gold- oder orangegelb.

Mehrjähıig. Blüht Juli Auguft. Vorwiegend aul Kalk.

Befucher: Fliegen, befonder's Falter.

Früchtchen mit Haar-Fallfchirm: Windverbreitung. Alpen, Jura, Auvergne, Pyrenäen; Karpathen.

\section{Senecio aurantiacus. - Orangerotes Kreuzkraut. -} Wollhaarig, mit grundftändiger Rolette länglich ovaler, aufrechter, am Grunde verfilumälerter Blïtter. Stengel $20-40 \mathrm{~cm}$ hoch, aufrecht, unverzweigt, beblättert, trägt $1-6$ Blütenköpfchen mit dunkelbraunen Hüllblättern. Randblüten zungenförmig, orangerot.

Mehrjährig.

Blüht Mai bis Juli.

Beftäubung, Fruchtverbreitung wie bei vorigem.

Steinige Weiden, trockene Matten, liellen; auf Kalk.

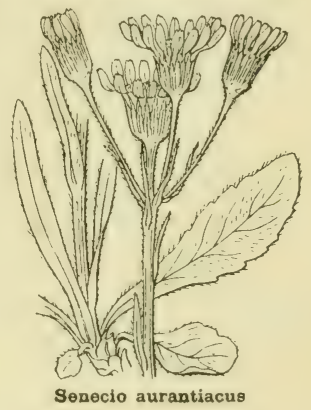

Ganze Alpenkette.

Senecio cordatus. - Herzblittriges Krenzkraut. Stengel $55-150 \mathrm{~cm}$ hoch, ftark gerillt, oberwärts verzweigt. Alle Blätter geftielt, herzförmig, ungleichmäßig gezähnt, unterleits etwas behaart. Blütenköpfchen zahlreich, gelb. Randblüten zungenförmig.

Mehrjährig. Blüht Juli Auguft.

Befucher: Fliegen, Schmetterlinge.

Früchtchen mit Hatr-Fallichirm: Windverbreitung.

Feuchte Weiden, Läger, in der Nähe der Semnhü̈ten.

Bis zur Nadelholzregion.

Alpen, Vogefen, fehlt dem Jura, 
Compositen.

Achillea nana. - Tafel $73 \mathrm{~A}$. - Weißwollig, zottig, rofettenbildend. Blätter lang, fiederfehnittig mit zahlreichen fchmalen Abfchnitten. Stengel 6-15 cm hoch, mit 6-10 Blütenköpfchen, die einen faft kugeligen Straufs bilden. Randblüten weiß, kurz zungenförmig.

Mehrjährig. Blüht Juli Auguft.

Befucher : Fliegen.

Früchtchen flachgedrückt, geflügelt: Windverbreitung.

Nur in den Alpen.

Achillea herba-rota. - Tufel 73 B. - Stengel zahlreich, aufrecht, 10-20 $\mathrm{cm}$ hoch, beblïttert. Blätter lanzettlich, ftark gezähnt. Blütenköpfchen geftielt, mit je う̄-6 gelben Zungenblüten und braunen Hüllhlättern, zu lockerem Strauf vereinigt.

Mehrjährig. Blüht Juli Auguft.

Befucher? Früchtchen?

Weftalpen (Frankreich, Italien).

\section{Achillea tanacetifolia. - Rainfarnblïtrige Schaf-}

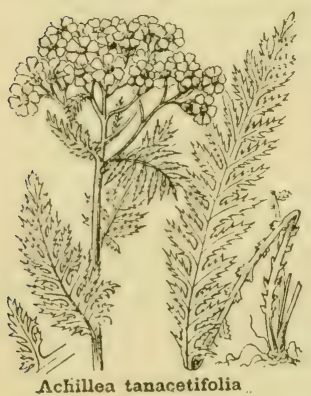

garbe. - Schwach behaart. Stengel aufrecht, bis $80 \mathrm{~cm}$ hoch. Blätter langlanzettlich, fiederfchnittig, mit fpitz gezähnten Abfchnitten. Randblüten weif bis rot.

Mehrjährig.

Blübt Juli bis Auguft. Befucher? Früchtchen durch Wind verbreitet. Trockene Matten, fchattige Fellen, Bergwälder.

Alpen von Savoyen, Dauphiné. 
Steinige Weiden, Moränen der alpinen Region.

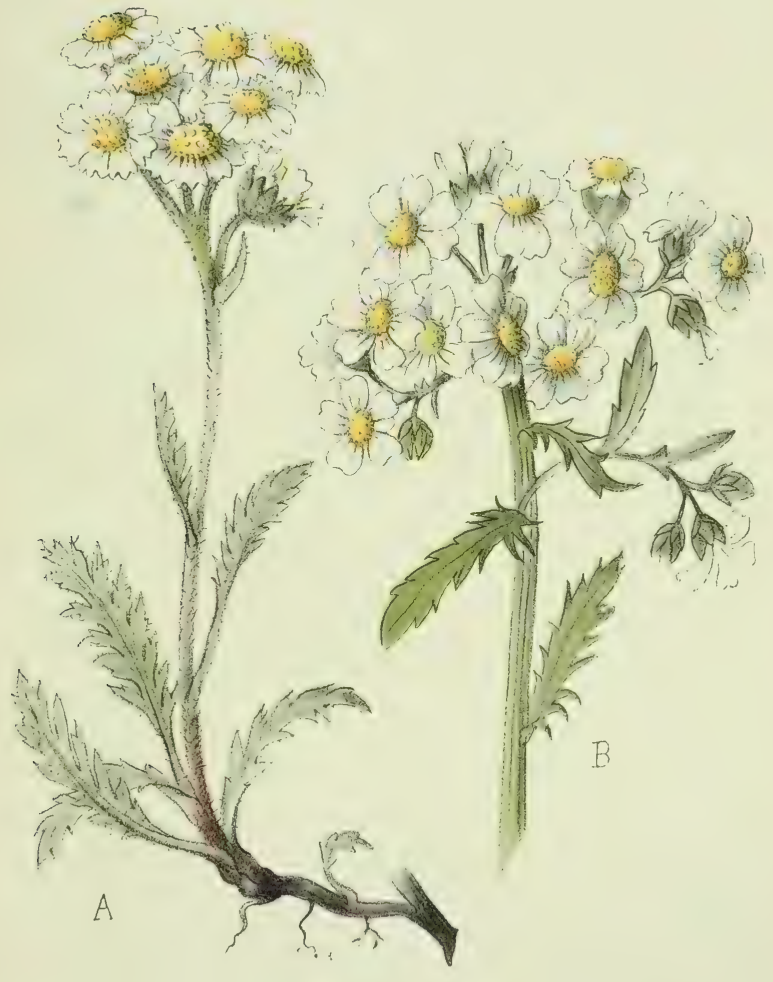

A. Achillea nana.

Zwerg-Schafgarbe. Achillée naine. Dwarf-Yarrow.
B. - Achillea herba rota.

Herba rota. Herba rota. Herba rota. 
Feuchte Felsen der Bergivälder und Weiden bis 1800 Meter.

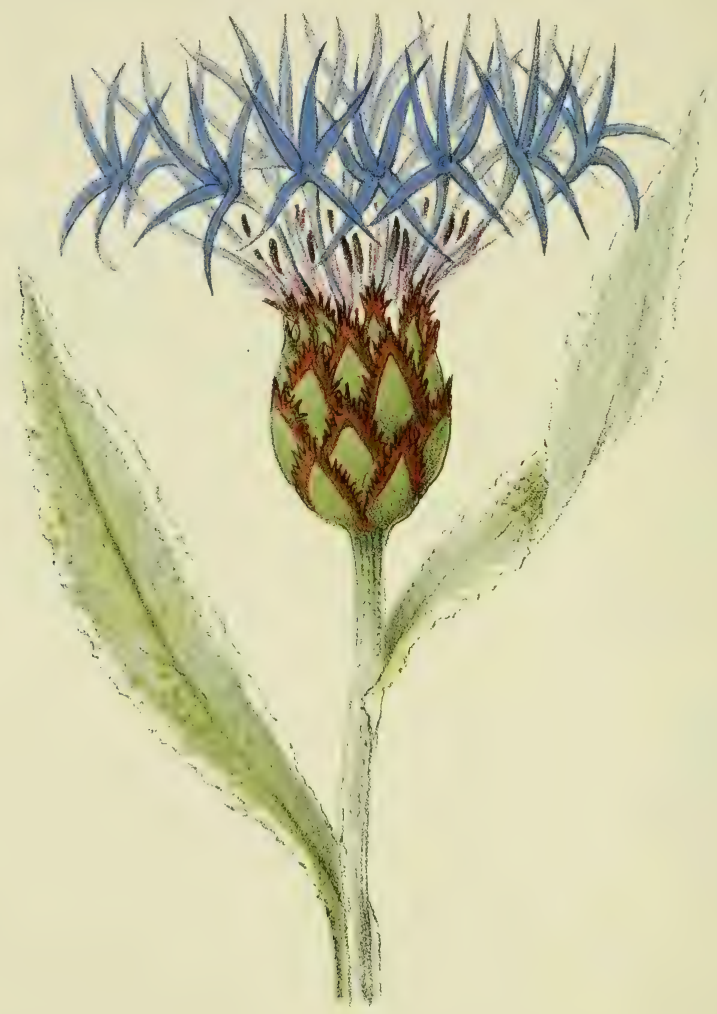

Centaurea montana.

Bergflockenblume.

Contauric, Bluct des montagnes. Mountain Corn-floner, Bluebottle. 
Centaurea montana. - Tafel $\%$ ́. - Pflanze fpinnwebeartig behaart. Blätter lanzettlich, zugefpitzt. Die Blattflïchen laufen als Flügel am Stengel herunter. Diefer 20-40 $\mathrm{cm}$ hoch, mit einem grofen Blütenköpfchen. Hüllblättchen grün, mit fchwarzen Franfen. Randblüten blau, trichterförmig, fünfzipflig. Innere Blüten kurz röhrenförmig, violettrot.

Mehrjährig. Blüht Juli Auguft.

Befucher: Bienen, Hummeln.

Früchtchen mit Haar-Fallfchirm: Windverbreitung.

Feuchte Matten, Waldlichtungen, feuchte Fellen.

Bis $1800 \mathrm{~m}$.

Alpen, Jura, Vogelen, Schwarzwald, Gebirge von Süddeutfchland; Auvergne, Cevennen, Pyrenäen.

Carlina acanlis. - Kurzftengelige Silberdiftel. -

Die kurzen Stengel tragen zahlreiche, rofettig angeordnete, kahle, fiederfchnittige Blätter mit ftachlig gezähnten Abfchnitten und ein grofes, von Itachligen Hüllblättern umgebenes Blütenköpfchen. Die inneren Hüllblättchen weif, zungenförmig zugefpitzt, täufchen Zungenblüten vor. Alle Blüten röhrig, unfcheinbar.

Mehrjährig. Blüht Juli Auguft. Bei Sonnenfchein und trockener Luft find die weißen Hüllblätter ftern-

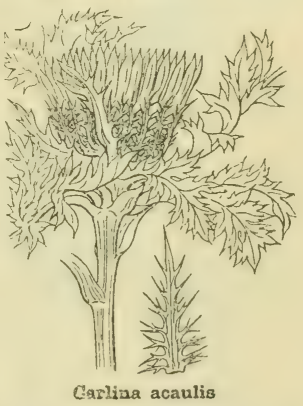

förmig ausgebreitet; bei Regenwetter fchliefsen fie üher dem Köpfchen zulammen: eine logen. hygrofkopifche Bewegung, die auch getrocknete (natürJich nicht geprefste) Exemplare ausführen. Die Skizze gibt eine mittlere Stellung der Strahlen wieder.

Befucher: Bienen, Falter.

Früchtchen mit Haar-Fallfchirm: Windverbreitung.

Trockene, fteinige Weiden, vorwiegend auf Kalk.

Berge von faft ganz Mitteleuropa, Alpen, Jura.

G. Senn, Alpenflora. 
Centaurea miniflora. - Tufel 75. - Stengel aufrecht, unverzweigt, 20-40 cm hoch, einköpfig. Blätter beidleitig weibwollig behaart, am Grunde verlchmälert. Hüllblätter der Blütenköpfchen braun bis f'chwarz, mit langer zurückgefchlagener, kammförmigg gezähnter Spitze. Blüten purpurrot. Randblüten zahlreich, grof, trichterförmig, fünfzipflig.

Mehrjährig. Blüht Juli Auguft.

Befucher: vermutlich Falter, daneben auch Hummeln.

Früchtchen mit Hatr-Fallchirm: Windverbreitung.

Alpen von Piemont, Dauphiné, Provence.

Centaurea nervosa. - Nervige Flockenblume. - Der vorigen ähnlich, aber grau behart und die Blattnerven auf ter Unterleite ftark hervortretend, an Blattrande oft in breite Zähne auslaufend.

Mehrjährig. Blüht Juli Auguft.

Befucher: vermutlich Hummen und Falter.

Fü̈chtchen mit Haar-Fallfchirm: Windverbreitung.

Truckene Wiefen, Weiden, 1500-2000 m.

Ganze Alpenkette.

Serratnla undicaulis. - Nacktfengelige Scharte. -

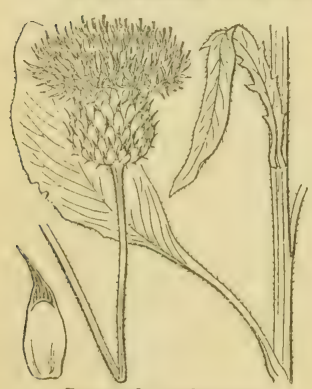

Serratula nudicaulis

Mähwiefen der Berge. Stengel 20-50 cm hoch, unverzweigt, einköpfig, oberwärts nicht beblättert. Blätter weich, die untern langoval, ann Grunde verlchmälert, die oberen l'chmallanzett, wenigzähnig, ungeftielt. Hüllblätter des Köpfchens mit fchwarzer, auswärts gerichteter Spitze. Alle Blüten röhrenförmig, violettrot. Mehrjährig. Blüht Juni bis Juli. Befucher: vermutlich Hummeln, Falter.

Früchtchen mit Haar-Fallichirm: Windverbreitung. Alpen, Cevennen, Pyrenäen. 
Mähwiesen über 1500 Meter.

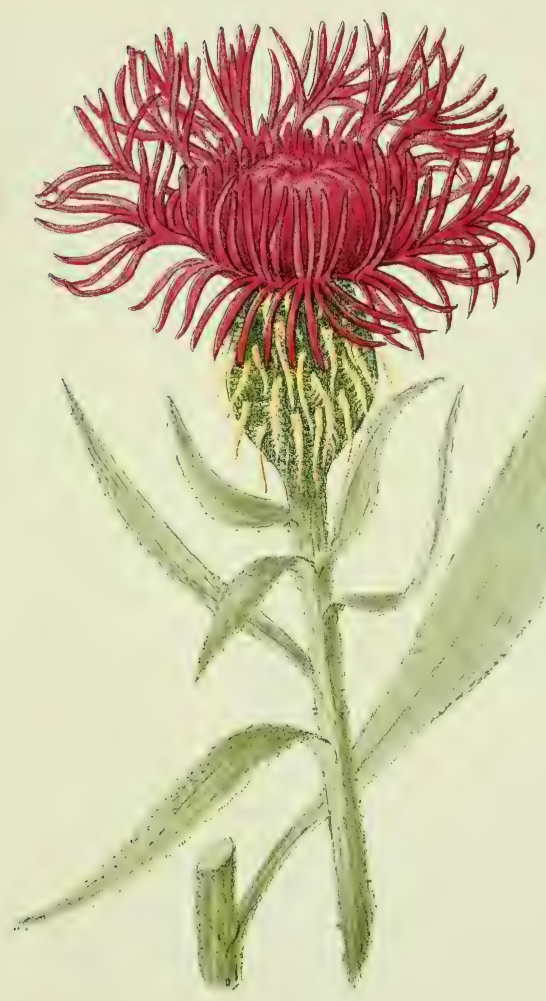

Centaurea uniflora.

Einblütige Flockenblume.

Centaurée à une fleur.

One-flowered Knapweed. 
Felsige Weiden, Gerölle der Hochalpen bis über 2500 Meter.

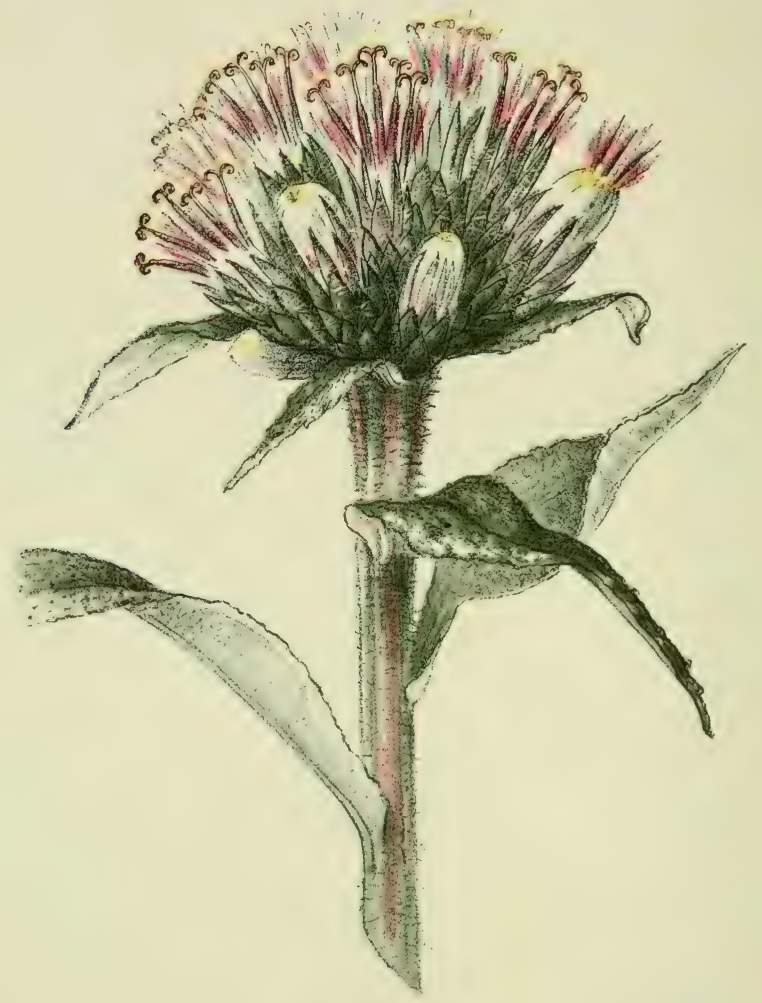

Saussurea depressa.

Saussurée déprimée.

Niedrige Alpenscharte.

Short Saussurea. 
Saussurea depressa. - Tafel 76 . - Stengel $3-8 \mathrm{~cm}$ hoch, beblättert. Blätter dichtftehend, lanzettlich, gezälınt und zugefpitzt, oberfeits grün, fpinnwebehaarig, unterleits weif wollhaarig. Blütenköpfchen in dichter Traube, oft von den Blättern überragt. Köpfchen mil angedrückten, wolligen Hüllblättern. Blüten rötlich.

Mehrjährig. Blüht Juli Auguft.

Befucher: Fliegen.

Früchtchen mit Haar-Fallfchirm: Windverbreitung.

Alpen von Frankreich, Italien und Tirol.

Saussurea alpina. - Alpenfcharte. - I)er vorigen ähnlich, aber größser, bis über $20 \mathrm{~cm}$. Die Blätter erreichen nie die Köpfchentraube.

Mehrjährig.

Blüht Juli bis Auguft.

Befucher: Fliegen.

Früchtchen mit Haar-Fall-

fchirm: Windverbreitung.

Felfen, fteinige Weiden.

Bis über $2300 \mathrm{~m}$.

Pyrenäen, Alpen, Karpathen,

Nordpolarländer, Ural, Himalaya.

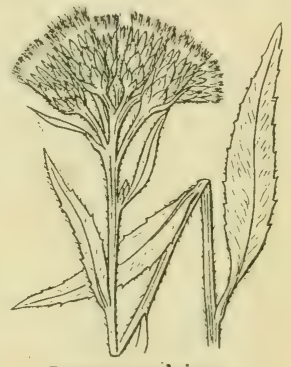

Saussurea alpina

Berardia subacaulis. - Kurzftengelige Berardie. Merkwürdige Pflanze mit großer Rofette ovaler oder rundlicher Blätter, die zuerlt weifwollig behaart find, lpäter oherleits grünlich werden. In ihrer Mitte ein großses kugeliges Köpfchen, das von zahlreichen veifs wollhaarigen, fchmalen, fpitzen Hüllblättchen umgeben ift, und zahlreiche weißse Röhrenblüten enthält.

Mehrjährig. Blüht Juli. Befucher?

Früchtchen mit Haar-Fallfchirm: Windverbreitung.

Felsblöcke, Gerölle, 1200-2500 m.

Nur in den Weftalpen (Piemont, Daupbiné, Provence). 
Prenanthes purpurea. - Tafel $7 \%$ - Stengel über $1 \mathrm{~m}$ hoch, dünn, aufrecht, kahl, mit abftehenden Äften. Blätter lang, mit ohrläppchenartig vorgezogenem Blattgrund; wachsgrün, nicht benetzbar. Trauben der Köpfchen fehr locker. Köpfchen klein, mit nur fünf violettroten zungenförmigen Blüten.

Mehrjährige Pflanze mit weißem Milchfaft.

Blüht Juli Auguft.

Befucher: Bienen, Hummeln.

Früchtchen mit Haar-Fallfchirm: Windverbreitung.

Im Schatten der Bergwälder (bis $2000 \mathrm{~m}$ ) von Mittelund Sïdeuropa; lo in den Alpen, Jura, Vogefen, Auvergne, Gevennen, Pyrenäen.

Lactuca perennis. - Mehrjäihriger Lattich. - Pflanze

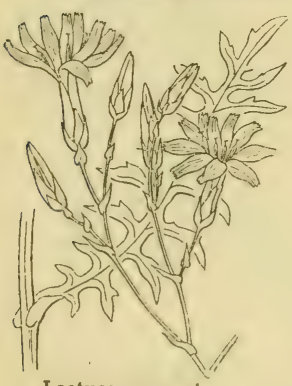

Lactuca peronnis kahl, $25-40 \mathrm{~cm}$ hoch, Stengel aufrecht, verzweigt. Blätter bläulichgrün, tief fiederfpaltig, mit fchmalen Zipfeln. Alle Blüten zungenförmig, hellblau oder violett.

Mehrjährig. Blüht Mai bis Juli.

Befucher: Fliegen.

Früchtchen mit Haar-Fallechirm:

Windverbreitung.

Felfen, Gerölle, Gefteinsfchutt, Rafenbänder.

Aus der Ebene bís in die Bergregion (ca. $1500 \mathrm{~m}$ ) von Süd- und Mitteleuropa. 
schatlige bergwalder his über 220 . Heter.

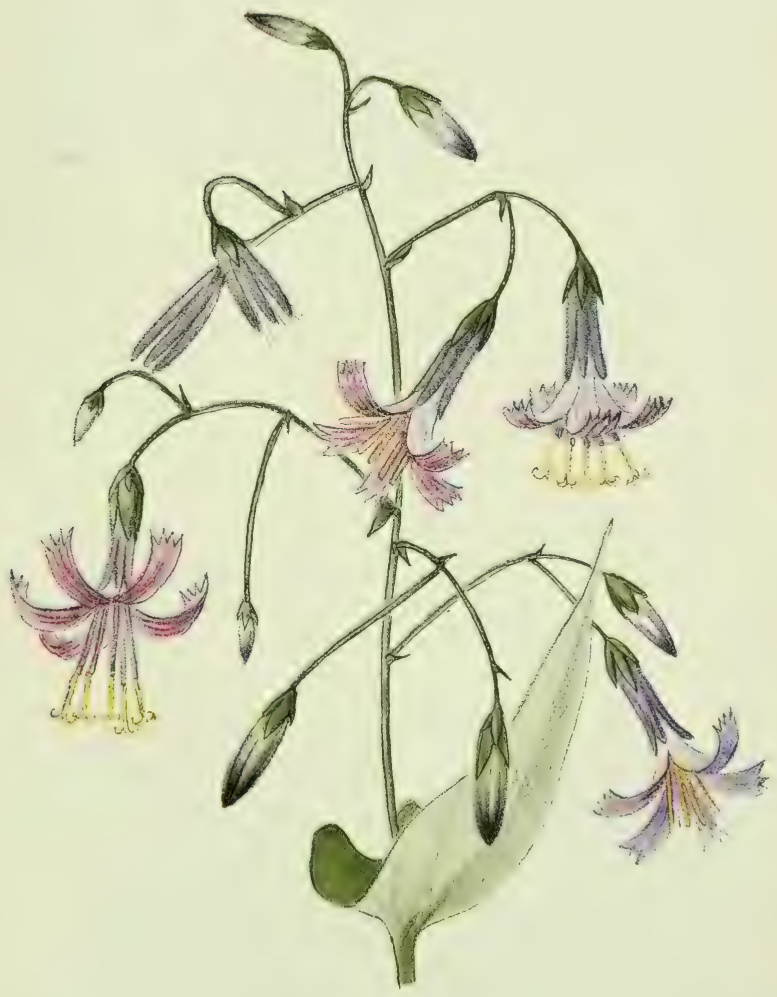

Prenanthes purpurea.

Laituc à fleurs pourpres.

Roter Ilasenlattich. Purple Lettuce. 


\section{$-78-$}

Fette Weiden, Wiesen 1000-2700 Meter.

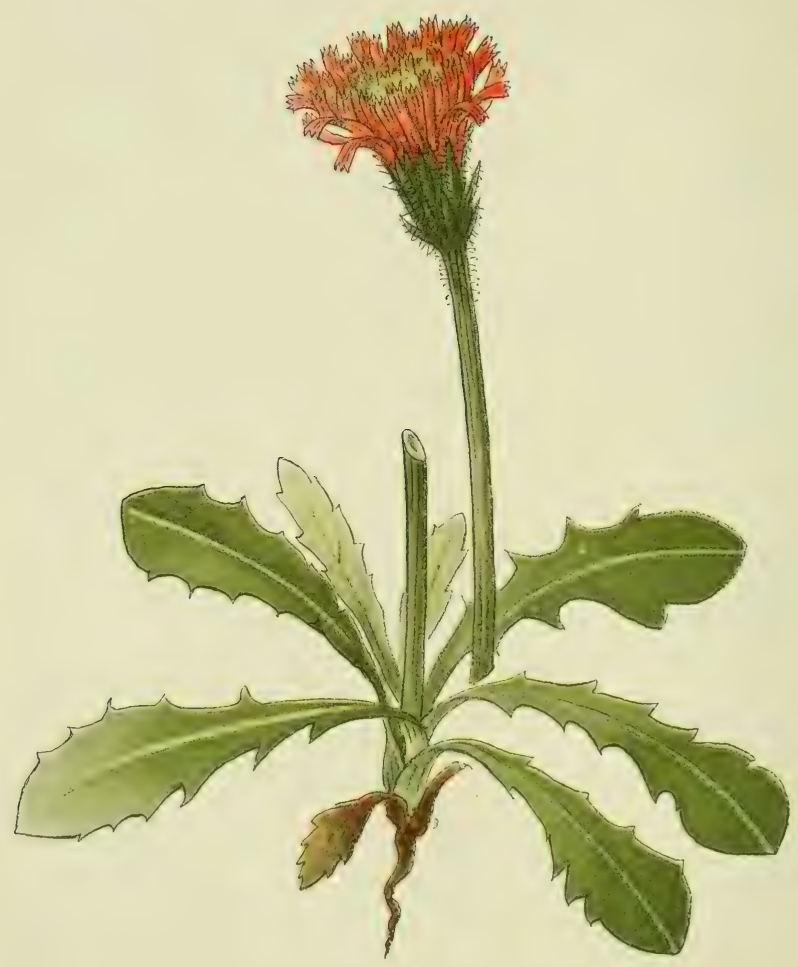

Grepis aurea.

Goldroter Pippau.

Crépide dorée.

Golden Hawksbeard. 
Crepis aurea. - Tafel 78. - Grundftändige Rofette länglicher, grob gezähnter, glatter, glänzender Blätter, die allmählich in den Blattftiel übergehen. Meift nur ein einziger, 6-30 $\mathrm{cm}$ hoher, lchwach behaarter Schaft mit einem aufrechten Köpfchen, das viele zungenförmige, orangerote Blüten enthält. Hüllblättchen mit langen, fteifen, fchwarzen Haaren.

Mehrjährige, vorzügliche Futterpflanze. Blüht Juli Aug. Befucher: vorwiegend Falter.

Früchtchen mit Haar-Fallfchirm: Windverhreitung. Alpen, Jura, Pyrenäen.

Crepis grandiflora. - Großblumiger Pippan. Stengel $40 \mathrm{~cm}$ hoch, aufrecht, verzweigt, fchwach beblättert, mit feinen Drüfenhaaren. Grundfändige Blätter lanzettlich, wie die des Lö w en za hns unregelmäßig, grob gezähnt. Stengelftändige Blätter mit ohrläppchenartig vorgezogenem Blattgrund. Jeder Zweig mit einem grofen, gelben Blütenköpfchen.

Mehrjährig. Blüht Juli Auguft.

Befucher: Käfer, Fliegen, wohl auch Hummeln, Falter.

Früchtchen mit Haar-Fallfchirm: Windverbreitung.

Weiden, befonders auf Urgeftein, bis $2000 \mathrm{~m}$.

Alpen, Appennin, Auvergne, Cievennen, Pyrenäen, Riefengebirge, Karpathen, Kaukafus.

Leontodon Taraxaci. - Pfaffenröhrlein-Löwenzahn. Grundftändige Rofette grob gezähnter Blätter. Blütenfchaft blattlos, unterhalb des Köpfchens verdickt und wie die Hüllblätter dunkel behaart. Alle Blüten zungenförmig, gelb.

Mehrjährig. Blüht Juli Aug. Befucher: Falter, daneben Fliegen, Bienen, Hummeln.

Früchtchen mit Haar-Fallfchirm: Windverbreitung.

Magere Wiefen, fteinige Orte über $1800 \mathrm{~m}$.

Alpen, Pyrenäen, Karpathen.

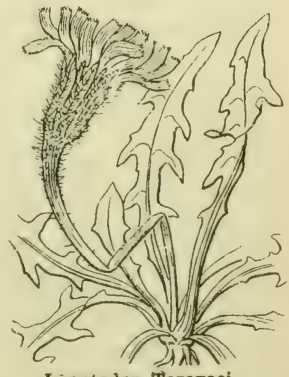

Lèontodon Taraxaci 
Crepis pygmaea. - Tafel 79. - Stengel niederliegend, rom Grund aus äftig. $5-15 \mathrm{~cm}$ hoch. Blätter länglich oval, gezähnt, allmählich in den langen Stiel übergehend, mehr oder weniger weifswollig hehaart. Köpfchenftiele lang, mit je einem blafsgelben Köpfchen, das von fchmalen, fpitzen Hüllblättchen umgeben ift.

Mehrjährig. Blüht Juli.

Befucher: vermutlich Hummeln, Falter.

Früchtchen mit Haar-Fallichirm: Windverbreitung.

Felsblöcke, Gerölle.

$1000-2700 \mathrm{~m}$; fteigt zuweilen tiefer hinab.

Alpen, Pyrenäen.

Crepis blattarioides. - Schabenkrantartiger Pippau.

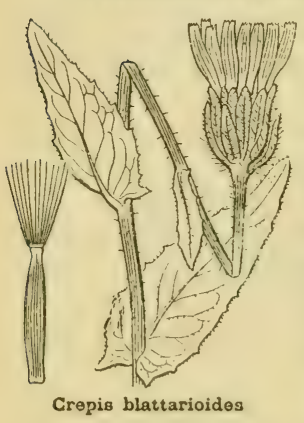

Crepis albida. - Weilblicher Pippau. - Stengel 10 bis $30 \mathrm{~cm}$ hoch. Blätter grundftändig, drüfig behaart, lanzettlich, groh gezähnt. Blütenköpfchen groß, zu 1-3, mit behaarten, am Rande weißen Hüllblättern.

Mehrjährig. Blüht Juni Juli.

Befucher: Fliegen, Bienen.

Früchtchen mit Haar-Fallfchirm: Windverbreitung.

Wiefen, fteinige Rafen, Gerölle, bis $2000 \mathrm{~m}$.

Franzöfifche und italienifche Alpen, Cevennen, Pyrenäen. 
Felsige Matten, Gerölle 1000-2700 Meter.

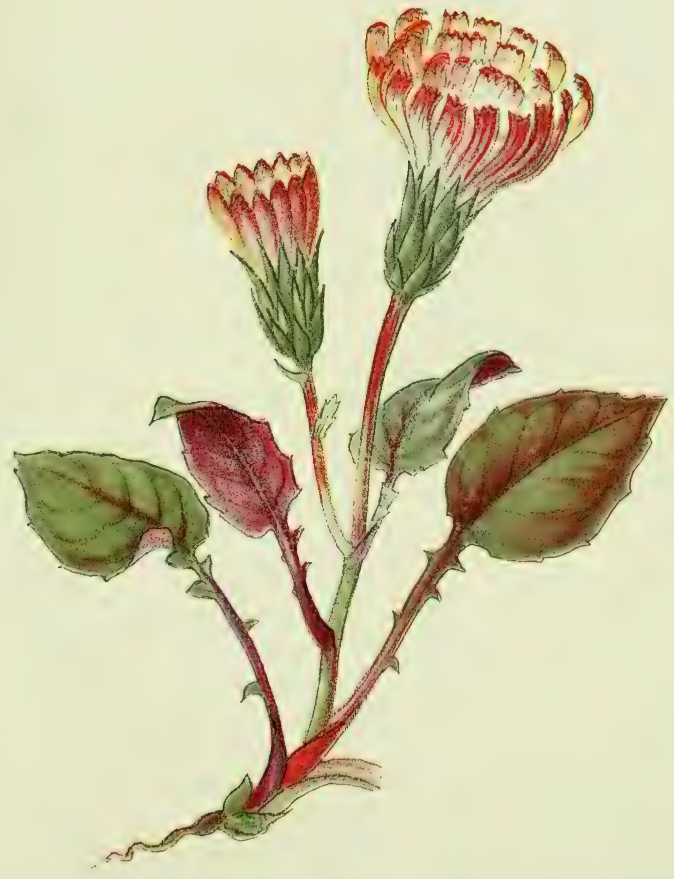

Grepis pygmaea.

Zwerg Pippau.

Crépide naine.

Dwarf-Hawksbeard. 
Felsen der Alpenregion bis über 2000 Meter.

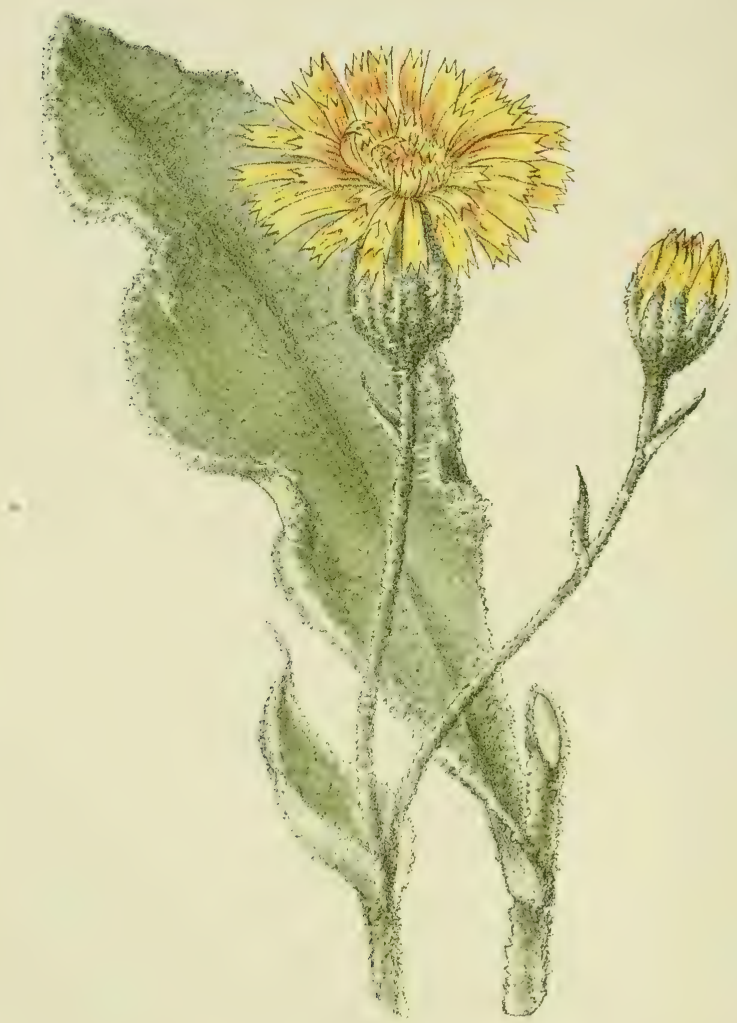

Hieracium lanatum.

Epervière laineuse.
Wolliges I Habichtskraut.

Woolly Hawk-iveed. 
Hieracium lanatum. - Tafel 80. - Ganze Pflanze mit dichtem Kleid von Wollhaaren. Stengel $15-40 \mathrm{~cm}$ hoch, faft vom Grund an verzweigt, mit langen $1-3$ köpfigen Äften. Blätter eiförmig zugelpitzt, geftielt, mit meift gewelltem Rande. Alle Blüten zungenförmig, gelb. Hüllblätter der Köpfchen ebenfalls lang behaart.

Mehrjährig. Blüht Mai bis Juli.

Befucher: vermutlich Fliegen und Falter.

Früchtchen mit Hatr-Fallichirm (diefer fteif, bröichig):

Windverbreitung.

Felfen bis über $2000 \mathrm{~m}$.

Sïdweft-Schweiz, franzöfifche und italienifche Alpen.

Hieracium Anricula. - Öhrchen-Habichtskraut. Rafenbildende Pflanze mit beblätterten, oberirdilchen Ausläufern. Blätter bläulichgrün, lanzettlich, nur an der Bafis behaart, in grundltändiger Rolette. Blütenfchäfte aufrecht, $10-20 \mathrm{~cm}$ hoch, falt blattlos, mit zwei bis fechs kleinen Köpfchen. Alle Blüten zungenförmig, hellgelb.

Mehrjährig.

Blüht Mai bis Oktober.

Befucher: Fliegen, vorwiegend Falter.

Früchtchen mit Haar-Fallfchirm: Windverbreitung.

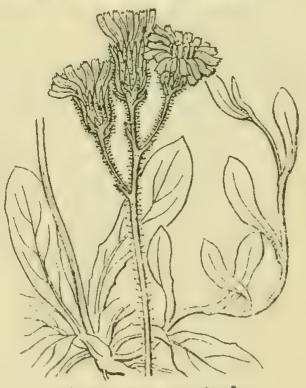

Hieracium Auricula

Hügel bis $2500 \mathrm{~m}$.

In ganz Europa (Alpen, Pyrenäen, Karpathen). 
Compositen.

Hieracium aurantiacum. - Tafel 81. - Faft alle Blätter in grundftändiger Rofette, lebhaft grün, lanzettlich, beiderfeits mit weichen abftehenden Haaren befetzt, ebenfo der 15-40 cm hohe Stengel, der 3-9 dicht Itehende Blütenköpfchen trägt. Hüllblätter mit abftehenden fchwarzen Haaren. Alle Blüten zungenförmig, orangerot.

Zwei- bis mehrjährig. Blüht Juni bis Auguft.

Befucher: Falter.

Früchtchen mit Haar-Fallfchirm: Windverbreitung.

Magere Wiefen, trockene, fteinige Weiden.

$1400-2600 \mathrm{~m}$.

Alpen, Vogefen, Karpathen, Auvergne.

Hieracium staticifolium. - Grasnelkenblattriges

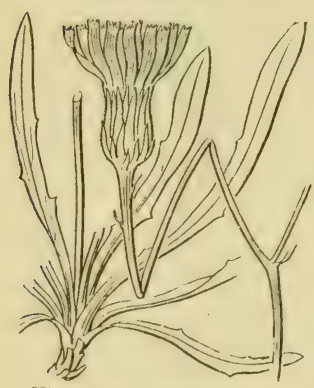

Hieracium staticifolium

Habichtskraut. - Stengel meilt unverzweigt, dünn, 1-2 blättrig, $15-40 \mathrm{~cm}$ hoch, mit unterirdifchen Ausläufern. Meift ganz kahl, bläulichgrün. Blätter fchmal, in grundftändiger Rofette. Blütenköpfchen mit lang zugefpitzten Hüllblättchen. Alle Blüten zungenförmig, fchwefelgelb.

Mehrjährig. Blüht Juli Auguft.

Befucher: Fliegen, vorwiegend Falter.

Früchtchen mit Haar-Fallichirm:

Windverbreitung.

Gerölle, Fellen und Felsblöcke, lteigt oft im Flußskies ins Tal (am Genferfee!), 800-3200 m.

Alpen, Jura. 
Magere Matten, steinige Weiden I400-2600 Meter.

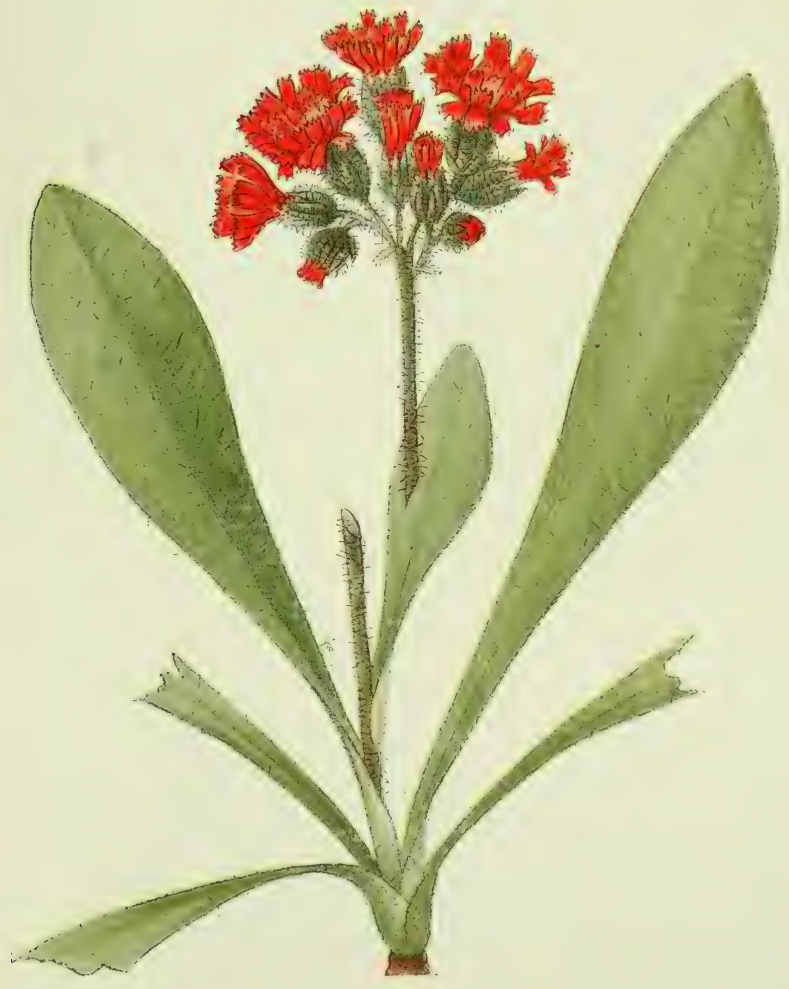

Hieracium aurantiacum. Eperriere orangee.
() Mallgerotes IInbichtsklatut. Grimm the Collier. 
Schattige Nadelholzwaldungen bis 2300 Meter.

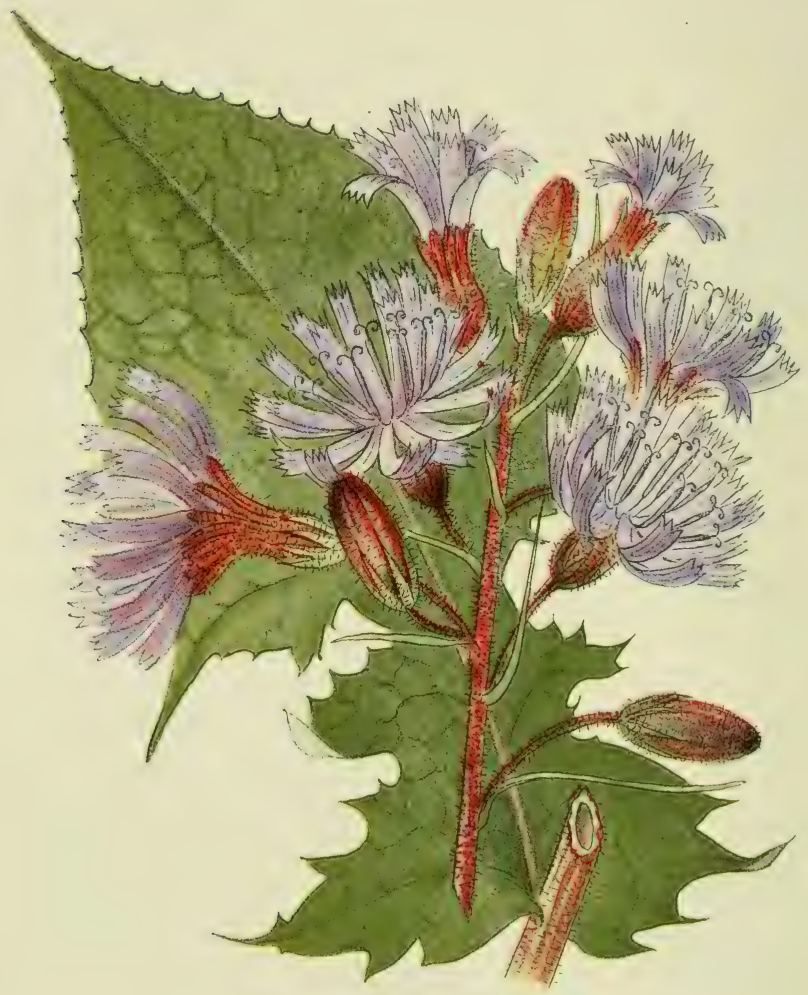

Sonchus alpinus.

Alpen-Gänsedistel. Laiteron des Alpes. Alpine Hare's Lettuce. 
Sonchus (Mulgedium) alpinus. - Tafel 82. - Bis $1 \mathrm{~m}$ hoch, mit unverzweigtem, aufrechtem, oben behaartem Stengel. Blätter faft kahl, breit fchrotlägeförmig eingelchnitten, mit grofem dreieckigem Endabfchnitt; unfaffen mit dem ohrläppchenartig vorgezogenen Grunde den stengel.

Zahlreiche Blütenköpfchen, zu länglicher, drülig-behıarler Traube vereinigt. Alle Bläten zungenförmig, blauviolett.

Mehrjährig. Blüht Juli Auguft.

Befucher: Bienen, Hummeln, Falter.

Früchtehen mit Haar-Fallfchirm: Windverbreitung.

Schattige Nadelholzwälder, Grünerlengebülch, bis $2300 \mathrm{~m}$.

Europäifche Gebirge, z. B. Alpen, Jura, Vogefen, Auvergne, Pyrenäen.

\section{Sonchus (IIulgedium) Plumieri. - Plumiers Milch-} lattich. - Dem vorigen ähnlich, jedoch oberwärts verzweigt, Blätter gleichmäßig eingefchnitten, umfalfen den Stengel ebenfalls mit ihren ohrläppchenartig abgerundeten Bafalzipfeln. Blütenköpfchen in breiter drüfenlofer Traube. Blüten blauviolett.

Mehrjährig. Blüht Juli Auguft. Befucher: vermutlich Bienen, Hummeln, Falter.

Schattige Wälder, Fellen des Bergwaldes, bis $2000 \mathrm{~m}$. Gebirge von Nordeuropa,

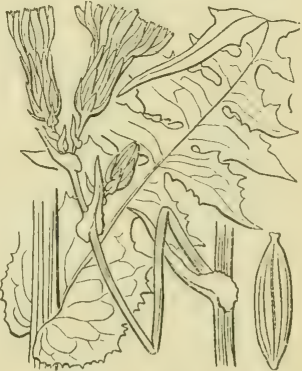

Sonchus Plumieri

Alpen, Vogelen, Gevennen, Pyrenäen. 
Die Campannlaceen find mit den Compositen durch jlıren allgemeinen Bau und die Struktur der Blüten nahe rerwandt und bilden fozulagen deren Vorltufe, auf welcher die belonderen Eigentümlichkeiten derfelben (Schwund des Kelches, Verwachliung der Staubliolben, Anhäufung der Blüten in Köpfchen) fchon angedeutet lind.

Campanula barbata. - Tafel 83. - Stengel 10 bis 35 cm hoch. Blätter lanzettlich. Blüten zu $2-7$ in endftändiger einleitiger Trauhe. Kelch behart, 2/ó-zipflig. Blumenkrone lıellblau, glockenförmigg, ㄴ-3 cm lang, bärtigg, mit 5 kurzen Zipfeln.

Mehrjährig. Blüht Juli Auguft.

Befucher: vorwiegend Hummeln.

Samen klein, flach: Windverbreitung.

Alpen, Sudeten, Transfilvanien.

\section{Campanula latifolia. - Breitblättrige Glockenblume.}

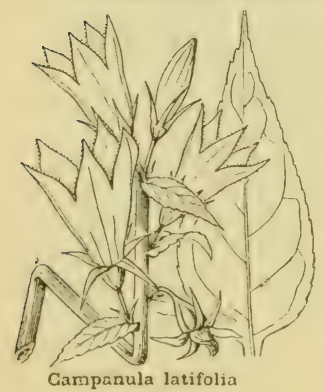

Bis $1 \mathrm{~m}$ hoch, mit dickem Wurzelftock, ftarken, unverzweigten, glatten Stengeln, die große, fpitzeiförmige, fchwach gezähnte Blätter und eine Blütentraube tragen. Blüten $4-5 \mathrm{~cm}$ lang, aufrecht. Krone glockenförmig, blau, 5-zipflig, bis auf $2 / 3$ verwachfen. Mehrjährig. Blüht Juli Auguft. Befucher: Bienen, Hummeln. Samen klein, flach: Windverbreitung.

Lichte Bergwälder, bis zur Waldgrenze.

Pyrenäen, Auvergne, Alpen, Jura, Vogefen, Schwarzwald, bis in den Ural und das Kafpi-Gebiet. 
$-83-$

Mähwiesen, Weiden 900-2800 Meter.

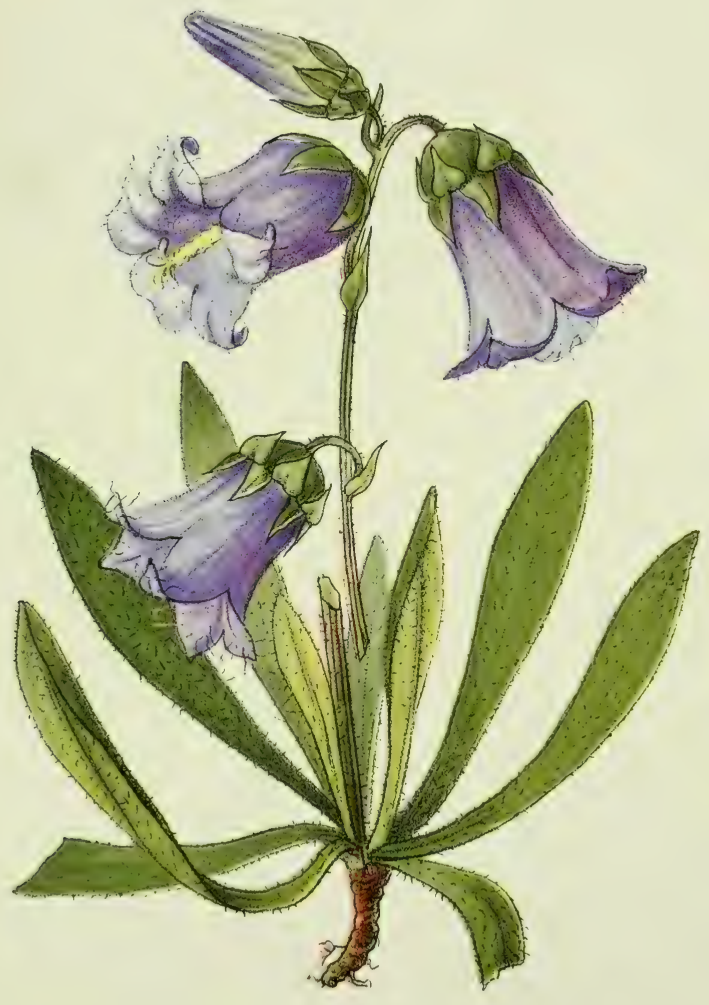

Campanula barbata.

Campanule barbue.

Bärtige Gloclienblume.

Bearded Bell-flower. 
Trockene Weiden, magere Matten i500-2300 Meter.

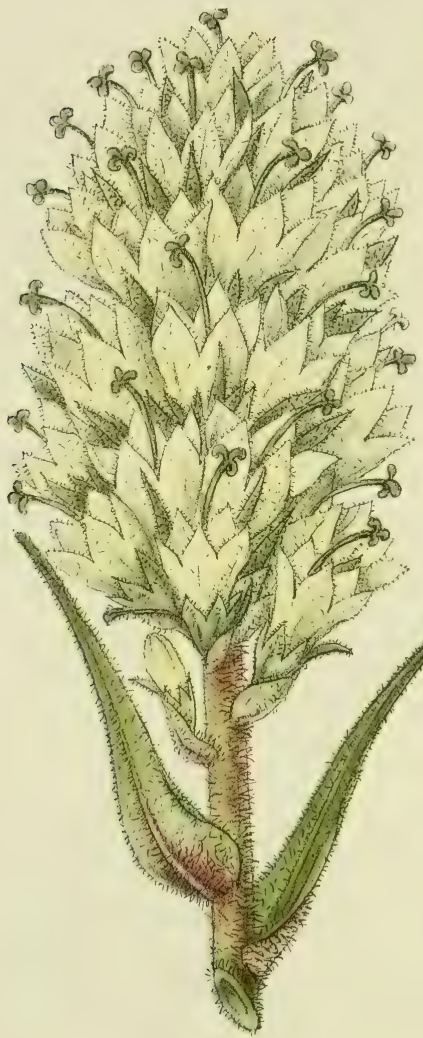

Campanula thyrsoidea. Campanule à fleurs en thyrse.
Straussblütige Glockenblume. Tufted Bell-flower. 
Campanula thyrsoidea. - Tafel 8x. - Rolette von langen li.hmalen, behaarten Blättern. Stengel dick, unverzweigt, 10-30 cm hoch, his zum Blütenftand heblittert. Dieler als dichte, eiförmige Ïlıre ansquebildet. Blüten blafgelb, fteifhaarig, j-zipflig, nur bis zur Nitte verwachlen.

Zveijährig. Blüht Juli Auguft.

Befucher: Hummeln, Falter.

Samen klein, flach: Windverbreitung.

Trockene Weiden, magere Natten, Rafenbänder, befonders auf Kalk, 1500--2300 m.

Alpen, Jura.

Campanula speciosa. - Schöne Glockenblume. Pflanze 20-50 $\mathrm{cm}$ hoch, mit dickem Wurzelftock, ftarken, unverzweigten, aufrechten, kantigen, ftark beblätterten Stengeln, die eine aufrechte Traube von $4-5 \mathrm{~cm}$ langen, lebhaft blauen Blüten tragen. Kelch wie bei Campanula barbata $2 \times 5$-zipflig.

Mehrjährig. Blüht Juni Juli.

Befucher: vermutlich Bienen und Hummeln.

Samen klein, flach: Windverbreitung.

Felfen, Gerölle der Kalkberge.

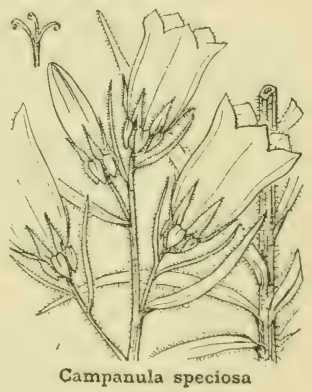
$800-1500 \mathrm{~m}$.

Pyrenäen, Gevennen, fehlt den Alpen.

Campannla medium. - Garten-(xlockenblume. Gleicht der vorigen, belitzt jedoch 5, ftatt nur 3 Narben, und eine 5 fächerige, ftatt 3 fächerige Frucht.

Stammt aus Südeuropa; in mehreren Varietäten mit weifen und rofafarbenen, einfachen und gefüllten Blumen kultiviert. 
Campanula Allionii (alpestris). - Tufel S5. Rafenbildende, Ausläufer treibende, niedere Pflanze. Stengel aufrecht, unverzweigt, an der Bafis mit lanzettlichen und lchwach behaarten Blättern dicht befetzt. Blüten einzeln, blauviolett, überhängend, mit behaartem, 2 , j-zipfligem Kelch. Blumenkrone $3-4 \mathrm{~cm}$ lang, kahl, mit j fehr kurzen Zipfeln.

Mehrjährig. Blüht Juli Auguft.

Befucher: vermutlich Hummeln.

Samen flach, klein: Windverbreitung.

Seealpen, Provence, Dauphiné.

Campanula linifolia. - Leinblätrige Glocken-

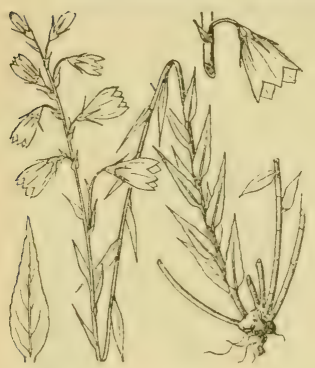

Campanula linifolia

blume. - Kurzer Wurzelltock ohne grundftändige Blattrofette. Stengel dünn, feft, von fchmalen, fpitzen, am Rande fchwach gezähnten, ungeftielten Blättern dicht befetzt. Blüten in endftändiger Traube. Kelchzipfel fpitz. Krone blauviolett, unbehaart, 1-2 cm lang, kurz 5-zipflig.

Mehrjährig. Blüht Juli Auguft. Befucher: vorwiegend Bienen und Hummeln, daneben Falter.

Samen flach, klein: Windverbr. Mähwiefen, trockene Matten.

Franzölifche Alpen, Jura, Vogefen, Auvergne, Cevennen, Pyrenäen. $1000-1800 \mathrm{~m}$.

Campanula rotundifolia. - Rundblätrige Glockenblume. - Der vorigen ähnlich, jedoch zarter. Die kurzlebigen, rolettenbildenden grunditändigen Blïtter lind rundlich, gezähnt; die ftengelftündigen liclımal. Blüten blauviolett, nicht fo zahlreich wie bei voriger.

Mehrjährig. Blüht Juni bis Oktober.

Beftäubung und Samen wie bei voriger.

Felfen, fteinige Orte der Berge.

Gemäßigte Zone der nördlichen Halbkugel, in Lappland bis $71^{\circ} \mathrm{n} . \mathrm{Br}$. 
Felsblöcke, Gerölle ı600-2600; Meter.

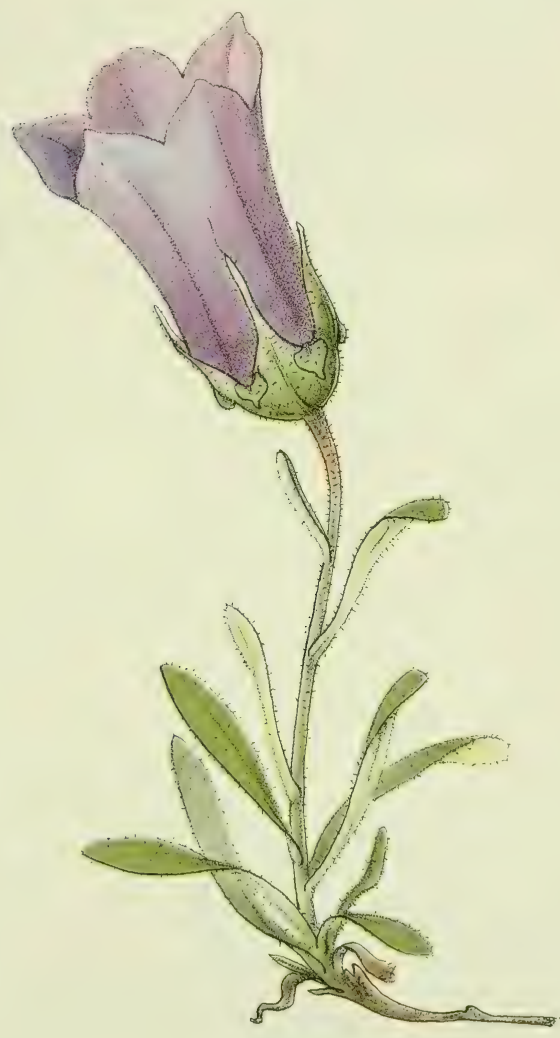

Campanula Allionii.

Campanule d'Allioni.
Allioni's Glockenblume. Allioni's Bell-flower. 
Steinige Orte, nicht über der Baumgrenze.

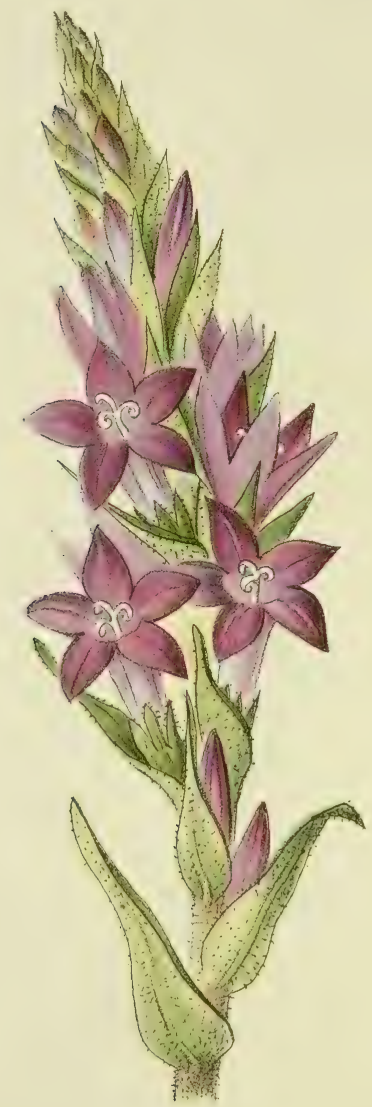

Campanula spicata. Campanule en épi.

Aehrige Glockenblume. Spiked Bell-flower. 
Campanula spicata. - Tafel 86. - Hohe, weifs behaarte Pflanze mit dicker, lpindelförniger Wurzel und aufrechtem, unten ftark beblïttertem Stengel. Blitter lang, fpitz, mit welligen Rändern, ungeltielt, bor'ttig behaart. Blüten in langer Älıre, die den gröfsten Teil des stengels in Anlpruch nimmt. Kelch und Krone behaart, letztere trichterförmig, blau, 5zipflig, bis auf ${ }^{2} / 3$ verwachfen.

Zweijährig. Blüht Juni Juli.

Befucher: vermutlich Käfer und Bienen.

Samen flach, klein: Windverbreitung.

Steinige, trockene Weiden und Halden der Alpen von Frankreich, Italien, der Südfchweiz und Tirol.

Campanula persicifolia. -- Pfirfichblittrige Glockenblume. - Ganze Pflanze kahl, glänzend, mit dünnem, kriechendem Wurzelftock, $40-80 \mathrm{~cm}$ hoch. Blätter fchmal-lanzettlich, fpitz, fchwach gezähnt, gegen die Batis in den Stiel verfchmälert. Der Stengel trägt eine lockere, 2-6blütige Ähre. Blüte 3-4 cm lang, blauviolett, unbehaart, weit geöffnet, mit 5 kurzen Zipfeln. Wie die meiften Campamula-Arten kommt auch diefe zuweilen weißblütig vor.

Mehrjährig. Blüht Juni Juli.

Befucher: Käfer, Bienen.

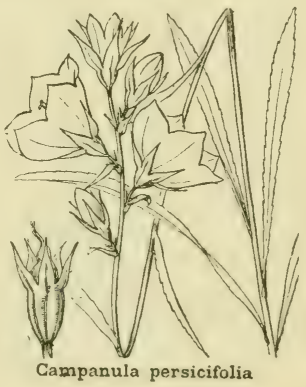

Samen klein, flach: Windverbreitung.

Lichte Bergwälder bis $1800 \mathrm{~m}$.

In faft ganz Europa bis Sibirien. 
Campanula cenisia. - Tafel 8\% - Nur 2-6 cm hoch, fein behaart, mit kriechendem Wurzelftock, der Rofetten kleiner, eiförmiger Blätter, und zuerft niederliegende, dann auffteigende, einblütige Stengel trägt. Blüten dunkelblau, aufrecht. Krone weit geöffnet, 19-15 mm lang, 5zipflig, nur am Grund verwachlen.

Mehrjührig. Blüht Juli Auguft. Befucher?

Samen klein, flach: Windverbreitung.

Weftalpen (Frankreich, Italien, Wallis), Tirol.

Campanula pusilla. - Kleine Glockenblume. - Nur

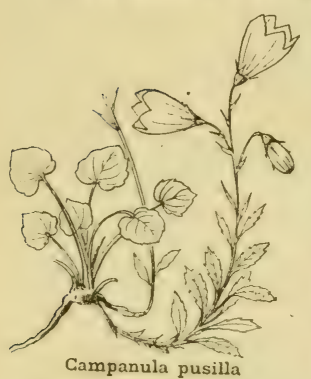

$5-15 \mathrm{~cm}$ hoch, mit zahlreichen Rofetten rundlicher, geftielter Blätter. Stengel dünn, mit f́chmallanzettlichen, gezähnten Blättern. Blüten hellblau, häng'end, in 1-4blütigen Trauben auf fehr' feinen Blütenftielen. Krone röhrig-glockenförmig, 10 bis $15 \mathrm{~mm}$ lang, kurz כ̌zipflig.

Mehrjährig. Blüht Juni Juli.

Befucher: Bienen, Hummeln.

Samen klein, flach: Windverbr. Steinige Weiden, Felsblöcke, bel'onders auf Kalk.

Alpen, Jura, Pyrenäen, Karpathen.

Campanula Schenchzeri. - Scheuchzers Glocken-

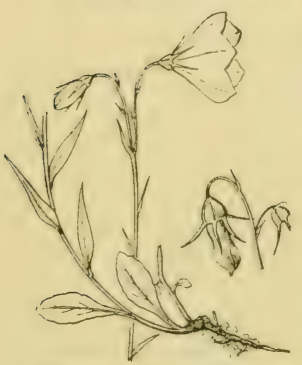

Campanula Scheuchzeri

blume. - Der vorigen ähnlich, bildet jedoch keine Ralen. Alle Blätter länglich. Blüten nickend, $15-20 \mathrm{~mm}$ lang, weit glockenförmig, oft einzeln am Ende des Stengels.

Mehrjährig. Blüht Juli Augult. Befucher: Bienen, Hummeln. Samen klein, flach: Windverbr. Trockene Matten, felfiger Boden. $1600-3000 \mathrm{~m}$.

Pyrenäen, Alpen, Jura, Transfilvanien, nordpolare Länder, Altai. 
Gesteinsschutt 2000-3300 Meter.

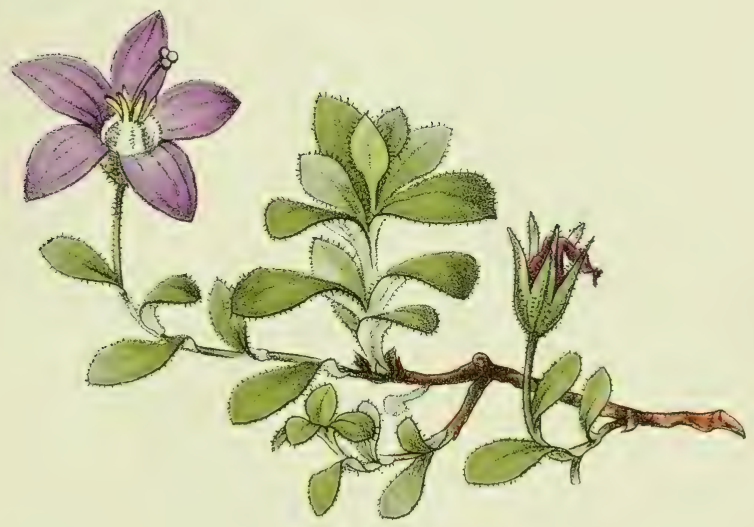

Gampanula cenisia.

Campanule du Mont-Cenis.
Glockenblume des Innt-Cenis. Bell-flower of Mt. Cenis. 
Fette Matten 700-2000 Meter.

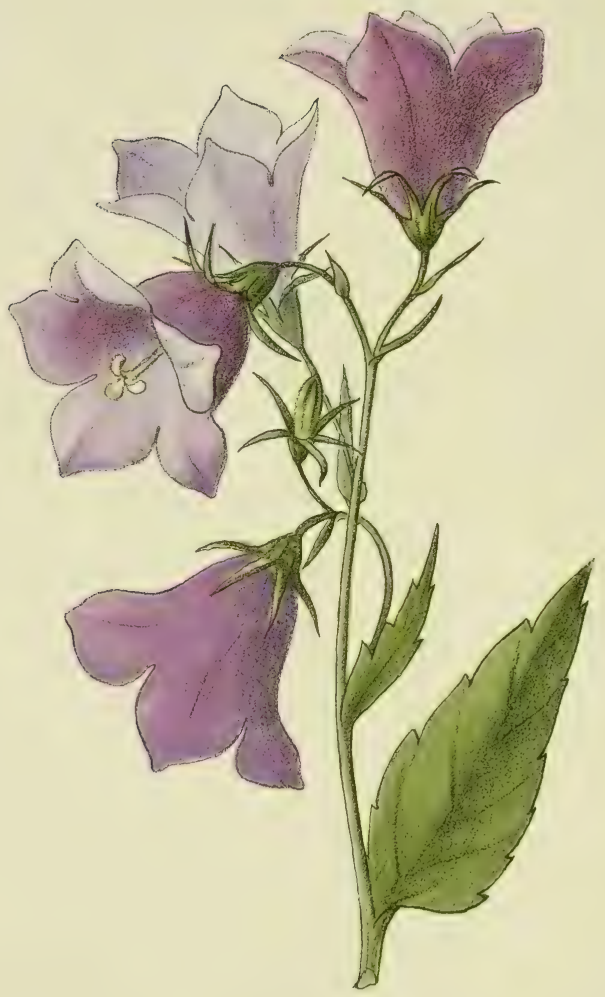

Campanula rhomboidalis. Rautenblättrige Glockenblume. Campanule à feuilles rhomboidales. Rhombic-leaved Bell-flower. 
Campanula rhomboidalis. - Tafel 8s. - Stengel 30-60 cm hoch, auf feiner ganzen Länge mit eiförmigen, 2-5) $\mathrm{cm}$ langen, am Grunde verbreiterten, ungeftielten Blättern beletzt, die feicht gezälnnt lind. Blüten blau, in 2-10 blütigen, einleitigen Trauben, aufrecht oder hängend.

Mehrjährig. Blüht Juni bis Auguft.

Befucher: Bienen.

Samen klein, flach: Windverbreitung:

Häufig auf Alpwiefen und fetten Weiden.

$700-2000 \mathrm{~m}$.

Alpen, Jura, Pyrenäen.

Campanula bononiensis. - Bolognefer Glockenblume. Wurzel rübenförmig. Stengel kräftig, $30-60 \mathrm{~cm}$ hoch. Blätter geftielt, herzförmig, unterfeits wollig weißhaarig. Blüten blau, fehr zahlreich, in langer dichter Traube.

Mehrjährig. Blïht Juli Augult. Befucher: Käfer, Bienen.

Samen klein, flach: Windverbreitung.

Bergwälder, fteigt in Deutlchland bis in die Ebene hinab. Europa, Afien bis zum Altai.

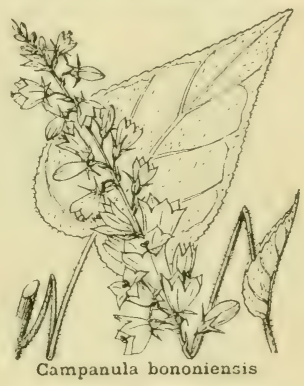

Campanula excisa. - Ausgefchnittene Glockenblume. - Zarte Pflanze mit zuerft kriechenden, dann auffteigenden dünnen Stengeln. Blüten blau, bauchig; am Grunde jedes der 5 Kronzipfel ein runder Ausfchnitt.

Mehrjährig. Blüht Juli Auguft.

Befucher: vermutlich Hummeln.

Samen klein, flach: Windverbreitung.

Gerölle, Gefteinsfchutt, Felsfpalten.

Ober-Wallis. 
Bei allen Phyteuma-Arten fitzen die langröhrigen, aufyefchlitzten Blüten, wie bei den rerwandten Compositen, in mehr oder weniger kitgeligen Köpfchen. Kelch aber noch blattartig, nicht haarförmig wie bei den Compositen.

Phyteuma betonicifolium. - Tafel 89. - Stengel aufrecht, unterwärts mit lang-eiförmigen, fpitzen, fchwach gezähnten und plötzlich in den langen Stiel verfchmälerten Blättern. Blüten blauviolett, in zuerft kugeliger, fich während des Blühens ftreckender Ähre.

Mehrjährig. Blüht Juli Auguft.

Befucher: Bienen, Hummeln.

Samen klein: Windverbreitung.

Pyrenäen, Auvergne, Italien, Alpen bis Transfilvanien.

Phyteuma Charmelii. - Charmelis Rapunzel. -

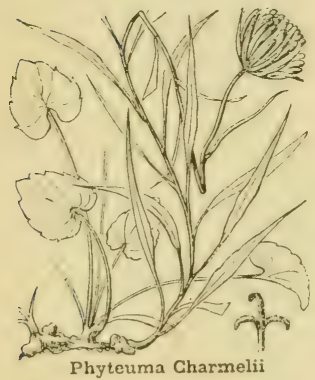

Kleine unbehaarte Pflanze mit mehreren zarten Stengeln. Grundftändige Blätter herzförmig, gezähnt; ftengelItändige fchmallanzettlich. Blüten blauviolett, in kugeligen, $12-15 \mathrm{~mm}$ großen Köpfchen, die von langen l'chmalen Blättchen umgeben werden.

Mehrjåhrig. Blüht Juli. Befucher? Spalten der Kalk-undDolomitfelfen. Hügelregion bis $2000 \mathrm{~m}$.

Weftalpen (Dauphiné, Provence, Italien), Gevennen, Pyrenäen.

Phyteuma Halleri. - Hallers Rapunzel. - Von den übrigen Phyteuma-Arten an ihren fchwarz-violetten, länglichen Köpfchen leicht zu unterfcheiden. Stengel aufrecht $50-100 \mathrm{~cm}$ hoch, bis oben beb]ättert. Grundftändige Blätter langgeftielt, herzförmig.

Mehrjährig. Blüht Juni Juli.

Befucher: Fliegen, Bienen, Falter.

Samen klein: Windverbreitung.

Wielen, Rafenplätze. $1000-2600 \mathrm{~m}$.

Pyrenäen, Transfilvanien, ganze Alpenkette. 
Trockene, steinige Orte 1200-2300 Meter.

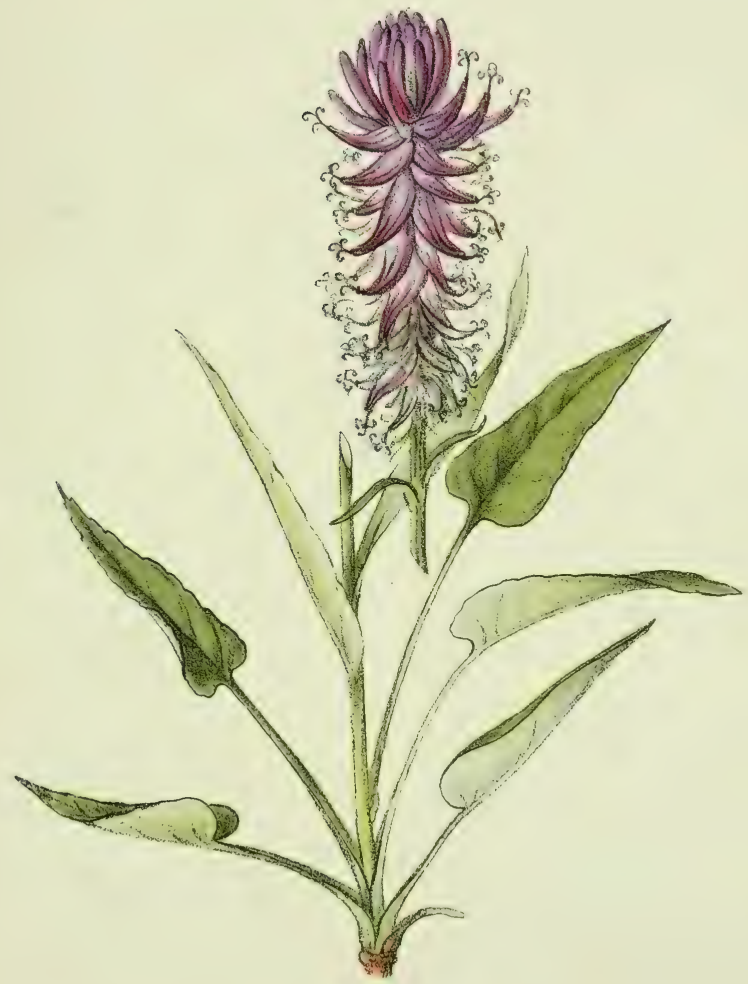

Phyteuma betonicifolium. Raiponce à feuilles de bétoine.

Betonicablättrige Rapunzel. Betony-leaved Rampion. 
Magere Matten, steinige Halden 400-2700 Meter.

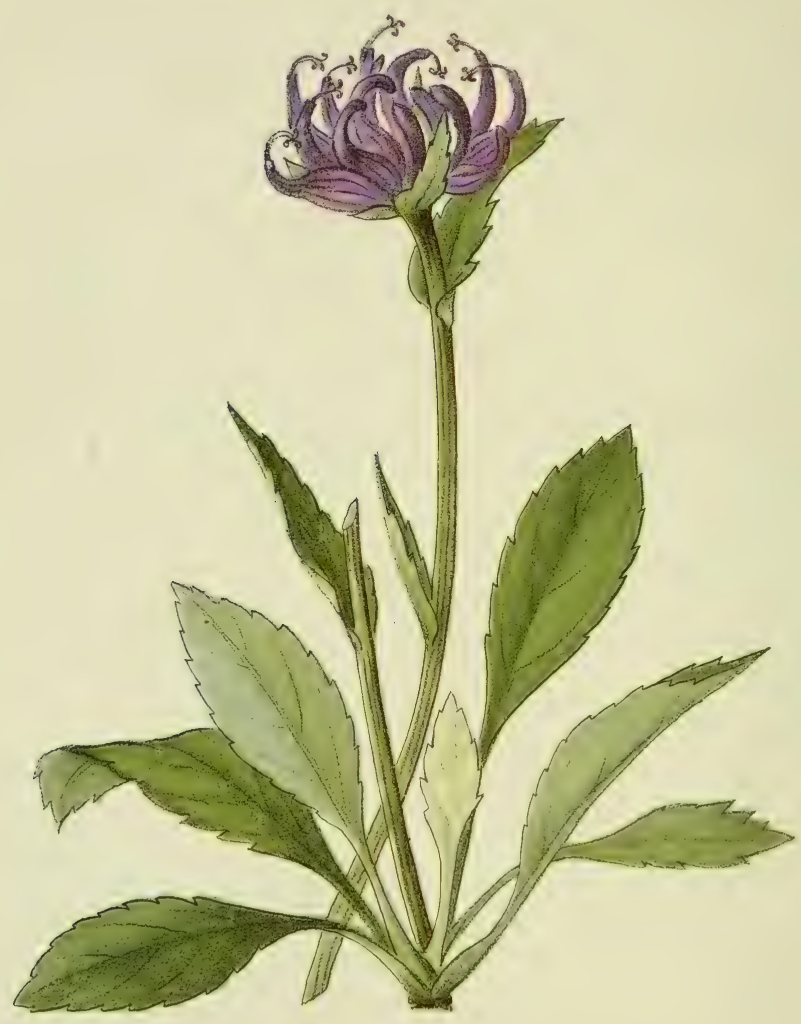

Phyteuma orbiculare. Raiponce à fleurs globuleuses.
Kugelige Rapunzel. Globular Rampion. 
Pliyteuma orbiculare. - Tafel 90. - Stengel aufrecht, gerade, fchwach beblättert. Blätler etwas lederartig, lang eiförmig, gezähnt; die grundftändigen plötzlich in den Stiel verlchmälert, die ftengelftändigen ungeftielt. Blütenköpfehen blauviolett, zuerft kugelig, dann eiförmig, 15--5.5 $\mathrm{mm}$ groß, mit l'chmal eiförmigen Hüllblättchen.

Mehrjährig. Blüht Juli Auguft.

Befucher: Hummeln, vorwiegend Falter.

Samen klein: Windverbreitung; befonders auf Kalk. Auf allen Bergen Mitteleuropas.

Phyteuma hemisphaericum. punzel. - Höchftens $10 \mathrm{~cm}$ hoch, mit dünnem, fchwach beblättertem Stengel. Blätter grasartig. Blüten blauviolett in kugeligem, $10-12$ blütigem Köpfchen; Hüllblättchen klein, fpitzeiförmig.

Mehrjährig. Blüht Juli Auguft.

Befucher: Bienen, Falter.

Samen klein: Windverbreitung. In niedrigem Rafen, humusreichen Matten.

$1200-3000 \mathrm{~m}$.

Alpen, Cevennen, Pyrenäen, Transfilvanien.

Halbkugelige Ra-

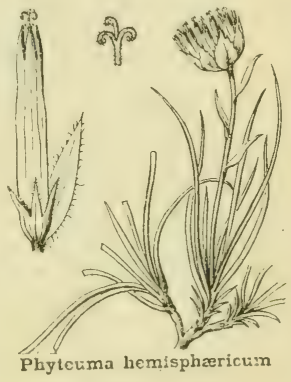

Phyteuma pauciflorum. - Wenigbliitige Rapunzel. Von voriger leicht zu unterfcheiden an den eiförmigen, rolettig angeordneten grundftändigen Blättern, und den nur $\tilde{a}-6$ blütigen, höchftens $1 \mathrm{~cm}$ groß3en Köpfchen, mit lpitzeiförmigen Hüllblättchen an ihrem Grunde.

Mehrjährig. Blüht Juli Auguft. Befucher: Hummeln.

Samen klein: Windverbreitung. Rafenbänder, Gefteinslichutt, auf Urgeftein. $1800-3300 \mathrm{~m}$. Alpen, Pyrenäen, Transfilvanien.

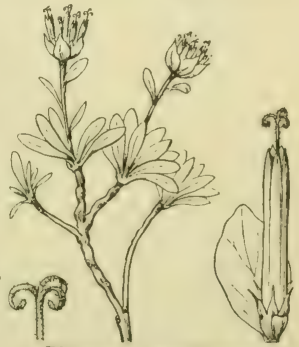

Phyteuma paucillorum 
Rhododendron ferrugineum. - Tafel 91. - Stark verzweigter, bis $80 \mathrm{~cm}$ hoher Strauch, mit knorrigen, unterwärts oft unheblätterten Äften. Blïtter winterhart lederig, am Rande umgerollt, lanzettlich, oberfeits dunkelgrün, kahl, unterfeits roftbraun. Blüten zu $4-8$ in Trauben. Krone 5zipflig, rofa, auf der Aufenfeite mit roftbramen Flecken.

Mehrjährig. Blüht Juli Augult.

Befucher: Hummeln, Bienen.

Samen klein, flach: Windverbreitung.

In humusreichem Boden, auf Weiden, in Wäldern, Torfmooren, befonders auf Urgeftein (im Jura auf Kalk, vergl. I. Teil Seite 42).

Alpen, Jura, Pyrenåen.

\section{Rhododendron hirsutum. - Ranhhaarige Alpenrofe.}

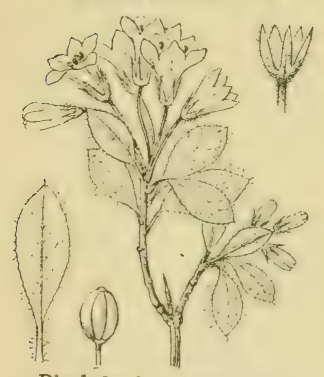

Rhododezdron hirsutum

Von voriger an den beidfeitig grünen Blättern zu unterfcheiden, die mit langen, fteifen Haaren befetzt find, fowie an dem behaarten Kelch.

Mehrjährig.

Blüht Mai bis Juli.

Befucher: Hummeln, Bienen.

Samen flach, klein: Windverbreitung.

Weniger weit verbreitet als vorige, befonders auf Kalk.

$1400-2600 \mathrm{~m}$.

Alpen der Schweiz, Italien, Öfterreich, Karpathen.

Mit den rorigen verwandt find folgende, in den Alpen ebenfalls weit verbreitete Sträucher:

Erica carnea, das lleifchrote Heidekraut, mit tannnadelartigen Blättern und lang-glockenförmigen Blüten, in dichter einfeitiger Traube. Blüht April, Mai.

Arctostaphylos uva ursi, die Bärentraube, breitet ihre niederliegenden Äfte teppichartig auf fteilen Abhängen aus. Blätter elliptifch, glänzend. Blüten weif oder rofa, fchellenartig aufgetrieben, in kurzen Trauben. Im Sommer trägt fie fchon die roten, kugeligen Beeren. 


\section{$-91-$}

Weiden, Bergwälder, Torfmoore i200-2700 Meter.

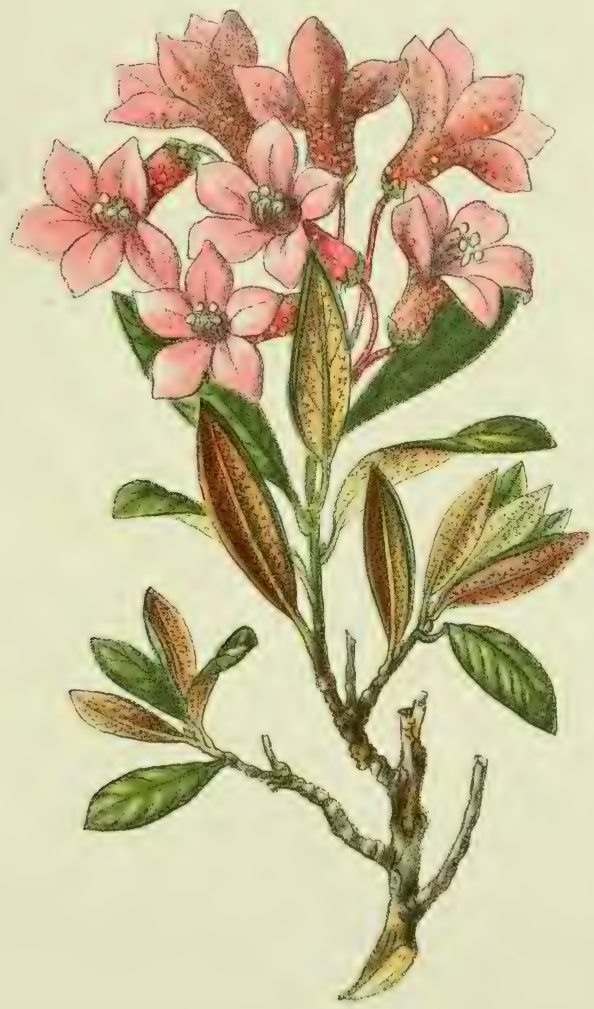

Rhododendron ferrugineum. Rhododendron ferrugineux.

Rustblätrige Mpenruse. Rust-leaved Rhododendron. 
Wälder, trockene Torfmoore, Heiden bis 2500 Meter.

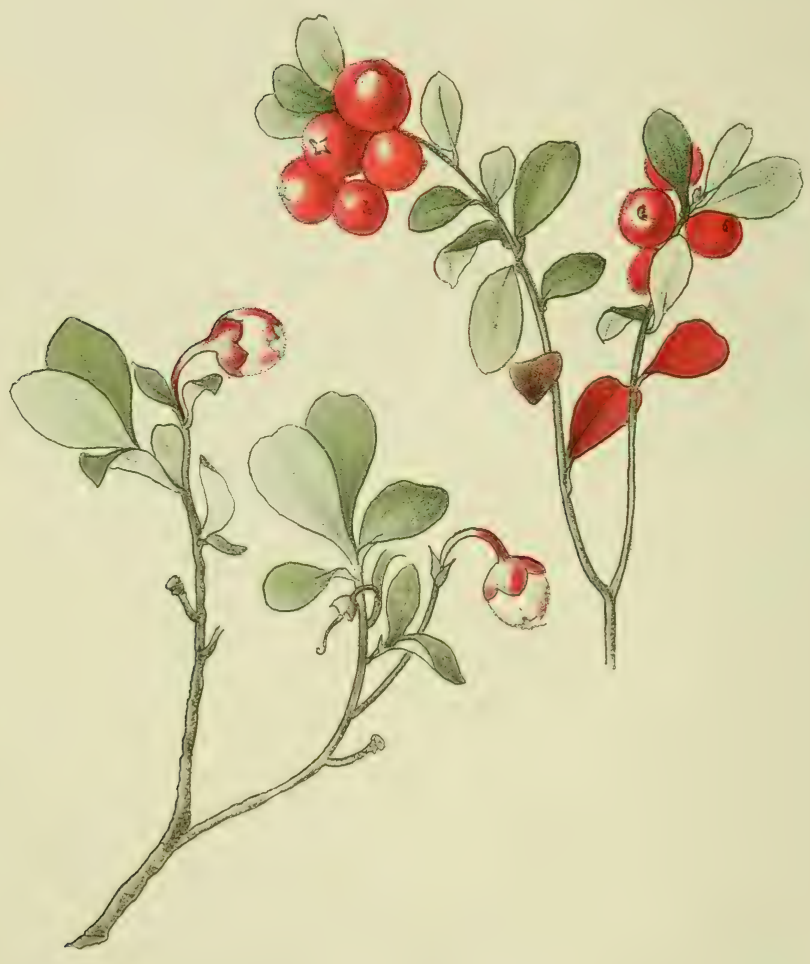

Vaccinium Vitis-Idaea. Airelle rouge, Canche.

Preisselbeere.

Cow-berry. 
Vaccinium Vitis Jdaea. - Tafel 92. - Strauch von 10 - 40 cın Höhe, mit eiförmigen, glänzenden, am Rande umgerollten, winterharten Blättern, die unterfeits punktiert lind. Blüten rofi, glockenförmiğ, in hänğenden Trauben. Kugrelige, rote, lauer l'chmeckende Beerenfrucht.

Mehrjährig. Blüht Mai bis Juli.

Befucher: Bienen, Hummeln.

Beeren durch Vögel verbreitet.

In humusreichem Heide- und Waldboden.

Weit verbreitete, noldifche Pflanze: Npen, Jura, Vogefen, Schwarzwald etc.; Auvergne, Cevennen, in den Pyrenäen fehr felten; Karpathen, Kaukafus, nordpolare Länder, Ural, Altai, Himalaya.

Vaccinium nliginosum. - Raufchbeere. - Bis $1 \mathrm{~m}$ hoher Strauch mit runden, verholzten Äften. Blätter eiförmig, flach, oberleits matt, unterfeits bläulichgrün, mit ftark hervortretenden Nerven; im Herbft abfallend. Blüten weiß oder rötlich, glockenförmig, in kleinen hängenden Trauben. Beere kugelig, l'chwarzblau, gefebmacklos.

Mehrjährig.

Blüht Mai Juni.

Befucher: Bienen, Hummeln.

Beeren durch Vögel verbreitet.

Sumpfige Wälder, Torfmoore,
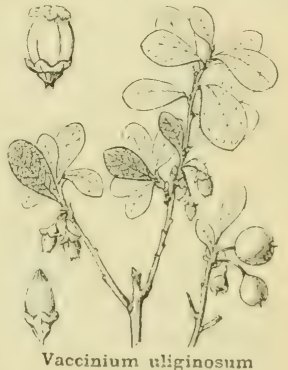

Vaccinium เliginosum in feuchtem, humusreichem Boden.

Ebene bis $3000 \mathrm{~m}$.

Alpen, Jura, Vogefen, Schwarzwald etc.; Auvergne, Cevennen, Pyrenäen; Karpathen, Kaukafus, nordpolare Länder, Ural, Altai.

Die Heidelbeere, Vaccinium Myrtillus, ift von del vorigen durch ihre krantigen, kantigen Äfte, die heiderleits grünen Blätter und die wohlfchmeckenden Beeren leicht zu unterfcheiden. 
Die Pinguicnla-Arten oder Fettkränter verdanken ihren Namen der fleifchigen Konfiftenz ihrer Stengel und Blätter. Letztere ftehen in ausgebreiteter, dem Boden angedrückter Rofette. Sie find auffallend gelbgrün gefärbt, mit aufwärts gebogenen Rändern. Mit den auf ihrer Oberfeite ftehenden klebrigen Drüfenhararen werden kleine Infekten gefangen unrl damm mit einer magenlaftartigen Flüffigkeit verdaut. Pinguicula ilt alfo ein Vertreter der logenannten fleilchfreffenden Pflanzen.

Aus der Mitte ihrer Blattrolette erheben fich 1-y höchftens $10 \mathrm{~cm}$ hohe Blütenfchäfte, mit je einer veilchenartigen Blüte, deren Blumenblitter aber untereinander verwachfen find.

Pinguicula vulgaris. - Tafel $93 \mathrm{~A}$. - Blüten violett, Sporn lang walzenförmig, fpitz.

Mehrjährig. Blüht Mai Juni.

Befucher: Bienen.

Samen klein: Windverbreitung.

Feuchte Felfen, Quellen, torfige Matten.

Ebene bis $2600 \mathrm{~m}$.

Europa, Afien, Amerika bis in den hohen Norden.

Pinguicula alpina. - Tafel $93 \mathrm{~B}$. - Blïten weiß, mit zwei gelben Flecken auf dem unteren Kronzipfel (Lippe). Sporn kurz kegelförmig, gebogen, ftumpf.'

Zweijährig. Blüht April bis Juli.

Befucher: vorwiegend Fliegen.

Samen klein: Windverbreitung.

Feuchte Felfen, Quellen, auf naffem Moos.

Ebene bis $2400 \mathrm{~m}$.

Alpen, Pyrenäen, Karpathen, nordpolare Länder, Ural, Altai, Himalaya. 
Feuchte Felsen, Quellen, torfige Matten

Ebene bis 2400 Meter. $\quad$ 1000-2600 Meter.

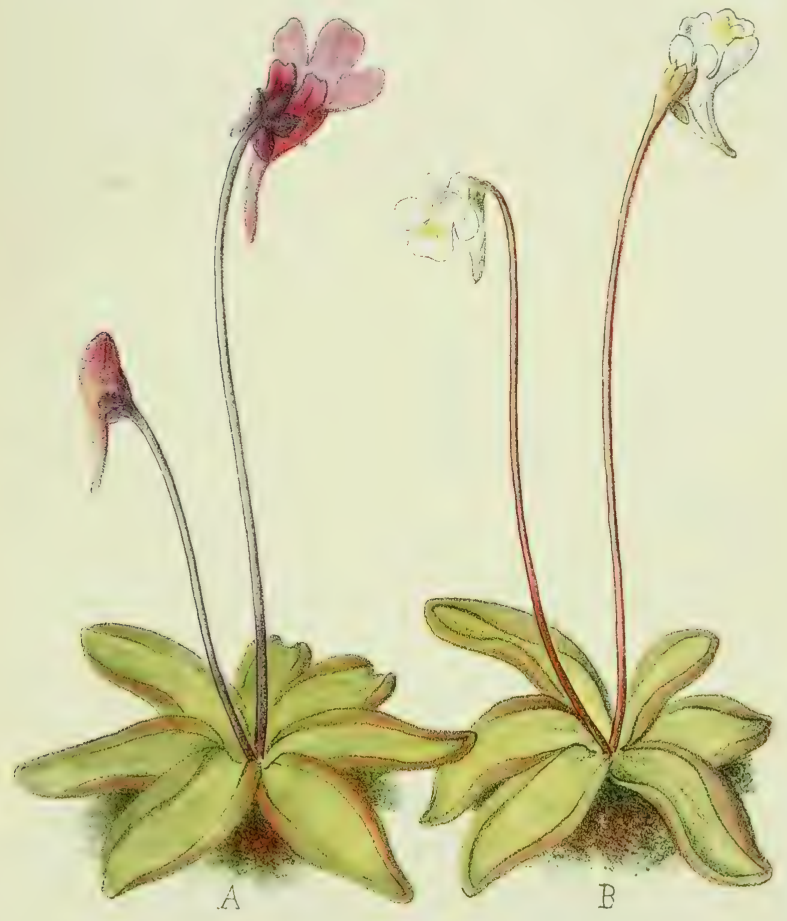

A. - Pinguicula vulgaris.

Gewöhnliches Fettkraut.

Grassette commune.

Common Butterwort.
B. - Pinguicula alpina.

Alpen-Fettkraut.

Grassette des Alpes. Alpine Butterwort. 


\section{$-94-$}

Feuchte Felsen, bewaldete Hänge i200-1900 Meter.

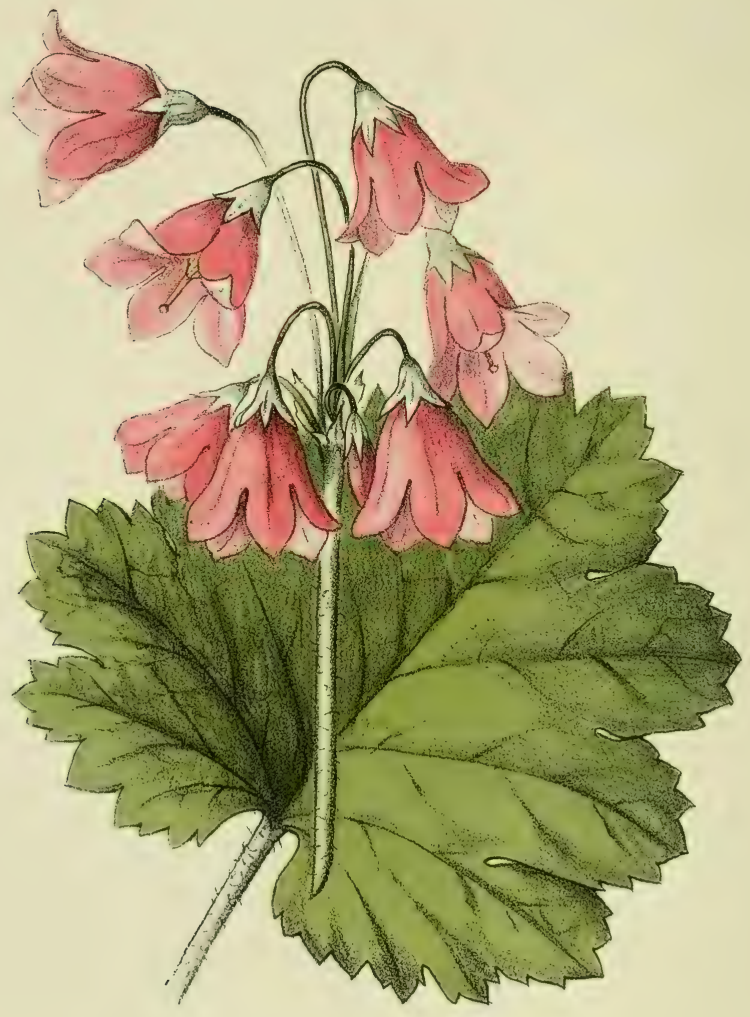

Cortusa Matthioli.

Cortuse de Matthiole.
Matthioli's Heilglöckchen. Matthioli's Mountain Sanicle. 
Die Primeln und ihre Verwandten gehören zum Anfiprechendften, was mam in den Alpen an Pflanzen findet. Ihr niedriger Wuchs mit den ungeteilten, zu Roletten vereinigten Blättern, aus deren Mitte fich der Blütenfchalt mit einer bald reicheren, bald ärmeren Dolde von verhältnismä̈ßig großen, 5zähligen, lieblich gefürbten Blumen erhebt, bietet ein in leiner Schlichtheit einzig fchönes Bild. Dasfelbe tritt durch den Kontraft mit dem Standort befonders hervor, indem fehr viele Formen die kahlen Felsritzen bewohnen, manche als fogenannte Polfterpflanzen von moosähnlichem Wuchs.

Cortusa Matthioli. - Tafel 94. - Stark behaarte Pflanze mit Rofetten von langgeftielten, rundlichen, unregelmäfisg gelappten und gezähnten Blätterm. Der 40-50 cm hohe Blütenl'chaft überragt die Blätter und trägt 4-12 zu einer Dolde vereinigte, zuerft rofa, dam violett gefärbte, wohlriechende Blüten auf zarten, ungleich langen Stielen. Blumenkrone glockenförmig, 5̃zipflig.

Mehrjährig. Blüht Mai Juni. Befucher?

Samen ohne Verbreitungsmittel.

Feuchte Fellen, bewaldete Hänge, felten.

Alpen von Savoyen, Schweiz, Bayern, Öfterreich; Nordafien, lüdweftlicher Himalaya. 
Soldanella alpina. - T'afel 95. - Die zu einer grundftändigen Rofette vereinigten Blätter find rundlich oder nierenförmig, ungezähnt, etwas lederig. Der zarte, violettrot gefärbte Blütenfchaft trägt $1-3$ überhängende, glockenförmige, violette Blüten, deren Krone von der Mitte an ausgefranft ift. Aus dem Krontrichter ragt der Griffel wie cin Glockenfchwengel hervor.

Mehrjährig. Blüht Mai bis Juli, gerade nach der Schneefchmelze (vergl. I. Teil Seite 7).

Befucher: Hummeln, Falter.

Samen ohne Verbreitungsmittel.

Sehr verbreitet auf humusreichen Matten, und in Schneetälchen; fteigt zuweilen aus ihrem eigentlichen Gebiet $(1500-3000 \mathrm{~m})$, in den Lawinenzügen tiefer ins Tal.

Alpen, Jura, Auvergne, Pyrenäen, Karpathen.

Soldanella pusilla. - K leines Alpenglöckchen. Ift in allen 'Teilen kleiner als voriges. Blüten meift einzeln, Krone rötlich-violett, faft zylindrilch, nur in äuferen Drittel gefranft. Der Griffel ragt nicht aus der Krone hervor.

Mehrjährig. Blüht Mai bis Juli.

Befuchèr: Hummeln, Fliegen.

Samen ohne Verbreitungsmittel.

Humusreiche Matten, Schneetälchen, 1600-3000 m. Alpen, Karpathen. 


\section{$-95-$}

Matten 1500-3000 Meter.

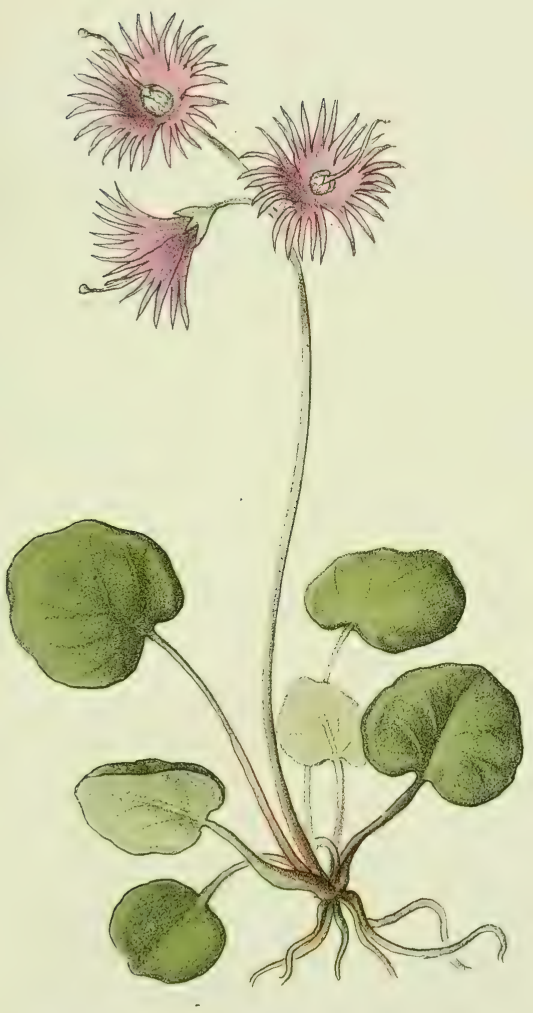

Soldanella alpina.

Alpenglöckchen. Soldanelle des Alpes. Alpine Soldanella. 
Schattige, steinige Gebüsche bis 700 Meter.

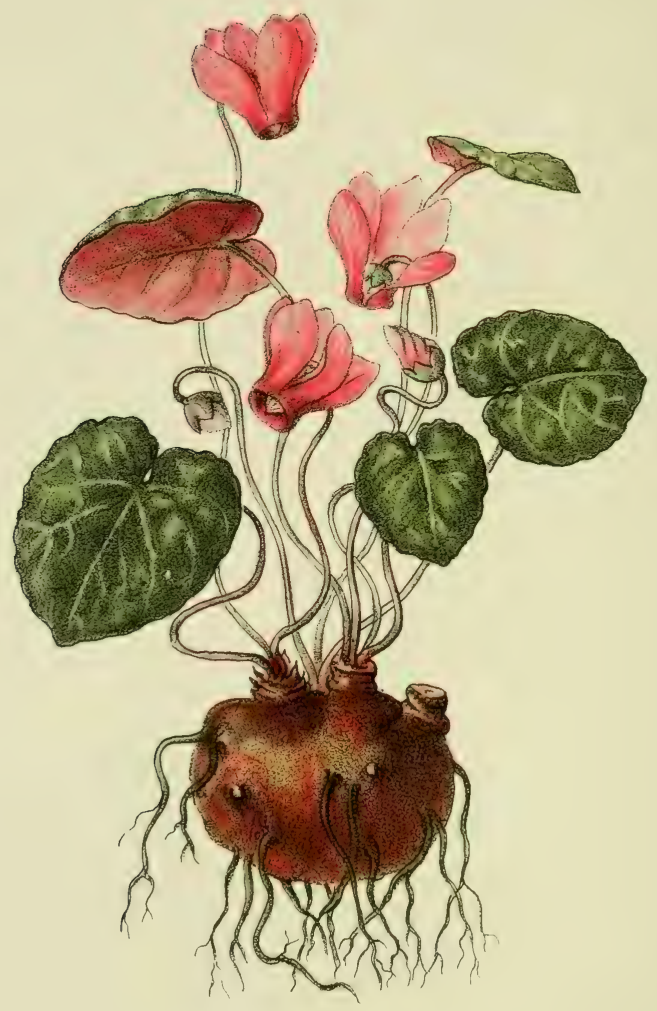

Cyclamen europæum. Cyclamen d'Europe.
Europaeische Erdscheibe. European Sow-bread. 
Cyclamen europaeum. - Tafel 96. - Abgelehen von der merkwürdigen Blüte mit den gegen den Stiel zurückgelichlagenen Blumenkronzipfeln und dem knollig verdickten Stengel ift auch Cyclamen eine typilche Primulacee. Aus der meilt etwas abgeplatteten Knolle entfpringt eine Rolette ceItielter, rundlicher, unterleits roter Blätter, deren Bafis to tief herzförmig ausgefchnitten ift, dafs fich die heiden Lappen berühren. Jeder Blütenftiel trägt nur eine Blüte, die rolia gefärbt und wie diejenige der Soldanellen abwärts geneigt ift.

Mehrjährig. Blüht Auguft bis Oktober.

Belucher: vermutlich Bienen, Hummeln.

Der nach der Blätezeit fich fchraubenförmig einrollende

Blütenftiel fällt mit der Frucht ab, und dient an

derlelben als häkelndes Organ: Tierverbreitung.

Gebülche, auf fteinigem Kalkboden.

Durch ihre Bevorzugung warmer Standorte (in der Schweiz als ftete Begleiterin der Eddellaftanie) verrät diefe Pflanze ihre füdliche Heimat. Den größsten Artenreichtum entfaltet Gyclamen in den Mittelmeerlïndern und in Weltafien, woher auch unfere kultivierten Arten ftammen.

Alpen, bis Böhmen.

Androsace imbricata. - Dichtbeblätterter Manns= fchild. - Niedrige Polfterpflanze mit kleinen, dachziegelartig fich deckenden, graufilzigen Blättern, die nach dem Abfterben an den Stengeln ftehen bleiben. Blüten weiß, am Schlunde rot.

Mehrjährig.

Blüht Juni Juli.

Befucher: vermutlich Fliegen.

Samen ohne Verbr.-Mittel.

Felsfpalten, befonders auf Kämmen; Urgeftein.

Hochalp bis $3000 \mathrm{~m}$.

Alpen, Pyrenäen.
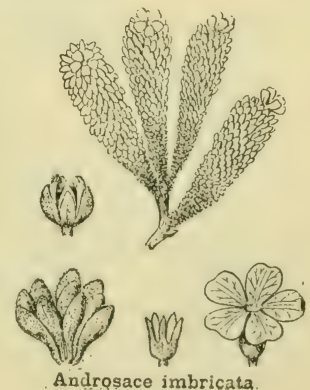
Primulaceen.

Primula graveolens. - Tafel $9 \%$ - Schwach behaart, mit dickem Wurzelftock. Blätter 5-10 cm lang, länglich oval, drüfenhaarig, außser der keilförmigen Balis feicht gezähnt. Blüten rotviolett, auf $10-15 \mathrm{~cm}$ hohem Schaft.

Mehrjährig. Blüht Juni Juli.

Befucher: vermutlich Falter.

Samen ohne Verbreitungsmittel.

Alpen der Schweiz (IVallis, Engadin), Savoyen, Dauphiné, Italien, Pyrenäen.

\section{Primula pedemontana. - Piemontefer-Primel.}

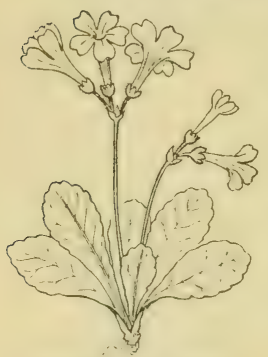

Primula pedemontana

Etwa $10 \mathrm{~cm}$ hoch. Die $4-6 \mathrm{~cm}$ langen, hellgrünen, länglich ovalen Blätter mit gewöhnlichen Haaren. Am fchwach gekerbten Blattrand rote Drülen. Der Schaft, der bedeutend höher ift als die Blätter, trägt 1-12 rotviolette Blüten mit langer Kronröhre.

Mehrjährig. Blüht Juni Juli.

Befucher, Samen wie bei voriger.

Weiden, fchattige Fellen.

1500-2400 m.

Savoyen, Schweiz (Wallis, Graubünden), Piemont.

Primula Auricula. - Aurikel, Fluhblume. - Ganze

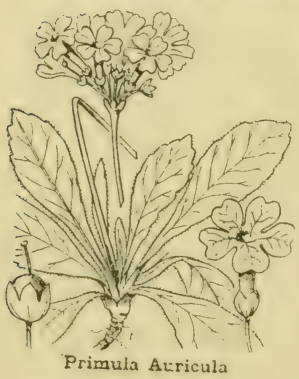

Pflanze infolge von Wachsausfcheidung wie mit Mehl beftäubt (vergl. I. Teil Seite 37). Blätter groß, eiförmig, dick fleifchig, fchwach gezähnt. Der Blütenfchaft kaum höher als die Blätter, mit 4-12 gelben, wohlriechenden Blüten. Mehrjährig. Blüht April bis Juli. Befucher: Falter.

Samen ohne Verbreitungsmittel. Felsfpalten. $1000-2600 \mathrm{~m}$. Alpen, Jura, Schwarzwald, Karpathen, Pyrenäen. 
Fisen 1 to0-2,00 Meter.

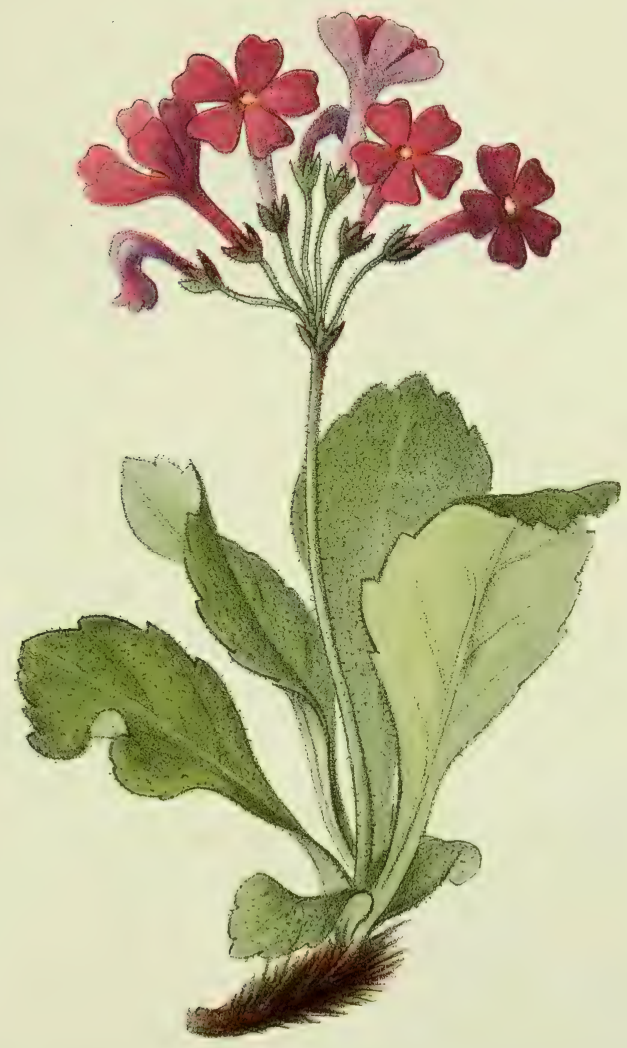

Primula graveolens (latifolia). Primevère puante.

Stinkende Primel.

Stinking Prime-rose. 
Felsen, felsige Weiden I500-3600 Meter.
Torfmoore, sumpfige Matten bis 2700 Meter.

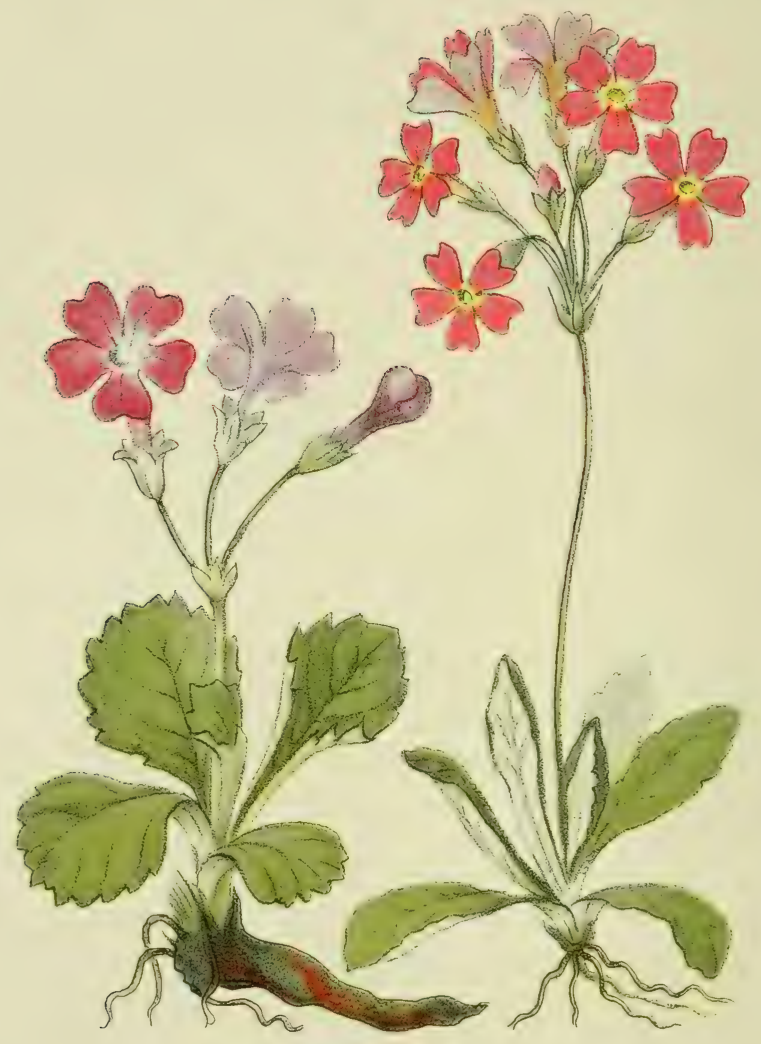

1. - Primula viscosa (hirsuta). Klebrige Primel. Primevère visqueuse. Sticky Bear's ears. li. - Primula farinosa. Mehlige Primel. Primevère farineuse. Bird's eye. 
Primula viscosa. - Tafel 98 A. - Der Primula grareolens ïhnlich, aber kleiner. Blätter beiderfeits klebrig, dunkelgrün. Blütenlchaft kaum höher als die Blätter. Blüten wenig zahlreich, violettrolia, in der Mitte weif.

Mehrjährig. Blüht Juni Juli.

Befucher: vermutlich Tagfalter.

Samen ohne Verbreitungsmittel.

Fellen, Rafenbänder, auf Urgeftein. $1500-3600 \mathrm{~m}$. Alpen, Pyrenäen.

Primula farimosa. - Tufel $98 \mathrm{~b}$. - Ganze Pflanze von Wachs weifs-mehligg beftäubt. Blïtter in grundländiger Rolette, langoval mit nach unten eingerollten Ründern, befonders unterleits ftark beftäubt. Dolde mit zahlreichen, 1 cm großen Blüten mit kurzer enger Röhre. Krone fleilchrot, in der Mitte gelb.

Mehrjährig. Blüht Mai bis Juli.

Befucher: Falter, in Norddeutfchland Hummeln (vergl. I. Teil Seite 27).

Samen ohne Verbreitungsmittel.

Torfmoore, fumpfige Wielen, bis $2700 \mathrm{~m}$.

Npen, Pyrenäen, Karpathen, Kaukafus, Norddeutfchlaud, nordpolare Lïnder, Ural, Altai, Himalaya.

Primula longiflora. - Langblitige Primel. - Der vorigen ähnlich, aber in allen Teilen ltärker. Dolden wenigblütig. Krone rofa, mit 2,5-3 cm langer Röhre.

Mehrjährig. Blüht Juli.

Befucher: Taubenfehwanz und

Wolfsmilchlchwärmer; die

Rüffel aller anderen Infekten zu kur»!

Samen ohne Verbreitungsmittel.

Matten der füdlichen Ketten. $1800-2300 \mathrm{~m}$.

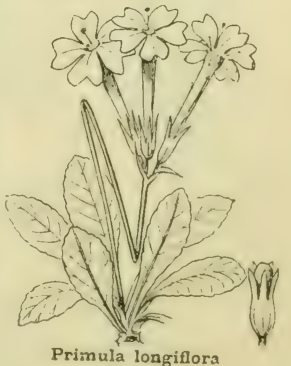

Primula longiflora Alpen, Karpathen.

G. Senn, Alpenflora. 
Androsace helvetica. - Tafel $99 \mathrm{~A}$. - Dichte Polfter bildende, $3-4 \mathrm{~cm}$ hohe, weisgrüne Pflanze. Die zahlreichen Zweige von $4 \mathrm{~mm}$ langen Blättchen dicht bedeckt; diefe umhüllen nach ihrem $\Lambda$ bfterben die Stengel wie mit einem Filz. Blüten weif, in der Mitte gelb, einzeln am Ende der Zweige, faft ungeftielt, dem Polfter anliegend.

Mehrjährig. Blüht Juli Auguft.

Befucher: vermutlich Fliegen.

Samen ohne Verbreitungsmittel.

Befonder's auf Gräten des Kalkgebirgs. Alpen.

Androsace pubescens. - Tafel $99 \mathrm{~B}$. - Lockere, graugrüne Polfter bildende Pflanze mit fchmalovalen, weif behaarten Blättern, die nach ihrem Abfterhen am Stengel ftehen bleiben. Blüten weißs, in der Mitte gelb, einzeln am Ende der Zweige, deutlich geftielt.

Mehrjährig. Blüht Juni Juli.

Befucher und Samen wie bei der vorigen Art.

Befonders auf Urgeftein.

Weft- und Zentralalpen, Pyrenäen.

Androsace villosa. - Zottiger Mannsfchild. - Ganze

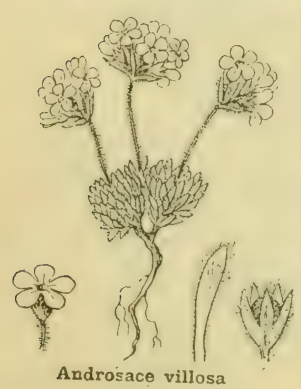

Pflanze zottig behaart, $3-6 \mathrm{~cm}$ hoch, weniger gedrungen als vorige Arten. Stengel unterwärts nicht von den alten - Blättern bedeckt. Blattrofetten kugelig, mit fchmalen Blättern, von den Blütenl'chäften überragt. Blüten weißs oder rola, in der Mitte gelb, in dichter $3-6$ blütiger Dolde.

Mehrjährig. Blüht Juli Auguft. Befucher: vermutlich Eliegen, Falter. Samen ohne Verbreitungsmittel. Spalten fonniger Felfen und Blöcke. $1600-2300 \mathrm{~m}$.

Franzöflifche, italienifche und öfterreichifche Alpen, Jura, Pyrenäen. 
Felsspalten 2100-3000 Meter.
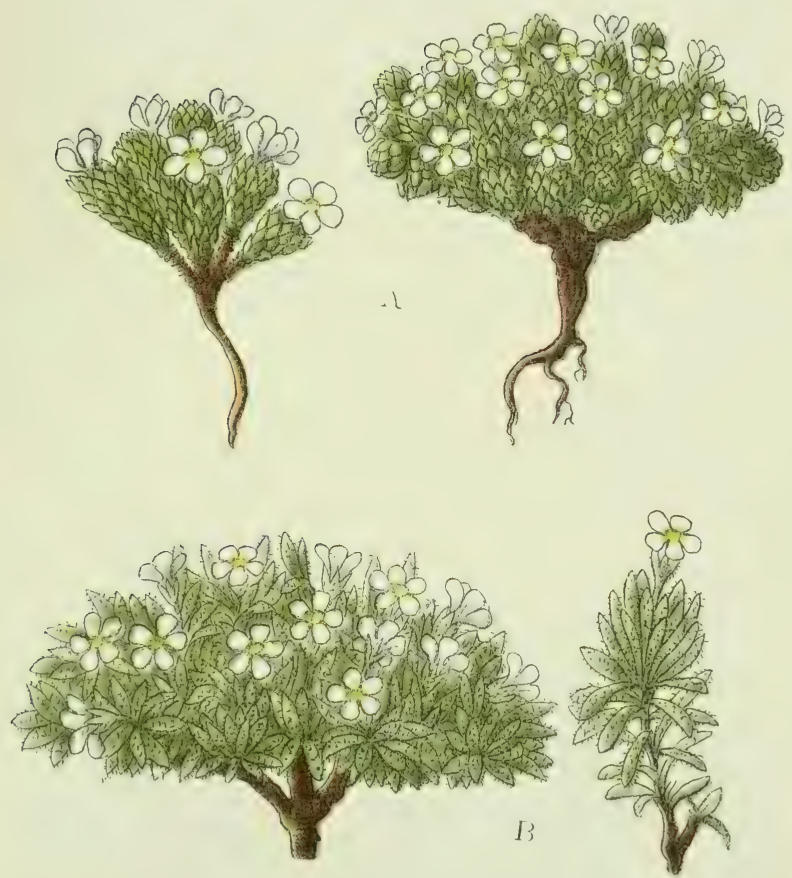

A. - Androsace helvetica. Schreizer-Mannsschild. Androsace de Suisse. Swiss Androsace.
B. - Androsace pubescens.

Weichhaariger Mannsschild. Androsace pubescente. Furrowed Man's-shield. 
Kalkfelsen

I600-2400 Meter.

Urgesteins-Felsen I600-3000 Meter.

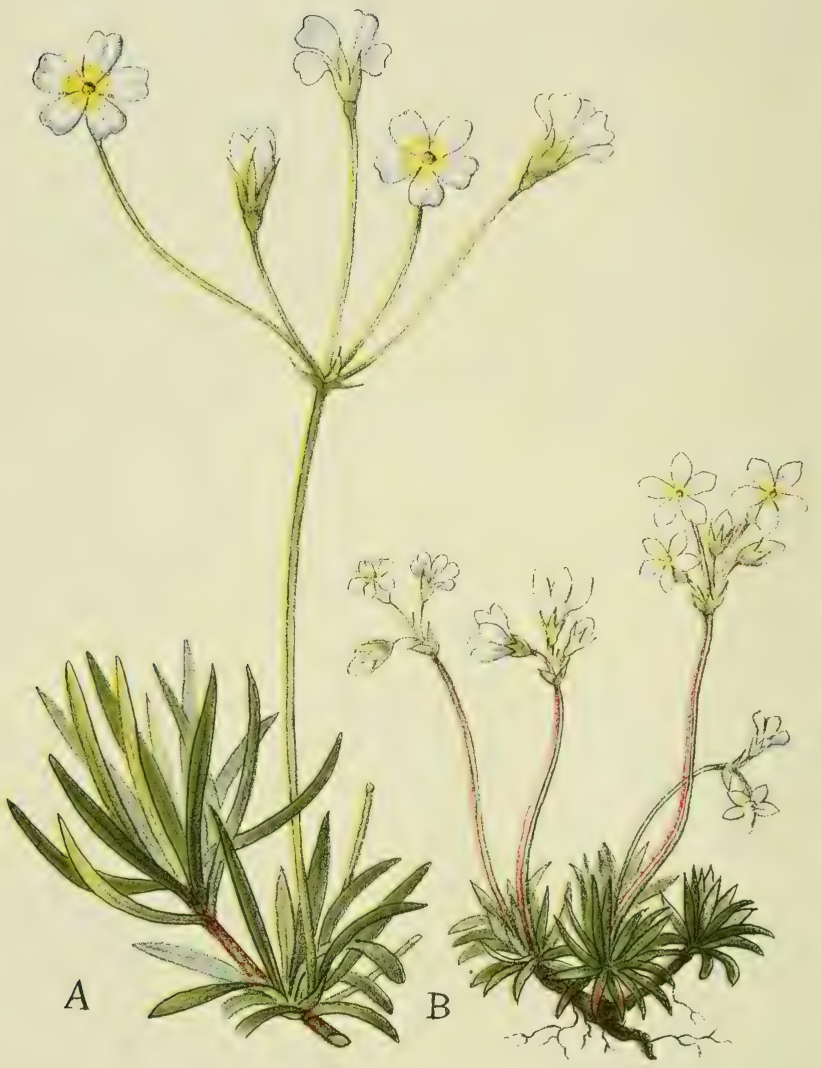

1. - Androsace lactea.

Milchweisser Mannsschild. Androsace blanc de lait. Milk-white Androsace.
13. - Androsace carnea.

Fleischroter Mannsschild. Androsace couleur de chair. Flesh-coloured Man's shield. 
Androsace Iactea. - Tufel $100 \mathrm{~A}$ - Rofetten zu lockeren Rafen vereinigt. Blitter $1-2 \mathrm{~cm}$ lang, fchmal, mit feiner Spitze, l'chwach behaart. Blütenlehtifte j-10 $\mathrm{cm}$ hoch, zart, aufrecht, kahl, mit 1-5 Blüten anf dünnen Stielen. Blumenkrone milchweif, in der Mitte gelb: ihre Zipfel ausgerandet.

Mehrjährig. Blüht Juli Auguft.

Befucher: vermutlich Fliegen und Falter.

Samen ohne Verbreitungsmittel. Auf Kalk.

1600 - $2400 \mathrm{~m}$, im Jura fchon bei $1100 \mathrm{~m}$.

Alpen, Jura.

Androsace carnea. - Tafel 100 B. - Rofetten zu niederen Rafen vereinigt. Blätter fchmil, fpitz, kurzhaarig, etwas zurïckgebogen. Blüten lchaft mit 2-10 rolafarbenen, l'eltener weifen, in der Mitte gelben Bläten. Kronzipfel nicht ausgerandet.

Mehrjährig. Blüht Juli Auguft.

Befucher: vermutlich Fliegen und Falter.

Samen ohne Verbreitungsmittel. Auf Urgeftein.

Alpen, Vogelen, Auvergne, Pyrenäen.

Androsace Chamaejasme. fehild. - Der Androsace villosa (Seite 99) ähnlich, aber Blattroletten geöffnet und Blätter nur am Rande behaart. Blüten weißs oder rötlich, in der Mitte gelb.

Mehrjährig.

Blüht Juni Auguft.

Befucher: Fliegen, feltener Falter.

Samen ohne Verbreitungsmittel.

In kurzem Rafen, auf humus-

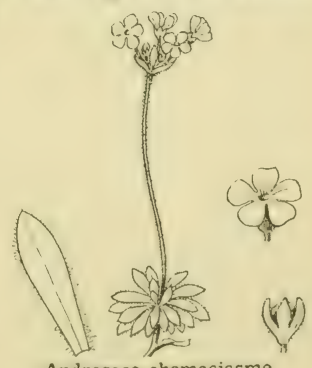

Zwergjasmin - Manns-

Androsace chamacjasmo reichen Felfen, fteinigen Weiden, befonder's auf Kalk. Alpen, Karpathen, Kaukafus, nordpolare Länder, Ural, Altai, Himalaya. 
Gregoria (Aretia) Vitaliana. - Tafel 101. - Den Androsace-Arten ähnlich, leitet zur Gattung Primula üher.

Ihre Blattrofetten bilden oft gröfzere Rafen. Blätter l'hmal, zugefpitzt. Blüten gelh, 1 'm lang, wie hei Primula mit langer Röhre, 5zipflig.

Mehrjährig. Blüht Juli Augult.

Befucher: vermutlich Falter.

Samen ohne Verbreitungsmittel.

Felfen, Gefteinsfchutt, Bergkïmme, 1400-3000 m.

Weft- und Oftalpen, Pyrenäen.

Androsace septentrionalis. - Nordifeher Manns-

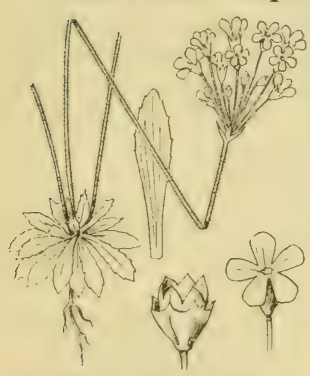

fchild. - Blätter in grundftändiger Rofette, gezähnt, fchwach behaart. Blütenf́chäfte hoch, mit こૅ-30 weißen oder rofaroten Blüten.

Einjährig.

Blüht Mai Juni.

Befucher: vermutlich Fliegen.

Samen ohne Verbreitungsmittel.

Felder, Rafenplätze.

In Mitteldeutfichland und in der ganzen Alpenkette zerftreut.

Androsace septentrionalis 
Felsen, steinige Matten 1400-3000 Meter.

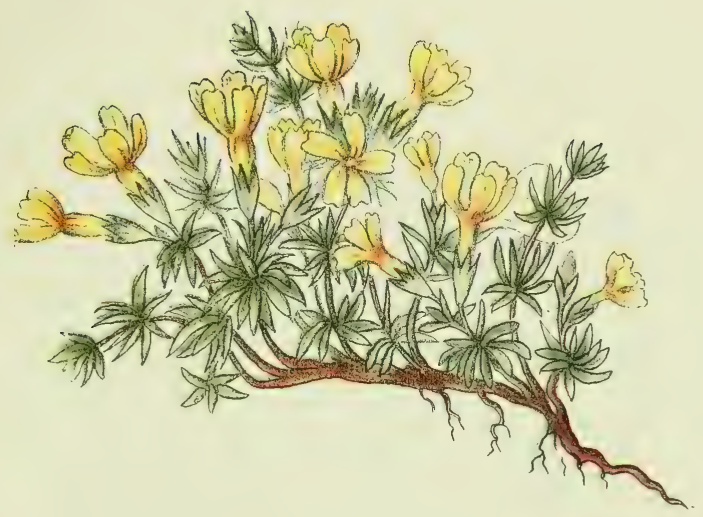

Gregoria (Aretia) Vitaliana.

Gemsenblümchen.

Fausse Joubarbe. Gregoria, Aretia. 


\section{$-102-$}

Felsspalten, Felsblöcke 2300-3600 Meter.

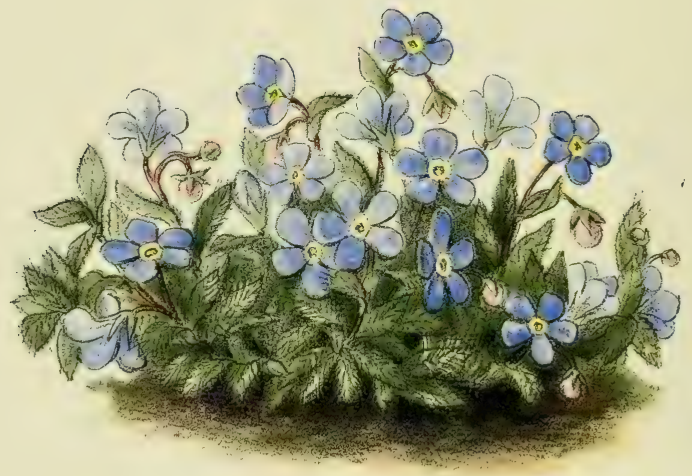

Eritrichium nanum.

Himmelsherold.

Myosotis nain.

Dwaif Forget-me-not. 
Die Boraginaceen find durch ihre verwachfene, regelmäßjig jzipflige Blumenkrone und die vier nufartigen früchtrhen ausgezeichmet. Nit Ausmahme von ('erinthe (Tafel 103) lind alle Boraginaceen fteif behaart.

Eritrichium nanum. - Tafel 102. - Stengel kurz, ftark verzweigt und dicht beblättert, polfterbildend. Blätter in Rol'etten, fchmal oval, weif behaart. Die alten Blätter bleiben an Stengel ftehen. Blühende Äfte aufrecht, $2-8 \mathrm{~cm}$ hoch, beblättert, mit :3-6 leuchtend hlaven, in der Mitte gelben Blüten.

Mehrjährig. Blüht Juli Augult.

Befucher: vermutlich Schmetterlinge.

Früchtchen geflügelt: Windverbreitung.

Felsfpalten, Blöcke, Felsgräte, nicht auf Kalk.

$2300-3600 \mathrm{~m}$.

Ganze Alpenkette, Kaukafus, nordpolare Länder, Altai; fehlt den Pyrenäen, dafelbft durch die ähnliche Myosotis pyrenaica vertreten.

\section{Myosotis alpestris. - Alpen-Vergifmeimnicht. -} Pflanze 5-15 cm hoch, mit lanzettlichen, ftark behaarten Blïttern. Blätentragende Stengel zahlreich, beblättert, am Ende mit zwei einfeitig eingerollten Blütenftänden. Blüten himmelblau, leltener weißs, in der Mitte gelb.

Mehrjährig; als Zierpflanze in mehreren Raffen kultiviert.

Blüht Juni Juli.

Befucher: vorwiegend Falter.

Früchtchen ohne Verbreitungsmittel.

Steinige Weiden, Gerölle.

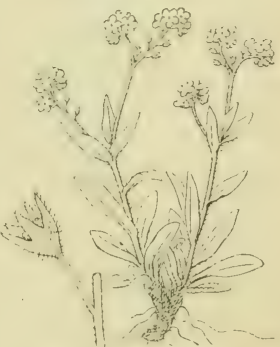

Myosotis aipestris $1600-3000 \mathrm{~m}$.

Alpen, Jura, Vogefen, Auvergne, Pyrenäen, Karpathen, Kaukafus, nordpolare Länder, Ural, Altai, Himalaya. 
Cerinthe minor. - Tafel 103. - Kahl, mit zahlleichen oberfeits verzweigten, ftark beblätterten, $20-50 \mathrm{~cm}$ hohen Stengeln. Blätter bläulichgrün, mit waclısartigem Glanz, umfaffen mit ihrer Bafis den Stengel. Blüten gelb unıl rot oder bläulich, eng glockenförmig, mit 5 langen, fehmalen Zähnen, zahlreich in dichten, anfangs eingerollten Ständen, die bis zur Spitze große Hochblätter tragen.

Ein-, zwei- oder mehrjährig.

Blüht Mai bis Juli.

Befucher: vermutlich Hummeln.

Früchte ohne Verbreitungsmittel.

Weiden, Bergwälder, befonders auf Kalk; bis $2000 \mathrm{~m}$. Mittelemropa, Alpen von Frankreich, Italien, Bayern, Öfterreich; fehlt in der Schweiz.

Cerinthe alpina.

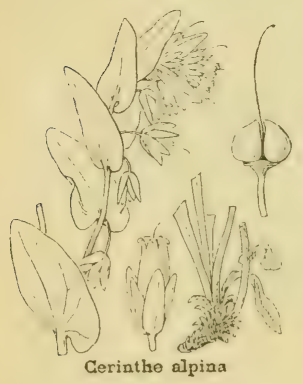

Alpen - Wachsblume. - Der vorigen ähnlich, aber Blüten länger (bis $14 \mathrm{~mm}$ ) mit 5 kurzen Zähnen, ftrohgelb mit 5 purpurroten Flecken. Mehrjährig.

Blüht Juni bis Augult.

Befucher: vermutlich Hummeln. Früchtchen ohne Verbreitungsmittel.

Steinige Halden, befonders auf Kalk, 1200-2300 m, fteigt oft mit den Bächen ins Tal. Ganze Alpenkette, auch in der Schweiz; Pyrenäen.

Die mit den Boraginaceen nahe verwandte Familie der Solanaceen, zu welcher die Kartoffelftaude und manche Giftpflanzen wie das Bilfenkraut, die Tollkir/che und die Tabakpflanze gehören, ift in der Alpenregion nicht vertreten. 


$$
-103-
$$

Weiden, Bergwälder bis 2000 Meter.

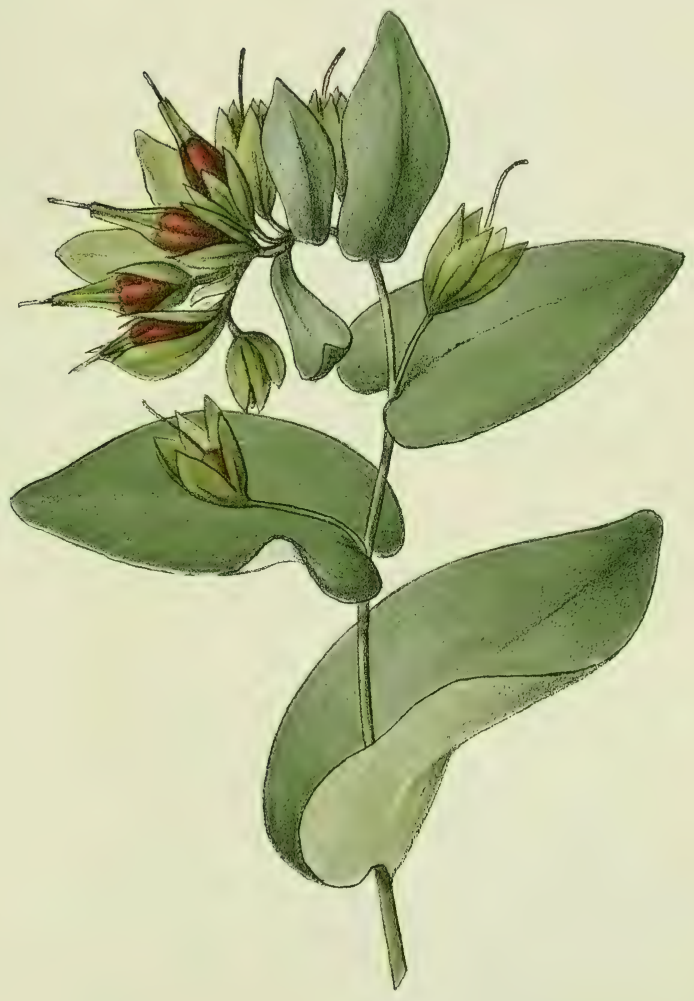

Gerinthe minor.

Mélinet à petites fleurs.
Kleine Wachsblume.

Lesser Cerinthe. 
Matten, kühle Weiden 1200-2700 Meter.

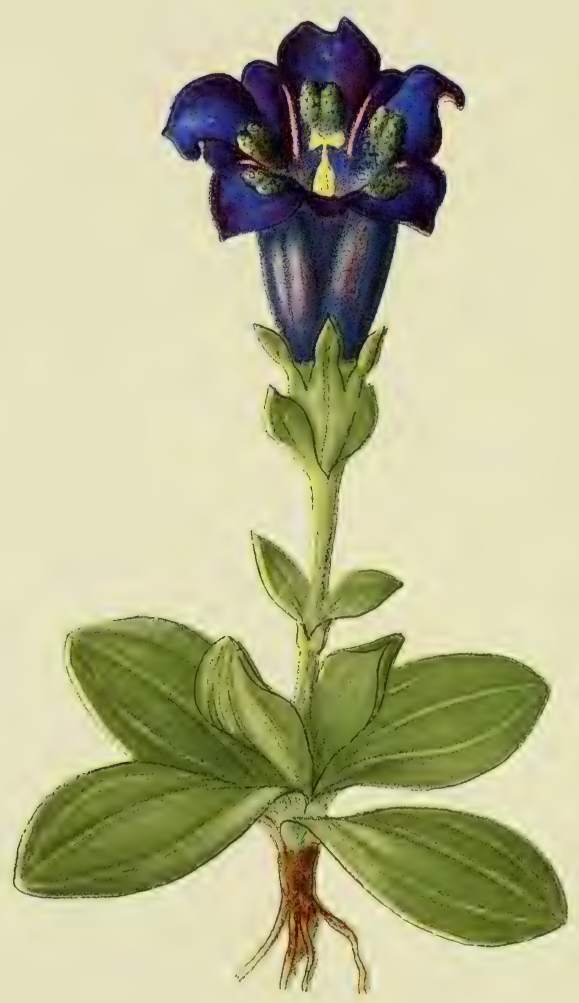

Gentiana Kochiana. Grande Gentiane bleue. 
Die Gentianaceen bilden mit ihren meilt tief blau gefärbten, oft großßen Blüten einen prächtigen Schmuck der Alpen. Mit Ausnahme von Menyanthes (Seite 110) haben fie gegenltändige Blätter.

Gentiana Kochiana (excisa, latifolia). - Tafel 101.Kahl, mit grundftündiger Rofette mattgrüner, weicher, eiförmiger Blätter. Stengel kurz, einblütig, mit zwei Blattpaaren. Blüte aufrecht, 4-6 cm lang; zwifchen den 5 fpitzen Zipfeln je ein abgerundeter Lappen. Krone oben dunkelblau, Kronröhre blaffer, mit olivgrünen Flecken.

Mehrjährig. Blüht Mai bis Auguft.

Befucher: Hummeln, Falter.

Samen ohne Verbreitungsmittel, aus der langgeltielten Kapfel ausgeftreut.

Alpen, Jura, Pyrenäen, Karpathen.

\section{Gentiana Clusii (vulgaris). - Euzian des Clusius. -} Dem vorigen ähnlich, jedoch Blätter lederartig, eiförmig zugefpitzt, und Krone im Innern fchwächer gefleckt.

Hat diefelben biologifchen Eigenfchaften wie voriger; beide fchliefsen fich in einem Gebiete gegenfeitig aus.
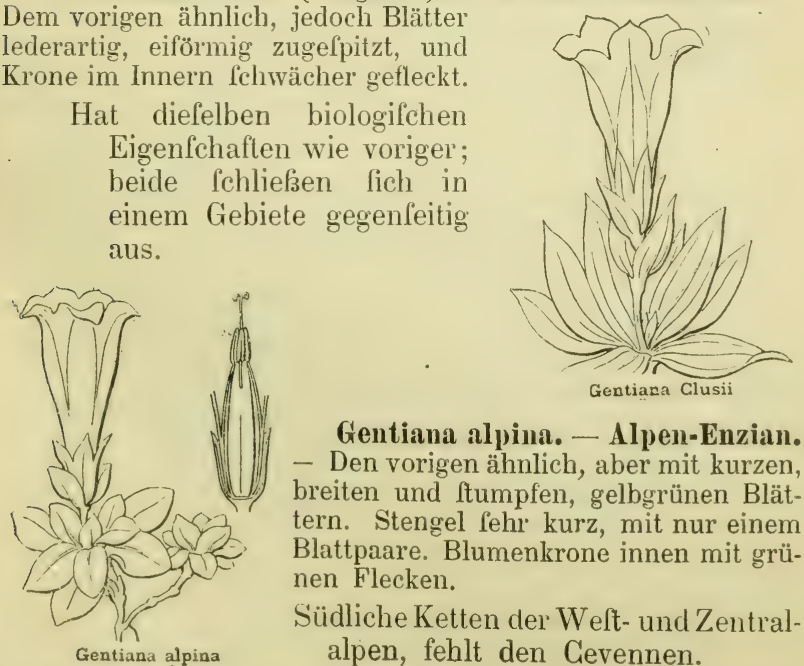

\section{Gentiana alpina. - Alpen-Enzian.}

- Den vorigen ähnlich, aber mit kurzen, breiten und ftumpfen, gelbgrünen Blättern. Stengel fehr kurz, mit nur einem Blattpaare. Blumenkrone innen mit grünen Flecken.

Südliche Ketten der Weft- und Zentralalpen, fehlt den Cevennen. 
Gentiana bavarica. - Tafel $105 \mathrm{~A}$. - Bildet mit ihren kriechenden Stengeln kleine Ralen. Blätter klein, elliptifch oder rundlich. Blütentragende Stengel aufrecht, $5-15 \mathrm{~cm}$ hoch, einblütig. Krone tiefblau, mit etwa $3 \mathrm{~cm}$ langer Röhre und 5 tellerförmig ausgebreiteten Zipfeln. Schlund durch weiße Lappen faft völlig gefchloflen.

Mehrjährig. Blüht Juli Auguft.

Befucher: Schmetterlinge, befonders der Taubenfehwanz.

Samen ohne Verbreitungsmiltel.

Nur in der Alpenkette.

Gentiana nivalis. - Tufel $105 \mathrm{~B}$. - Stengel zart, aufrecht, $3-15 \mathrm{~cm}$ hoch, zuweilen verzweigt, dicht beblättert, mit grundfändiger Rolette. Jeder Zweig trägt eine ultramarinhlaue, in der Mitte weifse Blüte, mit langen, l'chmalen Kelchzipfeln, und langer Kronröhre mit fpitzen Zipfeln.

Einjährig. Blüht Juli Auguft.

Befucher: vermutlich Schmetterlinge.

Samen klein: Windverbreitung.

Pyrenäen, Alpen, Jura, Karpathen, nordpolare Länder.

Gentiana verna. - Tufel 105 C. - Grundftändige Rolette von breit lanzettlichen Blättern. Stengel unverzweigt, beblättert, 3-12 cm hoch, einblütił. Blüte :3-4 cm lang, mit fpitzen, ausgrebreiteten Zipfeln. Krone dunkelblau, in der Mitte weif.

Mehrjährig. Blüht April bis Auguft.

Befucher: Falter, befonder's der 'Taubenfchwanz.

Samen ohne Verbreitungsmittel.

Alpen, Jura, Auvergne, Pyrenäen, Karpathen, Kaukafus, Altai. 
Weiden und Matten

I800-3600 Meter. $\quad \mathbf{1 8 0 0 - 2 9 0 0 ~ M e t e r . \quad E b e n e ~ b i s ~} 3300$ Meter.

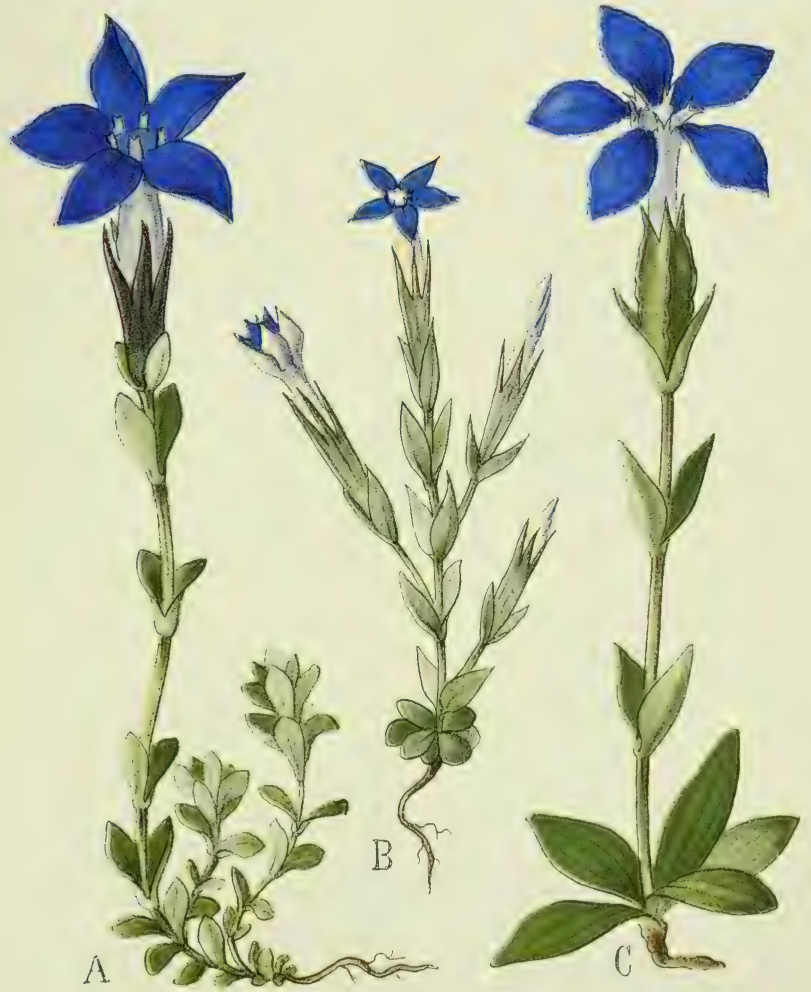

Gentiana bavarica. Gentiana nivalis. Gentiana verna. Bayrischer Enzian. Schnee-Enzian. Frühlings-Enzian. Gentiane de Baviere. Gentiane de's neiges. (ientiane frintaniere. Bavarian Gentian. Snow-Bitterwort. Spring-Felwort. 
Wiesen, Weiden, Bachufer roo0-2400 Meter.

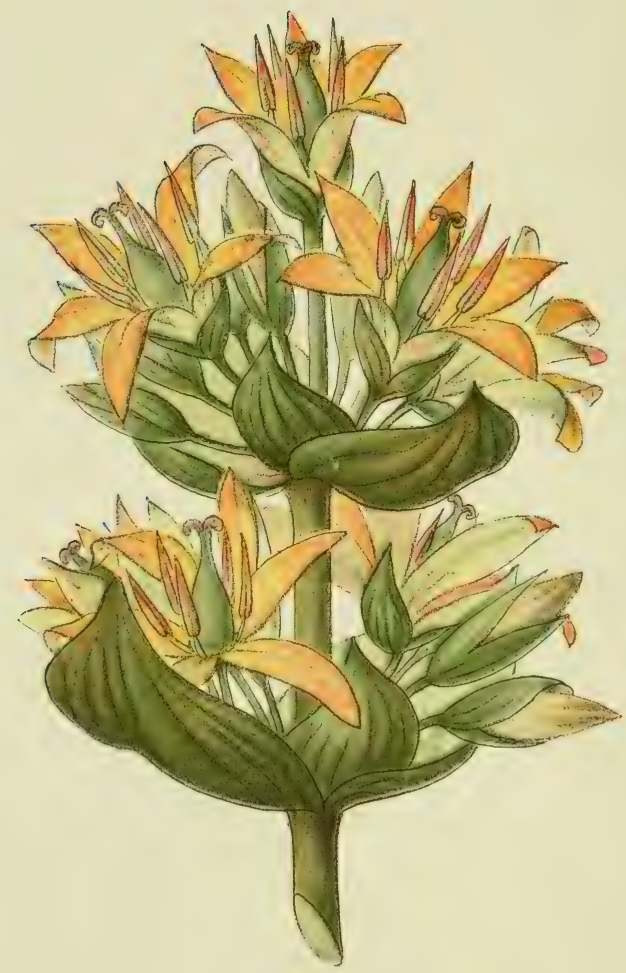

Gentiana lutea.

Gelber Enzian.

Gentiane jaune.

Yellow Bitterwort. 
Gentiana Intea. - Tafel 106. -- Starke, über $1 \mathrm{~m}$ hohe, kahle Pflanze mit dicker, fleifchiger, gelber Wurzel. (irundtändige Bläter 10-25) cm lang, breit elliptifeh, kurz helpitzt, mit 5-7 vorfpringenden Nerven. Stengel hohl, nit gegenftändigen Blältern, in deren Achfeln Büfchel gelber Blüten ftehen. Blumenkrone mit j-g kaun verwachlenen, lpitzen, ausgebreiteten Zipfeln.

Mehrjährig; liefert mit andern grofsen Enzianen einen in den Wureln enthaltenen Bitterftoff, der zur Bereitung von Likören verwendet wird.

Blüht Juli Augult.

Befucher: Käfer, Fliegen, Hummeln, Fialter.

Samen geflügelt: Windverbreitung:

Feuchte Matten und Weiden.

$1000--2400 \mathrm{~m}$, oft auch tiefer.

Alpen, Berge von Mittel- und Wefteuropa.

Gentiana Burseri. - Bursers Enzian. - Kräftige, $30-60 \mathrm{~cm}$ hohe Pflanze mit dicker Wurzel und elliptifchen 5-7nervigen Blättern. Blüten wie bei vorigem gelb, aber glockenförmig, mit längsgefältelter Krone und 6 fpitzeiförmigen Zipfeln; im Innern oft braun punktiert. Blütenftände nur in den Achleeln der alleroberften Blätter.

Mehrjährig. Blüht Auguft.

Befucher?

Weiden, lichte Wälder.

$2000-2300 \mathrm{~m}$.

Alpen des Dauphiné, Pyre-

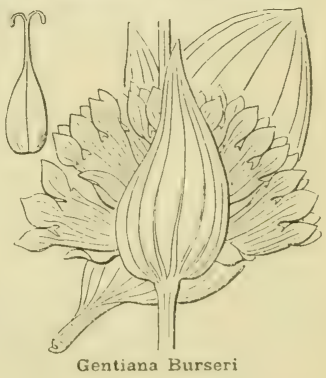
näen. 
Gentiana campestris. - Tafel 10\% - Stengel fteif, aufrecht, 5-20 cm hoch, mit fparrigen Äften. Blätter dunkelgrün, fpitz-eiförmis. Jeder Zweig trägt eine $3 \mathrm{~cm}$ lange, aufrechte, 4 zählige, violette Bläte. Kronzipfel tellerförmig' ausgebreitet, am Grunde mit aufrechten Borften.

Einjährig. Blüht Mai bis Oktober.

Befucher: Hummeln und Schmetterlinge.

Samen ohne Verbreitungsmittel.

Alpen, Cevennen, Pyrenäen; in Mitteleuropa zerftreut, polares Europa, Ural.

Gentiana germanica. - Dentfcher Enzian. -- Dem vorigen ähnlich, aber his $35 \mathrm{~cm}$ hoch, dicht beblïttert. Blüten zahlreich in dichten Ständen, 5zählig.

Einjährigg. Blülıt Auguft bis Oktober; in den Alpen früher als in der Ebene.

Befucher: Bienen, Hummeln.

Samen ohne Verbreitungsmittel.

Weiden der Ebene, his 2800 m, befonders auf Kalk. In ganz Mitteleuropa.

Gentiana asclepiadea. - Schwalbenwurzblaitriger

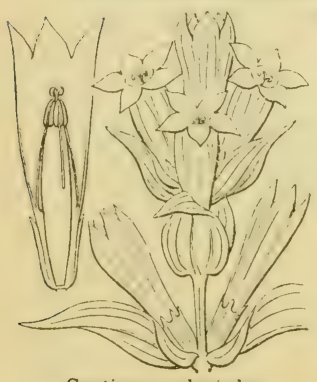

Gentiana asclepiadea Enziall. - Stengel 20-100 em hoch, fteif, nicht verzweigt, ftark beblättert. Blätter großs, eiförmig zugefpitzt, 5 nervig. Blüten $4 \mathrm{~cm}$ grof, blau, ungeftielt, einzeln oder zu zweien in den Achfeln der oberen Blätter. Kronröhre eng-glockenlörmig, nicht bebärtet. 5 Kelch- und Kronzipfel.

Mehrjährig.

Blüht Augult bis Oktober.

Befucher: Hummeln.

Samen geflügelt: Windverbreitung. Feuchte Weiden (dafelblt Blätter kreuzweis gegenftändig, 4 Zeilen bildend), lichte Wälder (dafelbft die Blätter nur ¿2 zeilig). Alpen, Jura, Vogefen, Karpathen. 


\section{$-107$}

Magere Rasenplätze, Weiden 900-2700 Meter.

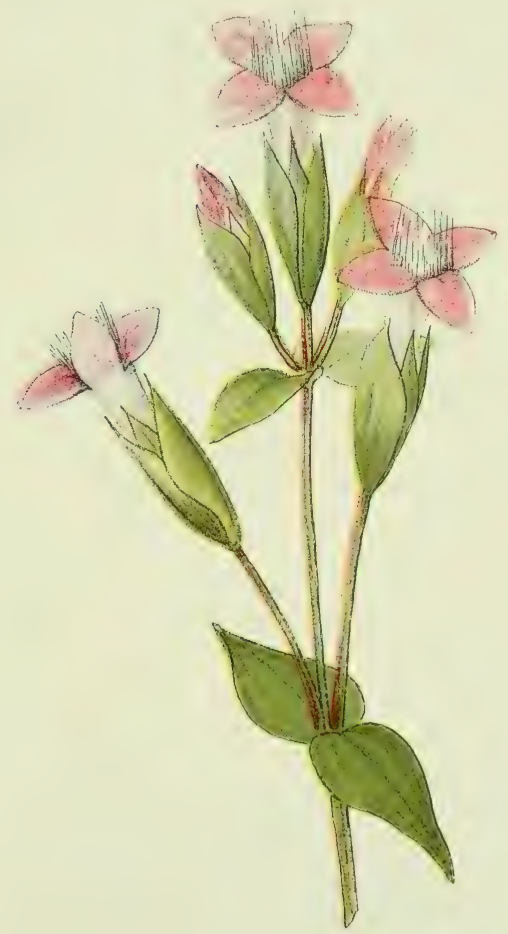

Gentiana campestris.

Feld-Enzian.

Gentiane champetre.

Ficld-Gentian. 
Weiden I 500-2800 Meter.

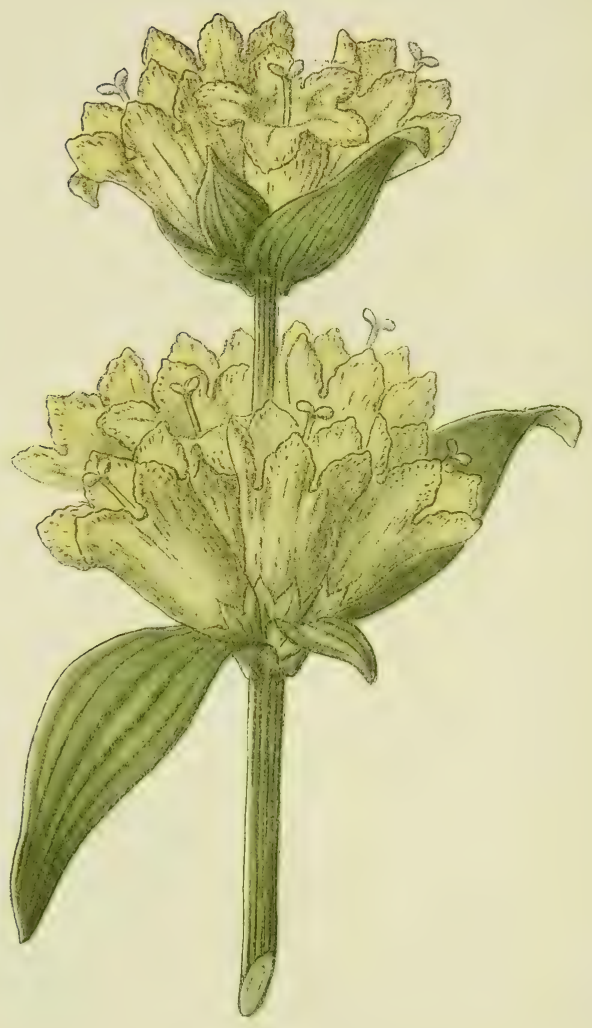

Gentiana punctata.

Gentiane ponctuée.
Punktierter Enzian.

Dotted Gentian. 
Gentiana punctata. - Tafel 108. -- Pflanze 20-60 cm hoch, mit dicker Wurzel und kräftigem, aufrechtem, unver. zweigtem Stengel. Blätter grof, fpitz-eiförmig. die untern reftielt. Die Blüten ftehen aufrecht, dicht beifammen in den Winkeln der oberen Blattpare. Kelch kurz olockenförmig, mit 5-S moleichen Zälnen. Krone glockenförmig, gelh orler grüngelh, bram punktiert, nit oi eiförmigen Zipfeln.

Mehrjährig. Blüht Juli Auguft.

Befucher: Hummeln.

Samen geflügelt: Windverbreitung.

Weiden. $1500-2800 \mathrm{~m}$.

Alpen, Karpathen, bis Macedonien.

Gentiana purpurea. - Purpurroter Enzian. - Dem vorigen ähnlich, aber Blüten weniger zahlreich, in den Achfeln des oberften Blattpaares. Kelch häutig, auf einer Seite bis zum Grunde gefpalten. Blumenkrone aufen dunkel purpurrot, innen gelb, feltener auch aufsen gelb, mit 6 eiförmigen Zipfeln.

Mehrjährig. Blüht Juli Auguft. Befucher: Fliegen, wahrfcheinlich auch Hummeln. Samen geflügelt: Windverbreitung.

Weiden, zwifchen Fels-

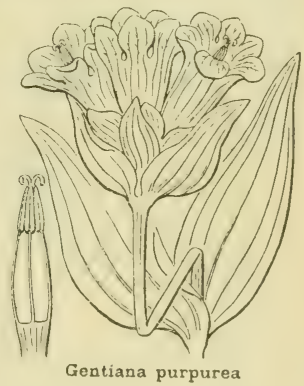
blöcken. $1500-2700 \mathrm{~m}$. Alpen, polares Afien.

Man fundet in den Alpen öfters Formen, die in ihrem Bau zwifchen Gentiana lutea und punctata oder purpurea die Mitte halten. Diefelhen find durch Kreuzung zwei verfchiedener Mutterarten entftanden: Baftarde. 
Gentiana ciliata. - Tafel 109. - Stengel 8-25 cm hoch, kantig, zuweilen verzweint, bis oben beblättert. Blätter lanzettlich, zugelpitzt, einnervig. Blüten blau, einzeln, vierzählig, etwa $4 \mathrm{~cm}$ lang, an den Enden der Zweige. Kronblïtter bis zur Mitte verwathlen, mit 4 am Rande gefranften Zipfeln.

Mehrjährig. Blüht Auguft his Oktober.

Befucher: Bienen, Hummeln.

Heiden, trockene Matten der Berge und Hügel, befonders auf Kalk; bis zur Waldgrenze.

Alpen, Jura, Vogrefen und Mitteldentfchland; Pyrenäen.

Gentiana tenella. - Zarter Enzian. - Nur 4-S cm

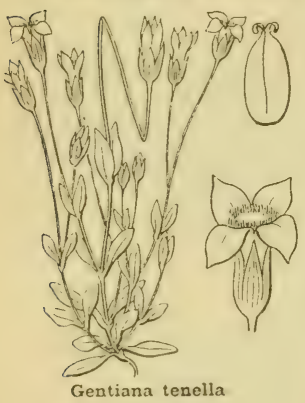

hoch, am Grunde verzweigt. Äfte lang, nur unterwärts beblättert, einblütig. Blüten klein $(8-12 \mathrm{~mm})$, blauviolett, 4 oder כa zählig, auf langen dünnen Stielen. Krone am Schlundeingang bärtig (ähnlich wie bei Gentiana campestris Tafel 107).

Einjährig.

Blüht Juli bis September.

Befucher: vermutlich Hummeln und Falter; bleiben diefelben aus, fo erfolgt Selbftbeftäubung. Samen lehr klein: Windverbreitung. Feuchte Matten, Schneetälchen.

$1900-2600 \mathrm{~m}$.

Pyrenäen, Apen, Karpathen, nordpolare Länder, Altai. 
Heiden, trockene Rasenplätze bis zur Baumgrenze.

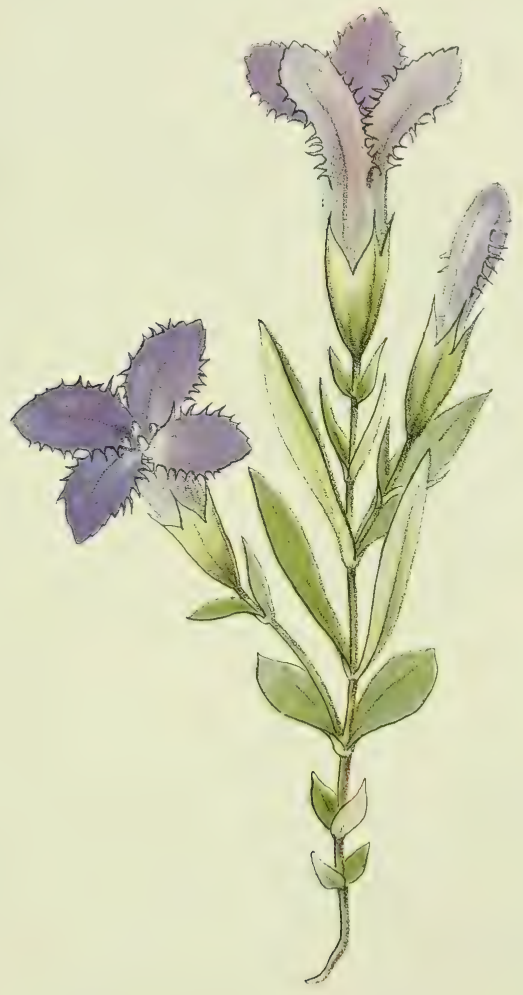

Gentiana ciliata.

Gentiane frangée.
Gefranster Enzian. Fringed Gentian. 


\section{$-110 \ldots$}

Tortige IViesen bis 2300 Meter.

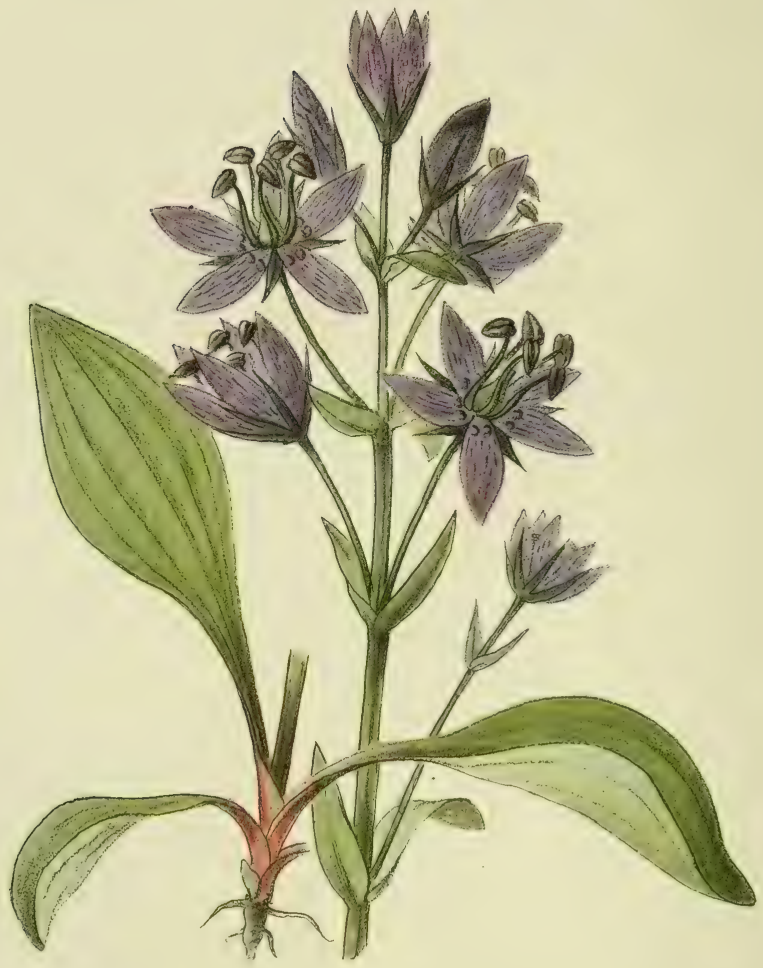

Swertia perennis.

Suertie vivace.
Blauer Tarant.

Perennial Swertia. 
Swertia perennis. - Tafel 110. - Stengel aufrecht, fteif, unverzweigt und fchwach beblättert, $20-60 \mathrm{~cm}$ hoch. Blätter länglich-eiförmig, gegenftändig, die unteren lang geftielt. Blüten fchmutzig-violett, am Ende des Stengels in aufrechter Traube. Die 5 fchmalen, lpitzen Kelch- und Kronblätter nur an Grunde verwachfen. Kronzipfel fternförmig ausgebreitet, tragen am Grunde je 2 Zuckerdrülen (Nectarien).

Mehrjährig. Blüht Juli Auguft.

Befucher: Fliegen, Käfer.

Samen geflügelt: Windverbreitung.

Torfige Matten, faftige Wiefen der Berge bis $2300 \mathrm{~m}$, im Norden auch in der Ebene.

Gebirge von Mitteleuropa, Alpen, Jura, Auvergne, Pyrenäen; Kaukafus, Sibirien bis Japan, Rocky Mountains.

\section{Menyanthes trifoliata. - Dreiblattriger Fieber-} klee. - Stengel dick, fleifchig, kriechend, trägt an feinem Ende die kleeartig dreiteiligen, langgeftielten, kahlen Blätter. Blüten rötlich-weifs, in aufrechter Traube auf geradem, unbeblättertem, 20-40 cm hohem Schaft. Kelch und Krone 5-zipflig; letztere trichterförmig, im Innern bärtig.

Mehrjährig.

Blüht April bis Juni.

Befucher: Käfer, Fliegen, Hummeln.

Samen ohne befondere Verbreitungsmittel.

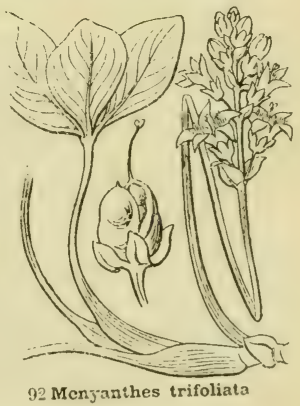

Torfige Matten, Sümpfe. Ebene bis $2000 \mathrm{~m}$.

In ganz Europa, Zentralafien bis Japan, nördliches Nord-Amerika, längs der Anden his Kalifornien. 
Die Familie der Scrophulariaceen bildet mit ihren fchönen, oft zu dichten Ständen vereinigten Blüten einen hervorragenden Schmuck der Alpen. In ihren Blüten läfst fich ein allmählicher Ühergang von gleichmäfig fternförmigen zu deutlich zweilippigen Geftalten verfolgen; alle befitzen jedoch als Frucht eine zweifächerige Kapfel.

Bartsia alpina. - Tafel 111. - Stengel aufrecht, unverzweigt, mit mehreren Paaren eiförmiger, runzliger, ungeftielter und grobgezähnter Blätter. Blüten dunkelviolelt, $2 \mathrm{~cm}$ lang, zweilippig in endfländigem, beblättertem Stande, deffen Blätter meift auch violett oder kupferrot gefärbt find.

Mehrjährig. Blüht Juni Juli.

Befucher: Hummeln.

Samen geflïgelt: Windverbreitung.

Torfige Matten, in kurzem Rafen.

$1200-2700 \mathrm{~m}$; fteigt zuweilen tiefer hinab.

Alpen, Jura, Vogefen, Pyrenäen, Karpathen, nordpolare Länder, Altai.

Rhinantus minor. - Kleinbliitiger Klappertopf. -

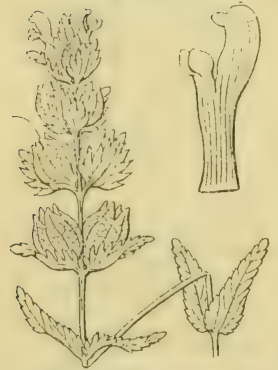

Rhinanthus minor

Stengel 5-40 cm hoch, zuweilen verzweigt. Blätter länglich-eiförmig, grob gezähnt. Blüten blaßggelb, in endltändigem, mit hellgrünen oder rötlichen Blättern durchfchoffenem Stande. Blumenkrone mit gerader, offener Röhre und zwei lichwach entwickelten Lippen. Einjährige, halbparafitifche, den Futterertrag beeinträchtigende Pflanze. Blüht Juni und Juli.

Befucher: Hummeln.

Samen geflügelt: Windverbreitung. Mäh wiefen, Matten. Ebene bis $2200 \mathrm{~m}$. In ganz Europa. . 
Torfige Matten, niederer Rasen I200-2800 Meter.

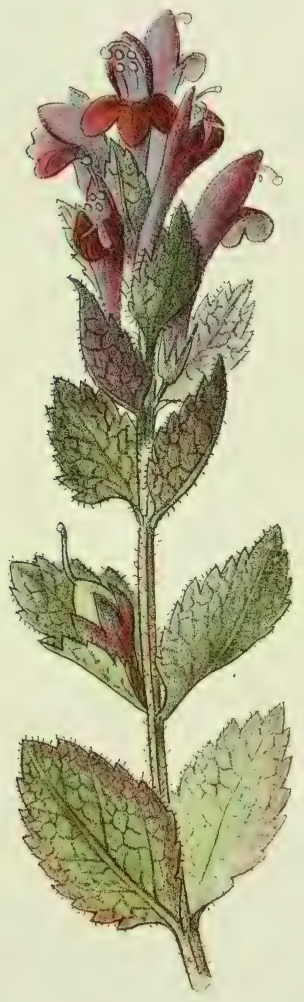

Bartsia alpina.

Alpen-Bartschie.

Bartsie des Alpes.

Poly-mountain. 
Saftige Weiden 1800-2700 Meter.
Steinige Weiden I400-2900 Meter.
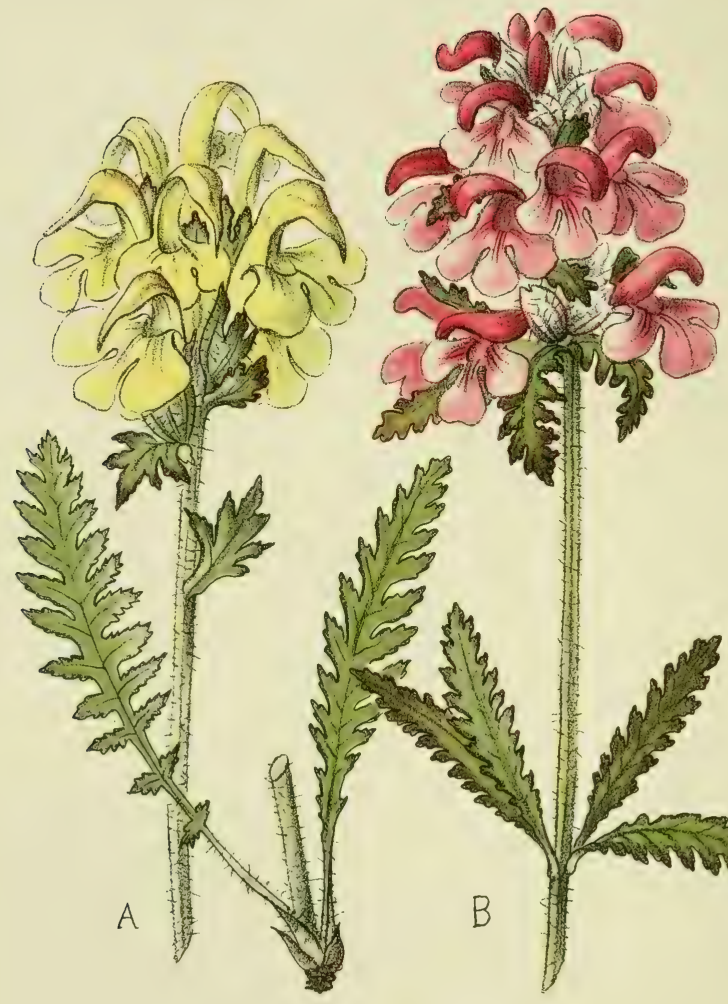
Die Gattung Pedicnlaris ift durch ilre deutlich zweilippigen Hummelblumen charakterifiert, die in dichtem, ährenförmigem, endftändigem Stande angeordnet find. Die Blätter find durchgehends fiederfpaltig. Sie find Halbparafiten, die teilweile auf' Koften der Futterpflanzen leben.

Pedicularis tuberosa. - Tafel 11\% A. - Behaarte Pflanze mit fpindelförmig verdickten Wrurzeln. Stengel 10 bis $25 \mathrm{~cm}$ hoch. Blüten hellgelb mit lang geflchnäbelter Oberlippe.

Mehrjährig. Blüht Juli Auguft.

Befucher: Hummeln, Falter.

Samen ohne Verbreitungsmittel.

Alpen; in den Pyrenäen felten.

Pedicularis verticillata. - Tafel 112 B. - Von allen andern Läul'ekräutern durch den Belitz von 4 auf gleicher Höhe, unterhalb des Blütenftandes entlpringenden (quirlfändigen) Blättern zu unterfcheiden. Stengel 5-20 cm hoch, unverzweigt. Blüten purpurn, mit faft gerader Oberlippe.

Mehrjährig. Blüht Juli Auguft.

Befucher: Hummeln, Falter.

Samen ohne Verbreitungsmittel.

Alpen, Auvergne, Pyrenäen; Karpathen, Kaukafus, nordpolare Länder, Ural, Altai.

\section{Pedicularis foliosa. - Beblittertes Läufekraut. -} Stengel aufrecht, kriftig, $10-60 \mathrm{~cm}$ hoch. Blüten groß, hellgelb, in dichten traubenartigen Ständen, die bis oben mit grofen fiederlpaltigen Blättern durchfchoffen find. Oberlippe oline Schnabel.

Mehrjährig. Blüht Juni Juli. Befucher: Hummeln.

Samen ohneVerbreitungsmittel.

Saftige Halden, Rafenbänder. $1400-2400 \mathrm{~m}$.

Alpen, Jura, Vogefen, Pyrenäen.

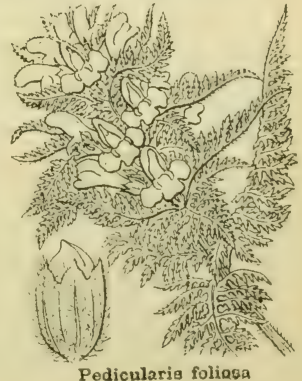

Pedicularis foliasa 
Linaria alpina. - Tafel 113. - Kahl; Stengel dünn, niederliegend, ftark verzweigt. Blätter klein, fchmal, bläulichgrün, je 4 beifammen. Blüten in kurzen Trauben. Krone dunkelviolett, 5-zipflig, deutlich zweilippig. Unterlippe am Grunde mit zwei erhöhten, rolgelben oder violetten Buckeln, die den Eingang zur Kronröhre verdecken, mit rückwärts geftrecktem, fpitzem Sporn (Honigbehälter).

Einjührig. Blüht Juli Auguft.

Belucher: Hummeln, Taubenfchwanz.

Samen geflügelt: Windverbreitung.

Alpen, Jura, Pyrenäen, Karpathen.

Linaria supina. - Niederliegendes Leinkraut. -l'flanze kahl. Blätter fchmal, zerftreut ftehend, bläulichgrüı. Blüten gelb, auf der Unterlippe mit dunklem Fleck.

Einjährig in der Ebene, ift in den $\mathrm{Al}$ pen mehrjährig. Blïht Juni bis September. In der Ebene ohne Geruch, von $800-1000 \mathrm{~m}$ an nach Vanille duftend. Befucher: vermutlich Hummeln.

Sandige, fteinige Weiden, Felfen. Ebene his $2800 \mathrm{~m}$. Italien, Südfrankreich, Cevennen, Pyrenïen.

Erinus alpinus. - Alpen-Leberbalfam. - Behaart, j-15 cm hoch. Blätter lpatelförmig,

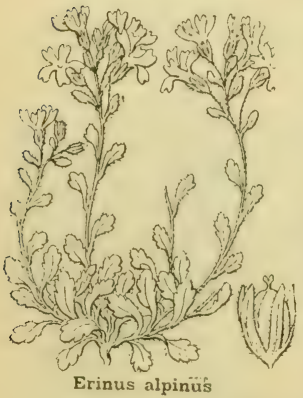
gezähnt, unregelmäfisige Rofetten bildend. Zahlreiche aufrechte Stengel mit kurzen Blütentrauben. Blüten rofafarben mit enger Kronröhre und 5 abftehenden, ausgerandeten, faft gleich großen Zipfeln.

Mehrjährig.

Blüht Mai Juni. Befucher: Falter. Samen ohne Verbreitungsmittel. Felsblöcke, Felsfpalten auf Kalk und Dolomit. $650-2400 \mathrm{~m}$.

Weft- und Zentralalpen, Jura, Cevennen, Pyrenäen. 
Gerölle i6oo-330o Meter.

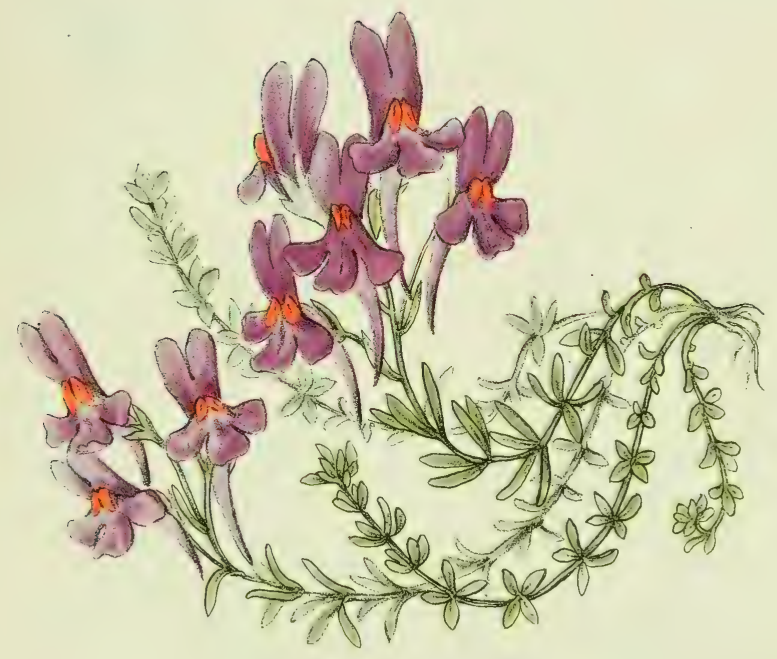

Linaria alpina. Alpen-Leinkraut. Linaire des Alpes. Alpine Todflax, Mother of thousands. 
Felsen, Grasbänder I300-2800 Meter.
Trockene Rasenplätze der alpinen Region.

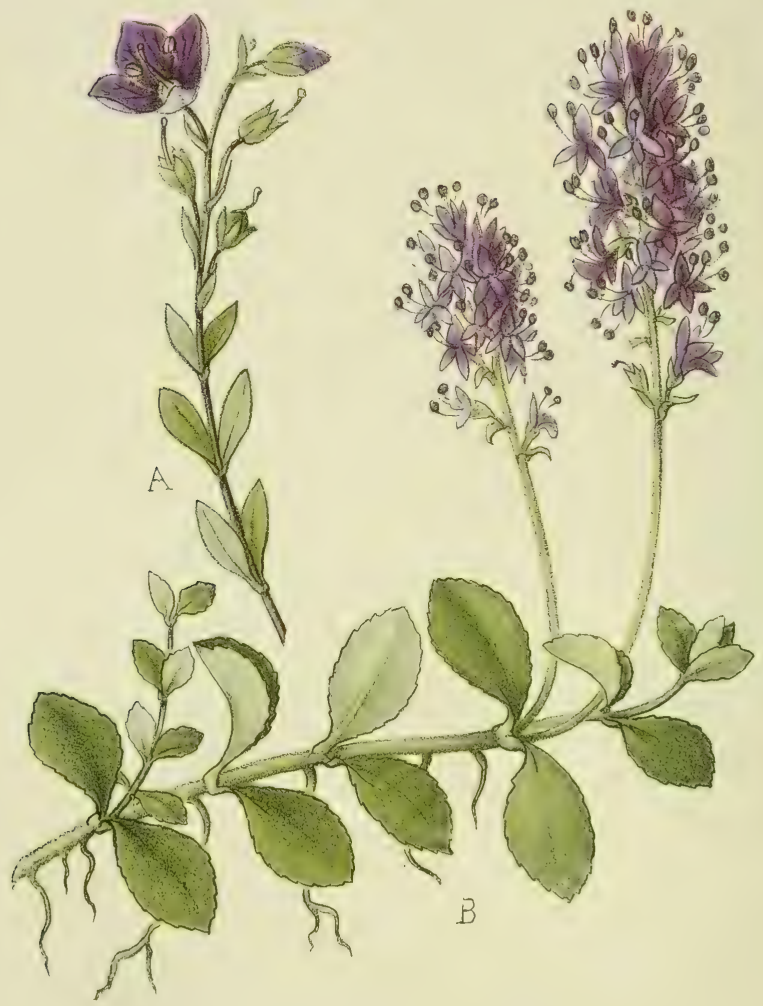

\section{A. - Veronica saxatilis.}

Felsen-Ehrenpreis.

Véronique des rochers. Rock-Speedivell.
B. - Veronica Allionii.

Allionis Ehrenpreis. Véronique d'Allioni. Allioni's Ground-hecle. 
Die Blüten der Gattung Veronica haben eine kurze Kronröhre mit 4 tellerförmig ausgebreiteten Zipfeln und nur 2 Staubgefäße. Durch die Streifung der Kronzipfel tritt die den Honig beherbergende Mitte der Blüte lehr ftark hervor: Schwebetliegenblume.

Veronica saxatilis (fruticans). - Tafel 114 A. Ältere Stengelteile niederliegend, holzig. Blühende Äfte aufrecht, bis $10 \mathrm{~cm}$ hoch, mit gegenltïndigen, lïnglich-ovalen Blättern. Blüten in kurzer Traube, lebhaft blau, mit roten Adern.

Mehrjährig. Blüht Juli Auguft.

Befucher: Fliegen, Bienen, Falter.

Samen geflügelt: Windverbreitung.

Alpen, Vogefen, Auvergne, Cevennen, Pyrenäen, Karpathen, nordpolare Länder.

Veronica Allionii. - Tafel 114 B. - Stengel kriechend, an den Kinoten wurzelnd. Zweige aufrecht. Blïtter gegenftändig, oval, kurz behaart. Blüten blauviolett, in kurzer Traube. Vorderer Kronzipfer kleiner als die ïbrigen.

Mehrjährig. Blüht Augult. Befucher?

Alpen von Savoyen, Dauphiné, Italien.

\section{Veronica aphylla. - Unbeblätterter Ehrenpreis. -} Nur 3--6 cm hoch, behaart, mit eiförmigen, gekerbten Blättern, die zu dichter, grundftändiger Rofette vereinigt find. Blütenfchäfte aufrecht, blattlos, mit 2-う blau- oder rotvioletten Blüten.

Mehrjährig. Blüht Juli Auguft. Befucher: Fliegen.

Samen geflügelt: Windverbr. Ralenbänder, lteinige, magere Weiden, auf Kalk.

$1500-2800 \mathrm{~m}$. Alpen, Jura, Pyrenäen, Kar-

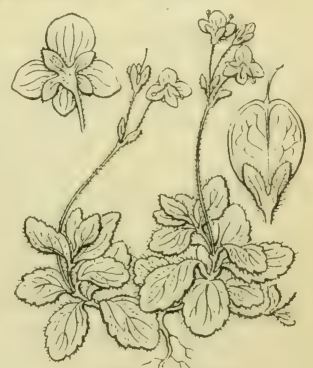

Veronica aphylla pathen, Kaukafus, Altai. 
Digitalis ambigua (grandiflora). - Tafel 115. Kräftige, $50 \mathrm{~cm}$ bis $1 \mathrm{~m}$ hohe Pflanze. Blätter oberfeits glänzend, kahl, am Rande und unterfeits auf den Hauptnerven kurz behaart, fchwach gekerbt. Blüten 3-4 cm lang, weit fingerhutartig, hellgelb, innen braun geadert, in lockerer Traube.

Mehrjährig. Blüht Juni Juli.

Befucher: Bienen, Hummeln.

Samen klein: Windverbreitung.

Alpen, Jura, Vogefen, Pyrenäen.

Digitalis lutea. - Gelber Fingerhut. - Unterfcheidet

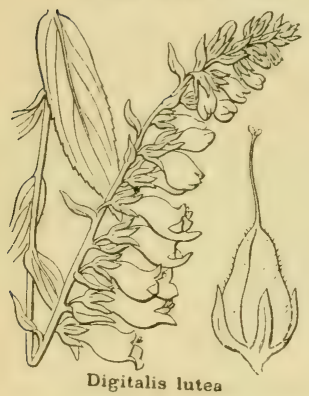

fich vom vorigen durch die nur $2 \mathrm{~cm}$ langen in langen, dichten Trauben ftehenden Blüten, durch lang-ovale Blätter und das Fehlen von Haaren.

Zweijährig.

Blüht Juni Juli.

Befucher: Gartenhummel.

Samen klein: Windverbreitung.

Steinige, waldige Abhänge der Berge und Voralpen.

Mittel- und Nordeuropa.

Digitalis purpurea. - Roter Fingerhnt. - Im allgemeinen der Digitalis ambigua ähnlich, jedoch Blätter beiderfeits wollig hehaart und Blüten 4-5 ('m lang, purpurrot, innen weik, mit dunkelroten Flecken.

Zweijährig. Oft kultiviert, ftirbt auf Kalkboden ab. Die Blätter enthalten das in der Medizin verwendete, giftige Digitalin.

Blüht Juli Auguft. Befucher: Gartenhummel.

Wälder, Waldlichtungen der Ehene und der Berge. Wefteuropa, fehlt in der Schweiz, dagegen in Vogefen und Schwarzwald, auch in Frankreich heimifch. 


\section{$-115$}

Schattige Weiden und Bergwälder bis zur Baumgrenze.

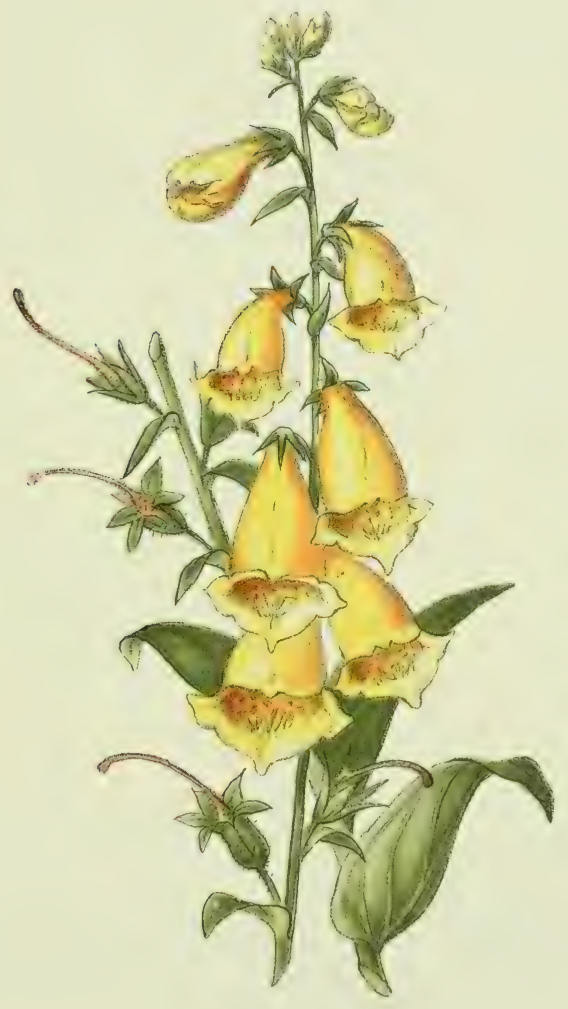

Digitalis ambigua.

Digitale jaune à grandes fleurs.

Blassgelber Fingerhut. Pale-Yellow Foxglove. 


\section{$-116$}

In sandigem, leichten Boden I100-1800 Meter.

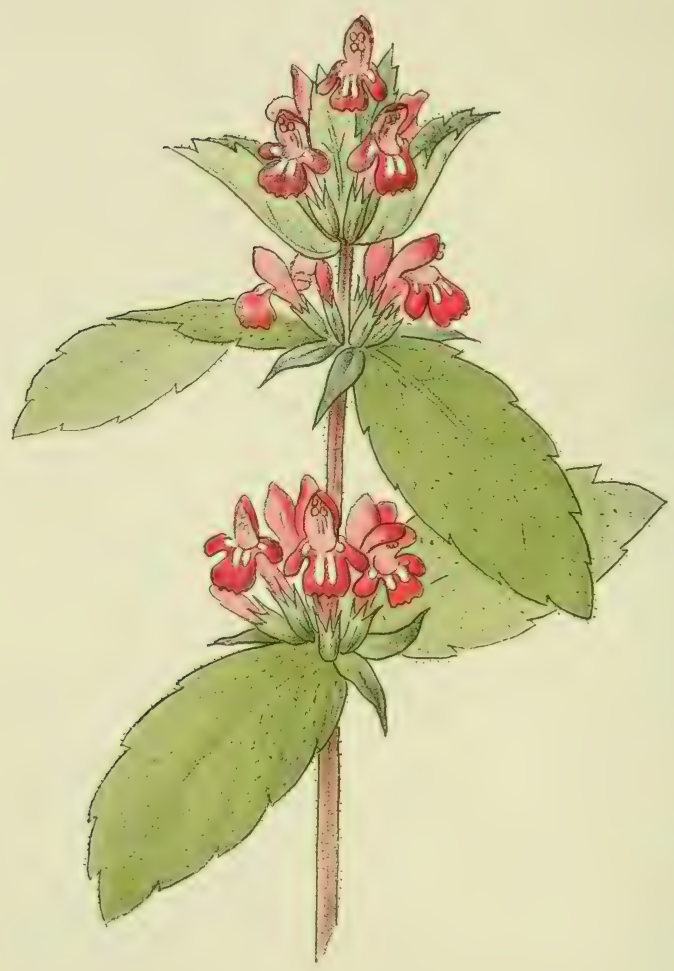

Galeopsis intermedia.

Mittlerer Hohlzahn.

Galéopsis à petites fleurs.

Middle Hemp-nettle. 
Die Lippenbliitler oder Labiaten verdanken ihren Namen der Zweilippigkeit ihrer Blüten. Sie gleichen in diefer Beziehung den Scrophulariacen, unterlicheiden fich jedoch von denlelben durch die 4teilige Frucht. Blätter immer zu zweien gegenftïndig. Faft alle Labiaten find lehr aromatifch, z. B. Lavendel, Thymian, Pfefferminz; fie werden daher zur Darftellung von Parfümerien oder anregenden (ietränken verwendet.

Galeopsis intermedia. - Tafel 11ti. - Ganze Pflanze mit abftehenten, fteifen Haaren. Stengel $10-40 \mathrm{~cm}$ hoch. Blätter eiförmig, hellgrün, grob gezähnt. Blüten purpurrot, 12-15 mm lang, in dichten Knäuehn in den Achleln der oberen Blätter.

Ënjährig. Blüht Juni Juli. Befucher: Hummehn. Frïchtchen häke]n fich mit den fpitzen Zä̈hnen des Kelches felt: Tierverbreitung.

Leichter Sandboden, auf Urgeftein. 1100-1800 m. Alpen der Schweiz, Italien und Frankreich; Auvergne, Cievennen, Pyrenäen.

Calamintha alpina. - Alpen-Saturei. - Stengel 10 bis $30 \mathrm{~cm}$ hoch, verzweigt, unterwärts etwas verholzt, mit kleinen, ovalen, behaarten Blättern. In den Achfeln der oberen ftehen lockere Büfchel 12_-20 $\mathrm{mm}$ langer, rotvioletter Blüten.

Mehrjährig.

Blüht Juni bis Auguft.

Befucher: Bienen, Hummeln, Falter.

Samen ohne Verbr.-Mittel.

Steinige Orte, Halden.

$1400-2300 \mathrm{~m}$.

Alpen, Jura, Karpathen, Au-

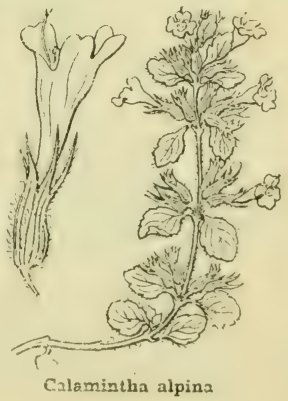
vergne, Cevennen, Pyrenäen. 
Scutellaria alpina. - Tafel 11\% - Mehr oder weniger behaart, $10-20 \mathrm{~cm}$ hoch. Der dicke Wurzelftock trägt zahlreiche, unverzweigte Stengel. Blätter oval, grob gezähnt. Blüten 2-3 cm lang, blauviolett, in dichtem Stande, der mit hreiten, grünen oder rötlichen Blättchen durchfchoffen ift.

Mehrjährig. Blüht Juli. Befucher: Hummeln.

Samen herausgefchleudert.

Felfen, F'elsblöcke, befonder's auf Kalk. 1100-2400 m.

Südweftalpen (Weftfchweiz, Frankreich, Italien), Cevennen, Pyrenäen; Ural, Altai.

Thymus Serpyllum. - Wilder Quendel. - Stengel niederliegend, kriechend, nur die Enden aufgerichtet, und dadurch kurze Teppiche bildend. Blätter länglich-oval. Blüten rotviolett, in kurzem, ährenförmigem Stande.

Die behaarte Form diefer verbreiteten Pflanze bezeichnet man als:

Thymus lanuginosus. - Wollhaariger Quendel. --

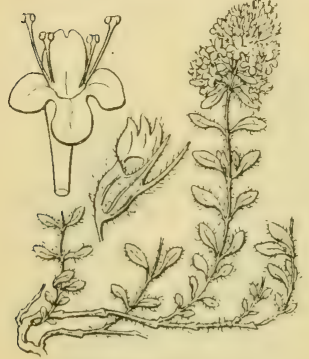

Thymus lanuginosus

Ganze Pflanze wollig behaart, fonft wie die vorige.

Beide Formen mehrjährig.

Blühen Mai bis Juli.

Befucher: Fliegen, Bienen, Hummeln, Falter.

Samen klein: Windverbreitung.

Trockene Matten, Felfen.

Thymus Serpyllum von der Ebene bis hoch in die Alpen hinauf. Alpen, Pyrenäen, Karpathen, Kaukafus, nordpolare Länder, Ural, Altai.

Thymus lamuginosus: füdliche Kette der Alpen, Pyrenäen $1200-1700 \mathrm{~m}$, wahrfcheinlich noch höher. 
Felsen und Felsblöche I I00-2400 Meter.

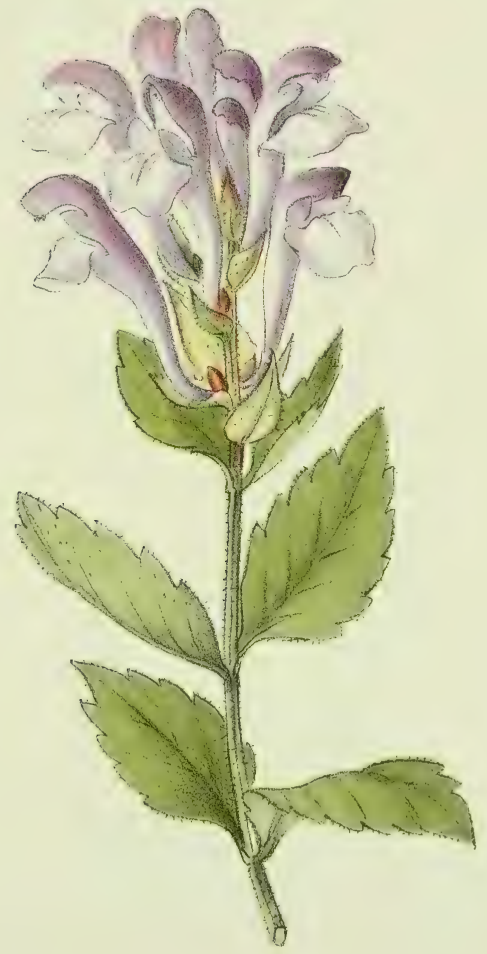

Scutellaria alpina.

Alpen-Helmkraut.

Toque des Alpes. Alpine Skull-cap. 
Mähwiesen, feuchte Weiden I400-2300 Meter.

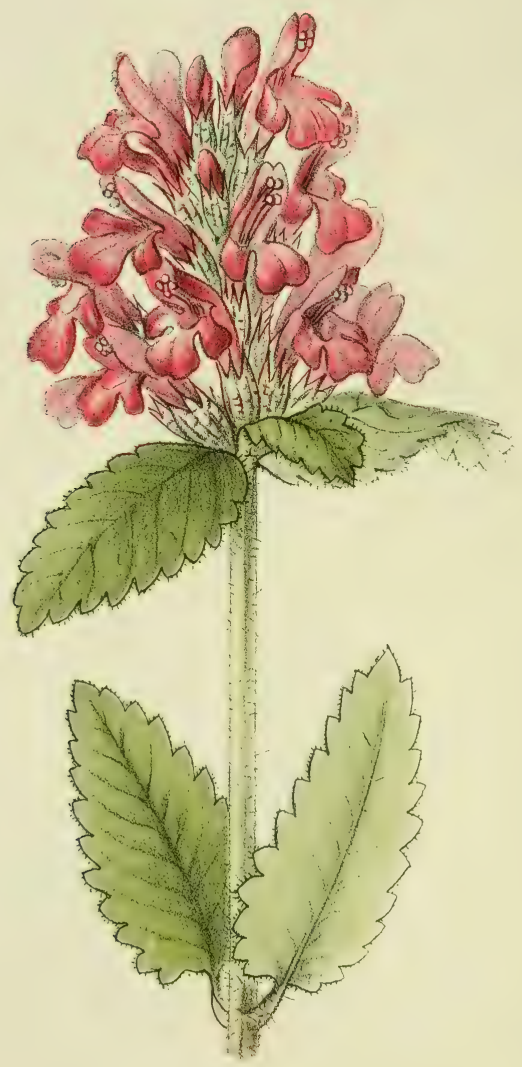

Betonica hirsuta.

Bétoine hérissée.
Rauhaarige Betonie. Rough-haired Betony. 
Betonica hirsuta (Stachys densiflora). - Tafel 118. Behaart, mit aufrechtem, $10-30 \mathrm{~cm}$ hohem Stengel. Blätter langoval, zugefpitzt, grob gezähnt. Blüten in dickem, ährenförmigem Stand, der in den Achfeln des oberften Blattpaares fitzt. Krone lebhaft rolia, etwa $2 \mathrm{~cm}$ lang.

Mehrjährig. Blüht Juli Auguft.

Befucher: vermutlich Bienen.

Früchte häkelnd: Tierverbreitung.

Südweftalpen, Pyrenäen; Tirol, Krain.

Betonica Alopecurus. - Fuchsfchwanz-Betonie. Von der vorigen durch die wollhaarigen, unterfeits weifen Blätter, und die blafigelben, etwas kleineren Blüten verfchieden.

Mehrjährig. Blüht Juli Auguft. Befucher: Bienen.

Früchte häkelnd: Tierverbreitung.

Felfige, bufchige Stellen der Krummholzregion. Oftalpen, Dauphiné, Pyrenäen.

Horminum pyrenaicum. - Pyrenäen-Drachenmaul. Dicker Wurzelftock, der große, ovale Blätter mit abgerundeten Zähnen und einen aufrechten, unverzweigten, fchwach beblätterten Stengel trägt. 4-6 voneinander entfernte Bülchel von großen violetten Blüten, die viel größer find als die Blätter, in deren Achfeln fie ftehen.

Mehrjährig.

Blüht Juni bis Auguft.

Befucher: Bienen, Hummeln.

Früchte ohne Verbreitungsmittel.

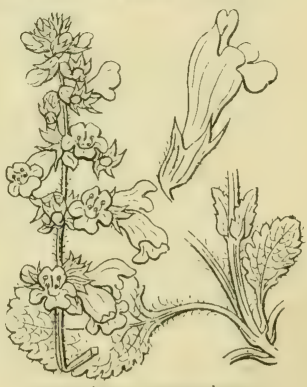

Horminum pyrenaicum

Steinige Weiden, zerftreut.

Alpen, Pyrenäen. 
Labiaten.

Lavandula rera. - Tafel 119. - Verholztes, 20 bis j) $\mathrm{cm}$ hohes Sträuchlein mit ftark verzweigtem Stengel. Blätter lang, fchmal, graufilzig. Blüten zweilippig, violett, in lockerem, ährenartigem Stand.

Mehrjährige Ebenenpflanze, die in den $\Lambda$ pen von Südfrankreich bis zu $1700 \mathrm{~m}$ Höhe gedeiht, und dort ihre Blüten in die Larendelbrennereien liefert.

Blüht Juni Juli.

Befucher: Bienen, Schmetterlinge.

Trockene, fomige Haldeu, auf Kalk. 500-1700 m.

Südalpen (Frankreich und Italien), füdlicher Jura, Cevennen, Pyrenäen; oft in Gïrten kultiviert.

Teucrium montanum. - Berggamauder. - Teppiche

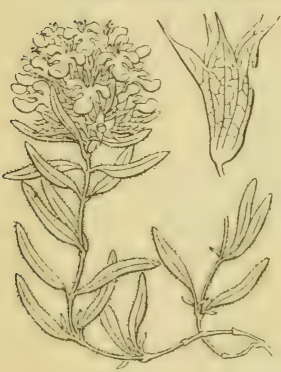

Teucrium montanum bildende, $5-25 \mathrm{~cm}$. hohe Pflanze, mit zahlreichen, zuerft niederliegenden, dann aufteigenden Stengeln, welche lehr l'chmale, unterleits weiß-wollige Blätter tragen, deren Rand nach unten umgerollt ift. Blüten gelblichweif, in kopfförmigem, ährenartigem Stand am Ende der Zweige. Krone nur mit Unterlippe.

Mehrjährig. Blüht Juni bis Auguft. Befucher: Bienen, Hummeln.

Früchtchen vom blafigen Kelch umgeben: Windverbreitung.

Felfen, trockene Halden, auf Kalk, in ter Hügel- und Bergregion.

Mittel- und Süddeutfchland, Alpen, Jura, Cievennen, Pyrenäen. 
Trockene, sonnige Halden 500-1700 Meter.

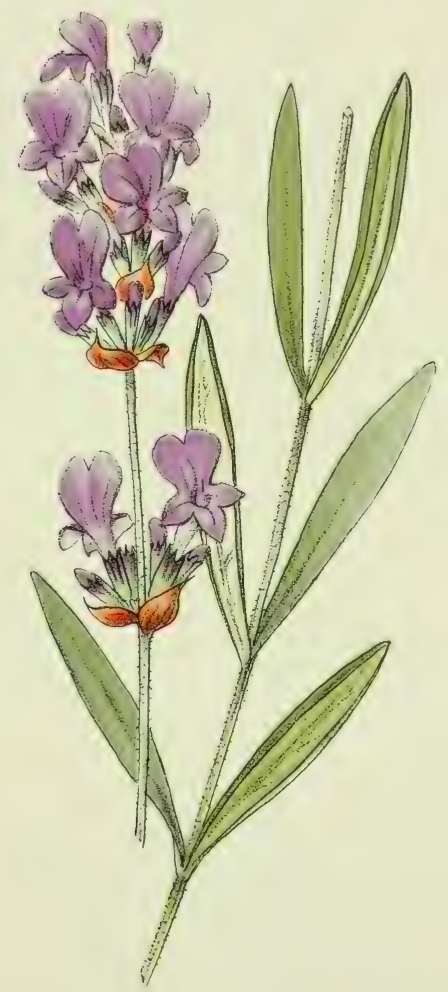

Lavandula vera.

Echter Lavendel.

Vraie Lavande. True Lavender. 
Weiden, Rasenbänder 1400-2000 Meter.

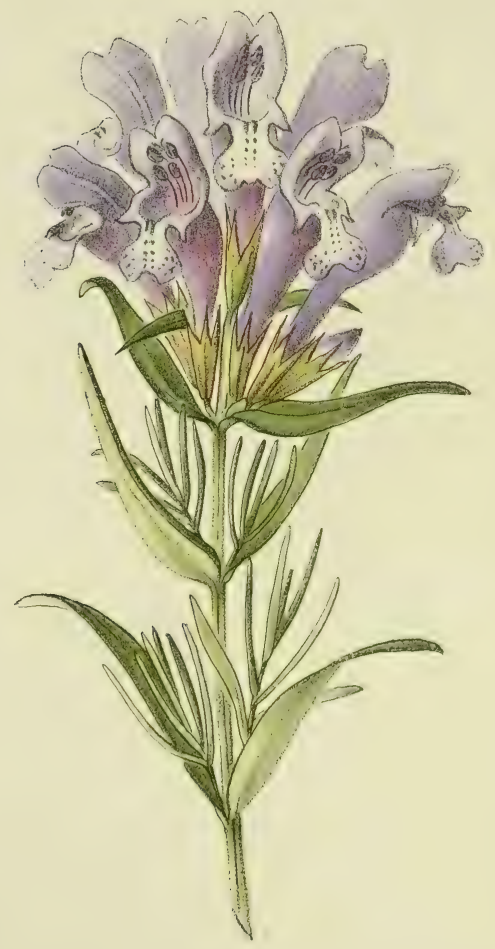

Dracocephalum Ruyschianum. Ruysch's Drachenkopf. Dracocéphale de Ruysch. Ruysch's Dragon's head. 
Dracocephalum Ruyschianum. - Tafel 120. - Stengel $10-30 \mathrm{~cm}$ hoch, unverzweigt aufrecht, mit fehr f'chmalen Blättern, deren Rand nach unten umgerollt ift. Blüten violett, 2-3 cm grof, 2-lippig, beharl, in eiförmigem, endftändigem, ährenartigem Stande.

Mehrjährig. Blüht Juli Auguft.

Befucher: vermutlich Hummeln.

Früchte ohne Verbreitungsmittel.

Matten und Weiden, befonder's auf Kalk, bis $2000 \mathrm{~m}$. Alpen, Pyrenäen, Kaukalus, Ural, Altai.

\section{Dracocephalım austriacum. - öfterreichifeher} Drachenkopf. - Von vorigem verfchieden durch ftarke Behaarung, tief fiederfpaltige Blätter mit fehr fchmalen Ablichnitten, und größsere, $4-5 \mathrm{~cm}$ lange Blüten mit bauchig erweiterter Kronröhre.

Mehrjährig. Blüht Mai Juni.

Befucher: vermutlich Hummeln.

Früchtchen ohne Verbreitungsmittel.

Steinige Weiden, bufchige Abhånge, felten.

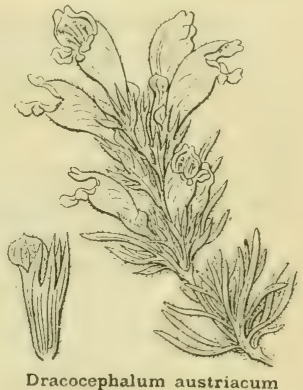

Alpen von Frankreich, der Schweiz, Tirol bis Böhımen. 
Ajuga pyramidalis. - Tafel 121. - Stark behaart; Stengel aufrecht, nicht verzweigt, ohne Ausläufer, im Gegenfatz zum lviechenden Günfel der Ebene. Blätter eiförmig, fchwach gelappt, kreuzweife gegenftändig, verurfachen durch ihre Annrdnung und die allmähliche Größenabnahme nach oben zu die 4feitige Pyramidenform der Pflanze. Blüten violett in endftändiger Scheinähre, welche von den oberen, rötlichen oder violetten Laubblättern durchfchoffen ift, die länger find als die Blüten.

Mehrjähıig. Blüht Juni Juli. Befucher: Hummelı. Früchte ohne Verbreitungsmittel.

Alpen, Auvergne, Pyrenäen; Kaukafus.

Die Plantaginaceen find mit den Scrophulariaceen nahe verwandt und liefern ein intereffantes Beilpiel für den Übergang typifcher Inlektenblütler zur Windbeftäubung. Während ihr Blütenbau auf urfprüngliche Infektenheftäubung hindeutet, wird die Beftäubung tatfächlich meift durch den Wind vollzogen. Dementfprechend find fie unfcheinbar, jedoch als Futterpflanzen l'ehr gefchälzt, in den Alpen befonders:

Plantago alpina.

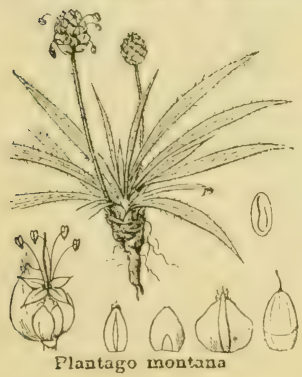

- Alpen-Wegerich, Adelgras. Schwach behart, $8-20 \mathrm{~cm}$ hoch, mit kräftigem, langem Wurzelftock, welcher über dem Boden zahlreiche, kurze Alte trägt, deren lange, fpitze Blätter ein dichtes grundfändiges Büfchel bilden. Blütenfchäfte blattlos, mit kurzer, endftändiger Ähre von kleinen weißen Blüten mit vier fternförmig ausgebreiteten Kronzipfeln und 4 langfädigen Staubgefäßsen.

Mehrjährig. Blülst Juni Juli.

Windbeftäubung.

Samen ohne Verbreitungsmittel. Auf gutem Matten- und Weideboden, 1500-2400 m. Alpen, Cevennen, Pyrenäen. 
Weiden, Rasenplätze 1000-2500 Meter.

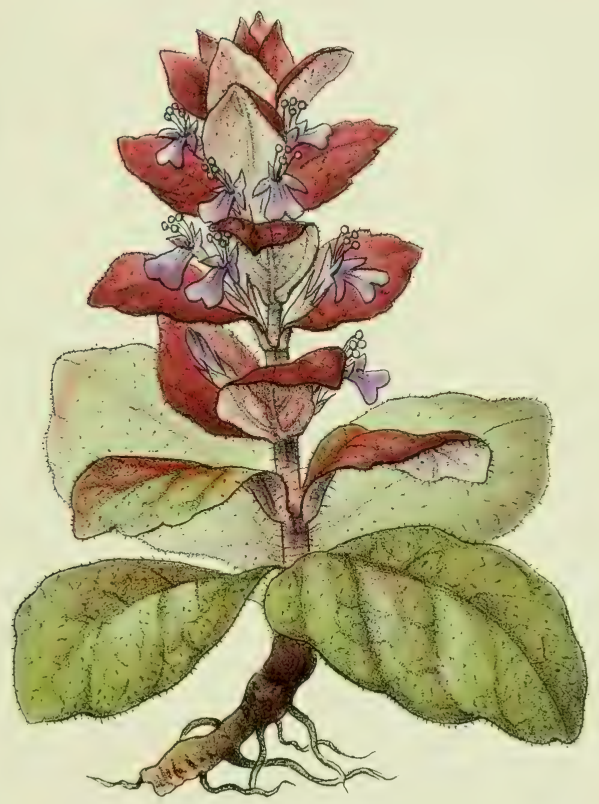

Ajuga pyramidalis. Bugle en pyramide.

Pyramidenförmiger (jünsel. Pyramidic Bugle. 
Sonnige Felsen und Felsblöcke bis 2600 Meter.

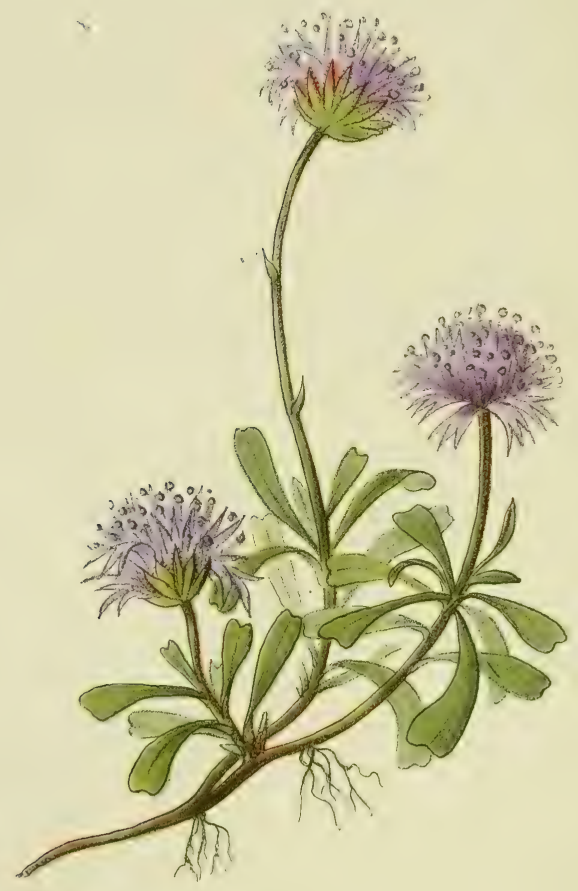

Globularia cordifolia. Globulaive à feuilles en cour.
Herzblätrige Kugelblume. Heart-leaved Globularia. 
Die Globulariaceen zeigen in ihrem Blütenftand grofe Ähnlichkeit mit den Compositen, der Bau der einzelnen Blüten hat jedoch mit demjenigen der Compositen nichts zu tun, fondern fchliefst fich durch die Zweilippigkeit, die Zahl der Staubgefäße und die Form der Frucht eng an die Scrophulariaceen und damit auch an die Plantaginaceen an. Während aber bei letzteren die Scrophulariaceen-Hummelblume zur Windblüte geworden ift, hat lie lich bei den Globulariaceen an die Beftüubung durch Falter angepaft.

Globularia cordifolia. - Tafel 122. - Niedriges Sträuchlein mit holzigen, nierlerliegenden Äften, die mit ihren Bülcheln kleiner, lederartiger, 4-7 $\mathrm{mm}$ breiter und vorn ausgerandeter Blättchen Teppiche und Spaliere bilden. Blüten ftahlblau, in halbkugeligen Köpfchen am Ende zarter, 5 bis $15 \mathrm{~cm}$ hoher Schäfte.

Mehrjährig. Blüht Juni Juli. Befucher: Falter.

Samen ohne Verbreitungsmittel. Befonder's auf Kalk. Alpen, Jura, Gevennen, Pyrenäen.

Globularia nana. - Zwerg-Kugelblume. - Der vorigen ähnlich, aber noch kleiner. Blätter in fehr dichten Rofetten, nur 2-4 mm breit. Die Blütenfchäfte find $2 \mathrm{~cm}$ lang und ragen kaum über die Blätter empor.

Mehrjährig. Blüht Mai Juni. Befucher: Falter.

Trockene Felfen und Felsblöcke des Kalkgebirgs ; mit Vorliebe auf Gräten, 1200-2200 m. Alpen der Provence, Ventoux, Pyrenäen.

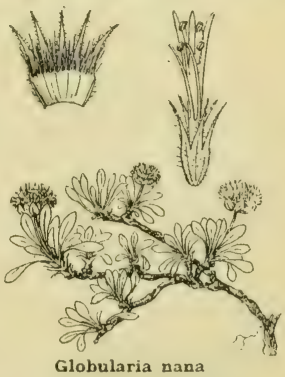


Die Polygonaceen befitzen kleine, wenig auffallende Blüten, die meiftens in dichten Ständen angeordnet find. Merkwürdig find die Blattfcheiden, welche wie diejenigen der Gräfer den Stengel vollftändig umgeben, zuweilen allerdings, z. B. beim Rhabarber, bauchig davon abftehen.

Polygonum viviparum. - Tafel $123 \mathrm{~A}$. - Dicker, knolliger Wurzelftock mit einem einzigen, aufrechten, 10 bis $15 \mathrm{~cm}$ hohen, unverzweigten, beblätterten Stengel. Blätter fchmal, mit nach unten umgerollten Rändern: die unteren lang geftielt. Blüten weifs oder rofa, in langer Ähre, in deren unterem Teil die Blüten durch Brutknöllchen (fiehe I. Teil S. 4) erfetzt find.

Mehrjährig. Blüht Juni bis Auguft.

Befucher: Fliegen, Bienen, Falter; trotzdem werden felten Samen gebildet. Die Fortpflanzung wird durch die Brutknofpen gefichert, die durch Vögel verbreitet werden.

Matten, fteinige Weiden.

$1400-3000 \mathrm{~m}$, oft fchon bei $1000 \mathrm{~m}$.

Alpen, Jura, Auvergne, Pyrenäen; Karpathen, Kaukafus, nordpolare Länder, Ural, Altai, Himalaya.

Oxyria digyna. - Tafel 123 B. - Dunkelbrauner, fchuppiger Wurzelftock, der eine Rofette langgeftielter, herzförmiger, etwas fleifchiger, kahler Blätter und einen aufrechten Blütenfchaft mit traubenartigem Blütenftand trägt. Blüten mit 6 roten, heraushängenden Staubgefäßen und zwei pinfelförmigen Narben. Früchte linfenförmig zufammengedrückt mit 2 roten Flügeln (auf der Tafel nur Früchte abgebildet).

Mehrjährig. Blüht Juli. Windbeftäubung.

Die geflügelten Früchte durch Wind verbreitet.

Diefelbe geographifche Verbreitung wie Polygonum viviparum. 


\section{$-12: 3-$}

Viesen, steinige Veiden 1400-3000 Meter.
Schattige Felsen, feuchte Gerölle 1700-2600. Meter.

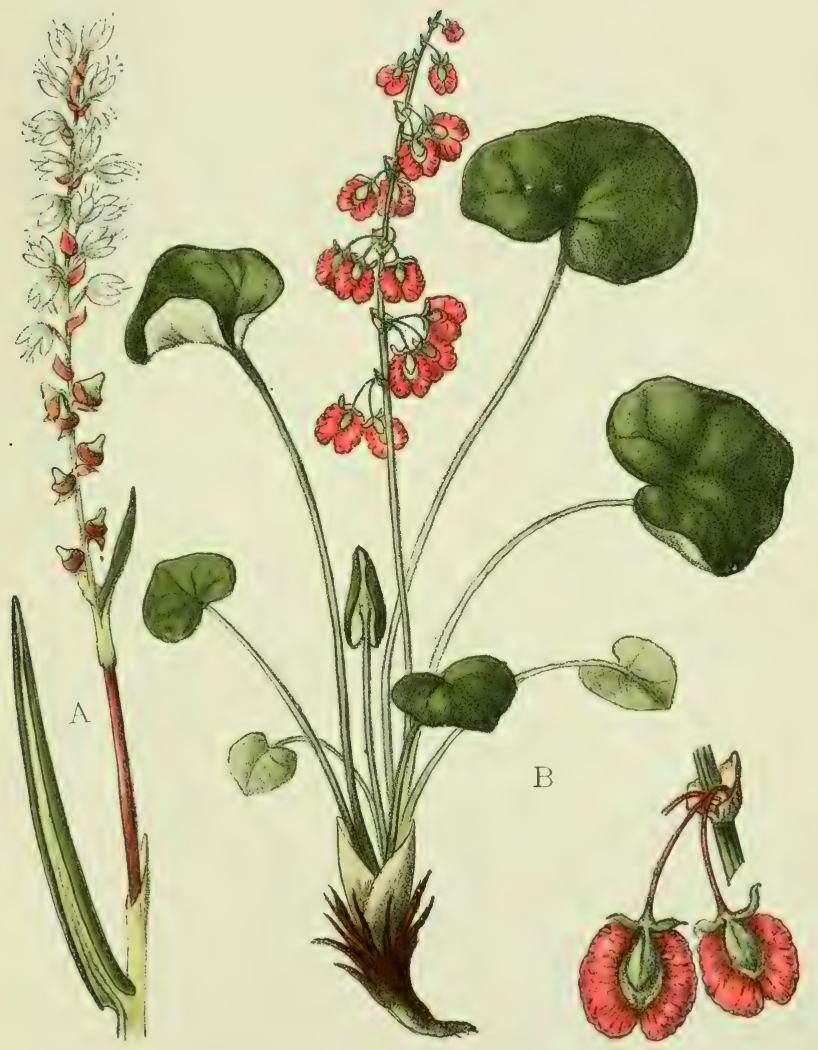

1. - Polygonum viviparum.

Knöllchentragender hinöterich. Renouée vivipare.

Bulbiferous Knot-grass.
13. - Oxyria digyna. Zweigriffliger säuerling. Oxyria à deux styles. Mountain Sorrel. 
Felsen, Rasenplätze i600-2500 Meter.

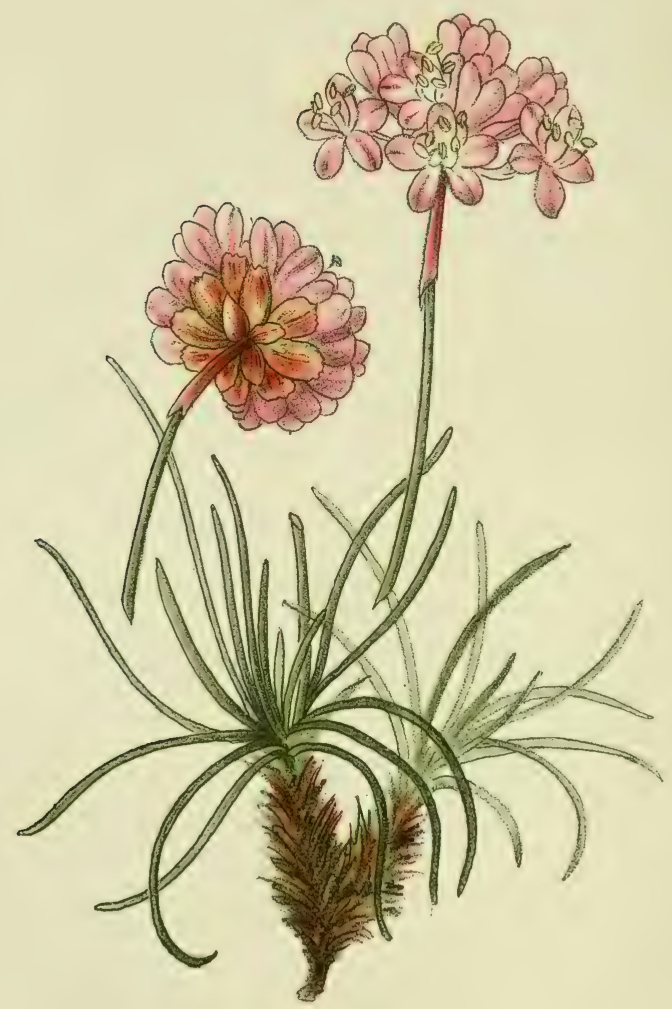

Armeria alpina.

Alpen-Grasnelke.

Statice des Alpes. Alpine Thrift. 
Die meiften Plumbagaceen find Meeresftrand-Pflanzen; einige gedeihen nur auf fehr falzhaltigem Boden oder gar nur in Salz-Sümpfen. Das Vorkommen von Plumbagaceen in den Alpen ift daher auffallend.

Armeria alpina. - Tafel 124. - Starker, kurzäftiger Wurzelftock, der von den Reften der alten Blätter befetzt ift. Blätter dreinervig, etwas fleifchig, nur $2-3 \mathrm{~mm}$ breit, grasartig, in dichten Büfcheln. Blütenfchaft fteif, aufrecht, $10-25 \mathrm{~cm}$ hoch. Blüten intenfiv rofa, in $2 \mathrm{~cm}$ yrofem, halbkugeligem Köpfchen, das von gelbbraunen, häutigen Blätt. chen umgeben ift.

Mehrjährig. Blüht Juli.

Befucher: Fliegen, Bienen, Falter.

Früchte mit häutigem Fallfchirm (Kelch): Windverbreitung.

Felfen und Rafenplätze der Koniferenregion. $1600-2500 \mathrm{~m}$.

Alpen, Pyrenäen, Karpathen.

Armeria maritima. - Meer-Grasnelke. - Der vorigen ähnlich, aber Blätter einnervig.

Strand des Atlantifchen Ozeans, in den Gärten oft als fogen. "Ipanifcher Rafen" zu Einfaffungen verwendet.

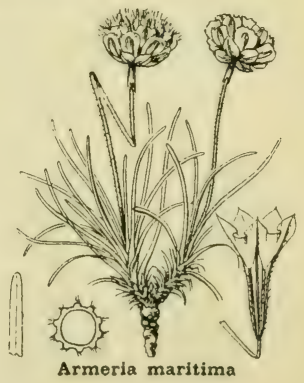


Empetrum nigrum. - Tafel $125 \mathrm{~A}$. - Heidekrautartiger, $15-40 \mathrm{~cm}$ hoher, ausgedehnte Büfche bildender Strauch mit holzigen, niederlieg'enden, dicht beblätterten Stengeln. Blätter 7-8 mm lang, fchmal, lederartig, immergrün ; ihr Rand ift über die Unterfeite umgerollt (I. Teil Seite 35). Blüten fehr klein, mit 3 rofafarbenen Kronblättern in den Achfeln der oberen Blätter.

Mehrjährig. Blüht Mai bis Juli.

Befucher: gelegentlich Fliegen, meift Windbeftäubung. Fleifchige, erft grüne, dam rote, zuletzt fchwar'ze Beeren; durch Vögel verbreitet.

Alpen (mit Ausuahme der warmen füdlichen Teile), Jura, Auvergne, Pyrenäen, Karpathen, Kaukafus, nordpolare Länder, Ural, Altai.

\section{Thymelaeaceen.}

Daphne striata. - Tafel $125 \mathrm{~B}$. - Stark verzweigtes, $10-20 \mathrm{~cm}$ hohes Strüuchlein mit braunen, gekrümmten Äften. Blätter immergrün, fchmal, unbehaart, etwa $2 \mathrm{~cm}$ lang. Blüten fehr wohlriechend, lebhaft rot, mit geftreifter Kronröhre, in dichter, faft kopfförmiger Dolde.

Mehrjähırig. Blüht Juni Juli. Befucher: Falter.

Beeren rot, durch Vögel verbreitet.

Zentral- und Oftalpen.

Daphne Mezeremm. - Seidelbaft. - Trägt die Blüten

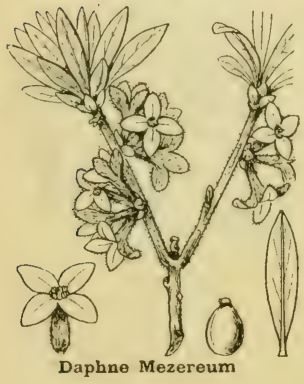
unterhalb des endftändigen Schopfes von nur einjährigen Blättern, die fich erft nach dem Blühen völlig entwickeln.

Mehrjährig.

Blüht März, in den Alpen bis Juli. Befucher: Bienen, Hummeln, Falter.

Beeren rot, giftig, durch Vögel verbreitet.

Steinige Wälder, zwifchen Felsblöcken. Ebene bis $2000 \mathrm{~m}$. Mitteleuropa, Alpen. 
Felsen, Halden, torfige Matten bis 2700 Meter.
Steinige Weiden, Felsen I 700-2800 Meter.

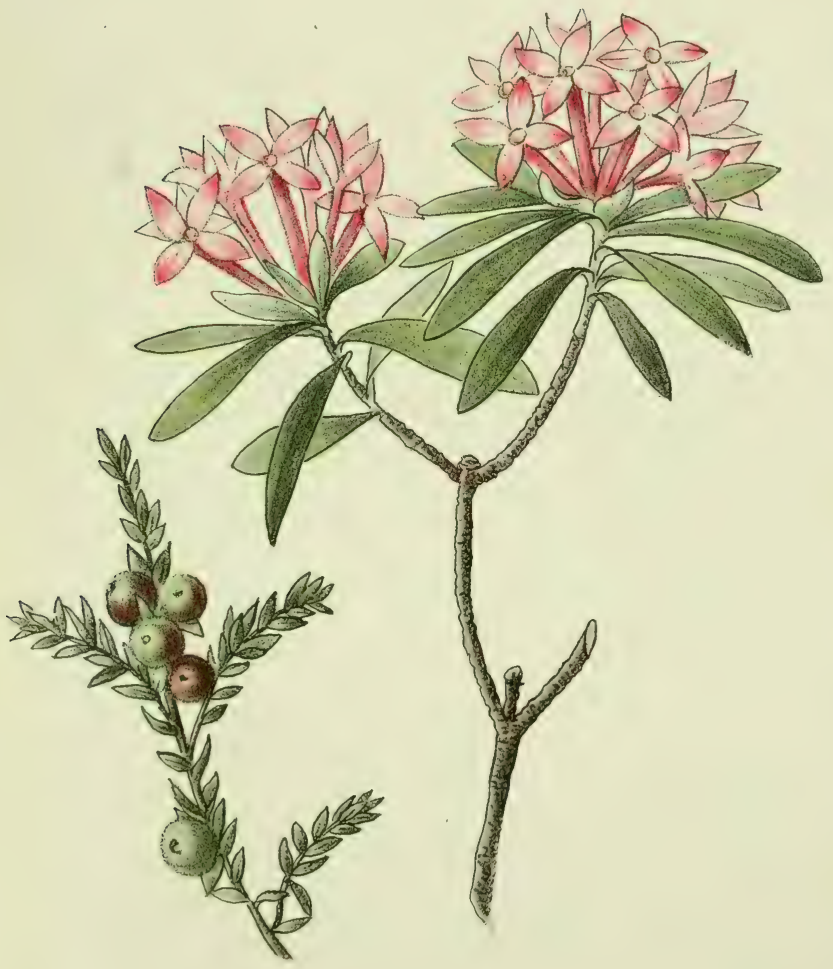

1. Empetrum nigrum. Schwarze Rauschbeere. Camarine noire. Crowbery, Crakebery.
B. - Daphne striata.

Gestreifter Kellerhals. Dapluné strié. Striped Mezereon. 


\section{$-126-$}

Feuchte Weiden I800-2600 Meter.

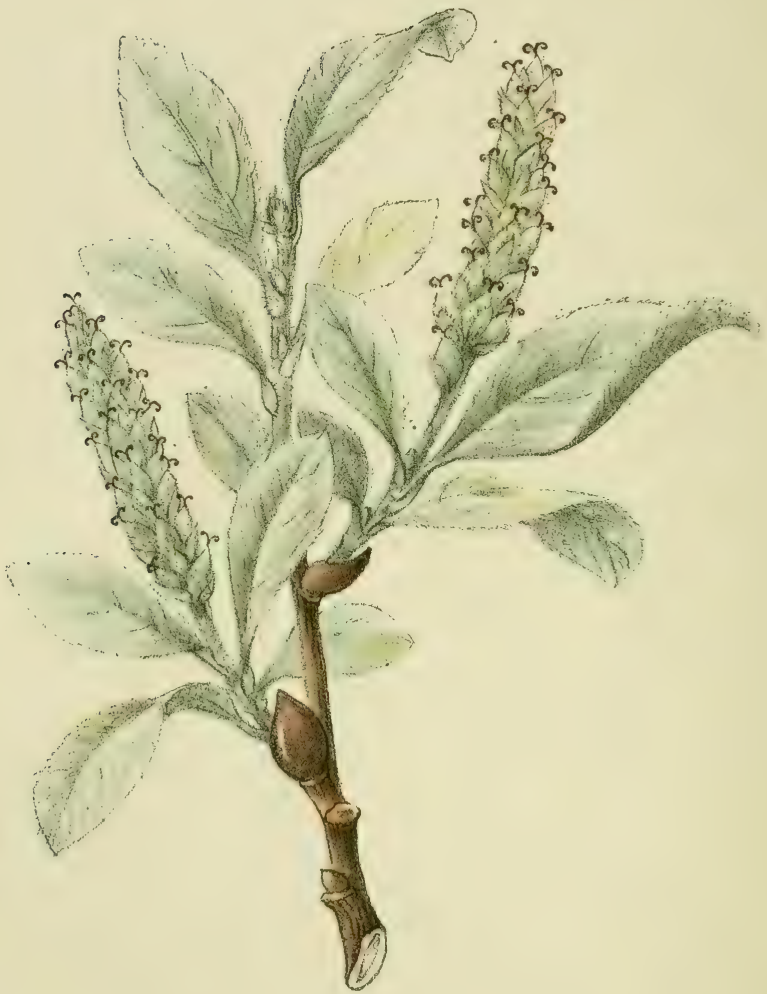

Salix glauca.

Saule glauque.

Graugrüne Weide.

Glaucescent Willow. 
Die Weidengewächse oder Salicaceen, die in der Ebene zu hohen Bäumen heranwachfen, find in der $\Lambda$ lpenregion nur durch niedere Sträucher vertreten, die fich oft lpalierartig dem Boden anfchmiegen. Die Bläten ftehen in dichten Ähren (Kätzchen), und zwar männliche (Staubgefäfße) und weibliche (Stempel) auf verfchiedenen Stöcken: Zweihäufigkeit, Dioecie. Obwohl eine eigentliche Blütenhülle fehlt, werden die Blüten von Infekten befucht, welche fie am ftarken Honiggeruch und an der gelben Färbung der Staubbeutel erkennen.

Salix glauca. - Tafel 126. - Bis $80 \mathrm{~cm}$ hoher, ftark verzweigter Strauch mit krummen Äften, die in der Jugend wie die Knofpen weif behaart find. Blätter lanzettlich, nicht gezähnt, beiderfeits lang feidenhaarig. Blüten in dichten, endftändigen Kätzchen: auf Tafel 126 nur lolche mit weiblichen Blüten abgebildet.

Mehrjährig. Blüht Juni Juli. Befucher: Hummeln. Samen mit Haarfchopf: Windverbreitung.

Alpen, Pyrenäen, Kaukafus, nordpolare Länder (geht unter allen Weiden am weiteften nördlich, bis $74,5^{0}$ n. Br.), Ural, Altai.

Salix Arbuscula. - Bufchweide. - Höchftens $50 \mathrm{~cm}$ hoch, dichte Bülche bildend. Blätter breit lanzettlich, gezähnt, oberfeits dunkelgrün, unterfeits etwas bläulich. Blütenähren auf kurzen Seitenälten, mit behaarten Decklchuppen. Der abgebildete Aft männlich, rechts ohen weibliches.Kätzchen.

Mehrjährig. Blüht Juni Juli. Befucher und Samen wie bei der vorigen.

Weiden, feuchte Fellen. $1400-2700 \mathrm{~m}$. Alpen, Pyrenäen ; Karpathen,

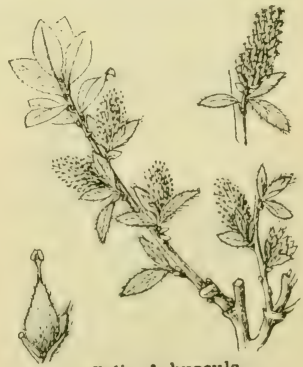

Salix Arbuscula Kaukafus, nordpolare Länder, Ural, Altai. 
Salix reticulata. - Tafel 12\% - Niedriges Spalierfträuchlein mit ftarken, holzigen Äften. Blätter breit elliptilch, lederartig, l'chwach behaart, mit umgerolltem Rand, oberfeits dunkelgrün, unterfeits bläulichgrün mit deutlich hervortretendem Adernetz. Blütenkätzchen deutlich höher als die Blätter. Blütenfchuppen rötlich.

Mehrjährig. Blüht Juli Auguft.

Befucher: Falter, wohl auch Fliegen und Hummeln.

Samen mit Haarfchopf: Windverbreitung.

Alpen, Pyrenäen, Karpathen (fehlt dem Kaukafus), nordpolare Länder, Ural, Altai.

Salix herbacea.

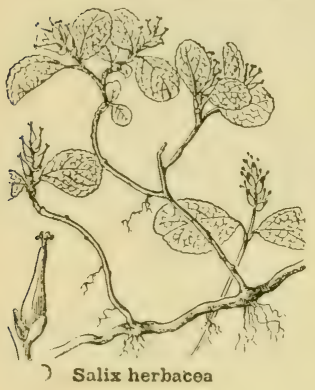

Salix retusa. - Stumpfblättrige Weide. - Gedrun-

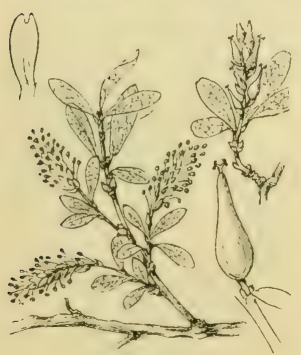

Salix retusa
Krautweide. - Kleinfte aller Weiden. Äfte dünn mit nur zwei breit eiförmigen, hellgrünen, beiderfeits glänzenden, dünnen, krautigen Blättern, dazwifchen die kurzen, wenigblütigen Kätzchen (in der Skizze weiblich, nur rechts unten männlich). Mehrjährig. Blüht Juli Auguft. Befucher: Fliegen, Hummeln. Samen mit Haarfchopf: Windverbr. Feuchte Felsblöcke, niederer Ralen, $1700-3000 \mathrm{~m}$.

Alpen, Pyrenäen, Karpathen, nordpolare Länder, Altai.

genes Spalierfträuchlein mit ftarken, knorrigen Äften. Blätter auch kahl, jedoch fchmal-eiförmig, vorn oft abgeftutzt. Kätzchen dichter als bei voriger (Skizze links männlich, rechts weiblich). Blütenfchuppen gelb.

Mehrjährig. Blüht Juli Auguft. Befucher, Samen wie bei voriger. Felsblöcke, niederer Rafen. $800-3000 \mathrm{~m}$.

Alpen, Pyrenäen; Karpathen, nordpolare Länder, Altai. 
Felsblöcke, magere Weiden 1600-3000 Meter.

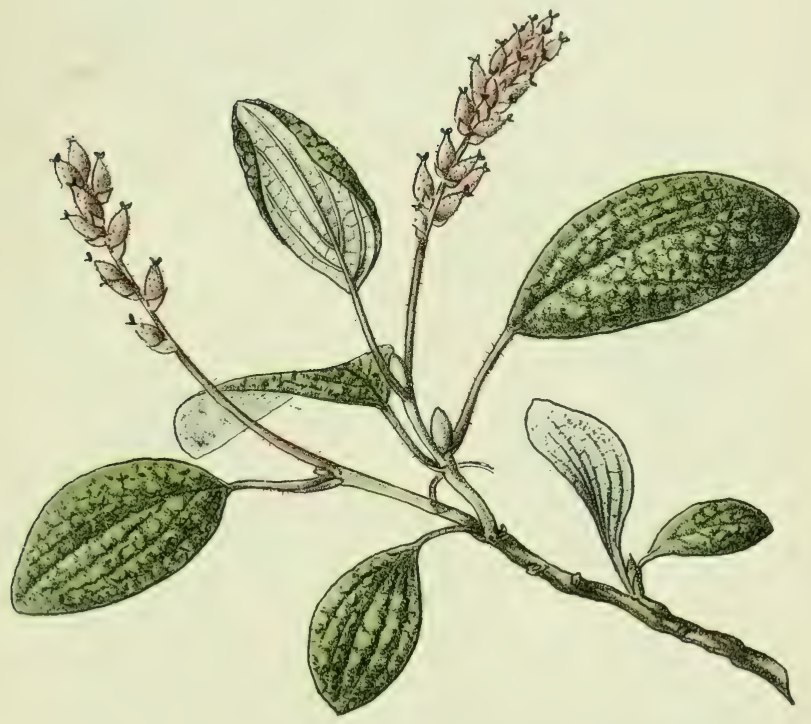

Salix reticulata. Saule réticulé.

Netzadrige Weide. Reticulated Willow. 
Schattige, feuchte Halden 600-2300 Meter.

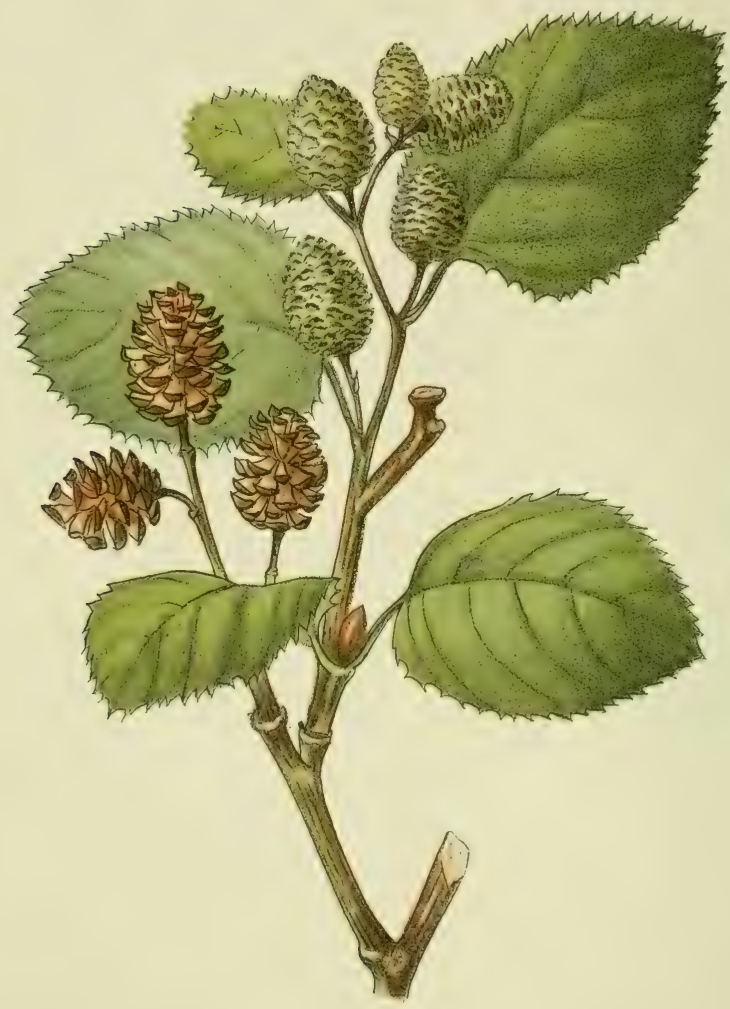

Alnus viridis. Aune vert.

Grün-Erle.

Green Alder. 
Die Betulaceen oder Birken- und Erlengewächfe tragen ihre Blüten wie die Weiden in dichten Kätzchen, aber männliche und weibliche auf demfelben Stocke: Einhäuligkeit, Monoecie. Honiglofe Windblütler.

Alnus viridis. - Tafel 128. - Bis $2 \mathrm{~m}$ hoher, ftark verzweigter Strauch mit elaftifchen Äften. Blätter eiförmig, l'pitz, am Rande gezähnt, beiderfeits grün, faft kahl. Die weiblichen Blütenftände (nur fie find auf Tafel 128 wiedergegeben) werden im zweiten Jahre zu holzigen, dunkeln Zäpfchen; die männlichen hängend, kleiner, hinfällig.

Mehrjähriger, dichte Beftände bildender Strauch, der als Feftiger des Bodens, Lawinenfchutz und Brennholzlieferant von grofem Werte ift.

Blüht Mai bis Juli. Windbeftäubung.

Samen geflügelt: Windverbreitung.

$1500-2300 \mathrm{~m}$; im Teffin fchon bei $600 \mathrm{~m}$.

Alpen, im Süden bis Korfika; Schwarzwald (fehlt Jura, Vogefen und Pyrenäen), Böhmerwald, Mähren, polares Afien und Amerika.

Betula nana. - Zwergbirke. - Nur etwa $50 \mathrm{~cm}$ hoher, ftark verzweigter Strauch mit dunkler Rinde. Älte meilt gerade, mit rundlichen, lederartigen, dunkelgrünen, nur $1 \mathrm{~cm}$ grofen, gezähnten Blättern. Kätzchen eiförmig bis zylindrifch, auf kurzen Seitenäften.

Mehrjährig. Blüht Mai Juni.

Windbeftäubung.

Früchtegeflügelt(Skizze rechts oben): Windverbreitung. Ausgefprochen nordilche Pflanze, die in Mitteleuropa nur hie und da als Reft

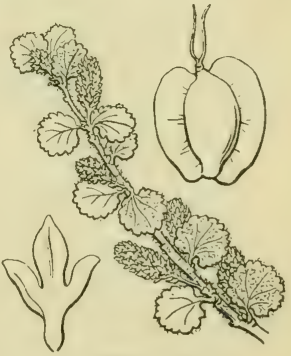

Betula nana der Flora der Eiszeit vorkommt, fo in den Torfmooren des Jura und der Ardennen, fehlt in den Alpen. 
Die Coniferen oder Nalelhölzer find durchgehends Holzpflanzen mit nadel- oder fchuppenarligen Blätterm. Die meiften find reich an Harzen, die zu Lacken etc. verwendet werden. Ihre Blüten ftehen auf einer niederen Entwicklungsftufe. indem die Samen nicht in einem gelchloffenen Gehäule, einen Fruchtknoten enthalten find, wie bei den übrigen, in diefem Buche behandelten Pflanzen, fondern nackt zwilchen den fie tragenden Blältern fitzen: Nacktfamige, Gymnofpermen. Heutzutage bilden diefelben nur noch einen kümmerlichen Reft einer formenreichen, uns aus Verfteinerungen und Abdrücken bekannten Flora vergangener Erdperioden.

Juniperus nana. - Tafel 129. - Ift von dem gewöhnlichen Wacholder ( $J$. communis), der auf trockenen Hügeln vorkommt, nur durch feinen gedrungeneren Wuchs mit oft lipalierartig am Boden und an Felsblöcken ausgehreiteten Äften verfchieden. Blätter kurz nadelförmig, unterfeits weifsgrün. Früchte beerenartig, kugelig (liche Tafel 129), bei der Reife l'chwarz.

Mehrjährig. Blüht Juli Auguft. Windbeftäubung. Samen durch Vögel verbreitet.

Hëchft hinauffeigende Holzpflauze (I. Teil Seite 11). Apen, Jura, Auvergne, C'evennen, Pyrenäen; Karpathen, Kaukalus, nordpolare Länder, Ural, Altai, Himalaya.

Juniperus Sabina. - Sadebaum. - Vom vorigen

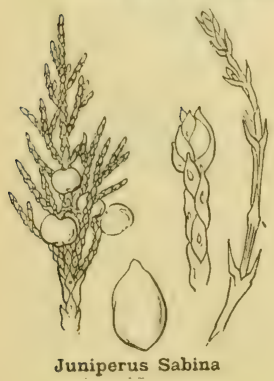

durch die winzig f'chuppenförmigen, dem Stengel eng anliegenden Blätter und den höheren Wuchs verfchieden. Mehrjähırige, zum Teil giftige Pflanze. Blüht April Mai. Windbeftäubung. Früchte beerenartig, durch Vögel verbreitet.

Felfen, fteinige Matten, befonders auf Kalk.

$1400-1800 \mathrm{~m}$.

Alpen, Südtirol, Krain, Pyrenäen. 
Felsige Rasemplätze, Gerölle r600-3600 Meter.

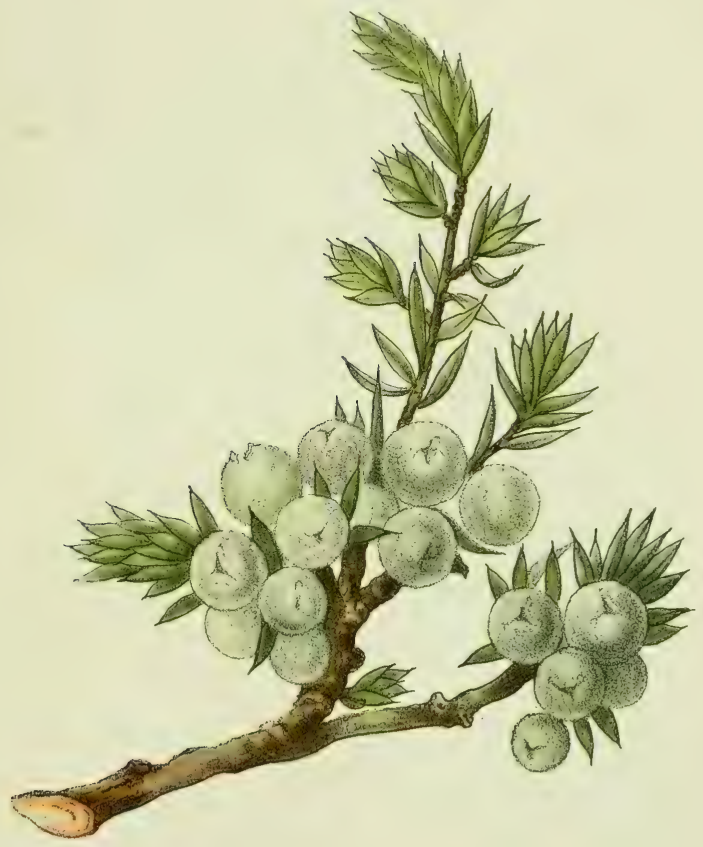

Juniperus nana.

Genévrier nain.
Zwerg-Wachholder. Divarf-Juniper. 
$-130-$

Matten, feuchte Weiden 850-2500 Meter.

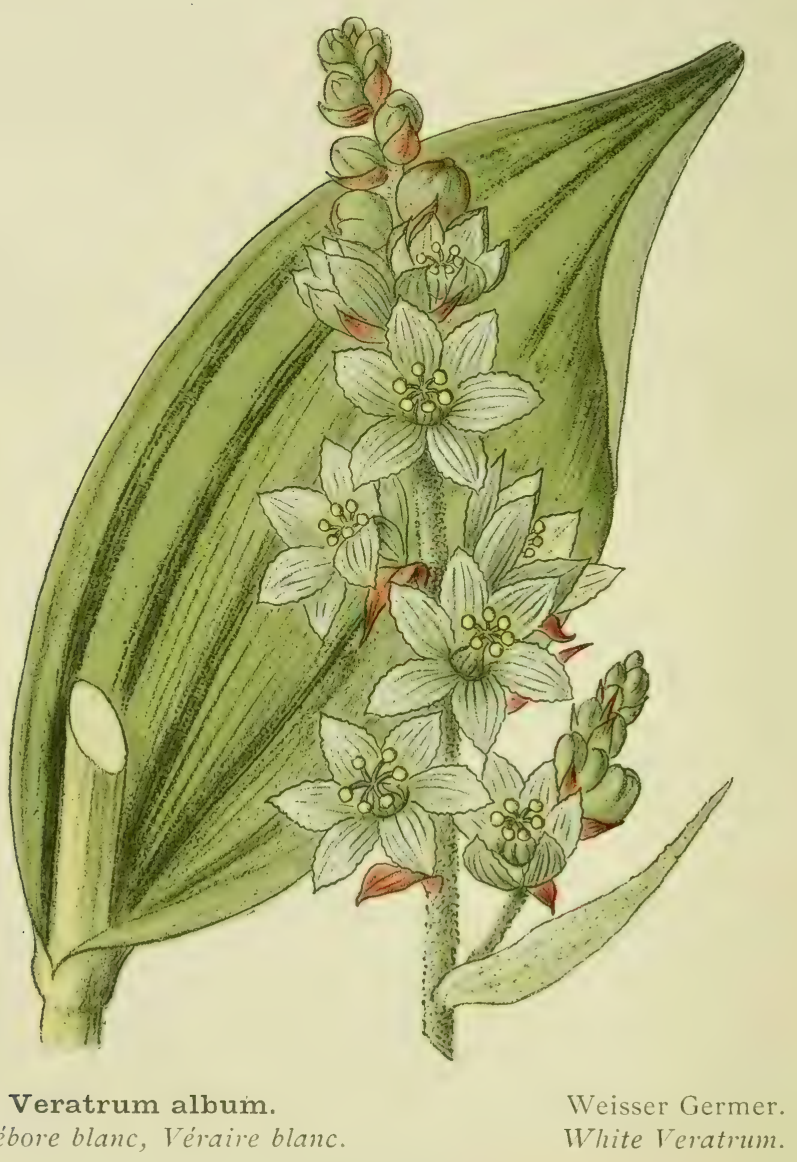


Die Colchicaceen unterfcheiden fich von den Liliengewächfen nur durch die abweichende Art rles Auffpringens der Früchte. Inr bekanntefter Vertreter ift die Herb/tzeitlofe (Colchicum autumnale), deren Blüten in Herbft, deren Blätter im Frühling erfcheinen.

Veratrum album. - Tafel 130. - Bis $1 \mathrm{~m}$ hohe, weichhaarige Pflanze mit langem, dickem Wurzelftock. Stengel aufrecht, gleichmäßig beblättert. Blätter groß, fpitz-eiförmig, umfaffen mit ihrem Grunde den Stengel, mit ftark hervortretenden, bogig verlaufenden Nerven. Den Blättern der Gentiona lutea (Tafel 106) älınlich, jedoch behaart und nicht zu zweien gegenftändig. Blüten unfcheinbar, grünlich, in großen endftändigen Trauben.

Mehrjährige Giftpflanze, daher vom Vieh gemieden.

Blüht Juli Auguft.

Befucher: Fliegen, feltener Falter, niemals Bienen. Samen geflügelt: Windverbreitung.

Matten, feuchte Weiden, Bachufer, $850-2500 \mathrm{~m}$.

Alpen, Jura, Vogefen, Mitteldeutfchland; Auvergne, Cevennen, Pyrenäen; Gebirge von Nordafien.

Bubocodium vernum. - Frihlings-Lichtblume. Zwiebelpflanze mit 2-4langen, fchmalen Blättern, die bei der Entfaltung der Blüten kaum entwickelt find. Diefe grof, hell rotviolett, trichterförmig, einzeln oder 2-3 vereinigt.

Mehrjährig.

Blüht März April, in der Nähe des fchmelzenden Schnees. Befucher : vermutlich Hummeln und Falter.

Samen ohne Verbreitungsmittel.

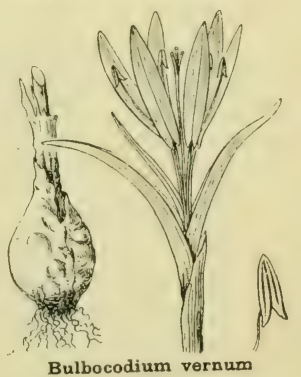

Matten der tieferen Lagen der Weftalpen (Wallis, franzöfifche und italienifche Alpen), Pyrenäen, Arragonien. 
Die Familie der Liliaceen oder Liliengewächfe ift äußerft reich an Arten, von denen manche, z. B. die Lilien, Tulpen, Hyacinthen etc., allgemein bekannt und beliebt find. Die meift fchön gefärbten Blüten find dreizählig, befitzen allo je $2 \times 3$ Blütenblätter und Staubgefäße, und einen dreifächerigen Fruchtkuoten. Die Blätter find ftets länglich, fchmal, mit faft parallel verlauferiden Nerven. Ihren einfachen Formen mit den klaren Linien haben diefe Pflanzen die häufige Verwendung in der Kunft zu verdanken.

Gagea Liottardi. - Tafel 131 A . - Höchftens $10 \mathrm{~cm}$ hoch, mit zwei übereinanderftehenden, von gerneinfamer Hülle umgebenen Zwiebeln. Die untere derfelben treibt ein oder zwei fchmale, rinnenförmige Blätter und einen dünnen Stengel, der zwei Blätter und dazwifchen 1-5 nacheinander fich öffnende, gelbe, fternförmige Blüten trägt.

Mehrjährig.

Blüht Mai bis Juli, fofort nach der Schneefchmelze.

Befucher: Fliegen, Hummeln, Falter.

Samen ohne Verbreitungsmittel.

Alpen, Pyrenäen, Kaukalus, Altai.

Lloydia serotina. - Tafel 131 B. - Zwiebel länglich, dünn, trägt 2-3 fadenförmige Blätter und einen $5-12 \mathrm{~cm}$ hohen, dünnen Stengel, der $3-4$ kurze Blätter und eine einzige, aufrechte, etwa $1 \mathrm{~cm}$ großse, weif und rofa geftreifte, in der Mitte gelbe Blüte trägt.

Mehrjährig.

Blüht Juni Auguft.

Befucher: Fliegen, kurzrüßlige Bienen.

Samen flach, geflügelt: Windverbreitung.

Alpen, Karpathen, Kaukafus, nordpolare Länder, Ural, Altai, Himalaya. 
Weiden, Schneetälchen

I 200-2500 Meter.
Felsen, Rasenbänder 1900-3000 Meter.

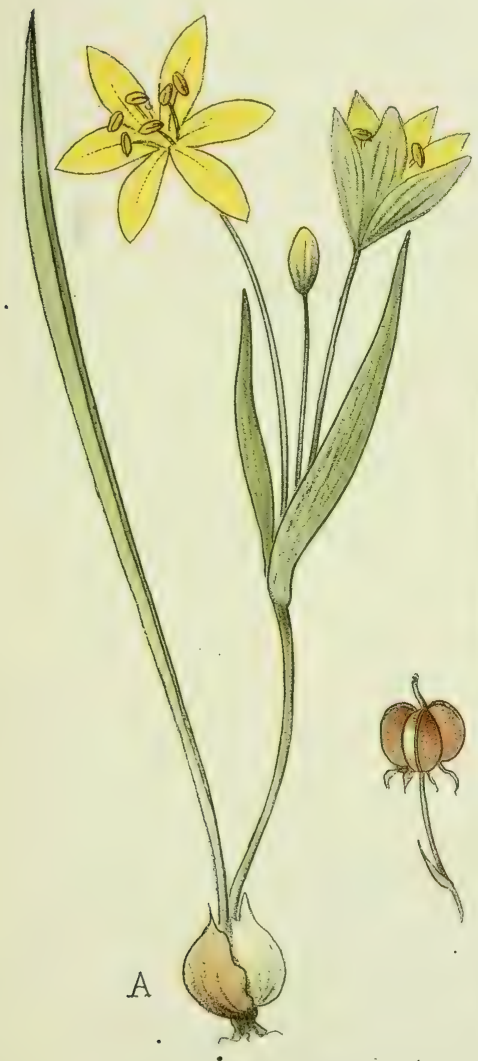

A. - Gagea Liottardi.

Liottard's Gelbstern.

Etoile jaune de Liottard.

Liottard's yellow star of Bethlehem.

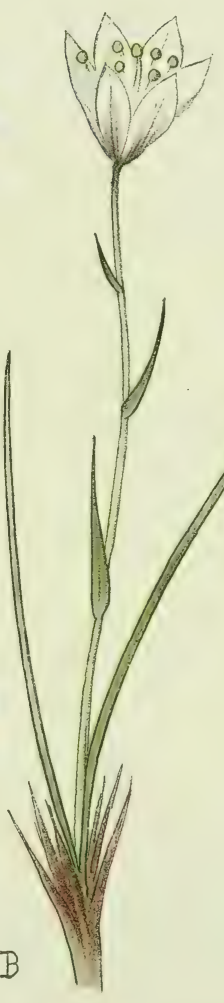

B. - Lloydia serotina.

Spátblühende Faltenlilie. Lloydie tardive. Late-flowering Lloydia. 
Rasenbänder, felsige Weiden 1000-2100 Meter.

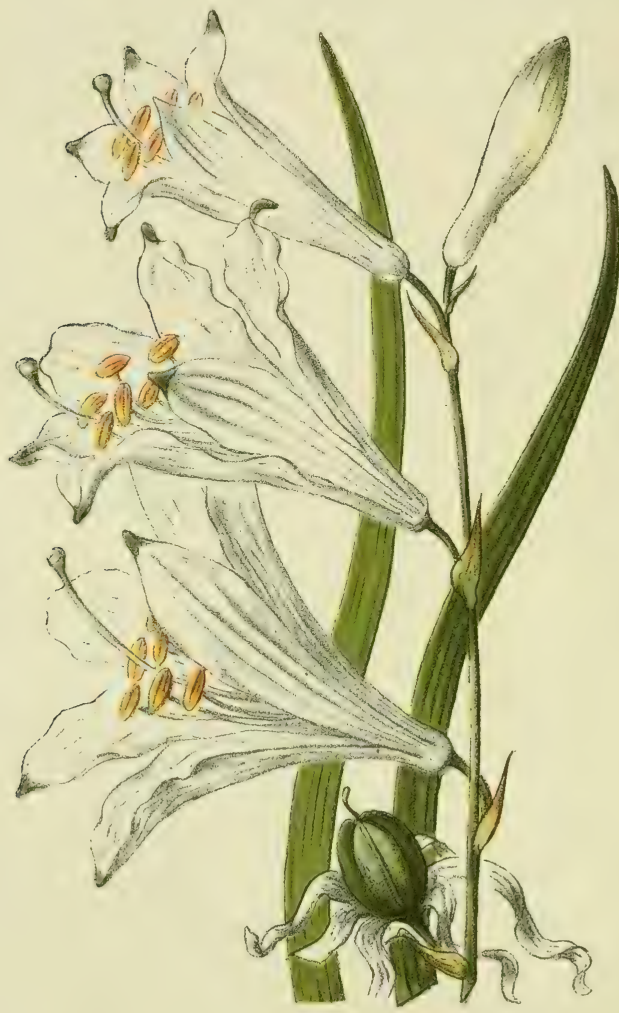

Paradisia Liliastrum.

Veisse Trichterlilie. Paradisie-lis. Lily-like Paradisia. 
Paradisia Liliastrum. - Tafel 132. - Zwiebel fehr dünn, trägt mehrere, nur etwa $1 \mathrm{~cm}$ breite Blätter, die ungefähr fo lang find wie die Stengel. Diefe $20-30 \mathrm{~cm}$ hoch, nicht beblättert, mit 2-5 weiß3en, 4-5 cm langen, trichterförmigen, nach einer Seite geneigten Blüten.

Mehrjährig. Blüht Juli Auguft.

Befucher: Falter, befonders die Gamma-Eule.

Samen ohne Verbreitungsmittel.

Alpen, Jura, Cievennen, Pyrenäen.

Asphodelus subalpinus. - Subalpiner Affodill. $1 \mathrm{~m}$ hoch, mit fpindelförmig verdickten Wurzeln. Blätter grundfändig, dreikantig, rinnenförmig, bläulichgrün. Blütenfchaft fteif, mit dichter Traube weißer, rofa geftreifter Blüten und braunen Deckfchuppen.

Mehrjährig. Blüht Juli.

Befucher: vermutlich Falter.

Samen ohne Verbreitungsmittel.

Fellen, Weiden, Abhänge.

800 bis $1700 \mathrm{~m}$.

Weftalpen (Dauphiné), Cévennen, Pyrenäen.

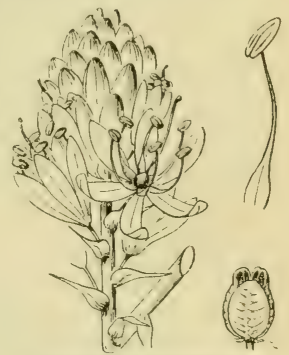

1sphodelus subalpinus

Fritillaria delphineusis. - Schachblume des Dauphiné. - Die Zwiebel (Skizze rechts unten!) trägt nur einen Stengel; diefer oberwärts mit 4-8 länglichen, flachen Blättern und einer nickenden, glockenförmigen Blüte; diefe gelb, braun- oder violettrot.

Mehrjährig. Blüht Mai Juni. Befucher : vermutlich Hummeln. Samen geflügelt: Windverbr. Weiden der fubalpinen Region. Alpen von Frankreich, Italien und Tirol, Korfika.

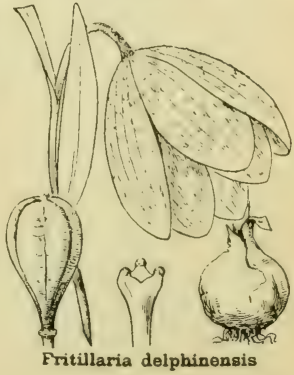


Die Allium- oder Lauch-Arten find an ihrem eigentümlichen, bekannten Geruche von den übrigen Liliciceen leicht zu unterl'cheiden.

Allinm Victorialis. - Tafel 133 A. - Grundltändige Blätter :3-5 $\mathrm{cm}$ breit, flach. Der 20-25 $\mathrm{cm}$ hohe Stengel trägt unterwärts 2-4 kurzgeftielte Blätter. Blüten klein, srïnlich- oder gelblichweif, in kugeliger Dolde, die am Grunde von einem einzigen, kurzen Hüllblatt umgeben ift.

Mehrjährig. Blüht Juli Auguft.

Befucher: Fliegen, daneben auch Falter.

Samen ohne Verbreitungsmittel.

Alpen, Jura, Vogefen, Auvergne, Cevemnen, Pyrenäen; Karpathen, Kaukafus, Ural, Altai.

Allium Schoenoprasum. - Tufel 133 B. - . Blätter grundftändig, bläulichgrün, meilt in Bülcheln, röhrenförmig, vorn fpitz. Blüten auf $20-40 \mathrm{~cm}$ hohem Schaft, rofa oder violett, in dichter, kugeliger Dolde, die von hreiteiförmigen Hochblättern umgeben ift.

Mehrjährig. Blüht Juni Juli. Befucher: Falter.

Samen ohne Verbreitungsmittel.

In den Gärten als Suppengemüle kultiviert, wild auf moorigen Wiefen.

Europa, Nord- und Mittelafien, in Nordamerika ron Kolumbien bis Labrador.

Allium fallax (senescens). - Täufchender Lauch. -

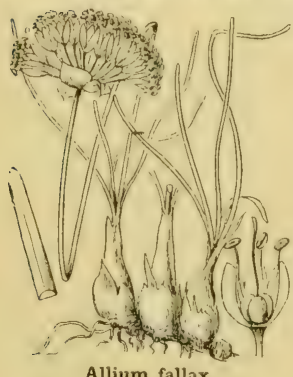

Allium fallax

Rafenbildend, $15-25 \mathrm{~cm}$ hoch. Jede

Zwiebel mit 3-8 langen, nur 1-3 mm breiten, rinnenförmigen Blättern, die vom Stengel etwas überragt werden. Blüten klein, violettrot.

Mehrjährig. Blüht Juli Auguft. Befucher: Fliegen, Bienen, Falter. Samen ohne Verbreitungsmittel. Felfen, feuchte Abhänge.

$1200-2000 \mathrm{~m}$.

Alpen, Jura, Auvergne, Cevennen, Pyrenäen; bis Oftafien. 
Gebüsche, feuchte IVeiden I 200-2200 Meter.
Rasenbänder, feuchte Felsen bis 2500 Meter.

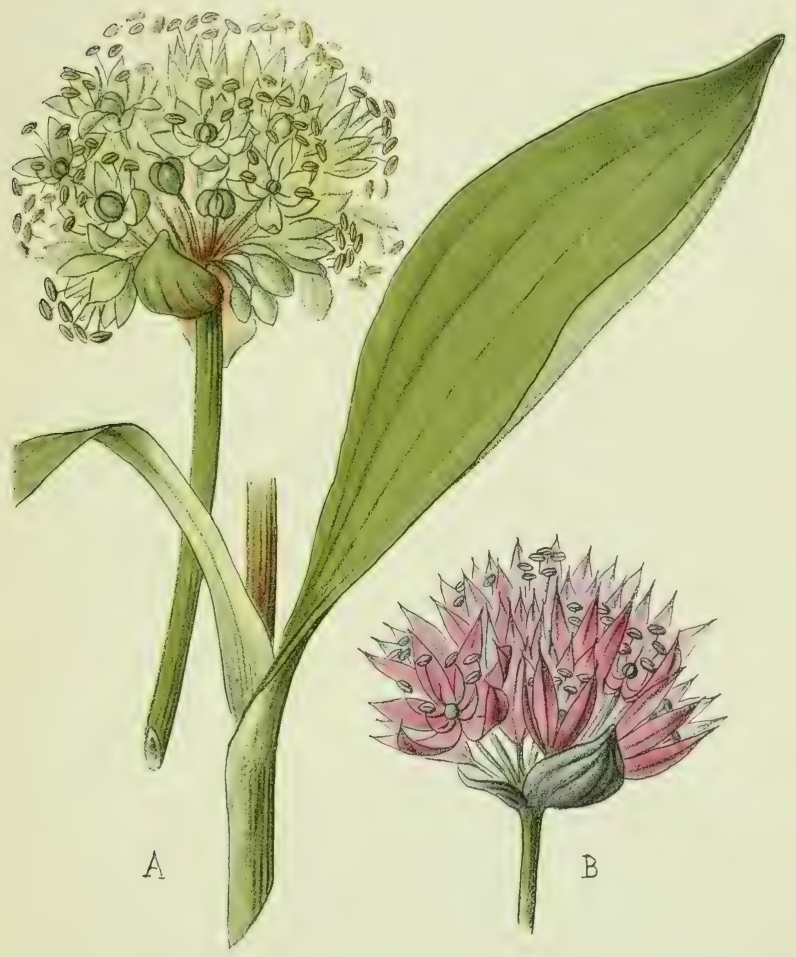

A. - Allium Victorialis.

Allermannsharnisch. Ail Victoriale.

Victory-leek.
B. - Allium Schœnoprasum. Schnittlauch. Ciboulette, Civette. Chives. 
Waldlichtungen, Gebüsche, Matten bis 2200 Meter.

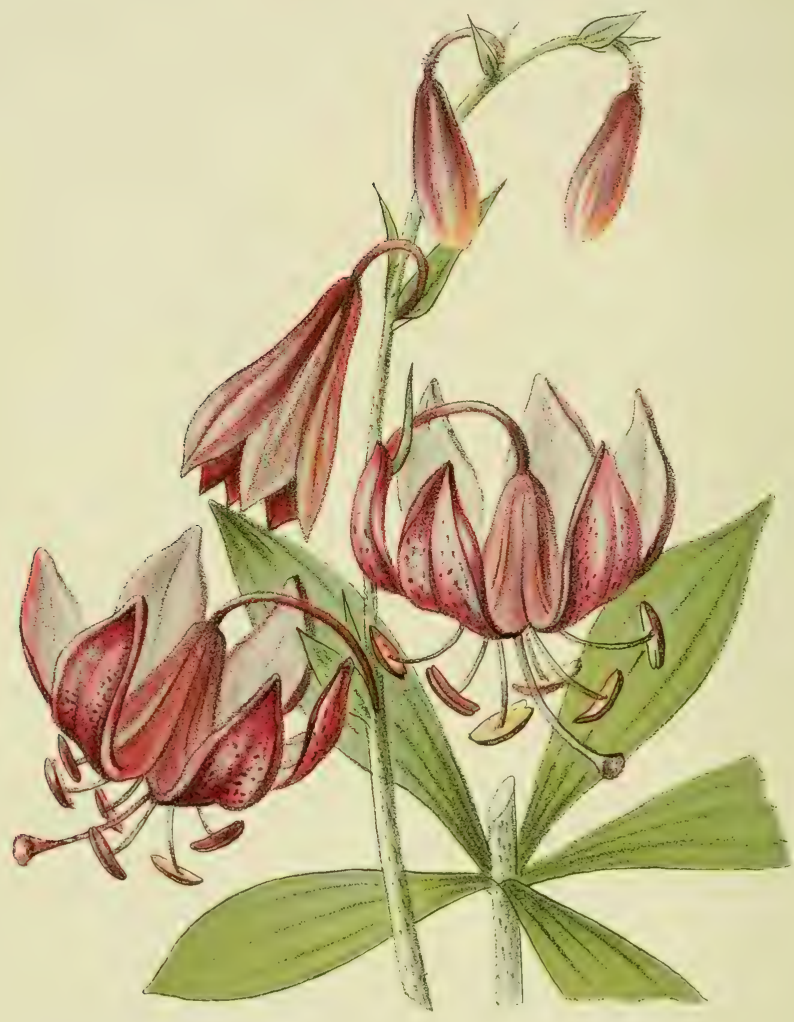

Lilium Martagon. Lis Martagon.

Türkenbund. Mountain-lily. 
Lilium Martagon. - Tafel 134. - Stengel $1 / 2$-1 in hoch, ohne grundftindige Bliitter, dagegen etwas unter der Mitte des Stengels ein (Guirl von 5-10 rofettig ausgehreitelen, hreit lanzettlichen Blïttern. Darüber eine lockere Traube von 3-8 grofen, violettroten, dunkelpunktierten Blïten, deren Blïtter beim Aufbühen nach rückwärts umgerollt werden.

Mehrjährig. Blüht Juni bis Auguft.

Befucher: Falter, befonder's der Taubenfelıwanz.

Samen geflügelt: Windverbreitung.

Waldlichtungen, Gebülche, fteinige IVeiden, auf warmen Kalkhügeln bis $2200 \mathrm{~m}$.

Alpen, Mittel- und Südeuropa, bis Sibirien und Japan.

Lilium croceum. - Fenerlilie. - Stengel $25-70 \mathrm{~cm}$ hoch, gerade, kantig, trägt bis zu den Blüten . hinauf zahlreiche, fchmallanzettliche, aufwärts gerichtete Blätter. Am Ende des Stengels 1-4 grofe, trichterförmige, aufrechte Blüten. Kronblätter gelbrot mit fchwarzen Punkten.

Mehrjährig. Blüht Juni Juli. Befucher: Falter, und zwar meilt folche, die wie die Blüten rot gefärbt find. Samen geflügelt: Windverbreitung.

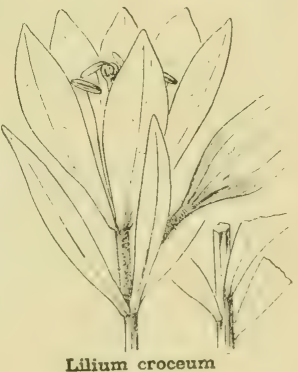

Wïlder, fellige Abhänge, befonders auf Kalk.

Bis $1800 \mathrm{~m}$.

Alpen, Jura, in Mitteleuropa zerftreut. 
Polygonatum verticillatum. - Tafel 135. - Wagerechter, dicker, weißer Wurzelftock mit dünnen Wurzeln. Derfelbe trägt am Ende einen einzigen, aufrechten, 30 bis $60 \mathrm{~cm}$ hohen Stengel, der in feinem oberen Teile mit 4 bis 5 zähligen Quirlen von fchmalen, fpitzen Blättern dicht befetzt ift. Zwifchen denfelben hängen kurze Trauhen von 2-3 grünlichweifen, geruchlofen, $6-8 \mathrm{~mm}$ langen Blüten herab.

Mehrjährig. Blüht Juni Juli.

Befucher: Hummeln, Falter.

Die kugeligen, erft roten, dann fchwarzen Beeren durch Vögel verbreitet.

Alpen, Jura, überhaupt in den Gebirgen von Europa bis zum Kaukalus und Himalaya.

Die Amaryllideen unterfcheiden fich von den Liliaceen nur dadurch, daf der die Samen enthaltende Fruchtknoten nicht mehr in der Mitte der Blüte fitzt, fondern unterhalb, derfelben, wo er als grüne kugelige Anfchwellung von aufsen fichtbar ift.

Narcissns poëticus. - Narziffe der Dichter. - Die

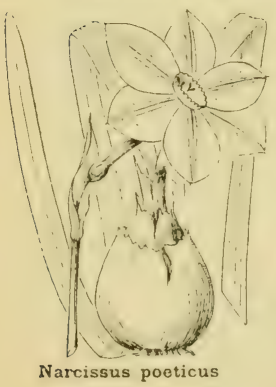

große, birnförmige Zwiebel trägt 3 bis 5 bandartige, $30-50 \mathrm{~cm}$ lange Blätter und in ihrer Mitte einen gefurchten, die Blätter etwas überragenden Blütenfchaft. Am oberen Ende desfelben ein häutiges, trichterförmiges Blatt, in deffen Grund eine weifse Blüte mit langer Kronröhre und fechs tellerförmig ausgebreiteten Zipfeln entipringt. In ihrer Mitte ein gelbes Krönchen mit rotem Rande.

Mehrjährig. Blüht April Mai. Befucher: Falter.

Samen ohne Verbreitungsmittel.

Feuchte Wiefen und Matten der Ebene bis $1800 \mathrm{~m}$. Alpen, Südweft-Europa. 
Schattige Wälder bis 2roo Meter.

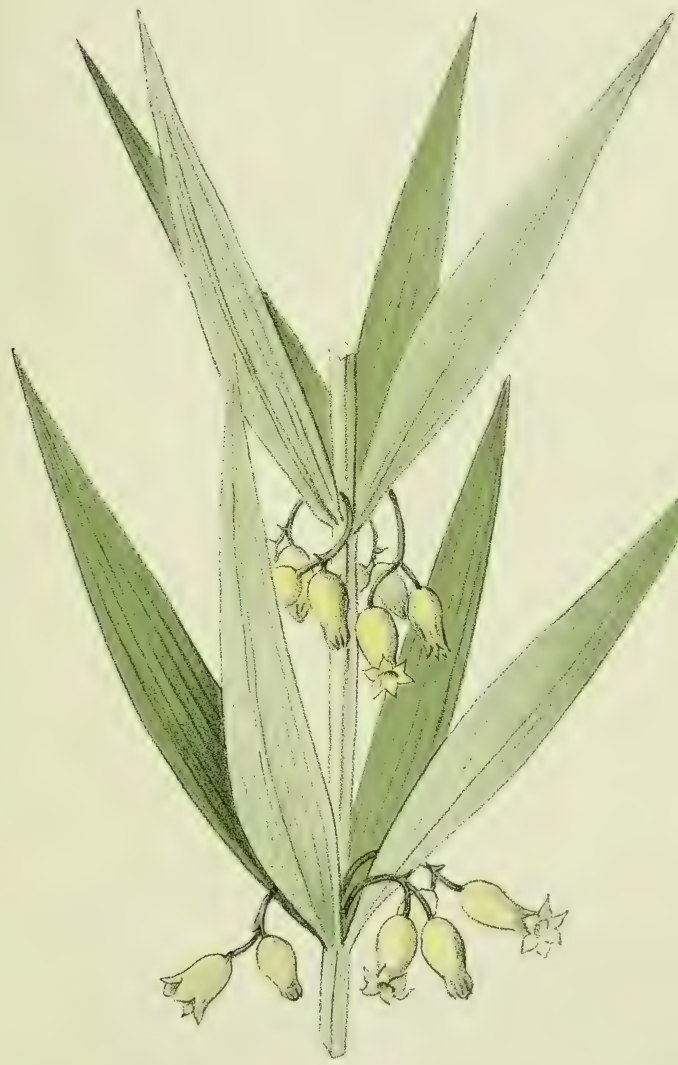

Polygonatum verticillatum. (2) uirlblättriger Salomonssiegel. Musruet verticillé. Verticillate Salomon's seal. 


\section{$-136$}

Matten, in kurzem Rasen 1300-2600 Meter.

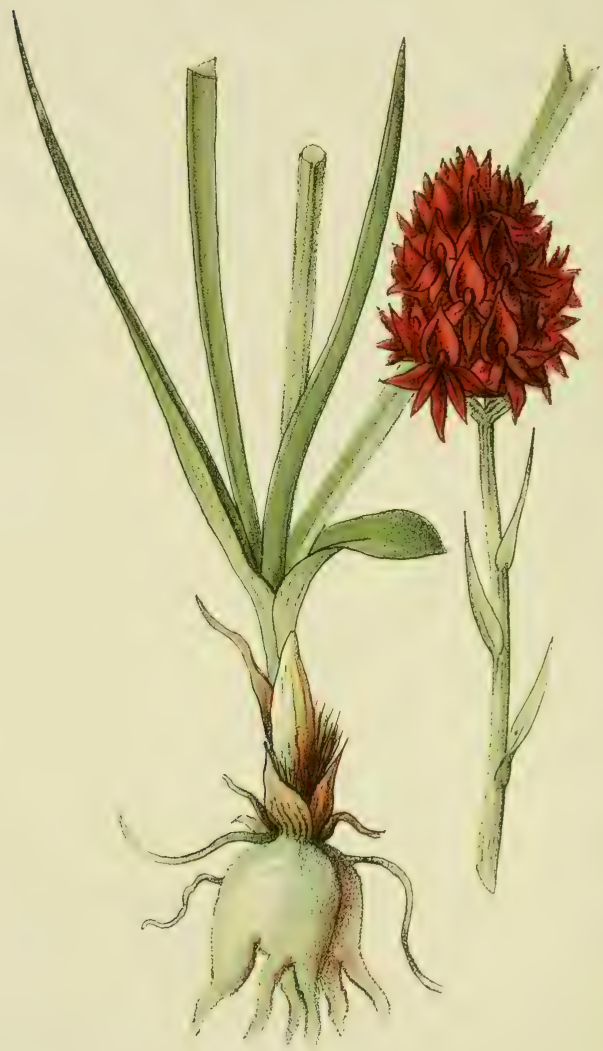

Nigritella nigra (angustifolia). Manette, Orchis vanillé.

Männertreu, Bränderli. Black Nigritella. 
Die Orchidaceen find befonders fchönblumige Pflanzen. In ihren Blüten ift derfelbe Bauplan zu erkennen wie bei den Liliaceen, aufser daf der Fruchtknoten wie bei den Amaryllideen unter die Blütenblätter hinabgerückt und dort als walzentörmiges, meift gedrilltes Gebilde lichtbar ift. Die Blumenkrone ift ftets zweilippig, was, zufammen mit dem häufigen Vorhandenlein eines lpornartigen Honigbehälters, auf hochgradige Anpaffung an den Befuch von Infekten hindeutet. Es find vorwiegend die intelligenteren, langrüßsligen Gruppen: Bienen, Hummeln und Schmetterlinge, welche die Orchideen beftäuben.

Nigritella nigra (angustifolia). - Tafel 136. - Zwei handförmig geteilte, 4-5-zipflige Wurzelknollen, deren ältere einen $10-30 \mathrm{~cm}$ hohen Stengel und einige fchmale, fpitze Blätter trägt. Blüten in kurzer, dichter Ähre, dunkel purjurn (felten rola, gelblich oder weif), mit ftarkem Vanillegeruch.

Mehrjährig. Blüht Juni bis Auguft.

Befucher: Falter.

Samen klein: Windverbreitung.

Alpen, Jura, Auvergne, Pyrenäen; Karpathen.

Herminium (Chamaeorchis) alpinnm. - Alpen-Zwerg" orehis. - Nur 6-12 cm hoch, mit zwei eiförmigen, kleinen Wurzelknollen und 5-7 fchmal bandförmigen Blättern, die lo lang find wie der Stengel. Derlelbe trägt am oberen Ende eine lockere Ähre von 5-6 gelbgrünen Blüten mit roter Zeichnung; geruchlos.

Mehrjährig. Blüht Juli Auguft.

Befucher: verınutlich Schlupfwefpen und Fliegen.

Samen klein: Windverbreitung. Feuchte Matten. 1900- $2700 \mathrm{~m}$.

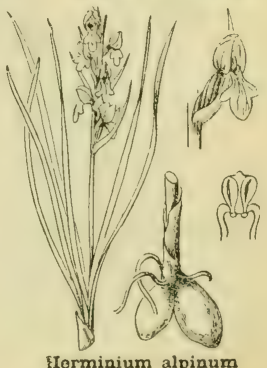

Elorminium alpinum Alpen, Karpathen, Skandinavifche Gebirge. 
Gymmadenia conopea. - Tafel 13\%. - Zwei handförmig geteilte, 4-5-zipflige Wurzelknollen. Stengel 40 bis $60 \mathrm{~cm}$ hoch, befonders unterwärts mit hellgrünen, fchmal bandförmigen, fpitzen Blättern befetzt.

Blüten klein, hellpurpurn, mit ftarkem Vanilleduft, in dichter Ähre. Die dreiteilige Unterlippe rückwärts in einen 13-15 mm langen, dünnen Sporn ausgezogen.

Mehrjährig.

Bläht Juni Juli.

Befucher: vorwiegend Tagfalter, felten Nachtfalter. Samen klein: Windverbreitung.

Magere Matten, Iteinige Weiden. 600-2300 m.

Alpen, Pyrenäen, überhaupt in ganz Europa bis Sibirien.

Gymnadenia odoratissima. - Wohlriechende Nackt-

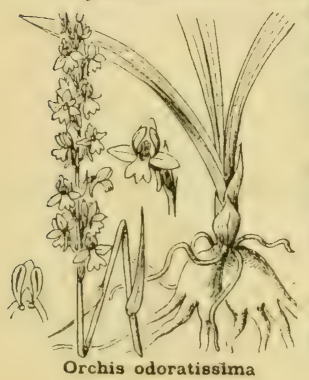
driife. - Der vorigen ähnlich, aber nur $15-50 \mathrm{~cm}$ hoch, und die blakrofafarbenen Blüten mit einem nur 4 bis $5 \mathrm{~mm}$ langen Sporn; in dünnerer Ähre. Vanillegeruch noch ftärker.

Mehrjährig.

Blüht Juni Juli.

Befucher: Falter, befonder's auch Nachtfalter.

Samen klein: Windverbreitung.

Magere, feuchte Matten, befonder's auf Kalk. $600-1900 \mathrm{~m}$.

Von den Pyrenäen durch Frankreich, die Alpen bis Ofteuropa verbreitet. 
Magere Matten, feuchte Weiden 600-2300 Meter.

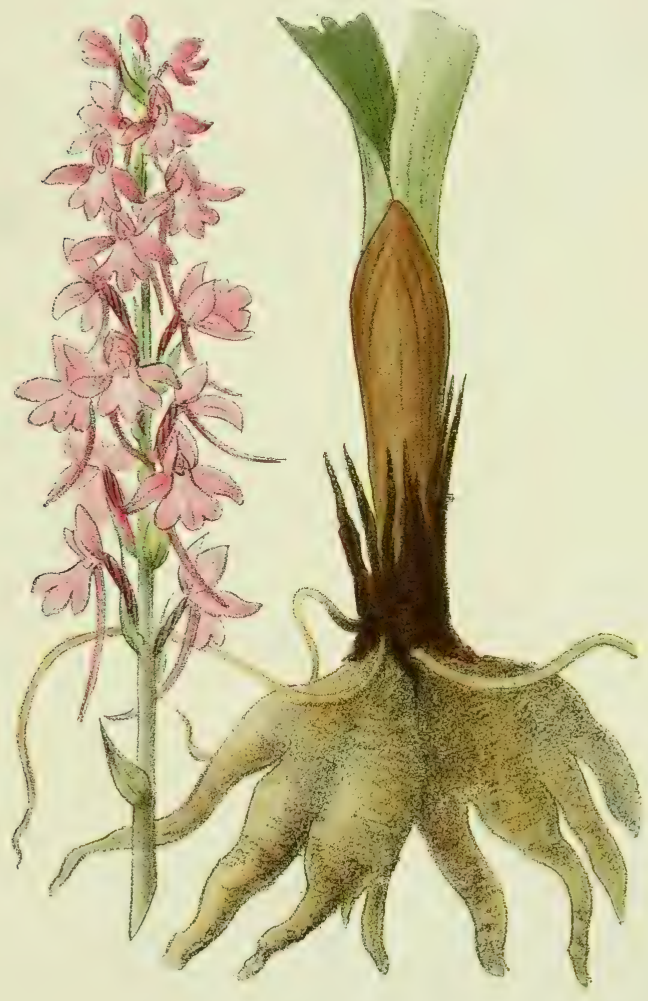

Gymnadenia (Orchis) conopea. Stechmüclien-Nackitdrüse. Gymnadénia à long éperon. Long-spured Gymadenia. 
Feuchte, torfige Matten bis Igoo Meter.

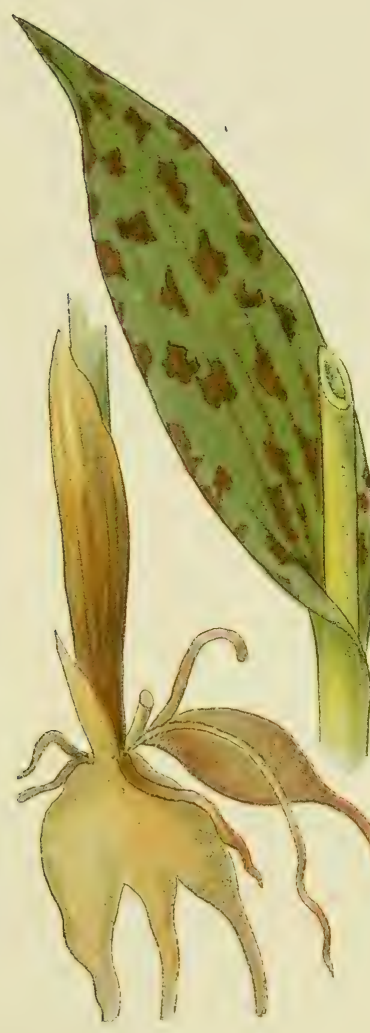

Orchis latifolia.

Orchis à larges feuilles.

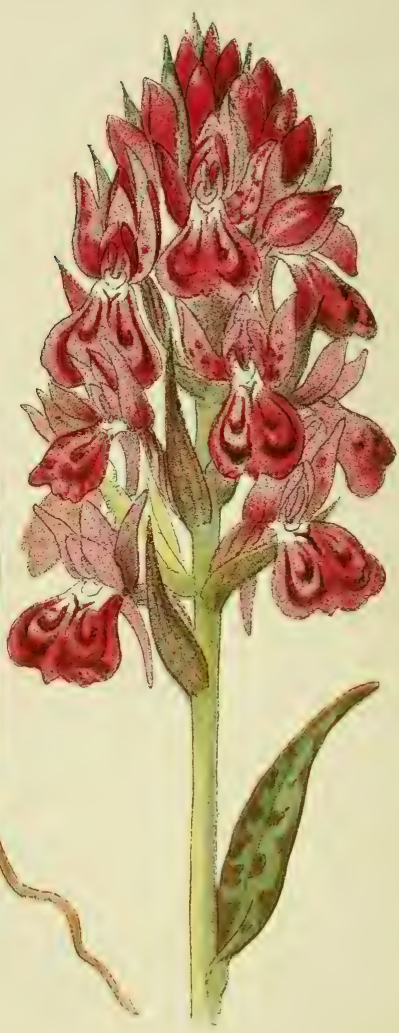

Breitblättriges Knabenkraut. Broad-leaved Orchis. 
Orehis latifolia. - Tafel 138. - Zwei handförniig geteilte Wurzelknollen. Stengel aufrecht, $15-45 \mathrm{~cm}$ hoch, mit braun gefleckten, fpitz-elliptifchen, oberwärts kleiner werdenden Blättern befetzt. Blüten mit meift rötlichen Deckblättern in dichter Ähre. Kronblätter rofa; Unterlippe l'chwach 3-zipflig mit dunkelroter Zeichnung. Sporn etwa lo lang als der walzenförmige Fruchtknoten.

Mehrjährig. Blüht Juni Juli.

Befucher: Bienen und Hummeln.

Samen klein: Windverbreitung.

Alpen, Pyrenäen, öftlich bis Kamtfchatka.

Cypripedium Calceolus. - Franenfchuh. - Pflanze mit dickem Wurzelftock. Stengel aufrecht, $30-40 \mathrm{~cm}$ hoch, mit einigen $10-12 \mathrm{~cm}$ langen, und 4 bis $5 \mathrm{~cm}$ breiten, etwas behaarten Blättern, die mit ihrem Grunde den Stengel umfaffen. Derfelbe trägt am Ende ein breites, grünes Hochblatt, und eine einzige, großse, hängende Blüte. Seitliche und obere Blütenblätter dunkel rotbraun, Unterlippe gelb, rot geadert, groß, fackartig aufgeblafen, oben offen.

Mehrjährig. Blüht Juni.

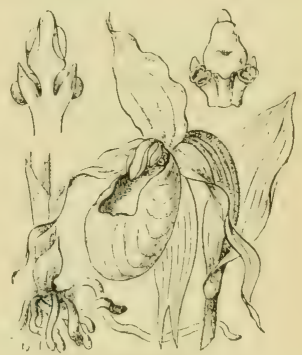

Cypripedium Calceolus

Befucher: kleine Bienen: Anthrena-Arten, die in die vordere Öffnumg der Unterlippe hineinkriechen, den darin befindlichen Honig ablecken, und fich bein Hinausfchlüpfen durch eine der beiden feitlichen Öffnungen mit einem Paket von Blütenftaub beladen, das fie beim Hineinkriechen in die nächfte Blüte an der Narbe abftreifen.

Samen klein: Windverbreitung.

Bufchige Wälder, befonders auf Kalk.

Pyrenäen, Alpen, von Oftfrankreich bis Oftfibirien. 
Coeloglossum viride (Orehis viridis). - Tafel 139 A. Stengel aufrecht, $10-25 \mathrm{~cm}$ hoch, mit zwei breiten, 2- oder 3-teiligen Wurzelknollen. Blätter kurz, länglich oval, zugefpitzt. Blüten grün und braunrot, in langer, ziemlich lockerer Aehre. Obere Blütenblätter helnförmig zufammenneigend. Unterlippe 3-teilig, mit kurzem Mittellappen. Sporn kurz.

Mehrjährig. Blüht Juni Juli.

Befucher: vermutlich kleine Nachtfchmetterlinge.

Samen klein: Windverbreitung.

Pyrenäen, Berge von Frankreich, Alpen, Jura, Karpathen, Kaukafus, Ural, Altai.

Orehis sambucina. - Tafel 139 B. - Wurzelknollen 2--3-zipflig. Stengel $10-20 \mathrm{~cm}$ hoch, mit hellgrünen, langen, fchmalen und abftehenden Blättern befetzt, die ihn mit der Bafis umfaffen. Blüten in kurzer, lockerer Ähre, bald gelb, bald purpurn. Unterlippe mit dunklerer roter Zeichnung, feliwach "3-zipflig. Sporn fo lang als der Fruchtknoten.

Mehrjährig. Blüht Mai Juni.

Befucher: Hummeln.

Samen klein: Windverbreitung.

Alpen, Jura, Vogefen; Auvergne, Cievennen, Pyrenäen; im Often bis zum Ural.

Listera cordata. - Herzblättrige Liftere. - Zartes, $5-20 \mathrm{~cm}$ hohes Pflänzchen ohne Knol-

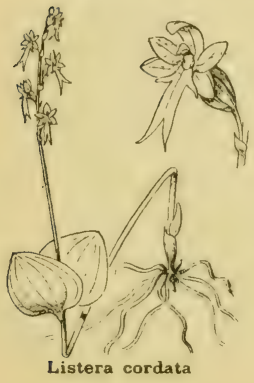
len. Etwa in der Stengelmitte zwei gegenftändige, herzförmige, ungeftielte Blätter. Wenige kleine, gelbe, rotgefleckte Blüten in lockerer Traube.

Mehrjährig.

Blüht Mai bis Juli.

Befucher: kleine Fliegen und Bienen. Samen klein: Windverbreitung.

Im Moofe fchattiger, feuchter Wälder. Bis $2300 \mathrm{~m}$.

Alpen, Jura, Vogefen, Süddeutfchland; Auvergne, Pyrenäen. 
Steinige Weiden bis 2400 Meter.
Waldlichtungen, Matten bis 2000 Meter.

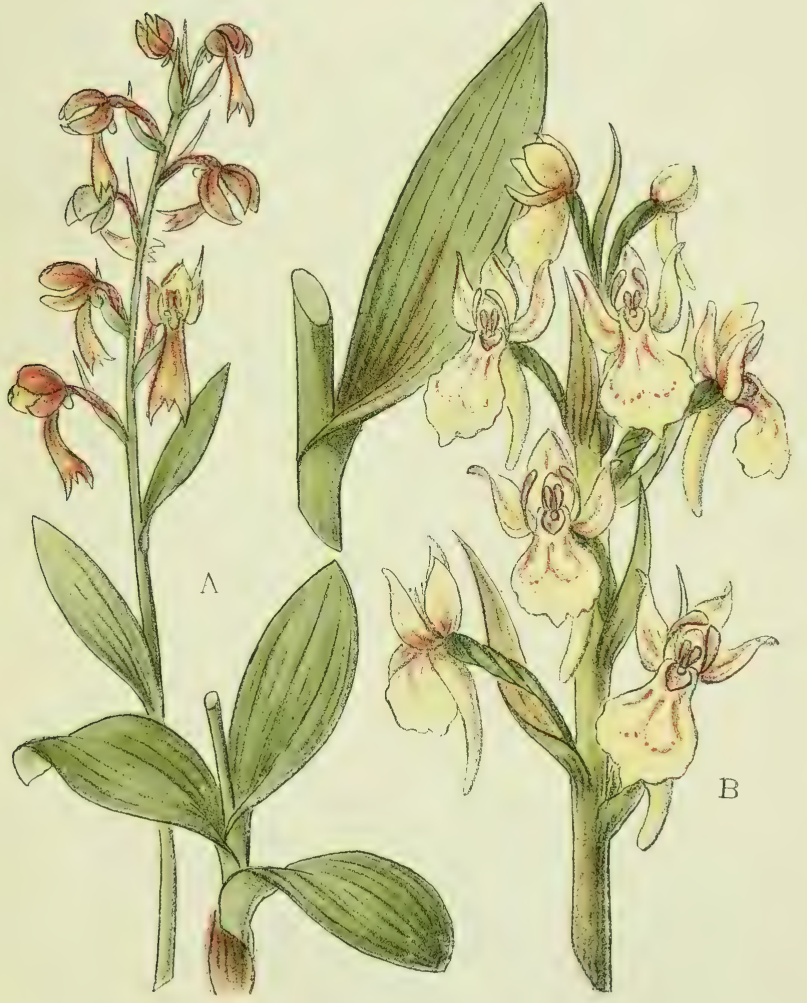

A. Coeloglossum viride.

Grüne Hohlzunge.

Orchis verdâtre.

Green Coeloglossum.
B. - Orchis sambucina.

Hollunder-Orchis.

Orchis à odeur de sureau.

Elder-smelling Orchis. 
Feuchte Matten, Rasenplätze 1000^2400 Meter.

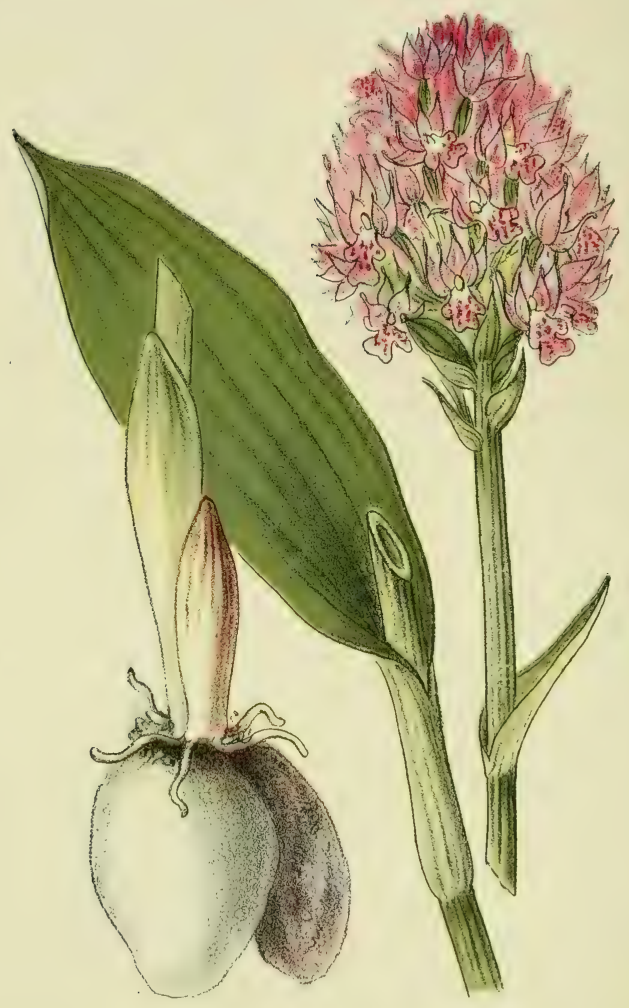

Orchis globosa.

Orchis globuleux.

Kugel-Orchis.

Globular Orchis. 
Orchis globosa. - Tafel 140. - Die beiden Wurzelknollen eiförmig, ungeteilt. Stengel $15-50 \mathrm{~cm}$ hoch, aufrecht. Blïtter lchmal bandförmig, aufrecht, umfaffen mit der Bafis den Stengel. Blüten purpur- oder rofarot, felten weif, f'chwach duftend, in dichter, erft kugeliger, dann länglicher Ähre.

Mehrjährig. Bläht Juni Juli. Befucher: Falter.

Samen klein: Windverbreitung.

Alpen, Jura, Sïddeutfchland; Auvergne, Pyrenäen.

Corallorrhiza immata. - Eingewachfene Korallenwur\%. - Gelbgrün, $10-25 \mathrm{~cm}$ hoch, ohne grüne Blätter. Wurzelftock ftark verzweigt mit angefchwollenen Aften, in welchen der die Pflanze wahrfeheinlich ernährende Pilz lebt. Blüten klein, gelblichgrün in lockerer Ähre. Lippe dreiteilig, weif, mit roter Zeichnung.

Mehrjährig.

Blüht Juni Juli. Befucher?

Samen klein: Windverbreitung.

In Wäldern zerftreut.

$1000-1900 \mathrm{~m}$.

Alpen, Jura, Vogefen, Süd- und

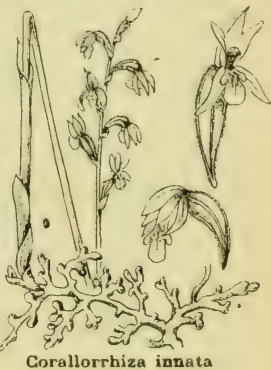

Mitteldeutfchland, Pyrenäen.

Epipogon aphyllus. - Blattlofer Widerbart. - Ganz weife, farbltoffreie Humuspflanze mit ähnlichem Wurzelltock, wie Corallorvhiza und gleicher Lebensweife. Stengel durchfcheinend, mit 2-3 fchuppenförmigen Blättern. 1-5 gelblichweife Blüten mit fleifchrotem Sporn; in lockerer Traube. Vanilleduft.

Mehrjährig. Blüht Juli Auguft. Befucher: Hain-Hummel.

Vereinzelt, felten, in Wäldern. Alpen, Jura, Süddeutfchland; Pyrenäen. 600-1500 m.

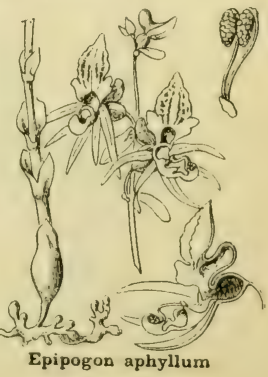


Die Cyperaceen find unfcheinbare, grasartige Gewächfe, die in der Vegetation der Sümpfe und feuchten Matten eine wichtige Rolle fpielen. Wegen der Härte ihrer Stengel und Blätter liefern fie kein gutes Heu. Ihre Blüten find der Windheftäubung entfprechend unfcheinbar, in aufrechten oder hängenden Ähren gehäuft. Zu ihnen gehören die Wollgrä fer, Eriophorum-Arten, die ihren Namen den feinen, weißen Haaren verdanken, die erft an der Frucht auswachfen, während fie an den Blüten kurz, diefelben daher unfcheinbar find.

Eriophorum vaginatum. - Tafel 141. - Grundftändige Blätter zahlreich, dreikantig, rauh, an den Rändern l'chneidend, fterben früh ab, ohne jedoch abzufallen. Blütenl'chaft $30-60 \mathrm{~cm}$ hoch, $3 \mathrm{kantig}$ glatt, mit einem kugeligen Blütenküpfchen, das nach dem Blühsen zu einem weifsen Wollköpfchen wird.

Mehrjührig. Bläht Mär\% April. Windbefäubung.

Früchte mit Haarfchopf, Mai Juni: Windverbreitung. Alpen, Jura, Vogefen, Mittel- und Nordeuropa; Auvergne, Cevennen, Pyrenäen.

Eriophorum alpinum. - Alpen-Wollgras. - Höch-

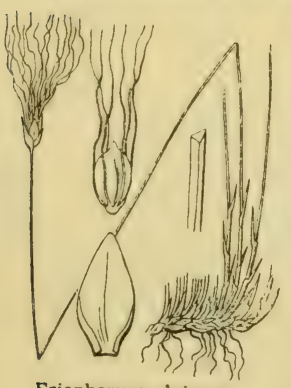

ftens $20 \mathrm{~cm}$ hoch. Die kriechenden Wurzelföcke bilden dichte Rafen, aus denen lich viele dünne, unterwärts kurz beblätterte Stengel erheben. Wollhaare der Früchtchen kaum $2 \mathrm{~cm}$ lang, gefchlängelt.

Mehrjährig. Blüht April Mai.

Windbeftäubung.

Früchte mit Haarfehopf, Juni Juli:

Windverbreitung.

Kurzrafige Moore.

Tiefland bis $2000 \mathrm{~m}$.

Alpen, Jura, Vogefen bis Norddeutfchland, Auvergne. 


\section{- 141 -}

Torfmoore der Ebene bis 2200 Meter.

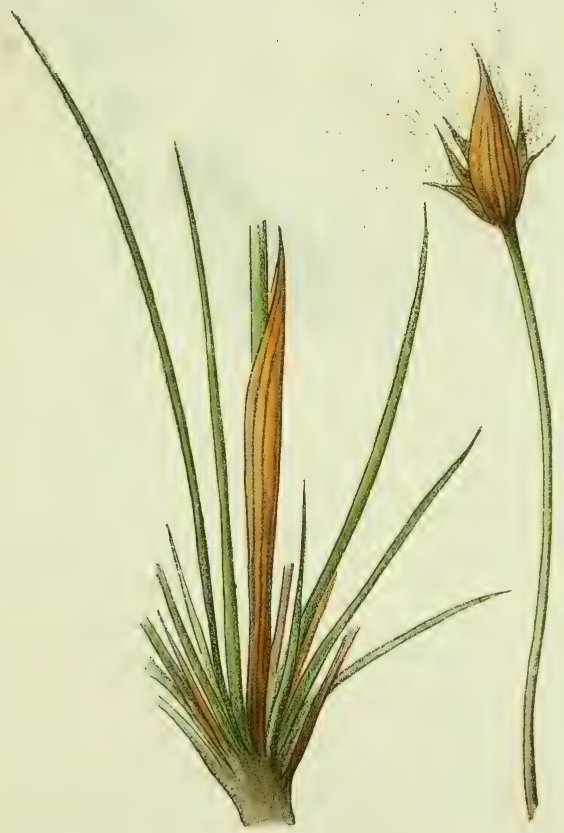

Eriophorum vaginatum. Linaigrette à gaine. Scheidiges Wollgras. Hare's-tail-rush. 
Felsen, Gerölle I200-2500 Meter.

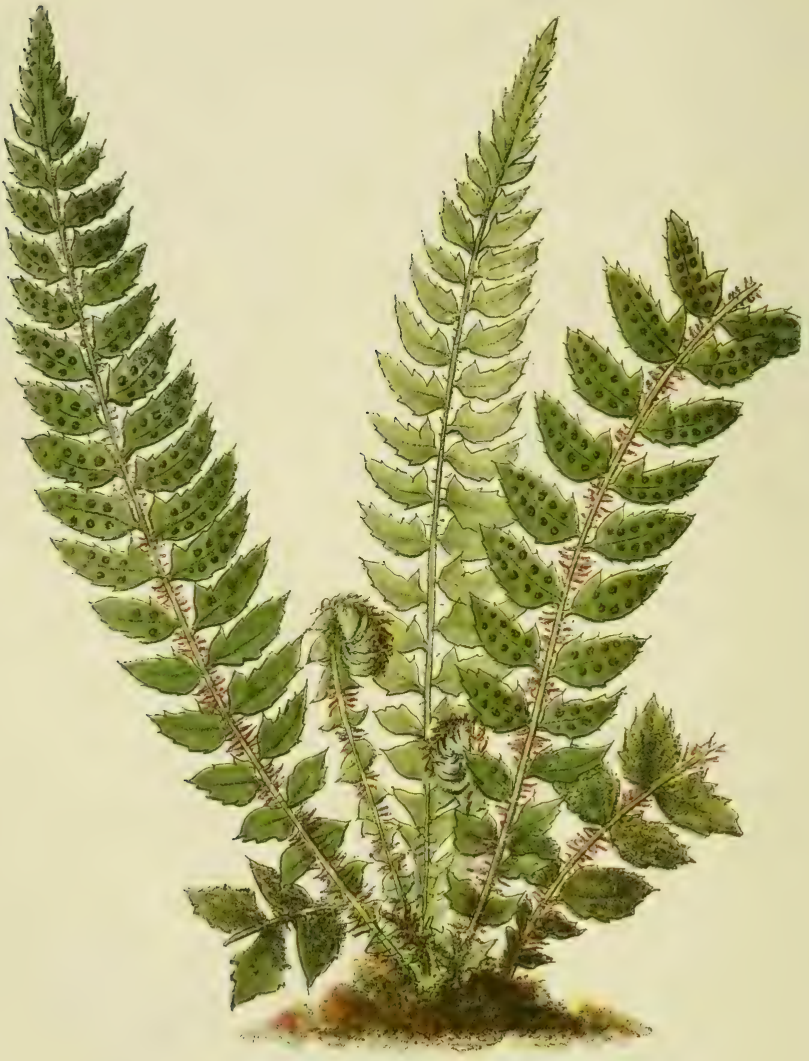

Aspidium Lonchitis.

Lanzen-Farn. Aspidnum lonchite. Holly-fern. 
Die Farue (Filices) haben weder Blüten noch eigentliche Samen. Ihre Hauptentwicklung liegt in den Blättern, die meift fiederförmig geteilt find. Auf ihrer Unterfeite tragen fie zahlreiche Häufchen kleiner, eben noch fichtharer grüner Behälter, welche bei der Reife platzen und einen braunen, aus kugeligen, einzelligen Gebilden, den Sporen beftehenden Staub austreten laffen. Jede diefer Sporen kamn auf feuchtem Boden zu einem kleinen, Lebermoos-artigen, der grofen Farnpflanze völlig unähnlichen Pflänzchen (Prothallinm) heranwachlen, das männliche und weibliche Organe trägt. Aus der befruchteten Eizelle geht dann wiecler das beblätterte Farnkraut hervor. Das Prothallium ilt auch noch bei den Blütenpflanzen vorbanden, allerdings nur noch als eir unfelb. ftändiges Organ der Blüte.

Die Farne find heutzutage nur noch in den Tropen mächtig, oft als Bäume entwickelt. In der Erdperiode, in welcher die Steinkohle abgelagert wurde (Steinkohlenzeit, Carbon), bildeten fie die Hauptvegetation.

Aspidium Lonchitis. - Tafel 142. - Dicker, fchwarzer Wurzelftock mit einer Rofette von 10-40 cm langen, ausgebreiteten, lederigen, fiederteiligen Blättern mit lanzettlichen, etwas gekrümmten und gezähnten Abfchnitten. Sporenhäufchen in einer Reihe zu beiden Seiten des Mittelnervs eines Blattabfchnittes.

Mehrjährig. Sporenreife Juli. Windverbreitung.

Alpen, Jura, Vogefen, Schwarzwald, Harz, Riefengebirge etc., Cevennen, Pyrenäen.

Aspidium Dryopteris. - Eichenfarn. - Blätter doppelt fiederteilig, auf hohen, fchwarzen Stielen,imUmrif dreieckig,entfpringen voneinander entfernt aus dem wagerecht kriechenden Wurzelftock.

Mehrjährig.

Sporenreife Juni Juli.

Windverbreitung.

Im Moos fchattiger Wälder und Felfen.

Mitteleuropa, Alpen, Pyrenäen.

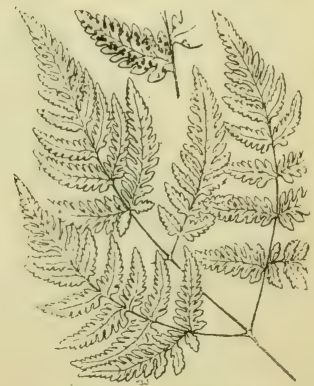

Polypodium Dryopteris 
Botrychium Lunaria. -- Tafel 143 A. - Kurzer Wurzelftock mit einem aufrechten, $5-20 \mathrm{~cm}$ hohen, etwas fleifchigen, fiederteiligen Blatt. Untere Partie desfelben grün mit halbmondförmigen Abfchnitten. Vom Grunde diefes grünen Blattteiles erhebt fich eine gelbliche Blattpartie mit fehr fchmalen, die Sporenhäufchen tragenden Abfchnitten.

Mehrjährig.

Sporenreife Juni bis Auguft. Windverbreitung.

Durch ganz Europa und Afien bis Kamlfehatka, Nordamerika, Grönland, Patagonien, Südauftralien, Tasmanien.

Aspleninm septentrionale. - Tafel 143 B. - Bildet dichte Rafen von 5-15 cm Höhe. Blätter dunkelgrün, in wenige, aufrechte, keilförmige Abfchnitte gegabelt. Blatt. unterfeite von den Sporenhäufchen vollftändig bedeckt.

Mehrjihrig. Sporenreife Juni. Windverbreitung.

Nur auf Urgeftein (vgl. I. Teil S. 41).

Nord- und Mitteleuropa, Gebirge der Mittelmeerländer,

Nord- und Mittelafien bis Himalaya, Gebirge von Neu-Mexiko.

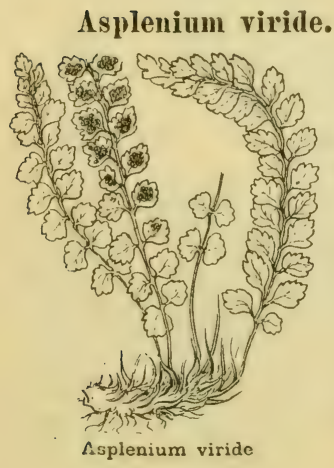

- Griiner Streifenfarn. -- Bildet $5-15 \mathrm{~cm}$ hohe Bülche. Blätter lang, fiederteilig, mit rundlichen, fein gekerbten Abfchnitten an grüner Spindel. Sporenhäufchen ftreifenförmig.

Mehrjährig.

Sporenreife Auguft.

Windverbreitung.

Spalten fchattiger, feuchter Felfen, befonders auf Kalk.

1200 bis $2500 \mathrm{~m}$.

Gebirge von Mitteleuropa und der

Mittelmeerländer, Nordafien, Himalaya, Nordamerika. 
Trockene Weiden I000-2800 Meter.

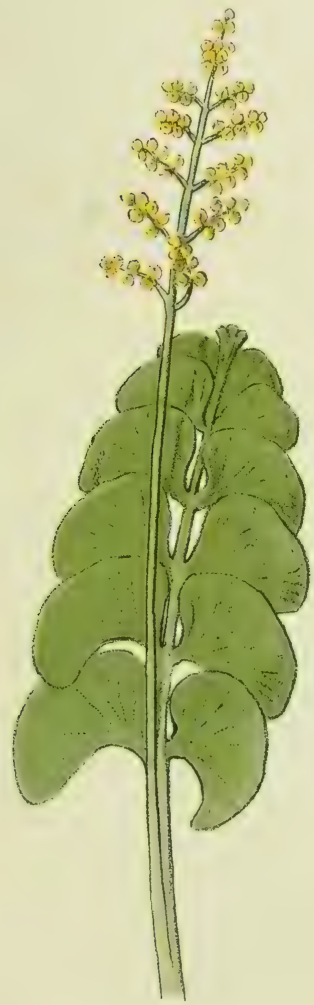

Spalten der Urgesteins-Felsen 600-2500 Meter.

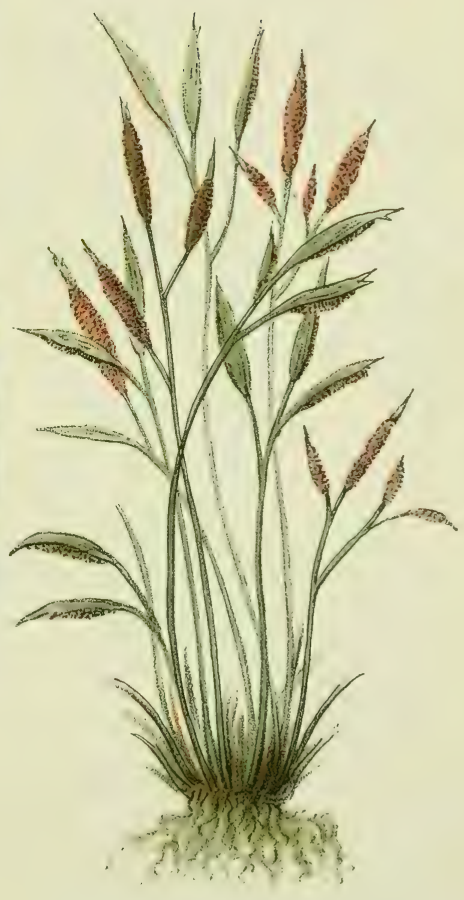

A. Botrychium Lunaria. B. Asplenium septentrionale.

Mond-Raute. Botryche en croissant. Moonvort.
Nordischer Streifenfarn. Doradille septentrionale. Northern Spleenvort. 
Schattige Felsen und Wälder I 200-23̋00 Meter.
Torfige Wälder, feuchte Rasenplätze bis 2300 Meter.

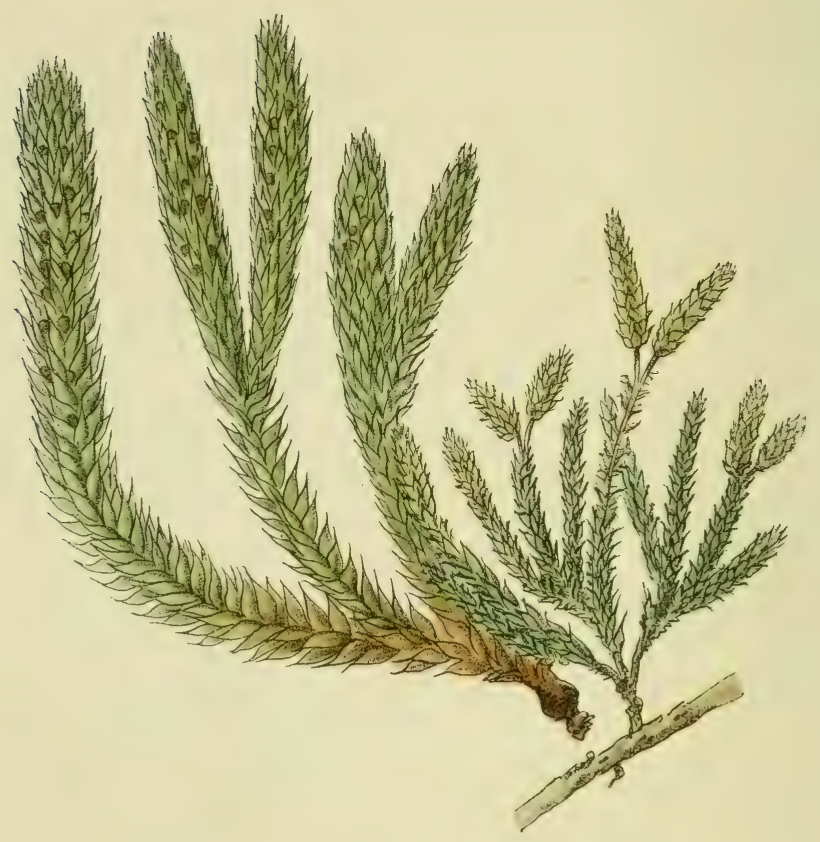

1- Lycopodium Selago. Tannen-Bärlapp.

Sélagine. Fir-moss.

B. - Lycopodium clavatum.

Keulen-Bärlapp.

Mousse-serpent, Lycopode à massue. Wolf's claw, Club-mosse. 
Die Lycopodiaceen oder Bärlappgewiichfe gehören auch $z u$ den Farnpflanzen. Sie haben das Ausfehen grofer Moofe, bilden jedoch nie wie jene geftielte Sporenkapfeln. Ihre Sporenhehälter fitzen zwifchen den Blättern der Zweigenden, die fich trotzdem von den unteren Stengelteilen zuweilen nicht unterfcheiden (Lycopodium Selago); zuweilen find jerloch die fporentragenden Blätter kleiner, so dafs ein zäpffchenartiges Gebilde entfteht (I. clavatum).

Lycopodium Selago. - Tafel 14tA. - Büfche von 10-20 cm Höhe, mit znerft nierlerliegenden, dann plötzlich aufgerichteten, dicht bebläterten Stengeln. Blätter lederartig, dunkelgrün, kurz, lpitz und vorwärts gerichtet; die fporentragenden von den unfruchtbaren nicht verfchieden.

Mehrjährig. Sporenreife Juli. Windverbreitung. Schattige Felfen, Wälder und Weiden.

\section{$1200-2300 \mathrm{~m}$.}

Über die ganze Erde verbreitet, nach den Polen, wie auf den Gebirgen bis zur Grenze des Pflanzenwuchfes; in den Tropen nur auf den höchlten Gebirgen.

Lycopodium clavatum. - Tufel $144 \mathrm{~B}$. - Stengel kriechend, fehr lang, ftark verzweigt, überall wurzelnd, rafenbildend, wie die ifte von fchmal dreieckigen, abftehenden oder rückwärts gekrümmten, weichen, hellgrünen Blättern dicht befetzt, die in eine weife Haarfpitze auslaufen. Sporenbehälter am Grunde kleinerer, gelbgrüner Blätlchen, zu länglichen Zäpfchen vereinigt. Neift $\underline{2}-3$ lolche am Ende eines verlängerten, kleinblättrigen, aufrechten Stieles.

Mehrjährig. Sporenreife Juli. Windverbreitung. Moorige Wälder, magere feuchte Matten, befonder's auf Urgeftein.

Ebene bis $2300 \mathrm{~m}$.

Alpen, Gebirge von Mitteleuropa, Pyrenäen. 


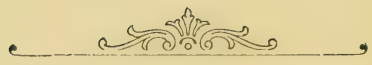

C. F. Winterfche Buchdruckerei.

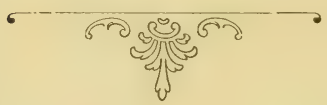



a. $)^{2}, 3$ 7) $3 y^{2}=5 \sqrt{2}$

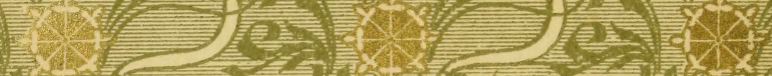

e. es ${ }^{4}$ 7. $7 v^{2}$.

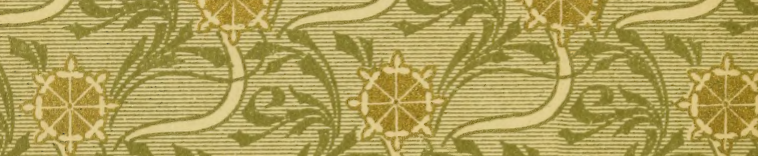
e. $\left.x^{2} \mathrm{e}\right)^{2}$

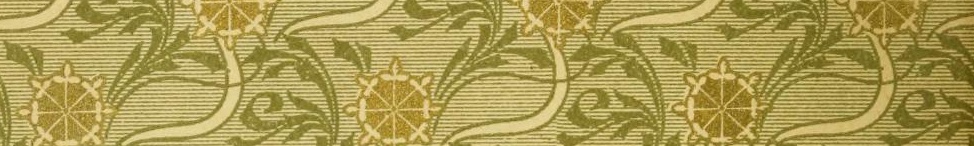

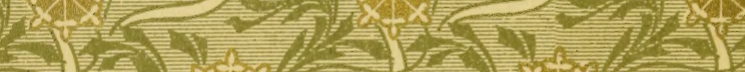
es $x$ en $x$ (a) (1) $>3$

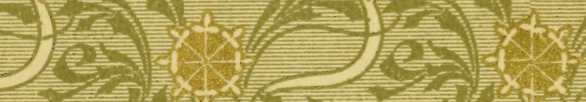
N 75 y.

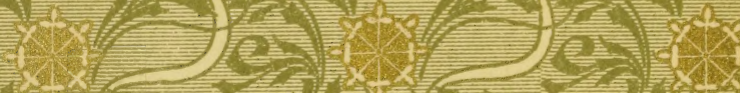

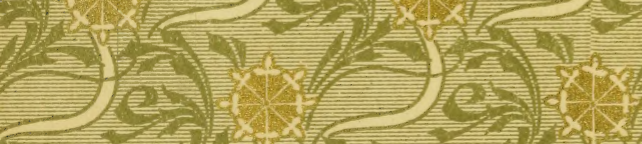
- $5 x^{4} p^{2}$ Jav y 


\section{New York Botanical Garden Library}

QK 315.S38

gen

Senn, Gustav/Alpen-Flora: Westalpen
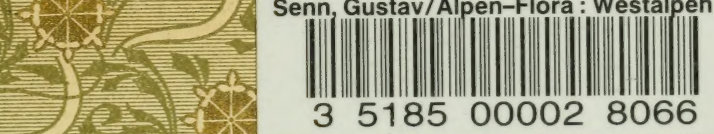

a 4

es) $a x$

35185000028066

- 10

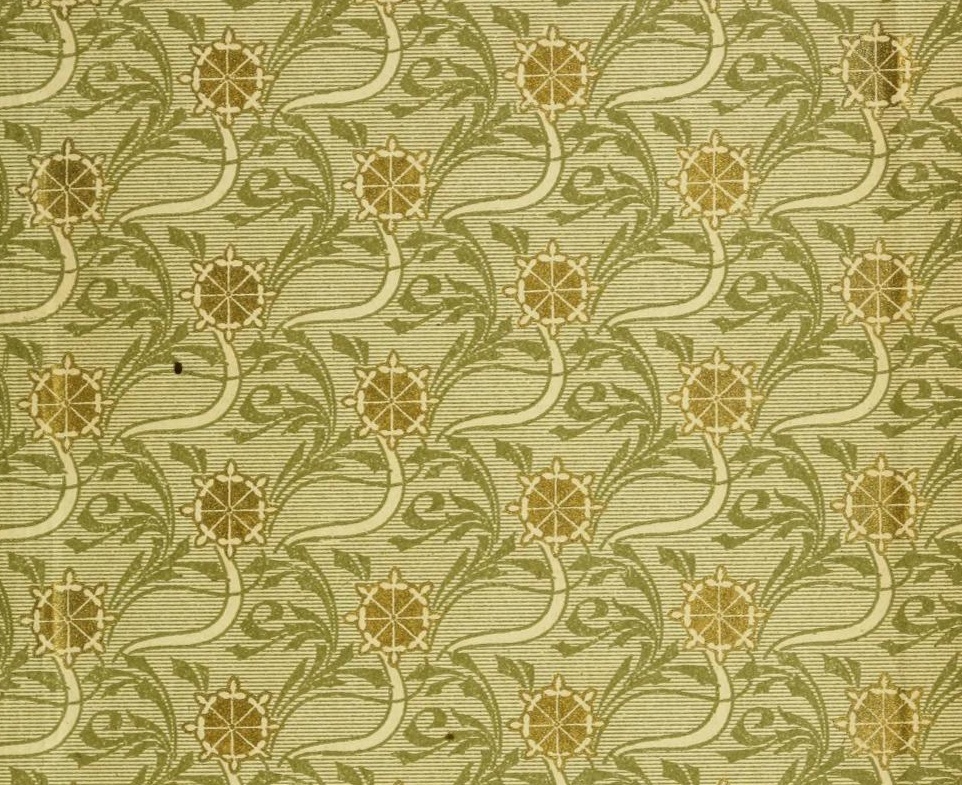

in

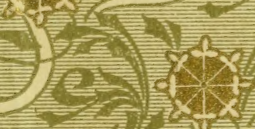

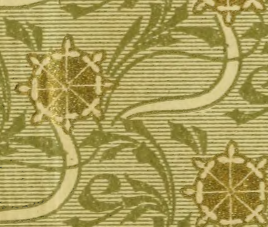

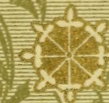


